\title{
HEALTH AND SAFETY RESEARCH DIVISION \\ PROGRESS REPORT FOR THE PERIOD \\ October 1, 1991 - March 31, 1993
}

\author{
Barry A. Berven
}

Director

Date published: September 1993

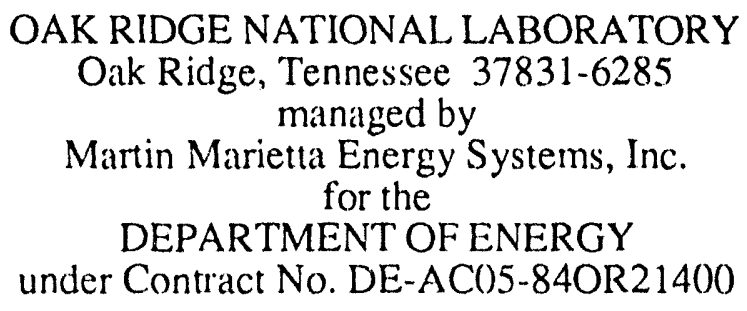




\section{HEALTH AND SAFETY RESEARCH DIVISION \\ PROGRESS REPORT FOR THE PERIOD \\ October 1, 1991-March 31, 1993}

\section{CONTENTS}

FOREWORD $\ldots \ldots \ldots \ldots \ldots \ldots \ldots \ldots \ldots \ldots \ldots$

1. ASSESSMENT TECHNOLOGY SECTION $\ldots \ldots \ldots \ldots \ldots \ldots$

Measurement Applications and Development . . . . . . . . . 6

Pollutant Assessments . . . . . . . . . . . . . . . 7

Measurement Systems Research . . . . . . . . . . . . 10

Dosimetry Applications Research . . . . . . . . . . . . . . 11

Dosimetry Research . . . . . . . . . . . . . . . . . . . . 14

Nuclear Medicine $\ldots \ldots \ldots \ldots \ldots \ldots \ldots$

2. BIOLOGICAL AND RADIATION PHYSICS SECTION $\ldots . .19$

Atomic, Molecular, and High Voltage Physics $\ldots \ldots \ldots \ldots . \ldots 21$

Physics of Solids and Macromolecules $\ldots \ldots \ldots \ldots \ldots$

Liquid and Submicron Physics $\ldots \ldots \ldots \ldots \ldots \ldots$

Analytic Dosimetry and Surface Physics . . . . . . . . . . . 25

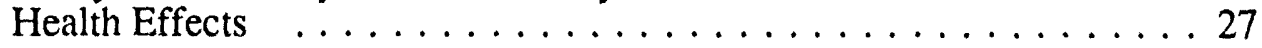

3. CHEMICAL PHYSICS SECTION $\ldots \ldots \ldots \ldots \ldots \ldots \ldots$

Molecular Physics $\ldots \ldots \ldots \ldots \ldots \ldots \ldots \ldots \ldots$

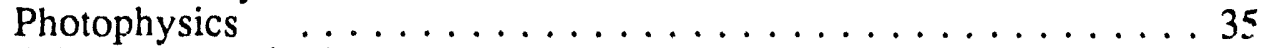

Advanced Monitoring Development $\ldots \ldots \ldots \ldots \ldots$

4. BIOMEDICAL AND ENVIRONMENTAL

INFORMATION ANALYSIS SECTION $\ldots \ldots \ldots \ldots \ldots 39$

Human Genome and Toxicology $\ldots \ldots \ldots \ldots \ldots \ldots$

Chemical Hazard Evaluation and Communication . . . . . . . . 43

Environmental Regulations and Remediation $\ldots \ldots \ldots \ldots$. . . . 46

Information Management Technology . . . . . . . . . . . . 48

5. RISK ANALYSIS SECTION $\ldots \ldots \ldots \ldots \ldots \ldots \ldots \ldots \ldots \ldots$

Environmental Restoration $\ldots \ldots \ldots \ldots \ldots \ldots \ldots \ldots$

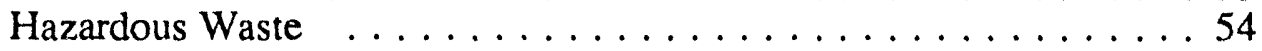

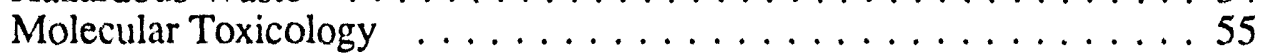

Risk Assessment Applications and Training . . . . . . . . . 56

Risk Data Systems . . . . . . . . . . . . . . . . . . 57

Waste Management ... . . . . . . . . . . . . . . . . . 59

Program Integration and Administration $\ldots \ldots \ldots \ldots$

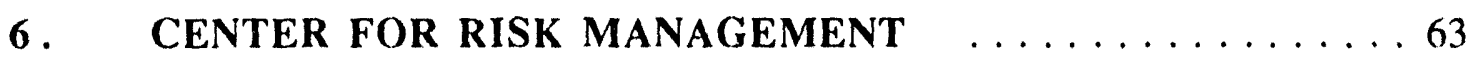


7. ASSOCIATE LABORATORIES FOR EXCELLENCE IN

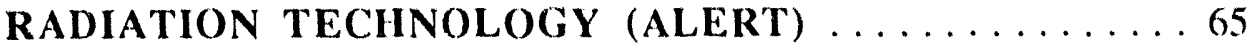

8. CONTRIBUTIONS TO NATIONAL AND LEAD

LABORATORY PROGRAMS AND ASSIGNMENTS-

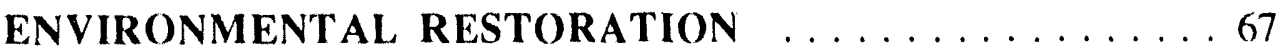

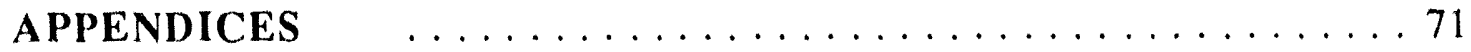

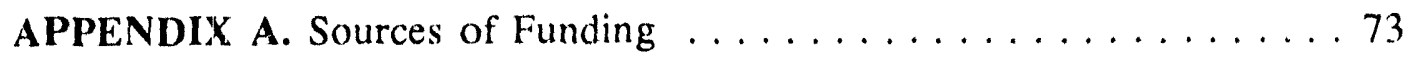

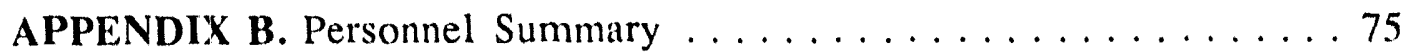

APPENDIX C. Organization Chart . . . . . . . . . . . . . . 77

APPENDIX D. Seminar Program . . . . . . . . . . . . . . . 79

APPENDIX E. List of Honors and Awards for Staff Members . . . . . . . . 81

APPENDIX F. Patents Granted to Staff Members . . . . . . . . . . . . . . 95

APPENDIX G. Meetings and Conferences . . . . . . . . . . . . . 97

APPENDIX H. Advisory Committee . . . . . . . . . . . . . . . . . . . 99

APPENDIX I. Presentations . . . . . . . . . . . . . . . . 101

APPENDIX J. Publications $\ldots \ldots \ldots \ldots \ldots \ldots \ldots \ldots \ldots$ 


\section{FOREWORD}

\section{Barry A. Berven}

The mission of the Health and Safety Research Division is to provide a sound scientific basis for the measurement and assessment of human health impacts from radiological and chemical substances. Our approach in fulfilling this mission is to conduct a broad program of basic and applied research using multidisciplinary teams working in areas of importance to federal agencies.

This report summarizes the progress of the division between October 1, 1991, and March 31, 1993. During this reporting period, large changes have occurred organizationally, and in the type and nature of our work. On January 1, 1993, I became the new director of this division. Subsequently, Paul Rohwer became the new associate director, and Dick Swaja became the new head of the Assessment Technology Section. The division staff levels have increased by about $6 \%$ reflecting a net increase of 12 new staff members and a net increase of 13 more guests to accomplish new work in human health (primarily in the area of risk analysis). At the end of this performance period, the division has a total of 218 staff and 187 guests (total of 405) working on 290 projects totaling over $\$ 35$ million in funding from various federal agencies. These numbers reflect the complexity and diversity of the work that we perform.

Our external environment is increasingly competitive due to shrinking research funds and a larger pool of researchers vying for work from federal agencies. We continue to experience significant declines in basic research funding across broad areas of our division. An increasing percentage of the limited available funding is going to universities. The decline in defense spending has compelled other national laboratories to seek new areas of funding (human health research among them).

Our internal environment continues to place a high emphasis on environmental, safety, health, and quality (ESH\&Q) concerns, which require greater infrastructure and places larger demands on the limited resources our researchers generate. The expression of these requirements comes in the form of more training for the staff, more rigor to ESH\&Q programs in the division and more time spent participating in and responding to audits. Additionally, we continue to have inadequate space for our growing organization. The space that we presently occupy is largely substandard and conditions have become more 
adverse for conducting research. We also suffer from inadequate capital funds to provide state-of-the-art equipment required to be competitive with our peers at universities and other national laboratories.

In spite of the rapidly changing environment, we have found challenge, opportunity, and success during the recent 18 -month reporting period. We were the recipient of two R\&D 100 Awards in 1992. C. H. Chen, S. L. Allman and F. C. Chen received an award for the "CFC/HFC Ratiometer." Tuan Vo-Dinh and David Stokes were the recipients of another award for the "Surface-Enhanced Raman Optical Storage (SERODS) System." Our division has received a total of 13 R\&D 100 Awards over the past 13 years. Many of our scientists have been recognized for their excellence in science and their contributions to their fields of study. A brief summary of these includes the following: Ray Garrett, Eph Klots and John Miller have all been named Fellows of the American Physical Society; Andy Francis and Sylvia Talmage have been certified as Diplomates of the American Board of Toxicology (the division now has four Board Certified Toxicologists - Bob Young and Kowetha Davidson were certified several years ago); Jim Turner was the recipient of the Distinguished Scientist Achievement Award from the Health Physics Society; Paul Rohwer and Jim Turner were elected President of the American Academy of Health Physics in successive years; Paul Rohwer continues to serve as Treasurer of the Health Physics Society; Bob Compton won the Jesse W. Beams Medal, received a Certificate of Merit from the Southeastern Section of the American Physical Society, and was named a Fellow in the Optical Society of America; Rufus Ritchie received the degree of Doctor Honoris Causa from the Universidad del Pais Vasco in San Sebastian, Spain; Prem Srivastava received a Distinguished Scientist Award from the United Nations World Development Program; Keith Eckerman and Rich Leggett were elected to numerous committees of the International Commission on Radiological Protection and the National Council on Radiation Protection and Measurements; Annetta Watson was appointed to a committee by the National Academy of Sciences to study health effects from certain chemical warfare agents. John Wassom was appointed to a task group by the International Commission for Protection Against Environmental Mutagens and Carcinogens; Barry Berven, Dick Gammage, and John Miller have edited books during this progress period; and Po-Yung Lu and John Wassom (with several EPA scientists) have coedited a symposium proceedings about information resources for health risk assessments. Patents, licences and Cooperative Research and Development Agreements (CRADAs) have recently become new 
measures of success by the Department of Energy (DOE). Since 1991, our division has been granted four patents, two licenses, and five CRADAs with private companies.

Several significant scientific advances have been made during this reporting period. Winston Chen and Steve Allman have succeeded in detecting polydeoxyribothymidylic acid oligomers up to 150 bases. This has significant potential to rapidly sequence DNA, RNA, protein and other complex biomolecules. Bruce Warmack and Dave Allison have been able to attach DNA molecules to a surface where they can be effectively viewed with scanning tunneling microscopy techniques. This ability will be useful in understanding the function of large, complex biomolecules by examining their structure. Russ Knapp has been successful in developing and promoting tumor diagnostics and therapy using a tungsten188/rhenium-188 generator. The Center for Risk Management is providing risk assessments in direct support of the DOE Office of Environmental Restoration and Waste Management to develop their Programmatic Environmental Impact Statement. This effort will evaluate human health, ecological impacts, and worker risks associated with remediation and waste management at all DOE facilities. Under the Strategic Environmental Research and Development Program initiative, the Biomedical and Environmental Information Analysis Section was requested by the U.S. EPA to develop methodologies to accommodate chemical and waste site situations specific to the Department of Defense (DOD) and DOE applications. These and other significant scientific endeavors in this division are detailed in the section-specific descriptions in this progress report.

I believe the future continues to be bright for our division. We have an excellent reputation for providing the highest quality research. We have a flexible staff that demonstrates a willingness to team with other organizations to work on complex projects. Our staff has a keen awareness of the new, more competitive environment in which we work, and the obstacles we must overcome to continue our high level of productivity. As a division, we are resolved to renew our commitment to scientific excellence, be responsive to our sponsor needs, and continue to seek new opportunities of national importance. 


\title{
1. ASSESSMENT TECHNOLOGY SECTION
}

\author{
R. E. Swaja, Head
}

Staff

Research:
K. R. Ambrose ${ }^{1}$
P. A. Brimer
J. S. Bogard
K. J. Brown
M. A. Buckner
A. P. Callahan
R. F. Carrier
W. H. Casson
S. S. Chang ${ }^{2}$
W. D. Cottrell
M. T. Cristy
T. A. Cronk
G. S. Danford 2
K. S. Dickerson'
C. S. Dudney
M. L. Espegren
D. E. Fields
R. D. Foley
R. B. Gammage
F. G. Gardner
D. W. Greene
J. W. Haas, III
D. K. Halford
S. C. Hall
T. L. Hatmaker
C. A. Johnson
G. D. Kerr
B. W. Kline ${ }^{2}$
F. F. Knapp, Jr.
D. C. Kocher
B. J. Krall
D. C. Landguth
R. W. Leggett
C. A. Little
L. M. McDowell-Boyer
D. W. McPherson
S. Mirzadeh
C. A. Muhr
N. B. Munro'
M. E. Murray
J. E. Peterson
D. A. Pickering
R. E. Rodriguez
P. S. Rohwer
C. S. Sims
P. C. Srivastava
D. R. Smuin
G. H. Stevens
R. E. Swaja
J. E. Thate
D. J. Thorne
M. S. Uziel
E. A. Wachter
S. J. Wallace
J. K. Williams
D. L. Wilson
M. J. Wilson
K. M. Woynowskie
E. A. Zeighami

Technical Support:

J. P. Abston

J. F. Allred

S. N. Burman

G. H. Cofer

R. L. Coleman

J. R. Davidson

R. C. Gosslee

M. K. Jensen

R. R. Knott

C. R. Lambert

R. P. Lenc

R. A. Mathis 

V. P. Patania
G. A. Pierce
E. M. Pilz
D. E. Rice
D. A. Roberts
D. A. Rose

T. R. Stewart

P. F. Tiner

J. Wade

J. E. Wilson

W. Winton

\section{Administrative Support:}

L. K. Ailey

D. K. Barslund

A. W. Brown'

B. B. Clark

L. E. Collins

D. F. Dickerson

T. J. Graves

T. L. Holmes ${ }^{1}$
S. E. Huckaba

L. R. Pyles

C. D. Retolaza

S. G. Rogers

R. G. Self ${ }^{1}$

G. G. Shearin

L. H. White ${ }^{\mathrm{l}}$

Guest Scientists:

Y. Chang-Qing

L. L. Cole

A. J. Ghilardi

V. M. Jacomino
E. C. Lisic

A. Moreno

T. Nakono

Consultants:

M. C. Corbett

M. M. Goodman

P. G. Kale

J. P. Niemoth

J. W. Poston

M. G. Stabin
J. B. Stubbs

S. R. Sturm

A. B. Tanner

W. F. Whicker

L. R. Williams

R. A. Zingaro

\section{Students:}

T. D. Arrington

M. A. Boyd

J. T. Behm

F. R. Butler

R. L. Cole

L. L. Foster

K. S. Gehrs

K. M. Jahn

C. M. Johnson

W. I. Kaechele

D. A. King

S. J. Lambert
A. T. LaSirena
E. B. Lee
C. J. Lewis
D. P. McDaniel
D. F. McDuffie
R. S. McKamey
D. D. McKinney
J. B. Miller
R. B. Sparks
S. C. Thompson
L. K. Watson 
Subcontractors:

T. M. Allen

M. F. Amer

J. M. Anderson

S. M. Berkoff

S. J. Blevins

W. H. Burke

S. E. Burns

A. C. Butler

F. I. Case

G. N. Case

N. L. Conklin

D. J. Corona

H. L. Dennis

J. C. DePriest

P. V. Egidi

D. B. Ertel

S. M. Field

D. S. Foster

W. L. Foutz

T. M. French

L. L. Friese

C. L. Gist

D. A. Gibson

C. Griffith

L. L. Friese

C. L. Gist

D. A. Gibson

C. Griffith

A. M. Hagwood

D. K. Hawkins

K. A. Hebbard

R. H. Holland

W. T. Howe

R. F. Hughes

A. R. Jones

S. S. Kilgore

L. R. Lesperance

N. F. Lewis

Postdoctoral Fellows:

T. E. Barber

W. G. Fisher

A. Hasan

M. A. Lindsay

D. S. List

M. S. List

D. A. Locke

J. M. Lovegrove

D. C. Marty

S. K. Mather

R. L. Meredith

K. E. Meyer

C. N. Millsaps

M. E. Mumby

S. M. Murray

T. A. Oliver

C. E. Ramsey

J. R. Rau

T. M. Rhea

J. A. Rice

S. Ricks

E. K. Roemer

P. D. Roundtree

M. E. Ruth

J. R. Sauvage

E. P. Schlauger

R. M. Schlosser

D. L. Sellers

W. H. Shinpaugh

S. M. Smith

J. M. Springer

G. X. Stowe

S. B. Swartz

F. R. Swisher

S. A. Tighe

H. A. Tochtrop

J. J. Walls

M. E. Ward

L. West

J. C. Wright

J. L. Zutman

R. D. Shelton

J.E.M. Storey 
Loanees from other divisions:
A. L. Beets ${ }^{3}$
P. M. Kearl ${ }^{4}$
J. C. Ryman ${ }^{6}$
N. E. Korte 4
A. L. Sjoreen 6
A. D. Laase ${ }^{4}$
R. C. Ward6
W. L. Robbins 5

1Part-time employee.

${ }^{2}$ Biomedical and Environmental Information Analysis Section.

${ }^{3}$ Chemical Technology Division.

${ }^{4}$ Environmental Sciences Division.

5 Instrumentation and Controls Division.

${ }^{6}$ Computing Applications Division.

Research, development, and operational applications activities continued to be the focus of the Assessment Technology Section during this reporting period. True to its mission, the section is focused on the development and application of advanced technologies to identify and quantify parameters of demonstrated importance in assessing human health. The capabilities and accomplishments of the section's six groups span a broad range from radiological and chemical surveys of federal facilities, development of new survey methodologies, and development of advanced photonics for environmental measurements to measurement and calibration of instrumentation and dosimeters in radiation detection, development of radiation exposure-dose relationships, and design and development of radiopharmaceuticals and radionuclide generator systems for use in disease diagnosis and therapy.

Radiological and chemical environmental pollutant surveys are conducted by the Oak Ridge-based Measurement Applications and Development Group and the Grand Junctionbased Pollutant Assessments Group. Surveys are conducted for numerous programs and sponsors for a variety of purposes (e.g., characterization surveys to establish a need for remedial action, follow-up surveys to verify success of remediation, and methodology development and afplication to support facility performance assessments). Research and development in this area has improved in situ measurement capabilities in the field and seeks to replace expensive time-consuming laboratory analyses with quick, less-expensive field measurements.

The Measurement Systems Research Group is a.'so providing advanced field monitoring devices and capabilities. Research and development efforts of this group have 
produced in situ chemical pollutant measurement capabilities using fiber-optic devices and new radiological monitoring and screening tools for field measurement of actinides, transuranics, radon, and in situ measurements of alpha and weak beta radiation. Applied activities of the group include field monitoring for solvents and fuel contamination and renewed interest in indoor air quality with particular growth in programs for radon assessment and mitigation.

The focus of the Dosimetry Applications Research (DOSAR) Program continues to be improved radiation dosimetry. The Radiation Calibration Laboratory (RADCAL) has completed protocol manuals and uncertainty analyses as steps toward obtaining accreditation by the National Institute of Standards and Technology (NIST) as a secondary standards calibration laboratory. This facility is currently being used by Energy Systems organizations for research, instrument development, and calibration of instruments and dosime cers. It recently became available to outside users for these activities. An activc area of dosimetry research at DOSAR is the continuing development of "bubble detector" technology for neutron dosimetry. The DOSAR staff continues to conduct the internationally recognized Personnel Dosimetry Intercomparison Studies (PDIS) and has initiated a separate electronic PDIS in recognition of the rapidly increasing use of active personnel radiation dosimeters. It also continues to sponsor training and symposia such as the biennial Conference on Radiation Protection and Dosimetry.

Research efforts of the Biokinetics and Dosimetry Research Program in the Dosimetry Research Group continue to be directed toward the development of radiation exposure-dose relationships. A particular focus of the group is their development of anatomic and biokinetic models to appropriately describe the age-specific nature of the exposure-dose relationships.The works of this group continue to be cornerstones for radiation protection guidance documents of the National Council on Radiation Protection and Measurements (NCRP), the Medical Internal Radiation Dose (MIRD) Committee of the Society of Nuclear Medicine, and the International Commission on Radiological Protection (ICRP). The work of this group is also fundamental to the evaluation of diagnostic and therapeutic procedures involving radiopharmaceuticals and machine-produced radiation. At this point, the work of the Biokinetics and Dosimetry Research Program, Dosimetry Research Group, interfaces with that of the Nuclear Medicine Group.

The Nuclear Medicine Group specializes in the design and development of ne: tissuespecific radiopharmaceuticals for diagnostic and therapeutic applications in nuclear medicine. Specific research activities of the group include radiopharmaceutical synthesis and testing, biochemical determination mechanisms of radiolabeled agent uptake and 
retention, and preparation and development of processing techniques for radionuclides and radionuclide generators. Collaboration with more than twenty Medical Cooperative Programs at clinics, universities, and other research institutions in the United States and abroad continue to be of great benefit in the development and clinical testing of radiopharmaceuticals developed by this group.

Education, training, and university interactions are integral components in the technology transfer process in this section. Also, there have been a number of patent applications and invention disclosures from this group.

\section{MEASUREMENT APPLICATIONS AND DEVELOPMENT}

The primary activities of the Measurement Applications and Development (MAD) Group involve detecting radiological and chemical pollutants in the environment and assessing the impacts of these pollutants on the health and safety of exposed individuals. In support of these objectives, the group performs three major activities: (1) identifying potential locations of environmental pollutants; (2) characterizing radiological or chemical pollutants with regard to location, type, and concentration; and (3) conducting research and development of instruments and techniques to advance survey and assessment capabilities. Based on existing expertise and equipment, the MAD Group has the capability of detecting and characterizing any radiological or chemical pollutant of concern to the general public.

Much of the radiological characterization work performed during the report period was in support of the Department of Energy (DOE) Formerly Utili _ed Sites Remedial Action Project (FUSRAP), which is funded through the Office of Environmental Restoration and Waste Management. This work involved surveying and identifying properties requiring remedial action in the vicinity of sites designated by DOE. Funding for this work, which has been almost constant for the past few years, decreased slightly for the review period but should increase during the next period. Comprehensive radiological characterizations were conducted at Seymour, Connecticut; Beverly, Massachusetts; Tonawanda, New York; Lodi, New Jersey; Granite City, Illinois; and Oxford, Ohio. Preliminary surveys were conducled at Oxford and Fairfield, Ohio; Tonawanda, New York; and Maywood, New Jersey. In addition, surveys to verify remedial action were conducted in Seymour, Connecticut, and Schenectady, New York. Recent directives from DOE indicate that scoping, characterization, and verification activities in support of the FUSRAP effort will continue for several years. 
In addition to the FUSRAP work, major radiological pollutant characterizations were conducted at former Naval Reactor sites in Schenectady, New York, and at the Y-12 Plant in Oak Ridge, Tennessee. The Schenectady work included radiological and chemical site characterizations. At $\mathrm{Y}-12$, the group is currently conducting a radiological characterization of all indoor areas, which is scheduled to be completed at the end of FY 1994. Also, radiological characterization surveys in support of the ORNL Environmental Restoration Program were continued throughout the report period with five sites being characterized and summary reports issued. Results of these surveys are being used to identify and prioritize areas requiring remedial action at ORNL.

In addition to the radiological surveys, the group conducted chemical and mixedpollutant characterizations at the ORNL and K-25 sites in support of corporate environmental restoration programs. This work included field sampling to detect and assess all types of environmental pollutants, preparation of site-specific sampling procedures and health and safety plans, and evaluation and reporting of measured results. Staff members also coordinated (1) removal of several underground storage tanks at the three Martin Marietta sites in Oak Ridge; (2) soil gas sampling for organic pollutants at $\mathrm{Y}-12$; and (3) training for hazardous materials worker certification.

Other efforts in support of environmental pollutant characterization included preparation of a radiological survey procedures manual for DOE's Office of Environmental Health, evaluation and application of liquid scintillation techniques to analysis of soil samples, development of a comprehensive computerized sample tracking and data management system, and development of surface contamination limits for release of material and buildings. The survey procedures manual is a major effort which will result in a document that will be the basis for all radiological contaminant surveys at DOE contractor and field office facilities. The experience and capabilities acquired through the expanding environmental pollutant characterization work will be used to continue to advance methods and instruments used for environmental assessments and to support technology transfer through publications, presentations, and workshops.

\section{POLLUTANT ASSESSMENTS}

The mission of the Pollutant Assessments Group (PAG) is to provide research, development, planning, and field characterizations to assess impacts to humari health and the environment from radioactive and chemical pollutants and encompasses federal programs and sites in the western United States.

In support of this effort, the group is committed to: 
In support of this effort, the group is committed to:

- maintaining and being recognized for high quality results;

- recognition by sponsors for responsiveness and orientation to their r:eds;

- providing accurate and useful progress and financial reports to spo isors;

- furnishing a safe environment for achieving personal excellence and growth for all employees;

- advancing state-of-the-art in environmental assessments by devcloping both methodologies and equipment;

- expanding capabilities to allow a comprehensive range of assessment services; and

- describing results in selected technical and lay publications.

The PAG has four major types of projects. First, the staff continues to be involved in field surveys for radiological contaminants at a variety of sites. Surveys are conducted to determine the need for remedial action or to verify the success of remedial action. Second, the staff conducts remedial investigation/feasibility studies (RI/FS) or Resource Conservation and Recovery Act (RCRA) facility investigations at federal facilities contaminated with a variety of chemical pollutants. These projects may include sampling of soil, soil vapors, surface water, groundwater, or biota from contaminated areas or wells installed in nearby aquifers. Third, the staff conducts performance assessments of new or proposed DOE waste disposal facilities to estimate the potential environmental transport and human health risk from operation of the facility. Last, and most important, the staff conducts research to refine, revise, or develop new technologies, equipment, or methods of conducting field assessments.

The PAG has been involved in a variety of projects associated with radiological contamination of the environment. Work in the Uranium Mill Tailings Remedial Action (UMTRA) Project is nearly complete. The group's Inclusion Survey Contractor activities have produced over 12,000 property survey reports during the last nine and one-half years. The PAG will continue to support UMTRA as the Independent Verification Contractor (IVC) for remedial actions in Grand Junction through FY 1994. The PAG also serves as the IVC for several other remedial action projects including the remedial action of the DOE Grand Junction Projects Office; properties at the Monticello, Utah, Superfund site under the auspices of the Environmental Protection Agency; facilities at the DOE Idaho National Engineering Laboratory (INEL), Idaho Falls, Idaho; and the Hanford Reservation, Washington. The PAG staff also conducted an extensive field survey of the former White 
Point Nike Missile Base in Southern California using the UltraSonic Ranging and Data System.

The PAG is currently conducting a variety of investigations of chemical contamination at DOE and Department of Defense facilities. The PAG has provided major support for the RCRA program at the DOE/Kansas City Plant. Staff members have also conducted RI/FS or similar projects at Fallon Naval Air Station, Nevada; Reno Air National Guard Base, Nevada; Tucson Air National Guard Base, Arizona; Paducah Gaseous Diffusion Plant, Kentucky; and Portsmouth Gaseous Diffusion Plant, Ohio.

Members of the group are conducting performance assessments of two new disposal facilities at the Savannah River Plant-the Saltstone Disposal Facility and the E-area vaults. These projects include development of exposure scenarios and modeling of environmental transport including groundwater transport, radionuclide decay, and food chain transport to forecast potential dose to intruders or surrounding populations. A major task on the Savannah River Plant Project has been the management of teams from INEL and Westinghouse-Hanford who contributed to portions of the modeling.

PAG staff are also conducting a variety of research projects to improve field accuracy and precision of in situ measurements. Measurements of natural colloids in groundwater were taken to develop the colloidal borescope, which is designed to provide in situ measurements of groundwater velocity. Such a device can greatly improve the input data used in groundwater transport models. The staff has DOE funding to develop a correlation between various field measurements and results of sampling and laboratory analysis.

Staff members are contributing to several technology demonstrations at DOE sites including Portsmouth, Ohio; Wilsonville, Alabama; and Paducah, Kentucky. These demonstrations were designed to test various remedial technologies in authentic field situations. For example, a process for using large-area microwave heating of soils to remove chlorinated solvents from soils will be tested at Paducah.

PAG staff members are also involved in a wide variety of other professional activities. Several members of the staff serve on national committees which include the DOE Performance Assessment Task Team, an ad hoc committee to revise DOE Order 5820.2A, an International Atomic Energy Agency committee for intercomparison of various environmental transport models, and the nominating committee of the Health Physics Society. PAG staff also serve as journal editors and meeting organizers. 


\section{MEASUREMENT SYSTEMS RESEARCH}

Providing new and state-of-the-art field monitoring devices and capabilities is the principal function of the Measurement Systems Research (MSR) Group. In doing this: a balance of basic research and applied field programs is maintained.

Basic research projects are mainly directed at the solution of specific problems. Research and development is conducted which yields innovative fiber-optic, field monitoring devices for in situ measurements. Specific examples include the fiber-optic derivative ultraviolet spectrometer for making down-well measurements of trace constituents of hydrocarbon fuels in groundwater at contaminated DOE sites (an advanced prototype is now available) and surface-enhanced Raman spectrometry (SERS). A new Raman spectroscope project with ORNL's Robotics Division for making direct chemical measurements inside waste storage tanks continued during the review period. New fiberoptic techniques are also being used to determine the spectroscopic properties of highly toxic warfare agents. This program is sponsored by the U.S. Army Chemical Research, Development, and Engineering Center.

New radiological monitoring and screening tools for site restoration, and decontamination and decommissioning are being promoted. Photoelectron rejecting alpha liquid-scintillation spectroscopy (PERALS) is being adapted for ultrahigh sensitivity field measurement of select actinide and transuranic radionuclides in soil, dust. and airborne samples. A modified procedure has allowed radon in water to be niedsured with a minimum level of detection of $5 \mathrm{pCi} / \mathrm{L}$. Based on the MSR Group's experience in solid state radiation dosimetry, a program has been started to evaluate integrating alpha-track detectors and exoelectron detectors. These passive devices can make in situ measurements of alpha and beta contaminants in difficult-to-access locations and can verify that decontamination has been completed satisfactorily.

Applied DOE site restoration activities are also expanding. The group has continued to develop a close working relationship with the Measurement Applications and Development Group and has collaborated in site characterizations at Portsmouth, Ohio. At Y-12, a major new project involving simultaneous field screening and reference laboratory analyses continued. In this project, soil samples for the sewer line upgrade are being collected and analyzed for both chemical and radiological contaminants to determine if these soils qualify as mixed waste.

In addition to projects directed at hazardous waste problems, the MSR Group has major programs in indoor air quaiiity research with an emphasis on indoor radon problems. 
A goal of the radon program of DOE's Office of Health and Environmental Research (OHER) is to identify the 100,000 "hottest" houses in the United States. To achieve part of this goal, it is important to understand the mechanisms causing seasonally magnified indoor elevations of radon in hilly karst regions of the southern Appalachians. Clusters of "hot" houses exist in regions where the natural uranium background is not particularly high. Large reservoirs of radon-bearing soil gas exist in networks of underground solution cavities. Houses able to tap these reservoirs at certain times of the year can qualify for the "hottert" category.

Radon measurements continued at 260 bases under the U.S. Navy's Radon Assessment and Mitigation Program (NAVRAMP). High radon levels in Mechanicsburg, Pennsylvania, Guam, and at a children's day care center in Bermuda, were confirmed during immediate, follow-on site assessments. The team also carried out temporary mitigation on problem buildings and training of personnel in radon detection and mitigation. NAVRAMP is in the general assessment phase with measurements being conducted at 100 bases where prior screening indicated indoor radon exceeded $4 \mathrm{pCi} / \mathrm{L}$. The use of 400,000 alpha-track, charcoal, and electret type detectors is required for completion of the assessment phase. A radon assessment program has been started for the U.S. Post Office. The first phase entails assessment of radon inside 34 buildings leased to the General Services Administration by the Post Office. Service is also being rendered to the U.S. Air Force for training in radon diagnostics and mitigation.

A study of toxic emissions from high sulfur coal briquettes that are being considered as alternative, domestic cooking fuels continued in Pakistan. The study is supported by the Agency for International Development. Additives of slaked lime, clay, and oxidant are intended to reduce the emissions of $\mathrm{SO}_{2}$ and smoke to levels that pose health hazards no greater than those posed by the burning of traditional fuels such as wood and dried cow dung.

Since the last progress report, programs in the group have increased in size and complexity. The ability to function successfully as a conduit, which brings together HASRD's more basic research groups and the applied field activity groups of the Assessment Technology Section, is requiring ever increasing integration and collaboration across group and section lines.

\section{DOSIMETRY APPLICATIONS RESEARCH}

Dosimetry Applications Research (DOSAR) Program activities are directed toward improving quantitative methods for determining radiation doses received by individuals. 
These activities are part of the division's mission of assessing impacts of energy-related technologies on human health. The Radiation Calibration Laboratory (RADCAL) is the DOSAR Program's primary research tool.

RADCAL is fully functional and is being used by DOSAR staff for research; Environment, Safety, and Health Compliance Directorate personnel for dosimetry calibration and development; and Instrumentation and Controls Division staff fo. instrument development and calibration. RADCAL recently became available to other U.S. Government agencies and the private sector for use on a cost-recovery basis through arrangements with ORNL's Work for Others office and DOE. Protocol manuals and uncertainty analyses have been completed in support of an application for certification by the National Institute of Standards and Technology (NIST) as a secondary standards calibration laboratory. The integration of RADCAL and other Energy Systems radiological facilities and expertise was initiated by creating the Associated Laboratories for Excellence in Radiation Technology (ALERT). ALERT provides coordinated health physics instrument and dosimetry services through a nucleus of partner ORNL divisions with extensive radiation dosimetry, monitoring, calibration, and $R \& D$ capabilities. These coordinated services are now available to other DOE facilities, government agencies, and the private sector.

The Seventeenth and Eighteenth Personnel Dosimetry Intercomparison Studies (PDIS 17 and PDIS 18) were conducted using various RADCAL radioisotopic sources in 1992 and 1993, respectively. A total of 67 participants submitted 1519 dosimeters for testing in PDIS 17. In PDIS 18 there were 60 participants who submitted over 1550 dosimeters. The results from PDIS 15 and PDIS 16 were analyzed and presented at an annual Health Physics Society meeting. Formal reports on each study are being prepared for publication in professional journals. These results are important to the health physics community because they provide an indication of the current status of international external dosimetry programs and their capabilities. Over one-third of the participants each year are from outside the United States.

The First and Second Electronic Personnel Dosimetry Intercomparison Studies (EPDIS 1 and EPDIS 2) were initiated and conducted during this reporting period due to the rapidly increasing popularity of active dosimeters and interest in their use for determining real-time radiation dose. The results of EPDIS 1, conducted in May 1992, have been analyzed and submitted to Health Physics for publication. This study involved 14 sets of dosimeters which were tested with various gamma, X-ray, beta, and mixed neutron and gamma isotopic sources. The second EPDIS is scheduled for May 17-23, 1993. 
During this reporting period, several DOSAR staff members participated in other important dosimetry-related activities as follows:

- The Third Conference on Radiation Protection and Dosimetry was held in Orlando, Florida, on October 21-24, 1991. Announcements and preliminary preparations have been completed for sponsoring the Fourth Conference on Radiation Protection and Dosimetry in October 1994.

- Staff members served on consensus standards committees such as ANSI N13.22, "Uranium Bioassay," and NCRP 57-15, "Uranium in Humans."

- A collaborative research initiative with Bubble Technology Industries and the Canadian Government for improved neutron dosimetry using the "bubble detector" iechnology was led by the DOSAR staff.

- DOSAR personnel served as assessors in the DOE Laboratory Accreditation Program (DOELAP) for personnel dosimetry programs.

- Staff members have worked with members of NIST and other participating members of the radiation community in establishing guidelines for the operation of federally owned secondary calibration laboratories.

- DOSAR personnel have participated in the laboratory assessment committee activities of the Health Physics Society laboratory accreditation program.

- DOSAR staff and RADCAL were used in the support of the ORNL Radiation Protection Upgrade Program. Support activities included the following: radiation characterization measurements at various locations at the Oak Ridge facilities; an experimertal neutron monitoring system incorporated at the Radiological Engineering Design Center; testing and characterization of various radiation instruments; and consultation with DOSAR staff on several ongoing radiological issues of importance to the laboratory.

- Several development and testing projects related to neutron monitoring and nuclear accident dosimetry were completed including development of a fixed nuclear accident dosimeter system and a personnel nuclear accident dosimeter system, a neutron area monitor systern, and an improved system for the analysis of blood sodium and hair sulfur activation for personnel dose assessment following a nuclear accident.

- A member of the DOSAR staff has become an adjunct assistant professor at the University of Tennessee. This appointment has facilitated the use of additional graduate students in the work at DOSAR, provided support for the University's growing Radiation Protection Engireering program, and 
allowed opportunity for several graduate students to gain practical experience in dosimetry-related activities.

\section{DOSIMETRY RESEARCH}

The main task of the Biokinetics and Dosimetry Research Program of the Dosimetry Research Group is to develop information on the radiation exposure-dose relationships through modeling the biokinetics of radionuclides within the body and modeling the deposition of ionizing energy within radiosensitive tissues from these radionuclides and from radiation externally incident upon the body. Such exposure-dose relationships are the cornerstone of radiation protection and also serve an important role in the evaluation of medical diagnostic procedures involving use of radiopharmaceuticals and X-ray machines.

Biokinetic models developed in the past to describe the behavior of radioactive elements have been derived on an empirical basis, i.e., by fitting simple mathematical expressions to available element-specific retention data for adult humans and laboratory animals. Such mathematical expressions provide some basis for calculating integrated doses from radionuclides but generally have no discernible correspondence to the physiological processes actually controlling behavior of the radionuclides in the body. Development of models describing the biokinetics in persons other than a hypothetical young adult male has required a substantial departure from this approach because of the scarcity of element-specific data for special populations.

As far as is practical, the biokinetic models currently being developed at ORNL explicitly depict the tissues and physiological processes controlling the movement or retention of radionuclides in the body. The advantages of a physiologically realistic approach are that it allows (1) incorporation of basic physiological information into the model, (2) realistic treatment of decay products formed in the body, (3) meaningful extrapolation of data from laboratory animals to humans, (4) meaningful analogies between an element of interest and physiologically similar elements, and (5) linkage between excretion of a radioactive element and movement among body tissues and blood. Biokinetic models developed by the group, as well as age-specific dosimetric models, are featured in Publication 56 of the International Commission on Radiological Protection (ICRP) in which data on the organ dose per unit intake for individuals of various ages are tabulated.

Members of the group are involved in work of various committees and task groups of the National Council on Radiation Protection (NCRP), the Medical Internal Radiation Dose 
(MIRD) Committee of the Society of Nuclear Medicine, and the ICRP. In addition, the group provides technical support to the work of the Radiation Effects Research Foundation

(RERF) regarding the dosimetry of the A-bomb survivors, and dosimetry expertise to the National Cancer Institute and various other working groups. Of particular relevance to research interests is the work of Scientific Committee 57 on Internal Emitters of the NCRP and ICRP Committee 2 on Secondary Limits (the task group on Revision of Reference Man, the task group on Age-Dependent Dose per Unit Intake, and the task group on Dose Calculations). The Dosimetry Research Group has prepared for publication Federal Guidance Report No. 12, which is the third report prepared by the group providing detailed guidance to federal agencies. The group also provides expert assistance to the local radiological health protection organization to help improve the quality of radiological protection provided to contractor employees, guests, and the public.

\section{NUCLEAR MEDICINE}

The Nuclear Medicine Program focuses on the development of radioisotope processing techniques, radionuclide generator development, and the development of new tissuespecific radiopharmaceuticals for diagnostic and therapeutic applications in nuclear medicine. This program continues to receive international recognition for the innovative design and development of new radiopharmaceuticals. Two major projects support radioisotope research, radionuclide generator development, and general radiopharmaceutical research.

The preparation and development of radionuclide processing techniques and radionuclide generator research are major areas of research, and the ORNL High Flux Isotope Reactor (HFIR) is an important resource for this program. The neutron flux values for the seven HFIR hydraulic tube positions have recently been systematically mapped to provide accurate neutron flux values which can be used to predict radioisotope yields. In 1992, the Nuclear Medicine Program also compiled and published the first comprehensive review of production capabilities of U.S. reactors for medical radioisotopes. New approaches have also been developed for processing a variety of radioisotopes of current interest in nuclear medicine, which include copper-64, copper-67, and holmium-166. The procedures developed and incorporated into the Nuclear Medicine Group Procedure Manual are the only procedures at ORNL which have been accepted for target irradiations in the HFIR hydraulic tube positions. 
Radionuclide generator development continues to be a major productive area of research. The fabrication and evaluation of large-scale, clinical prototypes of our tungsten188/rhenium-188 generator continues, and several cooperative programs have been established to pursue the use of rhenium-188 which may be superior to many radioisotopes currently used for attachment to tumor-specific antibodies for radioimmunotherapy. Collaborative studies are evaluating the effectiveness of rhenium-188-labeled antibodies in clinical trials. The ruthenium-103/rhodium-103m generator is a new system under development to provide the daughter radioisotope for therapy.

The synthesis and testing of a new radiopharmaceutical for in vivo nuclear imaging and therapeutic applications and development of new radiolabeling techniques for incorporation of radionuclides into tissue-specific agents are additional research areas. As an example, new radioiodinated antagonists specific for the cerebral and myocardial muscarinic-cholinergic-receptor are being designed, synthesized, and tested in animal models. Since changes in receptor activiiy or density have been implicated in many neurological diseases, these new agents hold promise for noninvasive in vivo imaging in the evaluation of various dementias. Multistep organic syntheses and the preparation of sterosisomers have resulted in the availability of several isomers which are currently under evaluation.

Collaboration with external organizations and technology transfer are important activities which bridge the gap between development and testing of new agents developed at ORNL and their use at other institutions. Several invention disclosures and patent applications were filed for new technologies developed at ORNL. The Medical Cooperative Programs involve joint research projects in conjunction with programs with special expertise for further preclinical testing in both in vivo and in vitro models and for clinical evaluation. Various new agents are evaluated in collaborative programs with over 20 Medical Cooperative Programs at clinics, universities, and other research institutions in the U.S. and abroad.

Finally, the clinical testing of new agents, developed in the ORNL Nuclear Medicine Program in conjunction with clinical investigators, illustrates not only the acceptance of our new technology but also the important transition from the laboratory to the clinic. In addition to the evaluation of rhenium-188-labeled antibodies described above, another recent example is the use of our new radioiodinated triglyceride analogue, which is currently in preliminary clinical tests for the evaluation of fat malabsorption resulting from pancreatic insufficiency. The use of this agent involves a simple urine analysis and may be an important improvement over the currently used methods. In addition, the iodine-123- 
labeled methyl-branched fatty acid analogue, BMIPP, developed in the ORNL program for evaluation of cardiac metabolism, is continuing clinical trials at several institutions in the U.S. and Europe, and is now being marketed in Japan as a clinical agent named "Cardiodine ${ }^{\mathrm{TM}}$ " by Nihon Medi-Physics, Inc. The balance between basic research and development at ORNL and interaction with key programs at other institutions continues to form the basis for a strong Nuclear Medicine Program at ORNL. 


\title{
2. BIOLOGICAL AND RADIATION PHYSICS SECTION
}

\author{
R. N. Hamm, Head
}

\section{Staff}

Research:

D. P. Allison

E. T. Arakawa

J. C. Ashley

T. A. Callcott ${ }^{1}$

J. G. Carter

L. G. Christophorou

O. H. Crawford

C. E. Easterly

M. W. England

T. L. Ferrell

B. E. Hingerty

D. R. James

T. D. Jones

S. P. McKenzie

L. A. Pinnaduwage

R. H. Ritchie

I. Sauers

T. G. Thundat

J. E. Turner

R. L. Tyndall

A. A. Vass

R. J. Warmack

A. P. Watson

H. Yoshida

Administrative Support:

J. E. Carrington

J. A. Cripps

S. L. Huling

D. C. Crowell

B. H. Kimmel

B. J. Norton

Consultants:

V. E. Anderson

J. S. Bertram

D. B. Boyles

S. R. Broshar

W. Gibson

C. B. Hamilton

G. H. Harman

H. H. Hubbell, Jr.

S. R. Hunter

T. Inagaki

R. C. Reddick

H. A. Wright

Guest Scientists:

E. K. Bowman

P. M. Echenique

B. Illman

R. D. Edge

F. Flores

J. Jia

P. Kale

F. J. Garcia de Abajoo

C. Kearney

J. P. Goudonnet

D. L. Hedden

B. H. Khare

R. G. Larsen

J. K. Hoffmeister

S. Mahajan

J. R. Manson 
D. L. McCorkle

J. S. Mittelman

T. A. Niewold

L. R. Painter
J. M. Pitarke

R. C. Reddick

C. C. Sung

A. A. Vass

\section{Students:}

D. B. Boyles

R. A. Cacheiro

M. P. Connolly

C. L. Cooksey

G. Chen

E. G. Furlong

A. Huang

T. Jaffke

P. A. Kreig

T. J. Kreutz

I. Lee

A. J. Lourenco

R. S. McKamey

R. Mackowski

C. Meisse

Postdoctoral Fellows:

P. G. Datskos

H. Faidas

I. Lee

R. C. Reddick

S. H. Sharp

Loanees from other divisions:

K. B. Jacobson ${ }^{2}$
E. J. Miller

M. J. Morowitz

M. D. Murray

C. W. Nebbe

J. E. Parks

J. P. Sawyer

S. H. Sharp

C. E. Smith

I. C. Stocks

H. A. Thorniley

L. J. Tkachuk

P. S. Tuminello

S. M. Weeresinghe

Z. C. Wu
T. G. Thundat

P. A. Vanderhoff

V. Zabel

$X$. Zheng

1Part-time employee.

2Biology Division.

${ }^{3}$ Instrumentation and Controls Division.

The Biological and Radiation Physics Section maintains a very diverse program of basic studies directed toward providing new scientific knowledge about the fundamental properties of matter in all phases (gas, liquid, and solid) and, in particular, of processes and mechanisms important in the interaction of pollutants with biological materials. The 
section also develops and improves methodologies to assess the impact and risk of various technologies on human health. Both theoretical and experimental studies are included in the section's research activities, which involve state-of-the-art technology in many areas, such as scanning tunneling microscopy, surface-enhanced Raman scattering, soft X-ray emission spectroscopy, and computer modeling. Some of the research highlights of the past 18 months in each of the five groups in the section are reported below.

Although much of our work is quite basic in character, we have remained alert to applications, and technology transfer is an important part of our mission. This is evidenced by the number of patents, licenses, and CRADAs in the section.

The section continues to have significant interactions with many other research institutions, both in the United States and abroad. Eight visiting scientists from foreign institutions, 17 visiting scientists from U.S. institutions, and 30 students worked within the section at various times during this reporting period.

\section{ATOMIC, MOLECULAR, AND HIGH VOLTAGE PHYSICS}

The research program of the Atomic, Molecular, and High Voltage Physics Group is devoted to the study of electron-molecule interactions and negative-ion processes, electronexcited molecule interactions, interphase physics, the electrical properties of the liquid state of matter, and the basic physics of gaseous dielectrics, pulsed power switches, and radiation detectors.

We have developed a method for studying electron attachment to short-lived $\left(<10^{-8} \mathrm{~s}\right)$ electronically excited states of molecules and have observed the first photo-enhanced electron attachment to such states. We have observed slow electron attachment to superexcited states (presumed to have lifetimes $\sim 10^{-9} \mathrm{~s}$ ) of tertiary amines, nitric oxide, and $\mathrm{H}_{2}$ using this technique; these states have an estimated electron attachment cross section over one billion times larger compared with those of the respective ground states. Additionally, we have observed photoenhanced electron attachment to specific excited electronic states of $\mathrm{SO}_{2}$ using a monoenergetic electron beam intersecting at right angles a laser and a molecular beam and using mass analysis of the resulting negative ions. Singlet $\mathrm{O}_{2}$ was found to dissociatively attach slow electrons about five times more strongly than ground state (triplet) $\mathrm{O}_{2}$.

A rather quantitative correlation has been found between the total electron scattering cross section and the static dipole polarizability of the ground and excited states of atoms. It was concluded that the enhanced electron scattering cross sections observed by a number 
of workers in the scattering of slow electrons from excited atoms are principally a consequence of the larger dipole polarizabilities of the excited states.

Basic experimental studies were conducted collaboratively between us and our colleagues at the Free University of Berlin on negative ion formation in clusters and on the effect of inelastic electron scattering by the cluster constituents on it as a function of the size and composition of the cluster. A profound effect of inelastic electron scattering via the 2.3 eV negative ion resonance $\left.\mathrm{N}_{2}{ }^{-}{ }^{2} \mathrm{Pg}\right)$ on the formation of $\mathrm{O}_{2}{ }^{-}$and $\left(\mathrm{O}_{2}\right)^{-}{ }_{2}$ ions in mixed $\mathrm{O}_{2} / \mathrm{N}_{2}$ clusters was observed.

Progress has been made in our efforts to measure electron-impact ionization as a function of fluid density.

We have improved our two-laser photoconductivity technique which allows measurement of binding energies of electrons to molecules/atoms/radicals in liquids and dense gases. The technique is currently providing valuable knowledge on the photodetachment cross sections and energetics of negative ions in liquids and dense fluids. The first results using this new technique have been obtained for $\mathrm{C}_{6} \mathrm{~F}_{6}-$ in liquid tetramethylsilane (TMS); they indicate that the photodetachment threshold for $\mathrm{C}_{6} \mathrm{~F}_{6}{ }^{-}$in $\mathrm{TMS}(\mathrm{T}=300 \mathrm{~K})$ is $1.51 \mathrm{eV}$, and that the photodetachment cross section for this anion exhibits maxima due to photoexcitation of the anion. Our work on the systematic study of the electron transport properties of fast dielectric liquids/mixtures provided the most accurate electron drift velocity and electron drift mobility data to date on these systems which proved valuable to the development of new media for advanced radiation detectors.

Temperature-enhanced electron detachment from parent negative ions has been observed and quantified using a newly developed technique. The autodetachment of c- $\mathrm{C}_{4} \mathrm{~F}_{6}{ }^{-}$and $\mathrm{C}_{6} \mathrm{~F}_{6}-$ anions was found to increase profoundly with increasing temperature (T) above ambient, especially above $\sim 450 \mathrm{~K}$. Under the same conditions, electron attachment to

c- $\mathrm{C}_{4} \mathrm{~F}_{5}$ and $\mathrm{C}_{6} \mathrm{~F}_{6}$ was found to vary little with $\mathrm{T}$. This is the first time that the effect of temperature on both processes (electron detachment and electron attachment) has been established. Conversely, as $\mathrm{T}$ was increased from ambient to $700 \mathrm{~K}$, the dissociative altachment cross section for $\mathrm{CH}_{3} \mathrm{Br}$ increased by more than two orders of magnitude.

A comprehensive review of electron-excited molecule/atom interactions was initiated and plans have been worked out for a NATO ASI entitled "Linking the Gaseous and the Condensed Phases of Matter: The Behavior of Slow Electrons" to be held at Patras, Greece, in September 1993. 


\section{PHYSICS OF SOLIDS AND MACROMOLECULES}

The Physics of Solids and Macromolecules Group concentrates on making basic measurements, by a variety of techniques, of the optical and electronic properties of solids, macromolecules, liquids, and thin films over a wide range of photon energies and temperatures. Other areas of research include resonance ionization spectroscopy, soft X-ray emission (SXE) and absorption spectroscopy, photoacoustical measurements, gas decomposition and ion chemistry studies, and measurements and calculation of low-energy electron mean free paths in solids and macromolecules. Studies in this program should lead to a better understanding of biologically interesting materials and biological systems and development of new low-level pollutant detectors.

With our collaborators at the University of Tennessee and the National Institute of Standards and Technology, we have continued our studies of SXE excited by electrons and by X-ray photons from the National Synchrotron Light Source (NSLS). A new monochromator utilizing a variable line spacing reflection grating used in grazing incidence was designed to replace the present transmission grating monochromator and installed in the summer of 1991. Studies are made on the electronic properties and bonding environment of light impurities in organic systems at concentrations of less than $0.1 \%$, the electronic properties of high $T_{c}$ superconductors, joint excitation by lasers and the synchrotron light source, and the effects of excitation near threshold. A proposal has been funded by the National Science Foundation through the University of Tennessee to construct a new SXE spectroscopy beamline at the Advanced Light Source at Lawrence Berkeley Laboratory, this beamline will provide 40 times greater excitation intensities than our present NSLS beamline, and will greatly extend the usefulness of this spectroscopic technique.

This group pioneered much of the early experimental work on photon interactions with surface plasmons. Modern mission-related research due to these original efforts includes new forms of biosensors for studying binding of compounds to bioreceptors and monitoring of anaesthetic gases, development of novel substrates for use in obtaining the surface-enhanced Raman spectra of pollutants in water, and other applications described below.

Using our laser desorption and ionization/time-of-flight mass spectrometer, we have measured the kinetic energy distributions of atoms and molecules desorbed after surfaceplasmon excitation. For all metals studied, $\mathrm{Ag}, \mathrm{Al}$, and $\mathrm{Au}$, a low-energy ( 0.08 to 0.09 $\mathrm{eV})$ thermal peak and a high-energy $(0.4$ to $1.0 \mathrm{eV})$ peak attributed to electronic excitation 
have been observed. Rhodamine B molecules were desorbed by this method without fragmentation. The yields of neutral metal atoms were found to agree well with the calculated energy density at the metal-vacuum interface.

We have combined a soft $X$-ray grating spectrometer with a scanning electron microscope (SEM) for the mapping of light elements. SEM images have been obtained of $\mathrm{Si}$ and $\mathrm{C}$ in various distributions. Efforts are being made to increase the signal to background ratio in order to increase the sensitivity for lower concentrations.

We have measured the optical properties of epitaxial $\mathrm{CoSi}_{2}$ films on Si from 0.06 to $2.75 \mathrm{eV}$ by ellipsometry and spectrophotometry. The energy dependencies of the dielectric constants show Drude behavior at energies lower than $\sim 0.2 \mathrm{eV}$ with Drude parameters $h \omega=\left(\begin{array}{lll}5.8 & 1 & 0.2\end{array}\right) \mathrm{eV}$ and $\mathrm{h} / \tau=\left(\begin{array}{lll}0.09 & 1 & 0.02\end{array}\right) \mathrm{eV}$. Using the measured optical constants, the $\mathrm{CoSi}_{2}$ film is shown to have maximum absorptance at a thickness of $\sim 10 \mathrm{~nm}$ for $\lambda>1.4$ $\mu \mathrm{m}$. We have also calculated the absorptance of a composite film of CoSi2 particles embedded in $\mathrm{Si}$ and found that the absorptance peak due to a surface plasmon resonance in the $\mathrm{CoSi}_{2}$ particles shifts to lower energy as the ellipsoidal particles become more elongated in agreement with recent observations.

Significant progress has been made in the development of a detection technique for the sensitive detection of the highly toxic decomposition product $S_{2} F_{10}$ in electrically stressed $\mathrm{SF}_{6} . \mathrm{SF}_{6}$ is widely used as compressed gas insulation in high voltage power equipment in electrical transmission and distribution systems and in compressed gas insulated transformers. This work is jointly sponsored under a cooperative research and development agreement (CRADA) by the Department of Energy, the Electric Power Research Institute, the Tennessee Valley Authority, the Bonneville Power Administration, the Canadian Electrical Association, and the Empire State Electric Energy Research Corporation. The ORNL program has played a key role in both the discovery of this important health issue and in the formation of the CRADA. As a result of this work, detection of $S_{2} F_{10}$ has been achieved at concentrations below $10 \mathrm{ppb}\left(1\right.$ part in $\left.10^{8}\right)$ in $\mathrm{SF}_{6}$ using a cryogenic enrichment gas chromatographic technique. This method is the only one capable of detecting $\mathrm{S}_{2} \mathrm{~F}_{10}$ in highly decomposed $\mathrm{SF}_{6}$ such as that found in high current power arcs at high sensitivity. In addition to application of this technique to laboratory corona, spark and arc discharges gas samples taken from field equipment have been examined for the presence of $S_{2} F_{10}$ for the first time. Work is in progress to develop improved sampling techniques, investigate decomposition product yields in spark discharges, and investigate the production of the oxygenated disulfur compounds $\mathrm{S}_{2} \mathrm{O} \times \mathrm{F}_{10}$, which may also be toxic. 


\section{LIQUID AND SUBMICRON PHYSICS}

Research in the Liquid and Submicron Physics Group concentrates on basic physics and upon the mission-related applications that invariably evolve from our studies. Applications include our invention of the photon scanning-tunneling microscope (PSTM); the PSTM permits topographical imagirig of samples with photons at a resolution 5-20 times better than conventional optical microscopes. This new instrument permits imaging of biological samples in air or other fluids and can simultaneously locally identify compounds spectroscopically by absorption, Raman, or fluorescent spectra. The major effort of the group for the mission-directed tasks is the imaging of DNA and proteins by electron scanning-tunneling microscopy and scanning force microscopy. We have developed substrate surface treatments that permitted us to obtain the first unambiguous electron scanning tunneling images of a DNA molecule containing complete genes, and have had similar success with scanning force imaging of DNA. Current work also includes the imaging of medically significant proteins.

This group has versatile sample preparation facilities and spectroscopic facilities that are used in both the basic research and our primary tasks. The basic research includes studies of the scattering of light and electrons from submicron particles, and aids in interpreting images obtained both in scanning probe microscopy and conventional electron and optical microscopes. Sample preparation work provides microstructured surfaces and chemically modified surfaces for both microscopy and spectroscopy.

In a joint project with the Physics of Solids and Macromolecules Group, we have carried out a feasibility study for a soft X-ray PSTM. We were able to show that this instrument may permit $0.36 \mathrm{~nm}$ resolution near the carbon $\mathrm{K}$ edge and thus may be important for imaging biomolecules in air with photons.

\section{ANALYTIC DOSIMETRY AND SURFACE PHYSICS}

The Analytic Dosimetry and Surface Physics Group undertakes basic studies of the interactions of radiation with matter, both for understanding the fundamental physics involved and for application to dosimetry, instrumentation, and modeling of the chemical and biological effects of radiation. Particular emphasis is given to matter in the condensed phase and to surface physics phenomena. The group conducts strong collaborative studies with the Biology Division on molecular mechanisms of radiation damage to biological systems. 
A number of studies were completed ur substantially advanced. The theory of surface plasmon-mediated ion emission from laser-bombarded $\mathrm{Ag}$ surfaces has been developed further; it will be tested in detail in experiments planned in the Chemical Physics Section. Review papers on "The Interaction of Charged Particles with Matter" and on "The Interaction of Swift Electrons with Surface Excitations" were published. The first was published in connection with the conferring of the degree Honoris Doctor Causa to one of the members of the group and the second as an invited keynote paper at the 1992 LatinAmerican Symposium on Surface Science.

A new formulation of the $Z^{3}{ }_{1}$ effect in the stopping of ions in matter was applied, in collaboration with a Spanish colleague, in the numerical evaluation of the magnitude of the effect for an electron gas. A new analytical form of the contribution of the three-vertex function was employed in this work. Theoretical energy losses by very low-energy electrons to thin layers of water molecules deposited on metal substrates have been evaluated. Experimental data obtained by a Canadian research group were matched very well in the energy loss range 0-0.2 eV by including only aloof losses. Experimenters in Frankfurt have found that when a swift ion emerges from a solid at an angle equal to that of the bulk plasmon wake cone of the ion, an augmented yield of electrons is observed. We have given a quantal analysis of this phenomenon by using the complete wake field as a perturbation, giving rise to energetic secondaries that originate mainly from the decay of the wake. Numerical work on this problem is in progress, and a manuscript is in preparation. A new approach has been made to the theory of the interaction of subexcitation electrons with water. Using many-body techniques, we have described electron scattering on acoustical phonons as well as on optical phonons in the medium; the contribution to the effective mass and the rate of energy loss from these interactions have been evaluated. Quantal interference effects in energy loss by an electron as it leaves its geminate ion are quantified. The decay modes of plasmons generated in condensed media have been of interest for some time, but little quantitative theory has been published for specific models of matter. We have devised a theory that gives definite predictions of the generation, decay, secondary-electron spectrum and the impact-parameter dependence of this phenomenon in a nearly free electron gas. Several applications of this theory are under development.

A number of other diverse theoretical investigations of current interest were carried out. In collaboration with physicists in the Autonomous University of Madrid, a study was begun of nonlinear effects in the charge-density wake in the hydrodynamic model. The Oak Ridge Electron-Transport Code, OREC, was modified to produce microdosimetric 
distributions for stochastic processes in irradiated water and used to predict distributions of ionization frequency and energy deposition in DNA-sized volumes in the basal plane of beta-irradiated skin. A comprehensive theoretical study concerning detection of surface plasmons via diffraction of visible light from a metal grating was performed. It was shown that the sinusoidal grating profile is the optimal one for observing surface plasmons and that a dielectric coating shifts the plasmon frequency. A mechanism was proposed for the ionization of polyatomic molecules by electron-positron annihilation, and supported by calculations. This theory explains, for the first time, why the process tends predominantly to produce fragment ions.

An electromagnetic wave that is totally internally reflected at the surface of a medium produces an evanescent wave outside that surface which is damped with distance from the surface and propagates parallel to the surface. A complete analytical description of the scattering of such an evanescent wave by a sphere was completed. In the limiting of zero damping, the general expressions were shown to reduce to those of the well-known Mie theory.

Computer modeling of DNA structures modified by chemical carcinogens has continued for the Human Genome Initiative. Native DNA sequences have also been investigated. In collaboration with the Engineering Physics and Mathematics Division, the use of parallel computer architectures has been initiated. Several DNA models that agree with Nuclear Overhauser Effect data have been published in the literature and new ones are in progress. New instrumentation for X-ray and neutron crystallography is being worked on in collaboration with the Biology Division. This is in preparation for the construction of the Advarced Neutron Source. In collaboration between ORNL and PNL, work has also been initiated on DNA structure modified by external ionizing radiation.

Studies continued on the modeling of the transport and interaction of radiation in water and molecular mechanisms of radiation damage to biomolecules. Measurements of radiolytic products from polynucleotides were also made with a Fourier transform mass spectrometer in collaboration with the Analytical Chemistry Division.

\section{HEALTH EFFECTS}

Human health can be affected by nearly every human activity, more so in the present age than earlier, due to the diversity of human endeavor and the extent to which these endeavors can be pursued. Characterization of human health impacts requires the development of new methods and the skillful application of existing knowledge. Long-term objectives include: 1) the placement of hazards from varying insults (e.g., chemicals, 
nonionizing electromagnetic energy, physical agents, ionizing radiation, and biological hazards) on a common scale, and 2) the placement of the common scale of hazards in perspective with consequences of normal daily life. Work within the group is highly varied as evidenced by the presentation of a few of the activities below.

One group member was invited to serve on the Committee to Survey the Health Effects of Mustard Gas and Lewisite. This committee was established by the Institute of Medicine of the National Academy of Sciences, and was charged by the Secretary of the Veterans' Administration with evaluating health effects of veterans' exposure to sulfur mustard and Lewisite warfare agents during military service. The exposed population included naval recruits on whom various protective clothing designs and equipment were tested with "live" chemical warfare agents in the 1940's. The committee's analysis required extensive literature reviews with much use of National Archive material dating from WWII, solicitation of written and interview material from the veterans, a public hearing, a technical workshop, as well as meetings of the committee. Literature and analysis performed by staff members during recent work during the generation of the Chemical Stockpile Disposal Program Preliminary Environmental Impact Statement and subsequent analysis provided the committee with a significant advantage toward their objective. A compilation of all findings have been published by the National Academy Press as a book, Veterans at Risk: The Health Effects of Mustard Gas and Lewisite.

Microbiological initiatives have been in support of reducing health risks by means of bioremediation techniques and evaluating changes in health risk by charting the changes in the mutagenic property of TNT as it is being degraded. While doing studies with ORNL's Analytical Chemistry Division on the reduction of toxicity and mutagenicity of composting as a way of degrading TNT, staff members tested the patented Amoebae/ Bacterial Consortia for its ability to degrade TNT. The consortia was found to be effective in the degradation of TNT which is both toxic and mutagenic. Subsequent to this finding, a private company, EODT of Oak Ridge, sought and obtained a patent license agreement for this technology. This license is the first patent license agreement for an ORNL bioremediation technology.

For synthetic fuels development, DOE was charged, in 1983 , to "justify the need to monitor specific unregulated substances and of providing threshold values above which these substances must be monitored." In response, the RApid Screening of Hazard (RASH) method was developed as a nonexpert, quick, chemical-scoring system to be used in the absence of compound-specific guidance from regulatory agencies. Since that initial work, we have been developing a relative potency method for understanding the potency 
ranking of chemicals. We were invited by the National Toxicology Program (NTP) to predict results of rodent bioassays currently being conducted on 44 chemicals.

Therefore, to predict the effectiveness of the two-year test dosages, we made predictions only for tested compounds for which we thought the RTECS data were adequate to define a reasonably accurate estimate of whether the product of the median relative potency and test dose was adequate for carcinogenic potentiation-about 30 compounds for mice and 30 for rats from the 44 being tested by the NTP. We posited that doses tested significantly below the bulk of the test-dose vs relative-potency comparisons could have a low probability of revealing a positive carcinogenic effect even if those compounds would test positive at higher doses (false negatives). On the other hand, doses significantly above the preponderance of the test-dose vs relative-potency comparisons might give false positive results through toxicity-associated compensatory cell proliferation. Additionally, we expected that the NTP result (whether "no evidence," "equivocal evidence," "some evidence," or "clear evidence") could vary with the magnitude of the test dose.

The application of RASH to the NTP tests has been encouraged by staff members of the NIEHS. To date, their evaluation has found that RASH evaluations "resemble predictions by experts more than evaluations based on chemical structure activity." In addition, the relative potency as computed from RASH seems to show a linear correlation with maximum doses tested for the different compounds in the long-term NTP rodent bioassays. 


\title{
3. CHEMICAL PHYSICS SECTION
}

\author{
J. C. Miller, Head
}

Staff

Research:

S. L. Allman

J. P. Alarie

W. R. Garrett

H. S. Carman, Jr.

C. H. Chen

G. D. Griffin

C. E. Klots

M. Uziel

R. N. Compton

T. Vo-Dinh

Technical Support:

G. H. Miller 1

R. C. Phillips

Administrative Support:

J. B. Cooper

N. S. Currence

D. G. Henderson ${ }^{2}$

D. Holt

Consultants:

J. Adcock

W. Christian

C. S. Feigerle

R. F. Haglund, Jr.

J. R. Haigis

G. S. Hurst

H. B. Kinser

M. P. McCann

P. W. Morrison, Jr.

M. Panjehpour

J. E. Parks

P. J. Phillips

M. S. Pindzola

M. J. Sepaniak

A. Tuinmann

P. M. Viallet

P. Williams

M. Yang

Guest Scientists:

V. Ananthanarayanan

D. Ding

W. F. Frey

H. B. Kinser

A. Pal

T. Pal
A. A. Puretzky
S. A. Taylor
B. R. Thomas 


\section{Students:}
D. P. Armstrong
J. E. Mathis
W. D. Brandon
E. Miller
L. E. Cuellar
A. Moore
K. P. Davis
A. Ononye
S. Davis
K. L. Patterson
J. J. DiCillo
K. A. Radford
S. R. Desai
D. L. Stokes
J. Dominguez
K. Tang
E. L. Furlong
W. E. Watts
M. L. Godwin
L. M. Winemiller
J.-C. Huang
J. E. Wray

Postdoctoral Fellows:

R. E. Haufler

C. Jin

Subcontractors:

J. P. Alarie

Loanees from other divisions:

H. A. Barnette 3

N. Ericson ${ }^{3}$

R. B. Jones

N. Taranenko

J. Sniatecki

${ }^{1}$ Leave of absence.

2Dual capacity.

${ }^{3}$ Instrumentation and Controls Division.

Activities within the Chemical Physics Section are diverse and interdisciplinary, spanning the fields of physics, chemical physics and physical chemistry, and biochemistry. Complementary theoretical and experimental approaches are directed toward important problems of fundamental science as well as to national needs of an applied or developmental nature. Studies are being conducted of basic chemical and physical processes relevant to radiological and chemical pollutants and their interactions with other chemical and biological species. Among these are investigations of photo-excitation and photoionization processes, molecular clustering phenomena, 
ion-molecule reactions, biochemical processes, and studies of chemical kinetics in gasand liquid-phase systems. These studies are related to problems of atmospheric chemistry and physics, pollutant characterization and detection, and radiation chemistry and biology. Lasers are used extensively in studies involving multiphoton excitation and ionization, laser fluorescence, surface-enhanced Raman spectroscopy (SERS), and resonance ionization spectroscopy (RIS) of atoms, molecules, clusters, and species absorbed on surfaces. Major portions of these studies are aimed at development of new principles for advanced analytical instrumentation for very low-level environmental pollutant detection. Lasers, fiberoptics, mass spectrometers, and chemical or biological sensors are the building blocks of these novel instruments.

The following brief summaries of activities in the Molecular Physics, Photophysics, and Advanced Monitoring Development groups provide general information on the accomplishments in the Chemical Physics program for the period October 1991 through March 1993.

\section{MOLECULAR PHYSICS}

The Molecular Physics Group performs experimental and theoretical research in science at the interface between physics and chemistry. Experimental studies involve the use of sonic nozzle expansions together with laser ablation in order to produce ultracold molecules and molecular clusters. Other experiments involve the production of macroscopic quantities (gram) of homogeneous and heterogeneous clusters. Of particular interest is the production and characterization of carbon-containing clusters, e.g., fullerenes $\left(\mathrm{C}_{60}, \mathrm{C}_{70}, \mathrm{C}_{84}, \mathrm{C}_{120}\right.$, etc.), metal-carbon clusters, and molecules of biological importance. Ultracold gas phase clusters are studied using laser, charged particle, and excited neutral beams. The newly synthesized macroscopic quantities of clusters are characterized by UV-IR spectroscopy, mass spectroscopy, small angle neutron scattering (SANS), and nuclear magnetic resonance (NMR). A strong motivation in these studies is to simulate condensed matter phenomena (solids and liquids) in the "gas phase" using large molecular clusters. In such studies one can observe the evolution from a single molecule to the condensed phase. Very fast radiation-induced processes in molecular clusters, liquids, and surfaces are probed with picosecond laser techniques. These studies are guided by theoretical investigations of stabilities and reaction dynamics of the evolving clusters.

A strong component of the program involves the study of nonlinear optical phenomena. This research has led to new ways of generating vacuum ultraviolet and 
infrared radiation. The Molecular Physics Group was responsible for the development of multiphoton ionization photoelectron spectroscopy. In the course of these studies, we discovered a now well-studied cancellation effect in multiphoton absorption. A major part of this research is directed toward the development of advanced instrumentation for health and environmental applications.

Laser ablation of surfaces has become a central focal point in the past years. Significant progress in the basic understanding of laser ablation has occurred as a result of the development of new experimental techniques in the group. Experiments have shown that the decay of surface plasmons in roughened silver induced by laser radiation gives rise to fast $\mathrm{Ag}^{+}$ions. In addition, the use of laser ablation has allowed for the creation of new materials, such as the fullerenes $\mathrm{C}_{60}, \mathrm{C}_{70}, \mathrm{C}_{84}$, etc., and their derivatives $\mathrm{C}_{60} \mathrm{~F}_{48}, \mathrm{C}_{60} \mathrm{O}$, etc.

The enormous impact that laser ablation studies are having in chemical physics will be emphasized at the Second International Conference on Laser Ablation (COLA '93), a DOE-sponsored workshop hosted by the Chemical Physics Section.

In recent years part of our program has been devoted to Rydberg charge exchange with electron attaching molecules in order to understand the details of "free" electron attachment to molecules. Of particular importance is our recent observation of electron attachment to carbon clusters and the observation that $C_{5}, C_{10}, C_{12}, C_{16}$, and $C_{18}$ are especially adept at attaching free electrons.

The study of multiphoton ionization (MPI) of complex molecules has revealed a number of surprises. Using rather modest power densities $\left(\sim 10^{10} \mathrm{~W} / \mathrm{cm}^{2}\right)$ from a pulsed $\mathrm{Nd}$ :YAG laser, multiply charged uranium ions (up to $\mathrm{U}^{6+}$ ) have been observed from MPI of $\mathrm{UF}_{6}$. For some wavelengths, the ions cbserved (e.g., $\mathrm{U}^{3+}$ ) require the absorption of up to 100 photons. The possible mechanisms for this rather striking result are being considered (e.g., collective excitation, nuclear excitation by electronic transitions, etc.). The multiphoton ionization of $C_{60}$ shows a number of interesting new features. The multiphoton ionization photoelectron spectrum (MPI:PES) of an effusive beam of $\mathrm{C}_{60}$ molecules shows prompt electrons resulting from direct two- photon ionization of $\mathrm{C}_{60}$, as well as a dominant low-energy delayed electron signal (thermionic emission) which follows an approximate thermal energy distribution (Ee-E/kT) with average energy $\varepsilon=0.321 \pm 0.08 \mathrm{eV}$. The data suggest an important role of intersystem crossing from the singlet to triplet manifold of $\mathrm{C}_{60}$. Multiphoton ionization of complex molecules, especially biologically important species, will be of increasing interest. 


\section{PHOTOPHYSICS}

Major efforts in this reporting period fall into five broad categories: (1) DNA sequencing by laser and mass spectrometry; (2) invention of freon detectors; (3) studies of nonlinear optical phenomena and molecular resonance ionization spectroscopy; (4) kinetics of irradiated materials; and (5) high $\mathrm{T}_{\mathrm{c}}$ superconductors. Each of these is described in detail below.

A facility that combines laser desorption, laser ionization, and mass spectrometry has been under construction. This facility is intended to be used for DNA sequencing with much faster speed than gel electrophoresis.

Two freon leak detectors were invented, and applications for U.S. patents have been filed. One leak detector is based on electron capture of freon molecules to reduce the gain of a proportional counter. Detection sensitivity better than $0.5 \mathrm{oz}$ per year was demonstrated. This is a simple hand-held detector that can detect not only CFC (chlorofluorocarbon) but also FC and HFC, such as R-134A. The other invention is intended to distinguish between different freons in freon mixtures.

We have continued our detailed studies of fundamental processes that affect RIS, including nonlinear processes that can strongly affect resonant multiphoton excitations of atomic and molecular systems. We have found that photon fields generated within the sample can greatly modify the atomic response to an incident laser field, resulting in reductions in expected resonant excitation and/or emission rate or in a strong shifting of resonant line positions at elevated pressures. Detailed experimental and theoretical studies have provided substantial understanding of a number of these cases.

A mass spectrometer was constructed and used to measure spectra of ions and neutral components desorbed and/or ablated from superconductors, metals, and fish scales. The information generated is valuable not only for determining the components of the target samples, but also for understanding the mechanism of desorption processes.

A new facility equipped with the capability of Fourier transform infrared (FTIR) spectroscopy, mass spectroscopy, emission spectroscopy, absorption spectroscopy, temperature-controlled substrates, and pulsed molecular beams was built. It can be used to monitor all gas species during the laser ablation process, as well as surface conditions. 


\section{ADVANCED MONITORING DEVELOPMENT}

The research program of the Advanced Monitoring Development (AMD) Group is aimed toward developing novel and unique monitoring technologies to measure chemical pollutants and related biological indicators of environmental exposure and human health effects associated with energy-related technology development. The research approach of the AMD Group involves multidisciplinary research efforts targeted toward three major areas: (1) cost-effective chemical and biological screening techniques, (2) biological and chemical sensors, and (3) basic technical advances of emerging monitoring technologies.

In order to selectively detect pollutants with specific chemical groups such as nitroPAHs, new spectrochemical detection methods were developed. A novel technique developed in the AMD Group over the last five years is the surface-enhanced Raman scattering (SERS) technique. The SERS technique can enhance the Raman signal of chemicals up to factors of $10^{7}$ when these chemicals are adsorbed on SERS-active substrates. The SERS continuous monitor technology developed in the AMD Group was recently licensed to Gamma-Metrics, Inc., a California-based company, through the technology transfer effort of DOE and Martin Marietta Energy Systems, Inc.

Fiber-optic technology in the AMD Group has recently been applied to global atmospheric concerns such as the ozone depletion problem. In collaboration with members of the research staff from the Environmental Sciences Division (ESD) and the Instrumentation and Controls (I\&C) Division, AMD research staff members have developed a fiber-optic microprobe capable of measuring profiles of ultraviolet (UV-B) light within plant leaves in order to assess the effect of increased levels of UV-B radiation on terrestrial plant life. UV-B radiation, which has increased because of ozone depletion, could cause adverse ecological effects for this and future generations.

An area of increasing importance to the mission of the group is the application of advanced detection techniques to "biological monitoring" of environmental and human exposure to chemicals. This is a challenging area for research and development, and advances in chemical detection methodologies and instrumentation are critically needed to analyze complex biochemical systems in the attempt not only to monitor the presence of chemicals in the environment but also to assess the ultimate human health effects associated with chemical exposure. As sophisticated chemical detection technologies have developed over the years, the staff has applied, improved, or developed techniques for the measurement of "biomarkers" of chemical exposure and health effects. 
Other recent research activities have involved the following areas: (1) studies on the toxicity of cultured cells of by-products of electrical decomposition of $\mathrm{SF}_{6}$ and development of rapid, sensitive chemical screening assays for certain highly toxic byproducts identified in the cell culture studies; (2) development of ultrasensitive photometric sensors which can be used to remotely detect and quantify luminescent bacteria in complex mixed bacterial consortia. In this joint effort with the Environmental Sciences Division, these bacterial sensors are used in bioremediation of complex chemical waste sites, and the luminescent organisms are used as "biomonitors" of effective waste bioremediation processes, since their luminescence genes are coupled to activation of chemicalmetabolizing systems; and

(3) biodegradation studies designed to study possible effects of electromagnetic fields (ELF) on certain membrane properties/functions, with possible future applications to biosensors for ELF exposure. Work has been focused on modulation of phospholipid phase transition by ELF exposure, and/or effects on gap junction intercellular communication produced by ELF interaction with cellular systems.

Deoxyribonucleic acids (DNA) are central to the biomarker program since the chetnical genotoxic initiating event involves a permanent fixation of chemical damage to DNA during mitosis. The extent of damage to DNA can be estimated by quantitative measurements of total DNA damage. The measurement of DNA damage that does not have inherently sensitive spectrometric properties is a major challenge. We are developing a group of reporter molecules that have, both the necessary spectrometric properties and the ability to selectively react with specific classes of damaged DNA. We have demonstrated that PAC diolepoxide damage and radiation damage can be detected using a cis,vic-diol selective reporter.

Fiber-optic antibody-based fluoroimmunosensors (FISs) have also been developed through collaboration between the group and the University of Tennessee. Monoclonal antibodies produced against the benzo(a)pyrene $(\mathrm{BaP})$ derived DNA-adduct are immobilized at the terminus of a fiber-optics probe or contained in a microsensing cavity within the FIS for use both in in vitro and in vivo fluorescence assays. High sensitivity is provided by laser excitation and optical detection. The FIS device utilizes the backscattering light emitted at the remote sensor probe. A single fiber is used to transmit the excitation radiation into the sample and collect the fluorescence emission from the antigen. The laser radiation reaches the sensor probe and excites the $\mathrm{BaP}$ bound to the antibodies immobilized at the fiber-optics probe. This technique has considerable potential to perform trace analyses of chemical and biological samples in complex matrices. Measurements are 
simple and rapid ( $12 \mathrm{~min})$, and the technique is applicable to other compounds provided appropriate antibodies are used. Recently, the FIS instrument has successfully been used to detect DNA adducts in human placenta samples. The placenta samples contained one molecule of adduct of $\mathrm{BaP}$ per $10^{7}$ base pairs. The limit of detection of the FIS for DNA adducts of $\mathrm{BaP}$ is about 14 attomoles $\left(14 \times 10^{-18} \mathrm{~mol}\right)$. 


\title{
4. BIOMEDICAL AND ENVIRONMENTAL INFORMATION ANALYSIS SECTION
}

\author{
P-Y. Lu, Head
}

\section{Staff}

Research:
W. J. Allen
C. B. Bast
H. T. Borges
M. M. Brown ${ }^{1}$
G. M. Caton
S. S. Chang
G. S. Danford
M. W. Daugherty
K. A. Davidson
M. C. Davidson ${ }^{1}$
A. R. Ehrenshaft
E. L. Etnier ${ }^{1}$
R. A. Faust ${ }^{1}$
L. M. Floyd
A. A. Francis
M. W. Francis
R. T. Haas
G. T. Hawkins
C. G. Heckman
L. M. Houlberg
P. S. Hovatter
S. M. Hubner

Technical Support:

S. J. Campbell

G. E. Groover

M. E. Langston

J. H. Swenson

J. W. Taylor

K. A. Weaver

J. M. Wyrick ${ }^{1}$

Administrative Support:

D. G. Arnwine ${ }^{1}$

W. J. Barnard
B. W. Kline
E. B. Lewis
B. K. Mansfield
K. H. Mavournin
I. C. Miller
J. O. Mynatt
D. M. Opresko ${ }^{1}$
E. T. Owens ${ }^{1}$
A. A. Richmond
R. H. Ross
K. G. Slusher ${ }^{1}$
R. S. Stafford
J. M. Stockstill ${ }^{1}$
S. S. Talmage ${ }^{1}$
S. Y. Uppuluri ${ }^{1}$
M. S. Uziel
J. S. Wassom
B. L. Whitfield
L. A. Wilson
R. A. Young
L. N. Yust ${ }^{1}$

\author{
T. L. DuArt
}

G. J. Johnson 
Consultants:
A. E. Adamson
J. P. Hitch
S. E. Arnold
T. I. Hutcheson
R. L. Bigbee
G. F. Jones
R. E. Bock
S. E. Joy
J. M. Byrd
S. A. Martin
C. D. Cochran
S. Milanez
J. L. Couch
J. P. Poston
T. D. Cox
G. G. Santore
B. K. Flesher
C. R. Seiber
D. D. Hatmaker
P. L. Sherwood
J. C. Haufe
R. D. Spencer
S. L. Hawkins
J. M. Stockstill

Students:
B. A. Broyles
D. K. Casey
C. D. Craven
K. A. Davidson
G. L. Duthey
L. A. Eaton
T. G. Elledge
J. M. Goergen
J. J. Harrington
J. M. Hood
T. D. King
K. A. Kremin
A. E. Langley

C. J. Leonard

J. A. Martin

M. L. Mathis

E. P. McDonald

B. K. McKinley

D. F. Nagy

C. A. Pach

S. A. Poston

J. D. Rowe

S. L. Tayloe

S. C. Thompson

T. J. Threlkeld

K. E. Vagle

Subcontractors:

T. L. Berndt

D. J. Brusick

J. Dragun

J. B. Favor

G. L. Ginsberg

D. F. Goldsmith

G. H. Lambert

D. W. Layton

M. B. Maine
K. Menon
P. E. Mirkes
G. Oberdorster
J. L. Perkins
R. E. Purdy
V. E. Rose
G. D. Stoner
G. Witz
C. P. Yu

1Part-time employee 
The Biomedical and Environmental Information Analysis (BEIA) Section has been a part of the research and development environment of the Oak Ridge National Laboratory (ORNL) since BEIA's inception as the Environmental Information Systems Office in 1971. BEIA has historically maintained its strength by the integration of staff's talents and experience in the following areas: (1) building and maintaining peer-reviewed data bases; (2) developing methodologies and preparing health risk assessment of chemicals; (3) conducting federal and state regulatory information analyses; (4) developing computing technology (primarily PC-based applications) to handle a large volume and type of data/information; and (5) developing award-winning technical information communication resource projects. Since the last review period, BEIA has two staff members who have become Diplomats of the American Board of Toxicology (a total of four in the section), and has recruited subcontract staff members who are licensed attorneys. The collection of these resources makes BEIA a unique set-up that is not available elsewhere and enables us to stay competitive and expand to new projects.

The following sections are technical highlights accomplished by each group during this review period of October 1, 1991, through March 31, 1993.

\section{HUMAN GENOME AND TOXICOLOGY}

The Human Genome and Toxicology (HGT) Group develops and maintains several toxicology data bases and information files that are used in the overall process of evaluating the toxicological hazards of chemicals to humans and other living organisms. In addition to this primary focus,communication resources (newsletters, technical reports, etc.) are also produced that facilitate research and information exchange among scientists, administrators, and health professionals. The group's project activities are divided into three major areas: genetic toxicology; human genome; and general toxicology.

In the area of genetic toxicology, work has continued on the updating of the EMIC data base since its inception in 1968. The EMIC file contains information on over 22,000 chemical agents from studies published in over 80,000 scientific papers. A subfile on selected chemicals from the EMIC file has been created that contains the 3-D structures and peer-reviewed test results for over 4,600 chemicals evaluated in one or more of 23 genotoxicity bioassays. All structures in this file have been assigned to three chemical classification schemes that allow for a quick means of segregating chemicals with common structural characteristics. This feature, coupled with the ability to visually examine the 
structures of chemicals within a specific class, has proved to be an immensely effective tool for studying the influence of chemical structure on genotoxic activity.

As a result of the HGT Group's expertise in the field of genetic toxicology, a close working relationship is maintained with the International Commission for Protection Against Environmental Mutagens and Carcinogens (ICPEMC). Recently, ICPEMC requested that the group participate in two genetic toxicology risk assessment projects. One of these was for the Canadian Department of Health and Welfare, who asked for an assessment of the genetic risks of the chemical "acrylamide." The other project was for EPA, who asked for a report on risk assessment guidelines.

Many documents were prepared during this review period. In particular, a document was prepared that contained a compilation of test results on chemicals evaluated in the Salmonella/mammalian microsome assay. This assay is the most widely-used test system in the field of genetic toxicology. Results in this document were presented at the 205th American Chemical Society National Meeting held March 28-April 2, 1993, in Denver, and will be used as part of a special issue of Mutation Research devoted to the Salmonella assay.

Work in support of the national and international effort to map and sequence the human genome is carried out under the Human Genome Management Information System (HGMIS) task area. HGMIS was inaugurated in March 1989 to serve as one of the primary information resources for the DOE Human Genome Program. As part of its work, HGMIS produces a bimonthly newsletter and two technical reports per year for DOE. One of these reports consists of DOE's annual report for the Human Genome Program. The other report is on subject matter presented by grantees and contractors at the annual meeting of DOE-funded Human Genome participants held each winter in Santa Fe, New Mexico.

The work of HGMIS has provided the DOE Office of Health and Environmental Research with the opportunity to draw attention to its role in the overall effort within the United States to map and sequence the human genome. As a result of its successful work for DOE, the National Center for Human Genome Research at the National Institutes of Health has joined DOE in support of HGMIS and publication of the bimonthly newsletter. The first issue of this joint publication, The Human Genome News, was published in May 1990. Through March 1993, 21 issues have been published. The newsletter presently has a circulation of over 13,000 and is available to individuals throughout the world. A Primer on Molecular Genetics was written by the HGMIS staff for use by individuals not specifically trained in genetics. This document is now in it's third printing (over 12,000 copies) and has been extensively used by instructors in colleges and medical schools. 
The Toxicology Information Response Center (TIRC) is maintained by the group for the purpose of providing toxicologists and others with access to the vast toxicology literature. A cost recovery mechanism is used to defray expense for this service that has received several hundred search requests from all over the world. TIRC also assists many ORNL investigators and sister groups in BEIA throughout the year by providing information on subjects relevant to cngoing projects.

Working in cooperation with Dr. Richard Woychik of the Biology Division, a data base on transgenic animals and targeted mutations is being developed. This data base will be used to catalog and organize information on lines of animals that have been generated worldwide using transgenic or targeted mutation methods. Extensive information about transgenic or targeted mutation constructs, including methods, expressions of the transgene or targeted mutation, and phenotypes, will be available from this new data base.

The group is working with the Institut de la Vie in Paris, France, and the Joint Institute for Energy and Environment located at the University of Tennessee in Knoxville, on the development of a Plant Genetics Information Center. The organizational concept of the center will be focused on the creation of a central computerized (yellow page concept) directory of all known plants located throughout the world, beginning with those classed as endangered or threatened. This file will be linked to other national and international data bases via INTERNET. The center will serve to enhance the timely and unrestricted exchange of information about the diversity of plants for use by scientists, conservationists, and others from all nations. Initiation of this project is planned for the fall of 1993.

\section{CHEMICAL HAZARD EVALUATION AND COMMUNICATION}

Federal and state governments are charged by congressional mandate with protecting public health and preserving environmental quality under various environmental regulations, such as the Toxic Substances Control Act (TSCA), the Clean Air Act (CAA), the Safe Drinking Water Act (SDWA), and Superfund and its amendments [Superfund Amendments Reauthorization Act (SARA)]. The staff members of the Chemical Hazard Evaluation (CHE) Group have assisted EPA, the Agency for Toxic Substances and Disease Registry (ATSDR), the Department of Defense (Air Force, Army, and Navy), and the states of New York and Tennessee in developing scientific documents and technical reviews on chemicals potentially subject to these and other regulations. These reports facilitate the decision-making process of establishing permissible toxic levels for chemical regulation. Types of reports include: Chemical Hazard Information Profiles; Health 
Advisory Documents; Health and Environmental Effects Documents; Methodology Development for Occupational Health Criteria; Problem Definition Studies; Reference Dose Profiles (oral and inhalation); Reportable Quantity (RQ) Profiles (chronic toxicity and carcinogenicity); and Water Quality Criteria Documents. A brief description of several recent and ongoing programs is presented in the following paragraphs.

In support of the Department of Defense Installation Restoration Program (IRP) and the Martin Marietta Energy Systems Environmental Restoration Program, CHE staff members are providing guidance on scientific and regulatory issues and defining clean-up criteria for hazardous wastes sites. The Army and Energy Systems have numerous waste sites that must be remediated in accordance with applicable EPA policies and guidelines. CHE scientists are using their knowledge of EPA's regulations and risk assessment strategies to define the necessary criteria for conducting initial hazard assessment. An example is the situation at East Fork Poplar Creek in Oak Ridge where mercury contamination of soil and sediment has been characterized as consisting of a tightly-bound insoluble form (e.g., mercuric sulfide). Consequently, a value of $0.04 \mathrm{mg} \mathrm{HgS/kg/day} \mathrm{was} \mathrm{derived} \mathrm{from} \mathrm{a}$ suitable study, which led to the withdrawn Integrated Risk Information System (IRIS) value of $0.0(0) 3 \mathrm{mg} \mathrm{Hg} / \mathrm{kg} /$ day for mercuric chloride. Use of the site-specific value would have significant impact on remediation cost and effort.

The first draft of the Evaluation of the Potential Carcinogenicity of Electromagnetic Fields document was prepared for the EPA, Office of Health and Environmental Assessment, to examine the possibility that nonionizing, electromagnetic radiation poses a risk or is a risk factor for the development of cancer in humans. ORNL and EPA scientists reviewed open-literature data that characterize the potential carcinogenicity or possible mechanisms for the carcinogenicity of extremely low frequency and radio-frequency fields. The major topics reviewed included mechanisms of action, epidemiology, bioassays, and biological effects. Completion of the revised and updated document, which will address the recommendations of an EPA Science Advisory Board Subcommittee and incorporate numerous new references, is tentatively scheduled for early 1995.

The Health Assessment Document for Diesel Engine Emissions has undergone EPA review and limited external review. EPA staff are currently revising their original quantitative assessment for inclusion in the final document. Research efforts are currently under way at the University of Rochester addressing additional areas of concern regarding the role of carbon particles in the process of diesel emissions-induced pulmonary carcinogenesis. In anticipation of finalizing the document, ORNL staff members are 
continuing to retrieve and evaluate new literature regarding the health effects of diesel engine emissions.

A Health and Environmental Assessment Document was researched and written on 11 nitrosamines. Subject areas included environmental fate, aquatic toxicity, pharmacokinetics and metabolism, subchronic and chronic systemic toxicity, carcinogenicity, genetic toxicity, and reproductive and developmental toxicity. The 11 nitrosamines are placed in EPA's Group B2 (probable human carcinogen). Slope factors (based in $\mathrm{q}_{1}{ }^{*}$ at low dose) and potency factors (1/ED10 at risk of $10 \%$ ) were calculated using EPA's multistage model. Although it is generally accepted that carcinogenic potencies of nitrosamines vary inversely with chain length for dialkylnitrosamines, $N$-nitrosodi- $n$-propylamine is more potent that either $N$-nitrosodimethylamine or $N$-nitrosodiethylamine. Among the cyclic nitrosamines, $N$-nitrosopyrrolidine is more potent than $N$-nitrosopiperidine, which is more potent that $N$-nitrosodiphenylamine.

RQ documents are prepared for EPA's Office of Solid Waste and Emergency Response. They are intended to provide health-related limits for emergency actions under Section 101 of the Comprehensive Environmental Response, Compensation and Liability Act (CERCLA). The RQ value of 1, 10, 100, 1000, or 5000 pounds is used to determine the quantity of a hazardous substance for which notification is required in the event of a release, as specified by CERCLA. BEIA is the focal point for the preparation of RQs based on carcinogenicity and chronic toxicity, two of the six primary criteria used to adjust $R Q$ s from their statutory level of one pound. Thus far, over $150 \mathrm{RQ}$ documents have been prepared by the CHE Group.

In conducting remedial investigations under the CERCLA Act of 1980 and its amendment, the SARA Act of 1986, it is essential to have chemical-specific Assessment of Applicable or Relevant and Appropriate Requirements (ARARs) and advisory criteria for all chemicals of concern. This includes both state and federal values for surface water, groundwater, air, soil, and sediment. This multimedia approach is necessary because risk assessments mus! consider all relevant exposure routes for many chemicals; human exposure by more than one exposure route is a very distinct possibility. BEIA is the focal point for the preparation of ARARs for the U.S. Army's Installation Restoration Program and for the Environmental Restoration Program at the Oak Ridge Reservation. The consolidation of this activity has proven to be a very cost- and time-efficient effort since much of the data is applicable to more than one remediation effort. The concept of resource consolidation to a major new project has just been started under the Strategic Environmental Research Development Program to: (1) develop toxicity values for specific chemicals of 
interest to the Department of Defense, DOE, and for other agencies at a later date; and (2) enhance the existing EPA's IRIS.

Literature on the environmental and human safety of two classes of nonionic surfactants, alcohol ethoxylates and alkylphenol ethoxylates, were reviewed for the Suap and Detergent Association. The assessment covered information with respect to product chemistry and analysis, biodegradation; environmental levels, including fate and distribution; aquatic toxicity; and human safety. The result is a critical review of the available data base and is a unique resource for those undertaking risk assessments on nonionic surfactants and formulated products containing nonionic surfactants. The assessment will be published in two reports by the National Technical Information Services and as a book by Lewis Publishers.

\section{ENVIRONMENTAL REGULATIONS AND REMEDIATION}

During this period, the Environmental Regulations and Remediation (ERR) Group has expanded its activities in the environmental regulatory arena, focusing on analyses and "Alert" activities. Regulatory analysis activities have been enhanced by law students and graduates from the University of Tennessee, who have teamed with the scientific staff to provide a versatile, well-balanced resource. The law personnel are currently provided through subcontract (one of whom will soon become a MMES employee), and the staff includes four licensed lawyers and several students. This has enabled the program to expand to include analysis of regulations for the Analytical Project Office (APO), the Decontamination and Decommissioning (D\&D) committees for both K-25 and ORNL, and the Army and DOE for the ARARs. They also provide an excellent resource for researching the regulations and DOE requirements needed to prepare Standard Operating Procedures for ORNL's Environmental Compliance and Documentation Section, the Environmental Restoration Program, and the K-25 Site.

In the environmental regulatory analysis area, work has continued on the collaboration with the Environmental Sciences Division to provide DOE with analysis of the environmental legislation, as well as information on pending legislation through publication of the Environmental Reference Books and the Regulatory Update Tables. These publications currently are sent to more than 800 requestors, DOE, and DOE-approved contractors and managers.

As the need for regulatory analysis information continues to expand, the Environmental Safety and Health News (ESHNEWS), a current-awareness weekly publication on issues 
of environment and safety, continues with new features developed this year. The circulation has steadily increased as the emphasis on rapidly changing information in regulations raised awareness of implications of responsibility.

To further expand on regulatory awareness, a special project, labeled APO Alert, has been developed for the Analytical Project Office (APO) of MMES. The Federal Register is scanned each week to provide analytical laboratories within MMES any new requirements or developments of interest. Additionally, the pending legislation (with the projected effective dates) likely to affect these laboratories has been identified and is tracked monthly through congressional offices to provide a "heads up" alert of items likely to affect laboratory operations.

A state regulatory data base is under development to track the status of promulgated and proposed regulations on a federal and state-by-state basis. Current projects involving state regulations have shown that there is a need for such a data base, and none appear available commercially or otherwise. Hard copies of surface, ground, and drinking water regulations have been collected for each of the 50 states and the District of Columbia (DC). Phone contacts have been established with state water officers of all states and DC to verify/clarify and regularly update the regulations. A test $P C$ version is under development. This is a natural growth from the Air Force Project which produced The Installation Restoration Program Toxicology Guide. This guide has a comprehensive chapter on federal and state water regulations. Further analysis of the state regulations show that surface water regulations are established by each state based on "use" classification of each body of water within the state. The surface water regulations would be indexed by water body, water use classification, chemical, and specific numeric criteria for each chemical or water use classification. Each state may have regulations for air, soil, hazardous waste, and radioactive waste media, which may or may not exceed federal regulations. BEIA is proposing to collect multimedia information for all states and to develop publication reports and user-friendly applications for computer-based products.

Since the U.S. Secretary of Energy Notice (SEN)-7A-90 directive no longer requires each site to report to the DOE via a monthly compliance report, the ERR-developed tracking systems have continued in their capacity of providing useful reports for the sites; but the massive reporting previously required is now a quarterly report. The ERR Group expanded the environmental compliance work by developing the program and procedures for migration from the current tracking systems to the Energy Systems Action Management System (ESAMS). This work is being done for Y-12 and for ORNL. ERR is to maintain the files for these compliance organizations on ESAMS. 
Specialized applications have been developed to support ES\&H activities. ERR completed the ManTrack (manual tracking) software and associated user's manual, which was developed for controlled document tracking, and as a user and reference guide. ManTrack is distributed to DOE contractors upon request. It is designed to facilitate the generation of reports pertinent to ES\&H compliance. This project was a collaborative effort with the Office of Operational Readiness and Facility Safety at ORNL.

Information management support has been provided to the Biofuels Feedstock Development Program. This program is national in scope and is an integral component of the United States' efforts to reduce dependence on fossil fuels, as well as to provide the country's farmers with additional financial opportunities. It is funded by DOE, Biofuels System Division, with technical management at ORNL provided by a group in the Environmental Sciences Division. Personal computer-based data bases were created or expanded to serve as repositories and analysis tools for the data and materials generated by the program's staff and the principal investigators. Energy Crops Forum, a newsletter designed to facilitate communication and an awareness of ongoing research among the research community, transfer research results to those outside the research community, and to identify and develop a constituency for energy crops research, is distributed to more than 2100 recipients worldwide. Thu extensive collection of multimedia resources has been organized and catalogued, and the development of customized information packages is under way.

The ERR Group maintains the Waste Document Library. In this capacity, ERR provides information support for a wide variety of chemical technology projects, such as: Zeolite studies; Iodine Chemistry Evolution; Mixed Waste Treatment Technologies; and Fluoride Volatility Studies. Other divisions are provided informational support, such as wiring diagrams for the D\&D waste management treatment technology sections of the K-25 and ORNL Sites. Additionally, a data base has been developed for the K-25 treatment technologies.

\section{INFORMATION MANAGEMENT TECHNOLOGY}

Expert systems applications and communication resources were used to respond to information management needs in many areas, from en $\%$ ironmental compliance to advanced materials. They are briefly described as follows:

A PC-based expert system was developed for the Health, Safety, Environment, and Accountability Division to assist in performing an internal assessment to determine the $\mathrm{Y}$ 12 Plant's compliance with environmental laws. These laws, on 11 different categories 
including Clean Air Act, Clean Water Act, RCRA, SARA, etc., are mainly federal laws, but also include some DOE Orders and plant standards. This system enabled data from different organizational units to be merged into a master system, thus providing a means of preparation for consolidated reports on noncompliance. A presentation and demonstration of this system was given at the American Chemical Society Annual Meeting.

Another expert system, National Environmmental Policy Act (NEPA) Environmental Review and Compliance, is being developed for the K-25 Environmental Management Department. This expert system, containing legislation, will help determine the type of documentation needed to respond to NEPA requirements and to prepare draft categorical exclusion documentation.

Other computer applications include a tracking system for NEPA documents for five Energy Systems sites (K-25, ORNL, Y-12, Paducah, and Portsmouth); a system to catalog en ironmental compliance correspondence; an inventory of federally funded Continuous Fiber Ceramic Composite (CFCC) research and development; and a contacts list for the CFCC Program.

In the communication resources area, desktop publishing techniques have been developed for several applications including the preparation of newsletters; revision of a Drinking Water Regulations poster; preparation and updating of reference books on legislation; development and preparation of symposia proceedings; preparation of a monthly summary report of projects concerned with technology development activities; and composition of brochures and public relations material. The international Ceramic Technology Newsletter communicates developments in the ceramic technology of advanced heat engines to over 1200 interested persons in the United States and abroad. The newsletter received Society for Technical Communication (STC) Awards in 1992 and 1993. Another international newsletter, Radon Research Notes, supports the DOE Office of Health and Environmental Research's Radon Research Program. It describes radon research conducted by DOE, other federal agencies, and the Commission of European Communities, and is distributed to over 2200 interested persons. This newsletter also received STC awards in 1992 and 1993. CFCC News, a Communication of the Continuous Fiber Ceramic Composite Program, was initiated and was well received. This newsletter is restricted to circulation in the United States and is concerned with the development of CFCC materials.

An internal newsletter, HASRD safety notebook, was produced to assist in communicating safety information to the Health and Safety Research Division staff. It won an STC award in 1992. 


\section{RISK ANALYSIS SECTION}

C. C. Travis, Head

\section{Staff}

Research:

L. M. Anderson

A. Q. Armstrong

C. J. Maxwell

B. P. Blaylock

C. W. McGinn

R. R. Bonczek

D. B. Miller

R. A. Brothers

P. D. Miller

H. C. Dees

J. M. Morris

D. M. Douthat

B. D. Nourse

M. D. Dykes

P. Y. Gray

G. L. Shrum

J. L. Skiles

A. D. King

M. E. Stack

M. L. Land

S. E. Stinnette

J. M. MacInnis

J. K. Thomas

R. K. White

Administrative Support:
A. G. Evers
S. L. Huling
J. L. Mellon
B. L. Ramsey

R. G. Self

L. E. Thurston

V. G. Vest

Technical Support:

A. L. King

Subcontractors:

R. L. Adams

B. E. Bergenback

M. J. Bailey

P. C. Bandy

B. P. Blaylock

L. R. Bond

R. R. Bonczek

S. M. Boyens

V. P. Breeding

R. A. Brothers

A. C. Campbell

D. M. Cox

K. L. Culp

I. C. Datskou

E. A. Davis

H. C. Dees

J. W. DeLoach

J. S. Foster

E. Gamliel

M. S. Hanson

J. B. Harstin

T. J. Hatcher

D. C. Henley

M. A. Herbert 
S. M. Holcomb

J. L. Holmes

J. F. Hutchinson

S. M. Ince

D. W. Johnson

R. J. Keller

A. D. King

R. C. Kramel

B. Ladd

C. W. Lanier

J. L. Legg

B. S. Mathis

L. A. Matthews

C. M. McCaskill

D. E. McGinley

K. C. McKown

I. S. Messer

L. H. Morgan

J. M. Morris

L. D. Nanstad

J. S. Nicholas

K. T. O'Kane

P. A. Pehlman

R. M. Perhac

R. H. Phillippi

Postdoctoral Fellow:

B. F. Lyon
S. D. Phillips

M. D. Piller

T. S. Purucker

S. K. Robers

M. W. Ross

L. Scott

G. L. Sharp

R. A. Shaw

R. E. Sherrod

J. P. Simek

W. M. Simmons

C. W. Smith

M. E. Stack

D. M. Steinhauff

J. F. Sutherland

D. J. Sutton-Simerly

A. L. Thayer

M. J. Waehner

E. R. Wheeler

W. W. Wheeler

K. A. Wilbert

C. J. Willey

D. A. Woolert

M. T. Worthington

Guests:

S. M. Book

R. L. Douglas

B. Tabor

Loanees from other divisions:

T. K. Evers ${ }^{1}$

D. M. Hetrick ${ }^{1}$

B. L. Nee' $v^{3}$

J. A. Holmes ${ }^{1}$

R. Hull ${ }^{2}$

M. R. Patterson 1

P. M. Ratledge 1

P. A. Scofield ${ }^{4}$

${ }^{1}$ Computing Applications Division.

${ }^{2}$ Environmental Sciences Division.

3Publications Division.

${ }^{4}$ Office of Environmental Compliance. 
The mission of the Risk Analysis Section (RAS) is to develop and apply methodologies for assessing the human health impact of environmental pollutants; to evaluate the costeffectiveness of proposed and ongoing environmental restoration and waste management activities; to implement effective waste management practices; and to provide programs in education and communication of risk. The section is divided into eight areas: hazardous waste; environmental restoration; waste management; risk data systems; molecular toxicology; D\&D applications; technology demonstrations; and education, training, and communication.

Clean up of hazardous waste sites will continue to be a national priority for the next 2030 years. There is an ongoing demand for research and development to enhance the costeffectiveness of remediation activities at DOE facilities. Members of the staff serve as national leaders in developing methodologies to accomplish this goal.

The section is also involved in improving computer-enhanced analyses of environmental data to support risk decision-making. The use of Geographic Information Systems (GIS) as an analysis and risk management tool is being promoted at local and national levels. The RAS staff, in conjunction with the Geographic Data Systems (GDS) section staff in the Computing Applications Division are developing GIS to support health assessments and other health studies at hazardous waste sites.

The staff of the molecular risk analysis laboratory are using molecular biology as a tool to perform research to reduce uncertainties in the risk analysis process. They are currently developing molecular biology-based, short-term screening assays to evaluate chemicals for carcinogenicity, to assess media contaminants, and to assess contaminant concentrations.

All staff members are involved in promoting awareness and increasing understanding of human health and environmental risks to various audiences, including school-aged children, the general public, and risk professionals. Staff members are also active in developing technical training workshops for public health professions in need of specialized training in the risk assessment area.

\section{ENVIRONMENTAL RESTORATION}

Formed in 1992, the Environmental Restoration (ER) Group is involved in deriving and applying risk assessment methodologies for all stages of environmental restoration activities, including analysis of health risks to members of the public from unremediated DOE hazardous waste sites. Current risk assessment methodologies are evaluated and modified to meet the specific needs of federal facilities. 
In addition to assessing baseline risk conditions at DOE sites, the ER Group determines the potential health risks incurred during remedial efforts at hazardous waste sites. The group is involved in the derivation and automation of a comprehensive remedial worker risk assessment methodology, which is the first comprehensive methodology designed to address risk to workers involved in environmental restoration activities.

The group evaluates and compares various environmental contaminant fate and transport models and develops methodologies that integrate the use of these models into standard risk assessment protocols.

The ER Group assists DOE Headquarters in the preparation of risk assessments in support of the Programmatic Environmental Impact Statement (PEIS), a comprehensive evaluation of public and worker risk from the ER activities scheduled for implementation across the DOE Complex. Other projects of this group include the investigation of sources of particular environmental contaminants, including mercury and dioxin.

\section{HAZARDOUS WASTE}

The Hazardous Waste Group's (HWG) activities are focused on the management of the DOE/ORO Environmental Restoration Risk Assessment Program. The group oversees all ER-related risk assessment activities conducted by the numerous Martin Marietta Energy Systems (MMES) subcontractors and other DOE prime contractors, as authorized by DOE/ORO; leads and manages the Risk Assessment Council (RAC); provides risk assessment support in the way of policy and guidance for the five MMES-ER plants: ORNL, Y-12, K-25, Paducah and Portsmouth; provides general risk assessment support to the D\&D Program; and conducts risk assessments for the ER Division.

The HWG has been mandated by DOE-ORO to oversee and report on all ER-related risk activities at the five Energy Systems sites. The group's objective is to ensure the technical defensibility of risk assessments conducted at ER sites. This responsibility is met by making sure the latest guidance from U.S. EPA and the RAC is followed by all contractors. The group works closely with MMES-ER project managers to evaluate the characterization information and methodologies applied in each risk assessment.

As the leader of the Risk Assessment Council, the HWG is responsible for focusing and integrating the efforts of the council with the needs of the site ER programs. The council provides guidance on appropriate risk assessment methodology and procedure, develops methodologies and procedures, and supports MMES-ER Program's risk assessment needs through research and development that critical risk assessment data gaps. 
In support of MMES-ER Programs, the group has appointed a liaison to each site to work on a daily basis to ensure that the risk assessment needs of the programs are met. Site-specific risk assessment strategies and guidance are addressed by the group. The group is responsible for presenting site-specific risk information to EPA, DOE, and the public.

The HWG is involved in developing a strategy for the implementation of human health and ecological risk assessment for the D\&D Program to serve as a basis for all risk assessment activities conducted at these facilities. This association presents opportunities for the development of methodologies supportive of the objectives of the ER Program as well as D\&D.

Although involved extensively in oversight and technical support responsibilities, the primary focus of the HWG is to perform human health risk assessments. The group has developed an approach in support of the operable unit strategy defining the extent of risk assessment necessary to justify various response actions. It is extensively involved in the risk evaluation of exposure to contaminants at ER source and integrator operable units to document the decisions made under the CERCLA process. The group's application-related activities include the evaluation of baseline risk, screening-level risk assessment, risk prioritization, and alternative evaluation.

\section{MOLECULAR TOXICOLOGY}

The Molecular Toxicology Group performs numerous applied and basic research projects, all of which are linked to the application of the newest, most sensitive, and specific molecular biology and biotechnological methods. They address questions of human risks from materials associated with energy use and production. The research includes studies designed to elucidate the basic molecular alterations that occur after exposure to chemicals or radiation. The group uses the new basic knowledge on the mechanisms of chronic and acute cellular damage to design molecular biology-based diagnostic assay technologies that can be used to give more accurate estimates of exposure risks from chemicals and radiation. In addition, this group is designing new assay methods to detect previous exposure of energy workers to toxic substances (biomarkers). New assays to improve the prediction of illness in workers with known exposures to toxic substances are also under investigation.

The group is applying the most modern biotechnology-derived methods to enhance biomass conversion in collaboration with other groups at ORNL. The ability of cellulose

degrading (wood eating) bacteria to degrade waste paper products is being enhanced using 
genetic engineering methods. These bacteria will be commercially used to address space problems in landfills caused by cellulosic waste volume and to successfully degrade waste cellulose to an alternative fuel.

This group serves as the source of molecular biology and biotechnology services for collaborative research efforts in the Health and Safety Research Division and other groups at ORNL. It also provides an environment for training undergraduate and graduate students in the most modern molecular biology methods.

\section{RISK ASSESSMENT APPLICATIONS AND TRAINING}

The Risk Assessment Applications and Training (RAA\&T) Group, formed during the current review period, has been involved in a number of activities centered around program development, conducting risk assessments at sites, workshop development and training, technology demonstration projects, and a MMES-ER project.

Of special note is the establishment of a matrix program with the Hazardous Waste Remedial Action Program (HAZWRAP) to manage the Risk Assessment Group for the Technical Operations Section. Staff from the RAA\&T Groun, the Waste Management Group, and existing HAZWRAP staff have formed a team to develop HAZWRAP's risk assessment program. Together they will conduct risk assessments for HAZWRAP sites, as well as provide overall program development, training, and contractor oversight.

The group also conducts risk assessments for the DOE and other government agencies. Risk assessments have been performed at the DOE Savannah River Plant and at Wright Patterson Air Force Base in Ohio. Currently, the group is working with the Uranium Mill Tailings Remedial Actions (UMTRA) Project, and the Programmatic Environmental Impact Statement (PEIS) to develop a probabilistic risk assessment approach and soil clean-up standards. Assistance in conducting site-specific assessments is also provided for UMTRA.

The RAA\&T Group has been actively involved in training for the Agency for Toxic Substances and Disease Registry (ATSDR) and for DOE. Workshops for ATSDR include Public Health Training Workshops, Module Training Workshops, an International Public Health Assessment Workshop, and a year-long series of workshops conducted for Air Force site personnel who will be involved with ATSDR on federal facility public health assessments. DOE workshops include general risk assessment training courses for DOE Headquarter's ER/WM organizations, and a course focused on representatives from the DOE operations offices. The group is developing a series of basic and advanced 
workshops covering a number of risk assessment issues that will be provided for the Office of Environmental Guidance at DOE.

Work with technology demonstration projects has centered on performance evaluations of remedial technologies for characterizing and treating uranium contamination in soils, focusing on the assessment of relative reduction in risk from various technologies and cost/benefit analysis, and relating reduction in risk to dollars spent. Methodological considerations for evaluating risks from soil exposure are being addressed and will serve to document clean-up levels developed.

Work continues at the Savannah River Plant in the form of additional risk assessments and participation in the development of quarterly information exchange meetings. Participation in the development of a risk assessment council similar to the Energy Systems Risk Assessment Council provided an opportunity to share HASRD experience with the Savannah River program.

Support for the MMES ER Program has been limited by the scope of our organization; however, the group is responsible for managing the ER Division's annual aerial survey conducted at the Oak Ridge Reservation.

\section{RISK DATA SYSTEMS}

The work of the Risk Data Systems Group involves (1) the creation and collection of health and environmental data to support risk decision-making; (2) the development of data base systems for efficient storage and retrieval of data for risk prioritization and analysis; (3) the use and enhancement of computer codes to model biological effects and environmental fate and transport; (4) the use and promotion of GIS as an analysis and risk management tool to support environmental restoration and human health assessment activities; and (5) the analysis of various assessment tools, methodologies, and remedial technologies to determine effectiveness.

Specific projects/accomplishments of the Risk Data Systems Group during this reporting period are highlighted below:

- A methodology was developed to quantify statistical uncertainty in cancer potency estimates by determining frequency distributions; uncertainty distributions for over 20 chemicals commonly found at DOE facilities have been determined. This approach is useful when conducting probabilistic risk assessments where the range and best estimate values, as opposed to most conservative values, are commonly used. 
- Results of a pharmacodynamic modeling project simulating simultaneous exposure to benzene and toluene in rats have been published in Toxicology Letters.

- Cancer modeling currently is being conducted as part of a DOE-funded project to analyze spontaneous and chemically induced hepatocarcinogenesis using a code that has been extensively modified and improver by Risk Data Systems staff.

- Comparison studies of MEPAS and other environmental fate and transport models or assessment methodologies were conducted.

- In collaboration with the Chemistry Division, a neural network program is being developed to compare neural networks with multiple linear regression. A prototype of the code has been completed.

- Various data bases were developed to support risk prioritization, including the worker risk analysis data base developed to support the DOE PEIS project and the Central Waste Management data base developed to prioritize projects based on their associated risk.

- In conjunction with the GDS Section staff in the Computing Applications Division, a prototype GIS system is being developed for ATSDR to support health assessments and other health studies at hazardous waste sites.

- Risk Data Systems staff provide interface between ATSDR and DOE to facilitate ATSDR activities across the DOE complex.

- A workshop was held for DOE to address common issues of concern on groundwater remediation across the DOE complex, and three GIS Information Exchange meetings have been held for GIS practitioners in ER Programs at DOE facilities.

- A critical review of selected remediation technologies that are currently being used in the field or that are in the pilot test phase of implementation have been conducted; results have been published.

- Under the direction of DOE/EM-40, Risk Data Systems staff are performing a comparative risk assessment of the Molten Salt Oxidation (MSO) technology with the baseline technology of incineration and addressing additional alternatives to incineration.

- Risk Data Systems staff serve as development team leaders for the Oak Ridge Environmental Information System (OREIS), a system currently being 
developed to consolidate environmental measurement data from the five DOE/ORO sites.

\section{WASTE MANAGEMENT}

The Waste Management Group was formed in 1992 to provide risk assessment expertise on the seven types of DOE-managed waste and DOE waste management activities. The group is currently involved in a programmatic risk assessment of waste management activities for the DOE Programmatic Environmental Impact Statement (PEIS). These activities include the treatment, storage, and disposal of managed waste across the entire DOE complex.

The purpose of the PEIS is to provide DOE with information pertinent to consolidation alternatives for managed waste. This group is assessing the human health risks from waste management activities. It is divided into two teams: (1) The Worker Risk Team is concerned with the exposure of personnel directly involved in the treatment, storage, and disposal of DOE-managed waste. These personnel are in close proximity to the waste and are assessed separately from other populations; and (2) The Public Risk Team assesses the risks to on-site and off-site populations. All populations are assessed for exposure to chemicals and radionuclides released from routine operations and postulated accidents.

The Waste Management Group is also participating in a matrix program with HAZWRAP to provide additional risk assessment expertise when required. This program will provide the group with the opportunity to apply the knowledge gained from the PEIS to other projects within Energy Systems.

\section{PROGRAM INTEGRATION AND ADMINISTRATION}

The Program Integration and Administration Division (PI\&A) Technical Programs Activity Data Sheet (ADS) provides direct technical and administrative support to promote responsive and uniform Environmental Restoration (ER) and Waste Management (WM) program activities. The Technical Integration ADS serves to consolidate, perform, and manage critical field, analytical, reporting, and accounting services from a single multisite platform. This ADS synthesizes and coordinates DOE-ORO site characterization, remediation, and D\&D efforts to enhance the efficiency, coherence, and economy of Energy Systems environmental programs. 
The programs within this ADS provide essential technical support, integration, and oversight services to ensure the proper identification, characterization, remediation, and revitalization of contaminated sites.

Technical Programs provides interdisciplinary support on both a programmatic and project level basis. Responsibilities include the management and performance of technical support work in the following four program areas:

- Risk Assessment

- Groundwater Programs

- Federal Facilities Agreement/Tennessee Oversight Agreement (FFA/TOA) planning and implementation

- Technical Review Committee (TRC) Oversight

In addition, Technical Programs manages quarterly Westinghouse Savannah River Company (WSRC)/Energy Systems ER Technical Exchange Meetings, coordinates interactions between ER and the Center for Risk Management, oversees the development and implementation of risk assessment standards and methods, and directs ER roadmapping activities.

The mission of Technical Programs is to provide vital oversight, integration, and technical support to promote quality, consistency, and efficiency in DOE-ORO ER-WM activities. The paramount goal of Technical Programs is to serve as a center for excellence in the development, implementation, and management of scientifically and economically sound ER, WM, and D\&D practices and procedures. Technical Program's programmatic goals are to:

- $\quad$ serve as the lead contractor for DOE-ORO risk assessment development and implementation work;

- provide an integrated groundwater program through the Groundwater Program Office (GWPO), which encompasses all DOE-ORO groundwater characteri-zation and remediation activities and ensures technical quality and consistency in DOE-ORO site groundwater programs;

- coordinate and provide oversight for FFA/TOA planning and implementation activities, including the production, tracking, and control of FFA/TOA milestone documents;

- manage the Technical Review Committee (TRC), which serves as ER's primary, independent, technical review resource; and 
- coordinate the Westinghouse Savannah River/Energy Systems Technical Exchange quarterly meetings.

The following technical objectives are applicable to Technical Programs:

- provide overall coordination and direction for the technical components supported (e.g., Risk Assessment and FFA/TOA Implementation);

- maintain consistency and standardization across all program elements;

- ensure that ER site programs and DOE requirements are satisfied; and

- ensure integration of technical requirements and activities for DOE-ORO contractors (Radian, M. K. Ferguson, etc.).

The goal of the WSRC/Energy Systems ER Technical Exchange Meetings is for Westinghouse and Energy Systems to exchange information and lessons learned based upon their respective ER program experiences. 


\title{
6. CENTER FOR RISK MANAGEMENT
}

\author{
C. C. Travis, Director
}

The Center for Risk Management, established as a center of excellence in June 1991, is housed in the Health and Safety Research Division and was established with the support of the Environmental Restoration Program. A major mission of the center is to focus the laboratory's resources more strongly on evaluating risks to human health and prioritizing and solving environmental problems related to energy production and consumption.

The Center for Risk Management will (1) improve communication between scientists working in different divisions and programs; (2) ensure that risk assessments and analyses performed for all sponsors meet the highest possible standards of technical excellence; (3) provide a common focus for marketing a laboratory-level initiative in risk assessment, analysis, and management; (4) assure the prior application of technical, social, and political input into our assessments; (5) promote training and educational initiatives aimed at professionals in the field and the public; and (6) establish Energy Systems as a national leader in the risk assessment area. 


\title{
7. ASSOCIATED LABORATORIES FOR EXCELLENCE IN RADIATION TECHNOLOGY (ALERT)
}

\author{
J. S. Bogard, Manager
}

The Associated Laboratories for Excellence in Radiation Technology (ALERT) is a health physics instrumentation and dosimetry support program which coordinates calibration, testing, maintenance, research, and development capabilities at Martin Marietta Energy Systems, Inc., facilities. ALERT is a matrix organization comprised of three divisions at the Oak Ridge National Laboratory (Health and Safety Research, Instrumentation and Controls, and the Office of Radiation Protection) supplemented by unique capabilities at other Energy Systems facilities. An ALERT Manager is chosen from the organizational representatives to provide strategic planning and to act as the primary contact with clients. ALERT draws from the professional, technical, and administrative resources of its constituent organizations. This program utilizes staff expertise and unique Energy Systems facilities and is available as a service to DOE, other government agencies, and to the private sector.

The ALERT mission is to extend the leading edge of health physics technology and to provide services not otherwise available in the commercial market. This is accomplished by providing integrated multidisciplinary efforts to improve instrumentation, dosimetry, and calibration; by providing improved health physics support to the federal community; by supporting the implementation of new regulatory standards and guidelines; by addressing needs and charting future directions of health physics measurement issues; by improving the quality of health physics practices; and by providing services to customers as part of the National Institute of Standards and Technology (NIST)-supported national standards network. 


\title{
8. CONTRIBUTIONS TO NATIONAL AND LEAD LABORATORY PROGRAMS AND ASSIGNMENTS
}

\section{ENVIRONMENTAL RESTORATION}

\author{
P. Y. Lu, R. E. Swaja, and C. C. Travis
}

The Health and Safety Research Division (HASRD) has numerous and diverse initiatives with the Department of Energy (DOE) Environmental Restoration (ER) and Waste Management (WM) Program. These initiatives are at the local, national, and international level, and collectively represent a growth area of research in HASRD.

The Risk Analysis Section (RAS) contributes to both local and national environmental restoration research and development (R\&D) efforts. At the local level, the extent and choice of environmental restoration strategy depends, in part, on estimates of human health and environmental risks. This section provides risk assessment oversight of DOEOR facilities to ensure consistent and reliable estimates of human health and environmental risks. The leader of the Hazardous Waste Group in the section serves as the coordinator of the Central Risk Assessment Council (CRAC), and the ER Program; other staff serve as CRAC members. At the national level, a DOE environmental restoration priority is the development of technically feasible and cost-effective remedial alternatives for cleanup activities. DOE is currently conducting technical demonstrations of innovative remedial alternatives at various DOE facilities. RAS staff serve as leaders and members on these multifacility teams.

The RAS is performing the health and environmental risk analyses to be the basis of the Programmatic Environmental Impact Statement (PEIS) for the DOE environmental restoration effort. The PEIS is part of a process that will establish a consistent, integrated national approach to manage ER and WM activities at the more than 10,000 DOE hazardous waste sites across the country.

The Biomedical and Environmental Information Analysis (BEIA) Section performs a number of developmental tasks for the local ER Program. For the contaminants of concern, toxicity profiles are written that identify the key information required for health risk assessment. In addition, the profiles identify existing toxicity values (i.e., Reference Doses, Reference Concentrations and slope factors) and, when one of the toxicity values 
has not been calculated, data are presented that will serve as the basis of the calculation. In conducting remedial investigations under the Comprehensive Environmental Response, Compensation, and Liability Act (CERCLA) of 1980 and its amendment, the Superfund Amendments Reauthorization Act (SARA) of 1986, it is essential to have a chemicalspecific Assessment of Applicable or Relevant and Appropriate Requirements (ARARs) and advisory criteria for all chemicals of concern. This includes both state and federal values for surface water, groundwater, air, soil, and sediment. This multimedia approach is necessary because risk assessments must consider all relevant exposure routes for many chemicals; human exposure by more than one exposure route is a very distinct possibility. BEIA is the focal point for the preparation of ARARs for the U.S. Army's Installation Restoration Program and for the ER Program at the Oak Ridge Reservation. The consolidation of this activity has proven to be a very cost- and time-efficient effort since many of the data are applicable to more than one remediation effort. The concept of resource consolidation is applied to a major new project which has just been started under the Strategic Environmental Research Development Program to: (1) develop toxicity values for specific chemicals of interest to the Department of Defense, DOE, and for other agencies at a later date; and (2) enhance the existing EPA's Integrated Risk Information System.

A state regulatory data base is under development to track the status of promulgated and proposed regulations on a federal and state-by-state basis. Current projects involving state regulations have shown that there is a need for such a data base, and none appears available commercially or otherwise. Hard copies of surface, ground, and drinking water regulations have been collected for each of the 50 states and the District of Columbia (DC). Phone contacts have been established with water officers of all states and DC to verify/clarify and regularly update the regulations. A test PC version is under development.

A PC-based expert system was developed for the Health, Safety, Environment, and Accountability Division to assist in performing an internal assessment to determine the Y-12 Plant's compliance with environmental laws. These laws, on eleven different categories which includes the Clean Air Act, Clean Water Act, Resources Conservation and Recovery Act, SARA, etc., are mainly federal laws, but also include some DOE Orders and plant standards. This system enabled data from different organizational units to be merged into a master system. This provided enabled data from different organizational units to be merged into a master system, thus providing consolidated reports on noncompliance to be prepared. A presentation and demonstration of this system was given at the American Chemical Society Annual Meeting in October 1992. Another expert system, National 
Environmental Policy Act (NEPA) Environmental Review and Compliance, is being developed for the K-25 Environmental Management Department. This expert system, containing legislation, will help determine the type of documentation needed to respond to NEPA requirements and to prepare draft categorical exclusion documentation.

In addition to their large, applied programs in site characterization, the Assessment Technology (AT) Section is involved in environmental restoration R\&D activities on a national and international level. Staff members serve as members of the Environmental Assessments Task Group of the DOE's Risk-Based Standards Working Committee. In this capacity, they provide direction for environmental research activities, conduct research and development in support of committee needs, and prepare and review standards for environmental pollutant assessments and site characterization. Also, a detailed procedures manual on radiological site characterization was prepared for DOE and contractor facilities. This comprehensive manual provides specifications (procedures, instruments, quality assurance, sample analysis, etc.) for all types of environmental radiological surveys. The document was prepared as a joint effort with the Oak Ridge Associated Universities, Nuclear Regulatory Commission, ORNL, and DOE. At the invitation of DOE, staff members also continued to participate in an International Atomic Energy Agency (AEA) study of environmental pollutant transport models. This work was coordinated by the IAEA's Coordinated Research Program on the Safety Assessment of Near-Surface Radioactive Waste Disposal Facilities and was aimed at comparing results of various environmental pollutant transport models. The total effort included developing a near-field model to determine releases of radionuclides to the geosphere using the TIME-ZERO code, developing an intruder dose-assessment code (INTRUD) that considered construction and agricultural scenarios, modeling groundwater transport of radionuclides released from two disposal test cases, and preparing a report documenting results of the test cases. Information obtained from these studies was presented at the IAEA's Coordinated Research Meeting in Vienna, Austria. Staff members also serve on national environmental technical committees for the American Society for Testing and Materials (field screening and data quality), Health Physics Society (Environmental Section), and American National Standards Institute (survey instrument performance and evaluation). 
APPENDICES 


\section{APPENDIX A. SOURCES OF FUNDING}

FY 1992

$(\$ \mathrm{~K})$

\section{DEPARTMENT OF ENERGY}

Biological and Environmental Research

Remedial Action and Waste Technology

$\$ 6,502$

Environmental Research and Development

3,270

Electric Energy Systems

1,430

Defense Waste and Environmental Restoration

440

Solar Energy

4,420

127

Industrial Energy Conservation

Transportation

Basic Energy Sciences

Laboratory Technology Transfer

DEPARTMENT OF DEFENSE

Air Force (including HAZWRAP)

1,195

Navy (including DSRD)

1,407

Army

1,137

Defense Nuclear Agency

OTHER FEDERAL AGENCIES

Environmental Protection Agency

Department of Health and Hluman Services

2,999

National Library of Medicine

Agency for Toxic Substances and Disease Registry

430

National Institute of General Medical Sciences

1,339

335

Nuclear Regulatory Commission

Bureau of Land Management

1,302

United States Postal Service

\section{OTHER DOE}

Schenectady Naval Reactors Office

Los Alamos National Laboratory

153

Bendix

Sandia National Laboratories

Savannah River National Laboratory $\quad 1,597$

Chem-Nuclear Electrical

EG\&G Reynolds Electrical

Allied Signal

$\mathrm{Y}-12$

$\mathrm{K}-25$

ORO/ORAU

Multiplant 
$\begin{array}{lr}\text { ORO/Energy Systems } & 23\end{array}$

Portsmouth $\quad 754$

PGDP $\quad 500$

$\begin{array}{lr}\text { DOE/DOE } & 10\end{array}$

Bonneville Power Administration $\quad 50$

\section{PRIVATE, STATE AND LOCAL GOVERNMENT}

Universities

New York University

Cornell University

Colorado State University

Federal Republic of Germany

6

American Petroleum Institute

83

Soap and Detergent Association

Tennessee Valley Authority/CRADA

\section{INTERNAL ORNL}

Seed Money and Discretionary Funds

1,076

Laboratory Overhead Accounts

TOTAL Division 


\section{APPENDIX B. PERSONNEL SUMMARY}

\begin{tabular}{lcccr}
\hline & & Technical & Administrative & Total \\
& Professional & Support & Support & Tor \\
Permanent & 120 & 26 & 33 & 179 \\
Temporary & 21 & 4 & 0 & 25 \\
Part-time & 12 & 1 & 2 & 15 \\
Leave of absence & 0 & 1 & 0 & 1 \\
Off-site assignment & 1 & 0 & 0 & 1 \\
Division-supported loanees & 15 & 5 & 0 & 20 \\
\hline
\end{tabular}

Many types of employees are required to run the division effectively and efficiently. Several sources are used to staff the division to maintain the high standards. During this reporting period, we have had a total of 279 assignments to the division in the following categories: consultants, subcontractors, guests from universities, visiting scientists from other laboratories as well as private companies, postdoctoral fellows, and students who come to us under several different programs. Assignment terms vary in duration from a few months to a year or more. We view this as a very economical way to bring different and diversified talents to the division. 


\section{APPENDIX C. ORGANIZATION CHART}

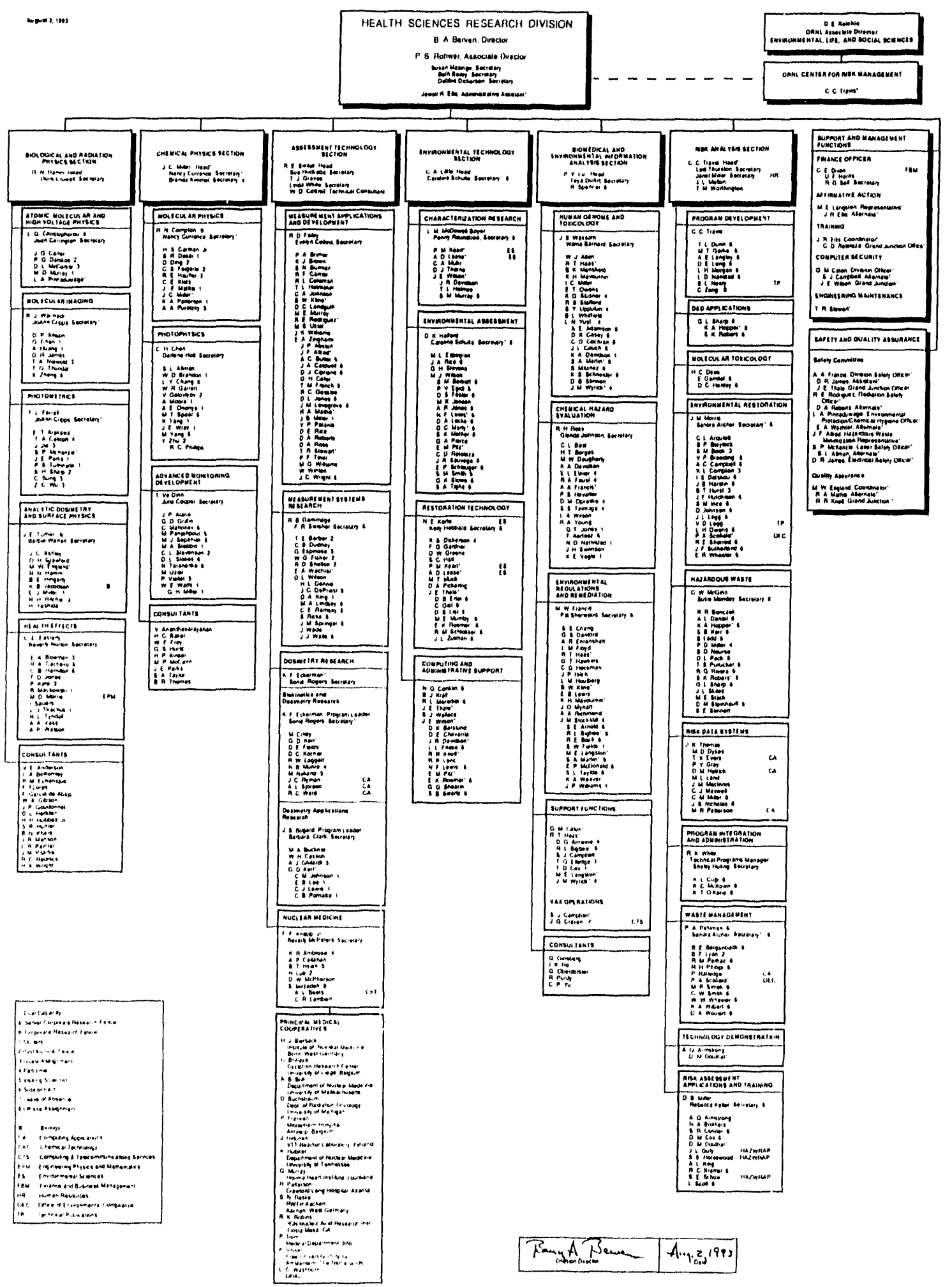




\section{APPENDIX D. SEMINAR PROGRAM}

H. S. Carman, Jr.

The coordinator of the Health and Safety Research Division's Seminar Program works with staff members to identify and attract distinguished seminar speakers from various research disciplines of interest to the staff. In addition, the division's Chemical Physics Section hosts the Chemical Physics Seminar Series (W. R. Garrett, Coordinator). These seminar programs facilitate the exchange of ideas and scientific information between division staff and scientists from industry, universities, national laboratories, and research institutions (including other divisions at ORNL).

During the period October 1, 1991, through March 31, 1993, the Division's Seminar Program hosted the 13 speakers listed below.

\section{Ron Jones}

Department of Chemistry, University of Illinois, Champaign, Illinois, "PhotoAssociated Excitation Spectroscopy of Excimer Molecules," October 28, 1991.

\section{Robert Haufler}

Department of Chemistry, Rice University, Houston, Texas, "Recent Experiments at Rice University - Including Synthesis of Fullerenes and Metal-Doped

Fullerenes," December 18, 1991.

\section{Alexander Weiss}

Physics Department, University of Texas at Arlington, Arlington, Texas, "Positron Annihilation-Induced Auger Electron Spectroscopy," December 23, 1991.

Harald Morgner

St. Francis Xavier University, Antigonish, Nova Scotia, Canada, "Liquid Surfaces: Investigation With Electron Spectroscopy and Computer Simulation," October 9, 1992.

\section{Peter Bauer}

Institut fur Experimental Physik, Johannes-Kepler Universitdt Linz, Linz, Austria, "Electronic Stopping of Light Ions: Influence of the Valence Electron States," November 10, 1992. 


\section{Lester Hulett}

Analytical Chemistry Division, ORNL, "Ionization of Large Organic Molecules by Low Energy Positrons," January 18, 1993.

\section{Ron Jones}

Health and Safety Research Division, ORNL, "Neutralization of Negative DNA Ions in the Gas Phase," January 25, 1993.

David Mullins

Chemistry Division, ORNL, "Characterization of Surface Reactions Using Synchrotron Radiation," February 8, 1993.

\section{Herbert Krause}

Physics Division, ORNL, "Interferences in Resonant Excitation of Hydrogenic Channeled Ions," February 27, 1993.

\section{Richard Haglund}

Department of Physics, Vanderbilt University, Nashville, Tennessee, "Nonlinear Optical Response of a Particle in a Box," March 1, 1993.

Lars Andersson

Physics Division, ORNL, "Double Ionization of Helium by High Energy Photon Impact," March 8, 1993.

\section{Jing $Y$. Zhang}

Department of Physics, Georgia Southern University, Statesboro, Georgia,

"Optical Parametric Amplifiers Using LBO and BBO Crystals," March 22, 1993.

\section{Michael Alford}

Department of Chemistry, Rice University, Houston, Texas, "Recent Results in the Studies of Metallofullerenes at Rice University," March 26, 1993. 


\section{APPENDIX E. LIST OF HONORS AND AWARDS FOR STAFF MEMBERS}

\section{SPECIAL HONORS}

R. N. Compton

Recipient of the 1991 Jesse W. Beams Medal and Certificate of Merit from the Southeastern Section of the American Physical Society for his extraordinary achievements and significant research in physics

\section{A. A. Francis}

Certified as Diplomate of the American Board of Toxicology in 1993

\section{R. H. Ritchie}

Elected as a Scientific Member in the Bohmische Physical Society for contributions to the field of particle-solid interactions by independent, original research

Recipient of a Doctor Honoris Causa degree from the Univeridad del Pais Vasco, San Debastian, Spain, in recognition of his high degree of scientific achievement and excellence in teaching

\section{S. S. Talmage}

Certified as Diplomate of the American Board of Toxicology in 1993

\section{J. E. Turner}

Recipient of the Distinguished Scientific Achievement Award of the Health Physics Society to acknowledge outstanding contributions to the science and technology of radiation protection

\section{R\&D-100 AWARD}

F. C. Chen, S. L. Allman, and C. H. Chen

"CFC/HFC Ratiometer"

Tuan Vo-Dinh and David L. Stokes

"Surface-Enhanced Raman Optical Data Storate (SERODS) System"

\section{SPECIAL AWARDS}

Anne Adamson, Denise Casey, Alicia Davidson, Betty Mansfield, Sheryl Martin, Donna Stinnett, Judy Wyrick, and Laura Yust

Recipients of the World-Class Teamwork Award presented by the Values Committee and Clyde Hopkins 
S. N. Burman

Health and Safety Research Division Distinguished Achievement Award for Technical Support for 1992

L. G. Christophorou and L. A. Pinnaduwage

Health and Safety Research Division Excellence in Research Award for 1992

K. A. Davidson

National Toxicology Program, Board of Scientific Counselors, Technical Review Subcommittee, 1991

A. A. Francis

Diplomate, American Board of Toxicology, 1993

Timi L. Holmes

Ms. Future Business Executive Award, Future Business Leaders of America, Phi Beta Lambda, 1993

Second Place, Human Resource Management Competition Exam, Phi Beta Lambda, State Leadership Conference

Susan W. Masingo

Health and Safety Research Division Distinguished Achievement Award for Administrative Support for 1992

S. S. Talmage

Diplomate, American Board of Toxicology, 1993

\section{PUBLICATION AWARDS}

Anne Adamson, Denise Casey, Alicia Davidson, Betty Mansfield, Sheryl Martin, Donna Stinnett, Judy Wyrick, and Laura Yust

Award of Achievement from the East Tennessee Chapter of the Society for Technical Communications for two publications, DOE 1991-1992 Human Genome Program Annual Report and Primer on Molecular Genetics.

Anne Adamson, Denise Casey, Alicia Davidson, Betty Mansfield, Sheryl Martin, Donna Stinnett, Judy Wyrick, and Laura Yust

Award of Merit from the East Tennessee Chapter of the Society for Technical Communications for two publications, DOE 1991-1992 Human Genome Program Annual Report and Primer on Molecular Genteics.

Gloria M. Caton, Tifini D. Cox, Marilyn E. Langston, and Judy M. Wyrick Award of Achievement for three publications, Ceramic Technology Newsletter, Ceramic Technology Project, and Radon Research Notes.

\section{Linda Houlberg}

Award of Achievement from the Society of Technical Communic ations under the category "Whole Periodicals" for the Environmental Regulatory Update Table. 


\section{COMMITTEE APPOINTMENTS}

K. R. Ambrose

Chairperson, ORNL Animal Care and Use Committee (ACUC), 1991 - present

\section{E. T. Arakawa}

Member, International Advisory Board, Vacuum Ultraviolet Radiation Physics Group, $1989-1992$

A. Q. Armstrong

Member, DOE Integrated Technology Demonstration Committee for Cleanup of Uranium Contaminated Soils, 1990 - present

B. A. Berven

Chairman, Environmental Section of the Health Physics Society Standards Committee, 1985 - present

\section{J. S. Bogard}

Chairman, Energy Systems OHIS Management Oversight Committee, 1991 - present

Member, Health Physics Society Standards Committee/American National Standards Institute N13.22, "Uranium Bioassay Standard," working group, 1989 - present

Member, National Council on Radiation Protection and Measurements Scientific Committee 57, Task Group 15, "Uranium: Radiation Protection Guidelines," 1987 present

Member, American Board of Health Physics Comprehensive Certification Panel of Examiners, 1991 - present

Member, Health Physics Society Laboratory Accreditation Policy Committee, 1993 present

Chairman, Health Physics Society Standards Committee/American National Standards Institute, N13.27, "Performance Specification for Pocket-Sized Alarming Dosimeters/Ratemeters," working group, 1993 - present

M. A. Buckner

Member, U.S. Navy Superheated Drop (Bubble) Dosimetry Working Group, 1989 present

\section{S. N. Burman}

Member, AIAA/ACGIH Hazardous Waste Member, 1992 - present

W. H. Casson, Jr.

Member, Health Physics Society Laboratory Accreditation Assessment Committee, 1992 - present

Chairman, Council of Ionizing Radiation Measurements and Standards Communications Committee, 1993 - present 
Member, Council of Ionizing Radiation Measurements and Standards Science and Technology Committee, 1993 - present

Member, Council of Ionizing Radiation Measurements and Standards Occupational Radiation Protection Subcommittee, 1991 - present

G. M. Caton

Member, Professionalism Committee of American Society for Information Science, 1991

L. G. Christophorou

Member, ORNL/Publications Selection Committee, 1990 - present

Chairman, ORNL Corporate Fellow's Council, 1990 - present

R. N. Compton

Member, Panel of Public Affairs (POPA), American Physical Society, 1989 - present

Member, Publications Committee of the American Physical Society, 1991 - present

W. D. Cottrell

Member, DOE Environmental Assessment Task Group, 1992 - present

M. Cristy

Member, Task Group on Dose Calculations, Committee 2 on Secondary Limits, International Commission on Radiological Protection, 1985 - present

Vice-Chairman, Task Group on Revision of Reference Man, Committee 2 on Secondary Limits, International Commission on Radiological Protection, 1985 present

Corresponding member, Task Group on Age-Dependent Dosimetry, Committee 2 on Secondary Limits, International Commission on Radiological Protection, 1988 present

D. F. Dickerson

Member, ORNL/Martin Marietta Energy Systems, Inc., Values Committee, 1991 . present

C. E. Easterly

Member, Electromagnetics Subpanel of the Free-Electron Hazards Advisory Panel, U.S. Army Environmental Hygiene Agency, 1988 - present

Member, Subcommittee on Dose Assessment, DOE Emergency Management Coordinating Committee, 1989 - present

Member, ASTM Subcommittee E34.70, Single Crystal Whiskers, Committee E-34 on Occupational Health and Safety, 1988 - present

Member, Monitoring and Modeling Subcommittee of the Oak Ridge Full-Scale Exercise Advisory Committee, 1988 - present 
K. F. Eckerman

Member, Task Group on Modeling and Scaling to Humans, DOE, 1985 - present

Member, Committee 2 on Secondary Limits, International Commission on Radiological Protection, 1982 - present

Chairman, Task Group on Dose Calculations, Committee 2 on Secondary Limits, International Commission on Radiological Protection, 1982 - present

Member, Task Group on Age-Dependent Dosimetry, Committee 2 on Secondary Limits, International Commission on Radiological Protection, 1988 - present

Member, Scientific Committee 57, Internal Emitter Standards, National Council on Radiation Protection and Measurements, 1979 - present

Member, Scientific Committee 64, Task Group 5, Public Exposure from Nuclear Power, National Council on Radiation Protection and Measurements, 1979 - present

Member, Scientific Committee 64, Task Group 6, Screening Models, National Council on Radiation Protection and Measurements, 1979 - present

Member, Advisory Group, Health Effects Model Revision, Nuclear Regulatory Commission, 1980 - present

Member, Scientific Committee '84, Radionuclide Contamination, National Council on Radiation Protection and Measurements, 1991 - present

M. L. Espegren

Member, DOE Committee to Revise DOE Order 5820.27, 1993 - present

R. D. Foley

Member, ORNL Radioactive Operations Committee, 1990 - present

R. B. Gammage

Member, Indoor Air Quality Committee, American Industrial Hygiene Association, 1985 - present

Member, DOE Research Development Demonstration Testing and Evaluation Working Group for Instrumentation, 1989 - present

Board of Directors, ex-officio, International Society for Indoor Air Quality and Climate

Co-chair, Eleventh ORNL Life Sciences Symposium on Indoor Air and Human Health Revisited, March 28-31, 1993

D. K. Halford

Member, Independent Review Team for Radiological Performance Assessments for Idaho National Engineering Laboratory, 1992 - present

Member, DOE Performance Assessment Task Team, 1992 - present 
T. D. Jones

Member, DOE Environmental Standards Steering Committee, 1990 - present

S. V. Kaye

Member, Advisory Committee, ORAU/DOE Health Physics Faculty Research Award Program, 1991 - present

G. D. Kerr

Member, Working Group on Neutron Activation, Committee on Dosimetry for RERF, National Research Council-National Academy of Sciences, Washington, DC, 1991 present

Member, Task Group on Reference Man, Committee 2 on Secondary Limits, International Commission on Radiologic Protection, 1990 - present

F. F. (Russ) Knapp, Jr.

ORNL representative to ORAU/ORISE/ORNL Committee on Human Studies, 1992present

Organizing Committee, 1998 7th World Congress of Nuclear Medicine and Biology, Berlin, Germany

D. C. Kocher

Member, Standards Committee, Health Physics Society, 1987 - present

Member, DOE's Performance Assessment Task Team for Low-level Radioactive Waste Disposal, 1991 - present

Member, National Council on Radiation Protection and Measurements Scientific Committee on Risk Based Waste Classification, 1992 - present

Member, International Nuclear Waste Advisory Cornmittee Subgroup on Principles and Criteria for Raadioactive Waste Disposal, 1992 - present

D. C. Landguth

Member, AIHA/ACGIH Hazardous Waste Committee, 1992 - present

R. W. Leggett

Member, Task Group on Dose Calculations, Committee 2 on Secondary Limits, International Commission on Radiological Protection, 1985 - present

Corresponding Member, Task Group on Reference Man, Committee 2 on Secondary Limits, International Commission on Radiologic Protection, 1990 - present

Member, Task Group on Age-Dependent Dosimetry, Committee 2 on Secondary Limits, International Commission on Radiological Protection, 1990 - present

Member, National Council on Radiological Protection Scientific Committee on Dosimetry and Metabolism of Radionuclides (SC-57)

Member, National Council on Radic'ogical Protection's Committee on Uncertainties in Biokinetics and Dosimetric Models (SC57-16) 
C. A. Little

Member, Nominating Committee, Health Physics Society, 1990 - present

P. Y. Lu

Member, National Safety Council, Executive Committee Chemical Section, 1985 present

Program Chairman, Chemical Health and Safety Division, American Chemical Society, 1990 - present

Member, DOE/OR Environmental Restoration Council, 1990 - 1991

L. M. McDowell-Boyer

Member, Cleanup Subcommittee of the DOE Advisory Committee on Nuclear Facility Safety, 1991 - present

P.D. Miller

Member, DOE/OR Technical Oversight Review Committee for Environmental Restoration, 1990 - present

M. E. Murray

Member, ORNL Radioactive Operations Committee, 1990 - present

\section{R. H. Ritchie}

Member, Executive Council, Southeastern Section, American Physical Society, 1986 present

Vice-chairman, Southeastern Section, American Physical Society, date ???

P. S. Rohwer

Member, ORAU/DOE Health Physics Fellowship Selection Committee, 1990 - present

R. H. Ross

Member, DOE/OR Environmental Restoration Council, 1990 - 1991

\section{Sauers}

Subcommittee Chairman, IEEE Gaseous Dielectrics Committee S-32-11, 1986 present

C. S. Sims

Chairman, Technical Committee on Procedures and Data for the Intercomparison of Personnel Dosimeters, International Atomic Energy Agency, 1984 - present

Chairman, Technical Committee on Assessment of Occupational Exposure to External Radiation for Monitoring Purposes, International Atomic Energy Agency, 1985 present

Chairman, ANSI N13.11 Review Working Group, Health Physics Society, 1987 present 
R. E. Swaja

Member, ANSI N319 Committee on Personnel Neutron Dosimetry, Health Physics Society, 1986 - present

Chairman, ASTM E10.04 Committee on Criticality Accident Dosimetry, 1986 - present

Member, DOE Environmental Assessment Task Group, 1992 - present

Member, DOE Environmental Radiation Technical Review Group, 1992 - present

D. J. Thorne

Participant, IAEA Coordinate Research Program Safety Assessment of Near-Surface Radioactive Waste Disposal Facility, 1991 - present

Member, DOE Performance Assessment Task Team, 1992 - present

C. C. Travis

Member, Science Advisory Board, National Center for Toxicological Research, Food and Drug Administration, 1987 - present

Member, Delivered Dose Work Group, American Industrial Health Council, 1987 present

Member, State of New Jersey Governor's Science Advisory Board on Health and Environmental Issues, 1988 - present

Member, Technical Advisory Committee (TAC) to the New York City Sludge Management Plan, 1989 - 1992

Member, National Academy of Sciences Board on Radioactive Waste Management to Review the Idaho National Engineering Laboratory activities, 1989 - present

Member, National Academy of Sciences Board on Radioactive Waste Management Committee to Review Hanford Single Shell Tanks, 1989 - present

Member, Advisory Panel, National Environmental Restoration Prioritization Program, 1989 - present

Member, National Academy of Sciences Committee on Biomarkers for Immunotoxicology, 1989 - present

Member, The Federal Insecticide, Fungicide, and Rodenticide Act (FIFRA) Scientific Advisory Panel, Environmental Protection Agency, 1990 - 1994

Member, Environmental Protection Agency Review Panel for Dermal Exposure Assessment, 1991

Member, Science Advisory Panel, Chemical Industry Institute of Toxicology, 1991

Member, National Academy of Sciences Committee on Remedial Action Priorities for Hazardous Waste Sites, 1991 - present 
Member, Advisory Panel for the Office of Technology Assessment on Research on Risk Assessment Methodology for Chemical Carcinogens, 1992 - 1993

Member, Gas Research Institute Project Advisory Group, 1992 - 1994

Member, Science Advisory Board, New Jersey Governor's Panel on Health and Environmental Issues, 1988 - 1991

J. E. Turner

Member, Comprehensive Certification Panel of Examiners, American Board of Health Physics, 1987 - present

Member, RERF Advisory Dosimetry Subcommittee, National Research Council, 1988 - present

Consociate Member, National Council on Radiation Protection and Measurements, 1983 - present

T. Vo-Dinh

Co-chairman, International Committee on Polycyclic Aromatic Compounds, 1985 . present

Chairman, Commission V.4 on Spectrochemical Methods, International Union of Pure and Applied Chemistry (IUPAC), 1991 - present

Chairman, Subcommittee on Fiberoptics, ASTM Committee E.13, 1989 - present

J. S. Wassom

Chairman, Communication and Archives Committee, Environmental Mutagen Society, 1982 - present

Councilor, Environmental Mutagen Society, 1987 - present

Member, Environmental Mutagen Society, Organization and Structure Committee, $1990-1991$

A. P. Watson

Member, Reentry/Restoration Subcommittee of the Chemical Stockpile Disposal Program Steering Committee, Department of the Army and the Federal Emergency Management Agency (FEMA), 1989 - present

Member, ORNL Publications Award Selection Committee, 1990 - present

R. K. White

Member, American Society for Testing and Materials (ASTM) Committee on Risk Assessment, 1991 - present

Member, DOE Environmental Occupational and Public Health Standards Committee, 1991 - present 


\section{JOURNAL ACKNOWLEDGMENTS}

\section{A. Buckner}

Reviewer, Health Physics, 1989 - present

F. F. Knapp, Jr. Member, Editorial Board, NucCompact-European/American Communications in Nuclear Medicine, 1989 - 1992

Member, Editorial Board, European Journal of Nuclear Medicine, 1992 - present

C. A. Little

Member, Editorial Board, Health Physics, 1993 - present

K. H. Mavournin

Member, Editorial Board, Environmental and Molecular Mutagenesis, 1985 - present

C. S. Sims

Associate Editor, Health Physics, 1990 - present

C. C. Travis

Editor-in-Chief, Risk Analysis: An International Journal, 1983 - present

Member, Editorial Advisory Board, Toxicological and Environmental Chemistry, 1989 - present

Member, Editorial Board, Health and Environmental Toxicology, 1989 - present

Member, Editorial Board, Toxicology and Industrial Health, 1990 - present

Member, Editorial Board, Journal of Hazardous Materials, 1990 - 1993

Member, Advisory Board, Critical Reviews in Environmental Control, 1991

J.E.Turner

Associate Editor, Radiation Research, 1991 - present

T. Vo-Dinh

Member, Editorial Board, Applied Spectroscopy, 1988 - present

Topical Editor, Polycyclic Aromatic Compounds, 1989 - present

Member, Advisory Board, Spectrochimica Acta Reviews, 1990 - present

Member, Advisory Board, Talanta, 1990 - present

Associate Editor, ANALUSIS, 1991 - present

E. A. Wachter

Member, Interagency Steering Committee on Standoff Detection, 1990 - present 
J. S. Wassom

Member, Board of Managing Editors, Mutation Research, 1975 - present

R. K. White

Book Review Editor, Risk Analysis: An International Journal, 1987 - present

\section{UNIVERSITY APPOINTMENTS}

\section{E. T. Arakawa}

Adjunct Professor of Physics, University of Tennessee, 1982 - present

W. H. Casson, Jr.

Adjunct Associate Professor, Department of Nuclear Engineering, University of Tennessee, Knoxville, 1992 - present

C. H. Chen

Adjunct Professor of Physics, University of Tennessee, 1990 - present

Adjunct Professor of Physics, Vanderbilt University, 1990 - present

L. G. Christophorou

Professor of Physics, University of Tennessee, 1969 - present

R. N. Compton

Adjunct Professor of Physics, Vanderbilt University, 1983 - present

Professor of Chemistry, University of Tennessee, 1985 - present

T. L. Ferrell

Professor of Physics, University of Tennessee, 1979 - present

D. C. Kocher

Faculty Affiliate, Department of Radiological Health Sciences, Colorado State University, 1990 - present

C. A. Little

Adjunct Professor of Radiology and Radiation Biology, Colorado State University, 1987 - present

Member, Advisory Committee for the Environmental Restoration Technology Curriculum, Mesa State College, 1992 - present

L. A. Pinnaduwage

Adjunct Assistant Professor of Physics, University of Tennessee, 1991 - present

R. H. Ritchie

Professor of Physics, University of Tennessee, 1965 - present

\section{Sauers}

Elected a Senior Member, Institute of Electrical and Electronics Engineers, Inc., 1993 
P. C. Srivastava

Adjunct Professor, Biomedical Sciences, University of Tennessee, 1991 - present

C. C. Travis

Senior Research Fellow with the Energy, Environment, and Resources Center, University of Tennessee, 1990 - present

J. E. Turner

Professor of Physics (part-time), University of Tennessee, 1981 - present

Adjunct Professor of Nuclear Engineering, University of Tennessee, 1990 - present

R. L. Tyndall

Associate Professor of Research, Zoology Department, University of Tennessee, 1978 - present

M. Uziel

Professor of Biomedical Sciences (part-time), University of Tennessee, 1968 - present

T. Vo-Dinh

Professor of Biomedical Sciences (part-time), University of Tennessee, 1987 - present

R. J. Warmack

Professor of Physics, University of Tennessee, 1983 - present

\section{OTHER}

\section{J. S. Bogard}

President-elect, East Tennessee Chapter of the Health Physics Society, 1.93 - 1994

M. A. Buckner

Assessor for the Department of Energy Laboratory Accrediation Program, 1993 present.

Received Master of Science degree, University of Tennessee, 1991

Reviewer, DOE Small Business Innovation Research Program, 1992

G. M. Caton

Chair, East Tennessee Chapter, American Society for Information Science, 1991

R. N. Compton

Elected Fellow, Optical Society of America, 1992

K. F. Eckerman

Consultant, Sloan-Kettering Memorial Medical Center, 1981 - present

W. R. Garrett

Elected Fellow, American Physical Society, 1992 


\section{B. E. Hingerty}

Consultant, New York University, 1978 - present

S. V. Kaye

Consultant, U.S. Department of Veteran Affairs, 1989 - present

G. D. Kerr

Consultant, Radiation Effects Research Foundation, Japan, 1975 - present

C. E. Klots

Recipient, NATO International Collaboration Grant, 1990 - present

Elected Fellow, American Physical Society, 1992

J. C. Miller

Elected Fellow, American Physical Society, 1993

Recipient, NATO International Collaboration Grant, 1987 - present

R. H. Ritchie

Member, Board of Directors, Pellissippi International, Inc., 1987 - present

Member, Advisory Board, Atom Sciences, Inc., 1984 - present

P. S. Rohwer

Treasurer, Health Physics Society, 1991 - 1993

President-elect, American Academy of Health Physics, 1991 - 1992

C. S. Sims

U.S. Dosimetry Contact for the Joint Standing Committee for Civil Nuclear Cooperation with Taiwan, Republic of China, 1985 - present

C. C. Travis

Elected Fellow, International Society for Risk Analysis, 1992

Elected Senior Research Fellow with Energy, Environment, and Resources Center at the University of Tennessee, 1990 - present

Recipient, NATO Scientific Affairs Division Grant, 1991

\section{J. E. Turner}

President-elect, American Academy of Health Physics, 1992

R. L. Tyndall

Consultant, Northern States Power Company, 1980 - present

Consultant, Perkin-Elmer Cetus, 1991

Consultant, Anderson County School System, 1991 
T. Vo-Dinh

Secretary, American Institute of Chemists (Tennessee Section), 1989 - present

A. P. Watson

Chair, Admissions Committee, Oak Ridge Chapter of Sigma Xi, 1989 - 1991 


\section{APPENDIX F. PATENTS GRANTED TO STAFF MEMBERS}

\section{PATENTS ISSUED}

F. F. Knapp, Jr., E. C. Lisic, S. Mirzadeh, and A. P. Callahan

"Tungsten-188/Carrier-Free Rhenium-188 Perrhenic Acid Generator System," U.S. Patent No. 5,186,913, February 17, 1993

\section{INVENTION DISCLOSURES}

Stephen W. Allison and Eric A. Wachter

"Fiber Optic Luminescence Based Ultraviolet Spectrometer," January 1993 (ESID 1257-X, S-77,526)

J. R. Davidson

"SmartCursor Customizable Cursor Movement Software," March 1992 (ESID 1147-X, S-76,010)

C. E. Easterly

"Ion Resonance Gun," August 1992 (ESID 1195-X, S-76,063)

T. L. Ferrell

"Scanning Atomic Pressure Optical Spectroscopy," August 1992 (ESID 1196-X, S-76,064)

David E. Fields and Chung-Hsuan Chen

"Delayed Electron-Coupled Transmitter of Light (DECTOL)," December 1991 (ESID

1024-C, S-74,848)

W. R. Garrett

"Nonlinear Spectroscopic-Based Concentration Measurement Instrument," June 1992 (ESID 1182-X, S-76,047)

Furn F. Knapp, Jr.

"Radioiodinated Agent to Evaluate Gastrointestinal Disease by Urine Analysis - The

"Wuerfel Test," January 1992 (ESID 1113-X, S-74,880)

Edward C. Lisic

"Simple Reduction of Radioactive Perrhenate to a Reactive $\operatorname{Re}(\mathrm{V})$ Intermediate," Novemicr 1991 (ESID 1092-X, S-74,844)

Lal A. Pinnaduwage and Loucas G. Christophorou

"Laser Based High Flux Negative Ion and Neutral Beam Source," March 1992 (ESID 1141-X, S-76,000)

Prem C. Srivastava and Ahmad Hasan

"Enzyme-'Targeted Diagnosis with Radiohalogenated Nucleosides - The Enzymometer," December 1991 (ESID 1107-X, S-74,867) 
Richard L. Tyndall and Arpad Vass

"Process for Degrading Napalm," November 1992 (ESID 1231-X, S-77,504)

Tuan Vo-Dink and Pierre Viallet

"Chemical Sensor Probe for Calcium and Other Metal Ions," August 1992 (ESID 1197-X, S-76,065)

T. Vo-Dinh

"Synchronous Luminescence System," August 1992 (ESID 1194-X, S-76,062) 


\section{APPENDIX G. MEETINGS AND CONFERENCES}

Third Conference on Radiation Protection and Dosimetry, Orlando, Florida, October 2124, 1992. Organizers: C. S. Sims and R. E. Swaja, Oak Ridge National Laboratory. Sponsors: Health and Safety Research Division and DOE/OHER.

First Annual USRADS Users Group Symposium, Grand Junction, Colorado, March 25 26, 1993. Chairpersons: D. K. Halford and M. L. Espegren, Oak Ridge National Laboratory. Sponsor: ChemRad Tennessee, Inc.

NATO Advanced Research Workshop on the Use of Biomarkers in Assessing Health and Environmental Impacts of Chemical Pollutants, Luso, Portugal, June 1992. Coorganizer: Curtis C. Travis, Oak Ridge National Laboratory. Sponsor: NATO.

Symposium on Radionuclide Generator Systems for Nuclear Medicine Applications, Washington, DC, August 24-28, 1992. Organizers: F. F. Knapp, S. Mirzadeh, and A. P. Callahan. Sponsor: American Chemical Society.

U.S. DOE Risk Assessment Seminar, Germantown, Maryland, September 1992. Course Director: Curtis C. Travis, Oak Ridge National Laboratory. Sponsor: DOE.

Symposium and Demonstrations on Computing Applications for Chemical Health and Safety Issues, American Chemical Society National Spring Meeting 1992, Atlanta, Georgia, April 5-10, 1992. Organizer: Po-Yung Lu, Oak Ridge National Laboratory. Sponsor: American Chemical Society.

Symposium on Issues in the Indoor Environment, American Chemical Society National

Fall Meeting 1992, San Francisco, California, August 23-28, 1992. Organizers:

Susan L. Rose, DOE, and Gloria M. Caton, Oak Ridge National Laboratory. Sponsor: American Chemical Society.

Symposium on Biotechnology and the Human Genome Program, American Chemical Society National Fall Meeting 1992, San Francisco, California August 23-28, 1992. Organizers: Tony Carrano, John S. Wassom and Po-Yung Lu, Oak Ridge National Laboratory. Sponsor: American Chemical Society.

Symposium on Current Topics in Hazard Communication, American Chemical Society National Spring Meeting 1993, Denver, Colorado, March 28-April 2, 1993. Organizer: Po-Yung Lu. Sponsor: American Chemical Society. 


\section{APPENDIX H. ADVISORY COMMITTEE}

\section{MEMBER}

Dr. Eugen Merzbacher

Professor

Department of Physics and Astronomy

University of North Carolina

Chapel Hill, North Carolina 27599

Dr. Genevieve Roessler

Route 1, Box 139H

Elysian, Minnesota 56028

Dr. Robert Snyder

Associate Director

Rutgers University

Environmental and Occupational Health

Sciences Institute

681 Frelinghuysen Road

Piscataway, New Jersey 08855-1179

Dr. F. Ward Whicker

Professor

Department of Radiological Health Sciences

Colorado State University

Ft. Collins, Colorado 80523

\section{AREA OF EXPERTISE}

Atomic Physics

Molecular Physics

Health Physics

Radiation Dosimetry

Nuclear Medicine

Toxicology

Risk Analysis

Information Management
Environmental Transport

Site Characterization 


\section{APPENDIX I. PRESENTATIONS}

Alarie, J.P., Vo-Dinh, T., Miller, G., Watts, W., Ericson, N., Maddox, R., Eastwood, D., Dominquez, M., and Lidberg, R., "Development and Testing of a Battery-Operated Portable Synchronous Luminescence Monitor," presented at the 44th Pittsburgh Conf./Expo. on Analytical Chemistry and Applied Spectroscopy, Atlanta, Mar.8-12, 1993

Allison, D.P., Warmack, R.J., Thundat, T., Sachleben, R.A., Brown, C.M., Jacobson, K.B., and Ferrell, T.L., "Scanning Tunneling Microscopy and Spectroscopy of Plasmid DNA," presented at the 38th Annu. Am. Vac. Soc. Symp./Top. Conf., Seattle, Nov.11-15, 1991

Allison, D.P., Warmack, R.J., Thundat, T., Bottomley, L.A., Woychick, R.P., and Schrick, J.J., "Scanning Tunneling Microscopy (STM) of DNA Chemically Immobilized on Gold Surfaces," presented at the Meet. on Scanning Microscopy and Food Structure, Chicago, May' 9, 1992

Allison, D.P., Warmack, R.J., and Thundat, T., "Scanning Probe Microscopy of DNA Chemically Immobilized on Gold Surfaces." presented at the Pittcon ' 92 Conf., New Orleans, Mar.13, 1992

Allison, D.P., Thundat, T., Bottomley, L.A., Jacobson, K.B., Woychik, R.P., Schrick, J.J., and Warmack, R.J., "Scanning Tunneling Microscope Imaging of DNA Chemically Attached to Gold Surfaces," presented at the 39th Annu. Am. Vac. Soc. Symp./Top. Conf., Chicago, Nov.9-13, 1992

Allison, D.P., Thundat, T., Bottonley, L.A., Jacobson, K.B., Woychick, R.P., Schrick, J.J., and Warmack, R.J., "Imaging DNA Chemically Attached to Gold Surfaces with the Scanning Tunneling Microscope," presented at the 59th Meet. Am. Phys. Soc., Southeastern Section, Oak Ridge, TN, Nov.12-14, 1992

Allison, D.P., Thundat, T., Ferrell, T.L., Doktycz, M.J., Jacobson, K.B., and Warmack, R.J., "Scanning Probe Microscopy of Complete Plasmids," presented at the DOE Contractors' Workshop, Santa Fe, NM, Feb.7-11, 1993

Allison, D.P., "Scanning Tunneling Microscopy of DNA Chemically Attached to Gold Surfaces," presented at the March Meet. Am. Phys. Soc., Seattle, Mar.22-26, 1993

Ambrose, K.R., "Design and Development of a New, Improved Radiopharmaceutical for the Clinical Evaluation of Pancreatic Insufficiency, " presented at the Health and Safety Research Div. Information Meet., ORNL, Oak Ridge, TN, Apr.14-15, 1992

Arakawa, E.T. ancं Lee, I., "Yields and Kinetic Energy Distribution of Laser-Desorbed Al, $\mathrm{Au}$, and Ag Atoms," presented at the Meet. Am. Phys. Soc., Indianapolis, Mar.16-20, 1992

Arakawa, E.T., "Physics of Solids and Macromolecules," presented at the DOE/OHER Five-Year Program Review, Oak Ridge, TN, June 17-19, 1992 
Armstrong, A.Q., "Performance Assessment Update Uranium Removal from Soils," presented at the ID FY-92 Kickoff Meet., Harrison, OH, Oct.7, 1991

Armstrong, A.Q. and Nuhfer, N.R., "Integrated Demonstration for the Removal of Uranium Substances from Soils," presented at the Technology Information Exchange Workshop, Augusta, GA, Nov.18-20, 1991

Armstrong, A.Q., "Environmental Contamination and Other Hazards Data Evaluation," presented at the Agency for Toxic Substances and Disease Registry Health Assessment Workshop, Salt Lake City, Jan.28-30, 1992

Armstrong, A.Q., "On-Site/Off-Site Contamination," presented at the Agency for Toxic Substances and Disease Registry Health Assessment/Risk Communication Workshop, Salt Lake City, Jan.28-30, 1992

Armstrong, A.Q., "Uranium Soils ID, Performance Assessment," presented at the DOE Mid-Year Program Review, Gaithersburg, MD, Mar.17, 1992

Armstrong, A.Q., "On-Site/Off-Site Contamination," presented at the Agency for Toxic Substances and Disease Registry (ATSDR) Workshop, San Antonio, TX, May 18-22, 1992

Armstrong, A.Q., "Data Evaluation," presented at the Agency for Toxic Substances and Disease Registry (ATSDR) Workshop, San Antonio, TX, May 18-22, 1992

Armstrong, A.Q., "Environmental Contamination and Other Hazards - Data Evaluation," presented at the Agency for Toxic Substances and Disease Registry/DOD Health Risk Communication Workshop, San Francisco, June 15, 1992

Armstrong, A.Q., "Environmental Contamination and Other Hazards - Data Evaluation," presented at the Agency for Toxic Substances and Disease Registry/DOD Health Risk Communication Workshop, Atlanta, July 13, 1992

Armstrong, A.Q., "On-Site/Off-Site Contamination," presented at the Agency for Toxic Substances and Disease Registry/DOD Health Risk Communication Workshop, San Francisco, June 15, 1992

Armstrong, A.Q., "On-Site/Off-Site Contamination," presented at the Agency for Toxic Substances and Disease Registry/DOD Health Risk Communication Workshop, Atlanta, July 13, 1992

Armstrong, A.Q. "Conclusions and Recommendations," presented at the Agency for Toxic Substances and Disease Registry/DOD Health Risk Communication Workshop, Atlanta, July 13, 1992

Armstrong, A.Q., "Conclusions and Recommendations," presented at the Agency for Toxic Substances and Disease Registry/DOD Health Risk Communication Workshop, San Francisco, June 15, 1992

Armstrong, A.Q., "Data Evaluation Exercise," presented at the ATSDR Health Assessment Training Workshop, Atlanta, Oct.20, 1992 
Armstrong, A.Q., "Pathways Analysis," presented at the Agency for Toxic Substance and Disease Registry/Dept. of Defense Health Risk Communication Workshop, San Antonio, TX, Sept.15, 1992

Armstrong, A.Q., "Performance Assessment Update and FY-93 Plans," presented at the Annu. Planning and Review Meet. of Uranium Soils ID Groups, Albuquerque, NM, Nov.4, 1992

Armstrong, A.Q., "Environmental Contamination and Other Hazards Data Evaluation," presented at the ATSDR Health Assessment Training Workshop, Atlanta, Oct.20, 1992

Armstrong, A.Q., "Exposure Pathways Exercise," presented at the ATSDR Health Assessment Training Workshop, Atlanta, Oct.20, 1992

Armstrong, A.Q., "Performance Assessment Activities of the Uranium Soils Integrated Demonstration," presented at the Information Exchange Meet. on Waste Retrieval, Treatment, and Processing, Houston, Mar.15-17, 1993

Ashdown, B.G., Berry, L.A., Berven, B.A., Cook, J.S., Degangi, S., Ekkebus, A.E., Hettich, R.L., Hicks, R., Nyquist, J.E., Poutsma, M.L., Sapp, V.J., and York, D.L., "Report of the Performance Improvement Process Committee on the Future Role of Libraries," presented at ORNL, Oak Ridge, TN, Sept.8, 1992

Ashley, J.C., "Interactions of Low-Energy Electrons and Positrons with Condensed Matter," presented at the DOE/OHER Five-Year Program Review, Oak Ridge, TN, June 17-19, 1992

Barber, T.E., List, M.S., and Haas, J.W., III, "Determination of Nicotine by Surface Enhanced Raman Spectroscopy (SERS) on Copper and Silver Electrodes," presented at the 44th Pittsburgh Conf./Expo. on Analytical Chemistry and Applied Spectroscopy, Atlanta, Mar.8-12, 1993

Bast, C.B. and Young, R.A., "A Molecular Equivalence Approach to the Quantitative Risk Assessment of Arsenicals," presented at the Annu. Meet. Soc. Toxicol., New Orleans, Mar.14-16, 1993

Berven, B.A., "New Initiatives," presented at the Health and Safety Research Div. Information Meet., ORNL, Oak Ridge, TN, Apr.14-15, 1992

Blaylock, B.P., Travis, C.C., and McKone, T., "A Fugacity Approach for Modeling Mercury in Vegetation," presented at the Annu. Meet. Soc. Risk Anal., San Diego, Dec.6-9, 1992

Blaylock, B.G., Frank, M.L., Hoffman, F.O., Miller, P.D., Purucker, S.T., Redfearn, A., and White, R.K., "Human Health Risk Assessment Screening Approach for Evaluating Contaminants at Source Control and Integrator Operable Units," presented at the Water Federation Environment Specialty Conf. on How Clean is Clean?, Washington, DC, Jan.13, 1993

Blaylock, B.P., "Municipal Waste Combustors: Mercury Emissions and Human Exposure," presented at the Int. Conf. on Municipal Waste Combustion, Williamsburg, VA, Mar.30-Apr.2, 1993 
Blower, P.J., Singh, J., Clarke, S.E.M., Lazarus, C.R., Reghibe, K., Callahan, A.P., and Knapp, F.F., Jr., "Optimisation of Simple Methods for Preparation of 186/188Re(V)DMSA for Assessment as Tumor Radionuclide Therapy Agents," presented at the 5th European Symp. on Radiopharmacy and Radiopharmaceuticals, Cambridge, Great Britain, Mar.21-24, 1993

Bogard, J.S., Downing, D.J., and Turner, J.E., "Limitations of Gaussian-Based Performance Measures in Very-Low-Background Counting Regimes," presented at the 37th Annu. Conf. on Bioassay, Analytical, and Environmental Radiochemistry, Ottawa, Oct.7-11, 1991

Bonczek, R.R., "Background and Community Health Concerns," presented at the Agency for Toxic Substances and Disease Registry (ATSDR) Workshop, San Antonio, TX, May 18-22, 1992

Bonczek, R.R., "Conclusions and Recommendations," presented at the Agency for Toxic Substances and Disease Registry (ATSDR) Workshop, San Antonio, TX, May 18-22, 1992

Bonczek, R.R. and McGinn, C.W., "Screening Risk Assessment," presented at the Meet. with EPA Region V, Chicago, Sept.3, 1992

Bonczek, R.R., Hull, R.N., and Kramel, R.C., "Ecological Risk Assessment at PORTS," presented at the Meet. with EPA Region V, Chicago, Sept.3, 1992

Bonczek, R.R., "Screening Risk Assessment - Accelerating the RFI/CMS/CMI Process," presented at the Paducah Gaseous Diffusion Plant Meet. with Science Applications International Corporation Staff, Paducah, KY, Oct.16, 1992

Bonczek, R.R., "Land-Use and Exposure Assessment at PORTS," presented at the Ohio Environmental Protection Agency (OEPA) Southeast Regional Headquarters Meet., Logan, OH, Oct.1, 1992

Bonczek, R.R., Hull, R.N., and Kramel, R.C., "Ecoiogical Risk Assessment at PORTS," presented at the Ohio Environmental Protection Agency (OEPA) Southeast Regional Headquarters Meet., Logan, OH, Oct.1, 1992

Bonczek, R.R., "Screening Risk Assessment - Accelerating the RFI/CMS/CMI Process," presented at the Ohio Environmental Protection Agency (OEPA) Southeast Regional Headquarters Meet., Logan, OH, Oct.1, 1992

Borges, H.T., "An Overview of Principles of Toxicology - VI. Toxicology of the Liver," presented at ORNL, Oak Ridge, TN, Nov.12, 1991

Borges, H.T., "An Overview of Principles of Toxicology - VII. Toxicology of the Kidney," presented at ORNL, Oak Ridge, TN, Nov.12, 1991

Borges, H.T., "An Overview of Principles of Toxicolcgy - V. Clinical Toxicology," presented at ORNL, Oak Ridge, TN, Nov.12, 1991

Borges, T., Stafford, R.S., Lu, P.Y., Kerr, G.D., and Young, R.A., "The Nuclear Regulatory Commission Health Physics Positions Data Base," presented at the 32nd Annu. Meet. Soc. Toxicol., New Orleans, Mar.14-16, 1993 
Bottomley, L.A., Haseltine, J.N., Allison, D.P., Warmack, R.J., Thundat, T., Sachleben, R.A., Brown, G.M., Woychik, R.P., Jacobson, K.B., Ferrell, T.L., and Schrick, J.J., "Scanning Tunneling Microscopy of DNA: The Chemical Modification of Gold Surfaces for Immobilization of DNA," presented at the 38th Annu. Am. Vac. Soc. Symp./Top. Conf., Seattle, Nov.11-15, 1991

Bottomley, L.A., Jones, J.A., Allison, D.P., and Warmack, R.J., "Scanning Tunneling Microscopic Imaging of Electrostatically Immobilized Nucleic Acids," presented at the Biomedical Optics '93, Los Angeles, Jan.16-22, 1993

Brandon, W.D., Allman, S.L., Chen, C.H., Garrett, W.R., Payne, M.G., and Parks, J.E., "Isotope Biases in RIMS Utilizing Broad-Band Lasers," presented at the 6th Int. Symp. on Resonance Ionization Spectroscopy and Its Applications, Santa Fe, NM, May 24-29, 1992

Brandon, W.D., Allman, S.L., Garrett, W.R., Chen, C.H., Payne, M.G., and Parks, J.E., "Isotope Biases in RIMS Utilizing Broad-Band Long-Pulsed Lasers," presented at the 6th Int. Symp. on Resonance Ionization Spectroscopy and Its Applications, Santa Fe, NM, May 24-29, 1992

Brothers, R., "Follow-Up Health Activities," presented at the Agency for Toxic Substances Disease Registry DOD Workshop, Salt Lake City, Jan.28-30, 1992

Brothers, R., "Health Outcome Data," presented at the Agency for Toxic Substances and Disease Registry Health Assessment Workshop, Salt Lake City, Jan.28-30, 1992

Brothers, R., "Toxicological Evaluation," presented at the Agency for Toxic Substances and Disease Registry Health Assessment/Risk Communication Workshop, Salt Lake City, UT, Jan.29-30, 1992

Brothers, R., Miller, D.B., and Armstrong, A., "Canyonville Case Study," presented at the Agency for Toxic Substances and Disease Registry Health Assessment/Risk Communication Workshop, Salt Lake City, Jan.28-30, 1992

Brothers, R., "Community Health Concerns," presented at the Agency for Toxic Substances and Disease Registry Health Assessment/Risk Communication Workshop, Salt Lake City, UT, Jan.28-30, 1992

Brothers, R.A., "Toxicological Evaluation," presented at the Agency for Toxic Substances and Disease Registry (ATSDR) Workshop, San Antonio, TX, May 18-22, 1992

Brothers, R.A., "Health Outcome Data Evaluation," presented at the Agency for Toxic Substances and Disease Registry (ATSDR) Workshop, San Antonio, TX, May 18-22, 1992

Brothers, R.A.," Follow-Up Health Activities," presented at the Agency for Toxic Substances and Disease Registry (ATSDR) Workshop, San Antonio, TX, May 18-22, 1992

Brothers, R.A., "Community Health Concerns Evaluation," presented at the Agency for Toxic Substances and Disease Registry (ATSDR) Workshop, San Antonio, TX, May $18-22,1992$ 
Brothers, R.A., "Community Health Concerns," presented at the Agency for Toxic Substances and Disease Registry Health/Risk Assessment Workshop, San Francisco, June :6, 1992

Brothers, R.A., "Community Health Concerns," presented at the Agency for Toxic Substances and Disease Registry Health/Risk Assessment Workshop, Atlanta, July 15, 1992

Brothers, R.A., "Community Health Concerns," presented at the Agency for Toxic Substances and Disease Registry Health/Risk Assessment Workshop, Dayton, $\mathrm{OH}$, Aug.25, 1992

Brothers, R.A., "Community Health Concerns," presented at the Agency for Toxic Substances and Disease Registry Health/Risk Assessment Workshop, San Antonio, TX, Sept.14, 1992

Brothers, R.A., "Follow-Up Health Activities," presented at the Agency for Toxic Substances and Disease Registry Health/Risk Assessment Workshop, San Francisco, June 17,1992

Brothers, R.A., "Follow-Up Health Activities," presented at the Agency for Toxic Substances and Disease Registry Health/Risk Assessment Workshop, Atlanta, July 15, 1992

Brothers, R.A., "Follow-Up Health Activities," presented at the Agency for Toxic Substances and Disease Registry Health/Risk Assessment Workshop, Dayton, OH, Aug. 26, 1992

Brothers, R.A., "Follow-Up Health Activities," presented at the Agency for Toxic Substances and Disease Registry Health/Risk Assessment Workshop, San Antonio, TX, Sept.15, 1992

Brothers, R.A., "Writing the Background Section," presented at the Agency for Toxic Substances and Disease Registry Health Assessment Workshop, Atlanta, Oct.19, 1992

Brothers, R.A., "Health Outcome Data Evaluation," presented at the Agency for Toxic Substances and Disease Registry Health/Risk Assessment Workshop, San Francisco, June 17,1992

Brothers, R.A., "Health Outcome Data Evaluation," presented at the Agency for Toxic Substances and Disease Registry Health/Risk Assessment Workshop, Atlanta, July 15, 1992

Brothers, R.A., "Health Outcome Data Evaluation," presented at the Agency for Toxic Substances and Disease Registry Health/Risk Assessment Workshop, Dayton, OH, Aug.26, 1992

Brothers, R.A., "Health Outcome Data Evaluation," presented at the Agency for Toxic Substances and Disease Registry Health/Risk Assessment Workshop, San Antonio, TX, Sept.15, 1992

Brothers, R.A., "Community Health Concerns Evaluation," presented at the Agency for Toxic Substances and Disease Registry Health/Risk Assessment Workshop, San Francisco, June 17, 1992 
Brothers, R.A., "Community Health Concerns Evaluation," presented at the Agency for Toxic Substances and Disease Registry Health/Risk Assessment Workshop, Atlanta, July 15,1992

Brothers, R.A., "Community Health Concerns Evaluation," presented at the Agency for Toxic Substances and Disease Registry Health/Risk Assessment Workshop, Davton, OH, Aug.26, 1992

Brothers, R.A., "Community Health Concerns Evaluation," presented at the Agency for Toxic Substances and Disease Registry Health/Risk Assessment Workshop, San Antonio, TX, Sept.15, 1992

Brothers, R.A., "Health Assessment Process," presented at the Agency for Toxic Substances and Disease Registry Health Assessment Workshop, Atlanta, Oct.19, 1992

Brothers, R.A., "The Background Section," presented at the Agency for Toxic Substances and Disease Registry Health Assessment Workshop, San Antonio, TX, Sept.15, 1992

Brothers, R.A., "Case Study Briefing," presented at the Agency for Toxic Substances and Disease Registry Health Assessment Workshop, Atlanta, Oct.19, 1992

Brothers, R.A., "Toxicological Evaluation," presented at the Agency for Toxic Substances and Disease Registry Health/Risk Assessment Workshop, San Francisco, June 17, 1992

Brothers, R.A., "Toxicological Evaluation," presented at the Agency ror Toxic Substances and Disease Registry Health/Risk Assessment Workshop, Atlanta, July 15, 1992

Brothers, R.A., "Toxicological Evaluation," presented at the Agency for Toxic Substances and Disease Registry Health/Risk Assessment Workshop, Dayton, OH, Aug.26, 1992

Brothers, R.A., "Toxicological Evaluation," presented at the Agency for Toxic Substances and Disease Registry Health/Risk Assessment Workshop, San Antonio, TX, Sept.15, 1992

Brothers, R.A., "Conclusions and Recommendations," presented at the Agency for Toxic Substances and Disease Registry Health Risk Assessment Workshop, San Antonio, TX, Sept.15, 1992

Brown, G.M., Thundat, T., Allison, D.P., Warmack, R.J., and Ferrell, T.L., "AFMSTM Investigation of Titanium Electrodes in the Active, Passive, and. Active-Passive Transition Potential Regions," presented at the 38th Annu. Am. Vac. Soc. Symp./Top. Conf., Seattle, Nov.11-15, 1991

Brown, G.M., Allison, D.P., Thundat, T., Jacobson, K.B., Warmack, R.J., and Ferrell, T.L., "Adsorption of DNA on Chemically Modified Surfaces," presented at the 39th Annu. Am. Vac. Soc. Symp./Top. Conf., Chicago, Nov.9-13, 1992

Brown, M.M., Haas, R.T., Wassom, J.S., and Lu, P.-Y., "A Compilation of Test Results on Chemicals Evaluated in the Ames/Salmonella/Genotoxicity Assay," presented at the 205th Am. Chem. Soc. Natl. Meet., Denver, Mar.28-Apr.2, 1993 
Buckner, M.A., "Advancement and Application of Bubble Detector Technology," presented at the 3rd Conf. on Radiation Protection and Dosimetry, Orlando, FL, Oct.21-24, 1991

Buckner, M.A., Casson, W.H., and Sims, C.S., "Advancement and Application of Bubble Detector Technology," presented at the 3rd Conf. on Radiation Protection and Dosimetry, Orlando, FL, Oct.21-24, 1991

Buckner, M.A., Sims, C.S., and Casson, W.H., "The Use of Bubble Detectors for Simple Neutron Spectrometry," presented at the 10th Int. Conf. on Solid State Dosimetry, Washington, DC, July 13-15, 1992

Buckner, M.A. and Sims, C.S., "A Complementary Neutron Spectrometer for Operational Applications," presented at the Meet. Health Phys. Soc., Columbus, OH, June 21-25, 1992

Buckner, M.A., "Dosimetry Past, Present and Future: An Overview," presented at the Society of Physics Students, Carson Newman College, Jefferson City, TN, Feb.25, 1992

Buckner, M.A. and Sims, C.S., "A Complementary Neutron Spectrometer for Operational Applications," presented at the Naval Surface Warfare Center Workshop on Superheated Drop (Bubble) Dosimetry-Applications, Armed Forces Radiobiology Research Inst., Bethesda, MD, July 10, 1992

Buckner, M.A., Sims, C.S., and Casson, W.H., "The Use of Bubble Detectors for Simple Neutron Spectrometry," presented at the 10th Int. Conf. on Solid State Dosimetry, Georgetown Univ., Washington, DC, July 13-15, 1992

Buckner, M.A., "NRRPT Review Course on External Dosimetry," presented at the East Tennessee Chapter of the Health Phys. Soc. NRRPT (Natl. Registry of Radiation Protection Technologists) Review Course, Oak Ridge, TN, Sept.8, 1992

Buckner, M.A., "Empirical-Theoretical Determination of the Neutron Response Function for Teflon Encapsulated TLD-600 Using the Harshaw Model 8800 Hot-Gas Reader," presented at the Harshaw Users Group Meet., San Antonio, TX, Nov.9-13, 1992

Buckner, M.A., "Empirical/Theoretical Determination of the Neutron Response Function for Teflon-Encapsulated TLD-600 Using the Harshaw Model 8800 Reader," presented at the Harshaw/QS (Quality Systerns) TLD (Thermoluminescent Dosimetry) User Symp., San Antonio, TX, Nov.9-13, 1992

Butler, F. and Fields, D.E., "Mathematical Model for the Leaching of Radioactive Waste Sequestered in Portland Cement," prosented at the Natl. Congress for the Advancement of Minorities, Washington, DC, Feb.24, 1993

Callahan, A.P., Mirzadeh, S., and Knapp, F.F., Jr., "L arge Scale Production of Tungsten-188," presented at the 204th Natl. Meet. Am. Chem. Soc., Washington, DC, Aug.23-28, 1992

Callcott, T.A., "Soft X-Ray Spectroscopy as a Probe of Electronic Structure and Bonding in Solids," presented at the DOE/OHER Five-Year Program Review, Oak Ridge, TN, June $17-19,1992$ 
Callcott, T.A., "Soft X-Ray Spectroscopy as a Probe of Electronic Structure and Bonding in Solids," presented at the DOE/OHER Five-Year Program Review, Oak Ridge, TN, June $17-19,1992$

Carman, H.S., Jr, "Collisions Between Rydberg Atoms and Molecules: Probes of Electron-Molecule Interactions," presented at the ORAU Traveling Lecture, Texas Christian Univ., Fort Worth, Feb.19-21, 1992

Carman, H.S., Jr., "Multiphoton Excitation, Ionization, and Reactions of Alkali Atoms," presented at Francis Marion College, Florence, SC, Mar.5, 1992

Carman, H.S., Jr.," Collisions Between Rydberg Atoms and Molecules: Probing Electron-Molecule Interactions," presented at a Seminar, Davidson College, Davidson, NC, Mar.27, 1992

Carman, H.S., Jr., "Rydberg Charge-Exchange Spectroscopy," presented at the OHER Five Year Review, Oak Ridge, TN, June 17-19, 1992

Carman, H.S., Jr. and Compton, R.N., "Electron Attachment to Small Carbon Clusters," presented at the 59th Meet. Am. Phys. Soc., Southeastern Section, Oak Ridge, TN, Nov.12-14, 1992

Casson, W.H. and Mei, G.T., "The Application of TLD's for Personnel Criticality Accident Dosimetry," presented at the 3rd Conf. on Radiation Protection and Dosimetry, Orlando, FL, Oct.21-24,1991

Casson, W.H. and Mei, G.T., "The Application of TLD's for Criticality Accident Dosimetry," presented at the Harshaw TLD (Thermoluminescent Dosimeter) User Symp., New Orieans, Nov.11-15, 1991

Casson, W.H., Sr., "Field Test of a Bubble Detector Pocket Dosimeter as a Daily Neutron Monitor," presented at the 37th Annu. Meet. Health Phys. Soc., Columbus, OH, June $21-25,1992$

Casson, W.H., Sr., "Applications of the Health Physics Research Reactor," presented at DOE Headquarters, Germantown, MD, Aug.5, 1992

Casson, W.H., Sr., "Facility Requirements for Installation of the Health Physics Research Reactor," presented at the LANL Special Seminar, Los Alamos, NM, Aug.26, 1992

Casson, W.H., Sr., "Status of the Design of an Advanced TLD-based Fixed Nuclear Accident Dosimeter," presented at the Centralized External Dosimetry System Meet., MMES, Oak Ridge, TN, Aug.25, 1992

Caton, G.M. and Haas, R.T., "Applications of PC-Based Expert Systems for Environmental, Safety, and Health Issues," presented at the Health and Safety Research Div. Information Meet., ORNL, Oak Ridge, TN, Apr.14-15, 1992

Caton, G.M., Haas, R.T., Haufe, J.C., Francis, M.W., and Lu, P.-Y., "PC-Based System for Integrated Assessment of Environmental Compliance," presented at the 204th Natl. Meet. Am. Chem. Soc., Washington, DC, Aug.24-28, 1992

Chen, C.H., "DNA Sequencing with Mass Spectrometer," presented at the Health and Safety Research Div. Information Meet., ORNL, Oak Ridge, TN, Apr.14-15, 1992 
Chen, C.H., Garrett, W.R., Allman, S.L., and Phillips, R.C., "New Mass Spectroscopic Methods for Waste Management," presented at the SPECTRUM '92, Int. Top. Meet. on Nuclear and Hazardous Waste Management, Boise, ID, Aug.23-27, 1992

Chen, C.H., "Energy Pathway and RIS Applications," presented at the DOE/OHER FiveYear Program Review, ORNL, Oak Ridge, TN, June 17-19, 1992

Chen, C.H., Phillips, R.C., Allman, S.L., Tang, K., and Jones, R.B., "Laser Ablation and Its Applications on Material and Biological Research," presented at the 59th Meet. Am. Phys. Soc., Southeastern Section, Oak Ridge, TN, Nov.12-14, 1992

Chen, C.H., "Laser Mass Spectrometry for Biopolymers," presented at the DOE Workshop on Advanced Laser Technology for Chemical Measurements, Santa Fe, NM, Oct.19-21, 1992

Chen, C.H., Phillips, R.C., and Morrison, P.W., "Kinetics of Photodeposition of Superconducting Films," presented at the Fall Meet. Mater. Res. Soc., Boston, Nov.30Dec. 4,1992

Chen, C.H., Garrett, W.R., DiCillo, J.J., Phillips, R.C., Payne, M.G., and Templeton, D., "Eye and Sensor Protection from Tunable Laser Beams," presented at the 4th Annu. TACOM Combat Vehicle Survivability Symp., Gaithersburg, MD, Mar.30Apr.1, 1993

Chen, C.H.W., "Matrix and Substrate Assisted Laser Desorption for Fast DNA Sequencing," presented at the Soc. Photo-Opt. Instrum. Eng. Conf., Biomedical Optics '93, Los Angeles, Jan.16-22, 1993

Chen, C.H.W., Allman, S.L., and Jacobson, K.B., "Laser Mass Spectrometry for DNA Sequencing," OHER Program Directors' Meet., ORNL, Oak Ridge, TN, Feb.2-3, 1993

Chidambariah, V. and Travis, C.C., "A Risk Based Approach for Rapid Prioritization of Underground Storage Tanks," presented at the HMCRI (Hazardous Materials Control Research Inst.) Federal Environmental Restoration Conf., Vienna, VA, Apr.15-17, 1992

Christian, W., Compton, R.N., and Stockdale, J.A.D., "Laser-Induced Ionization and Stimulated Electronic Raman Scattering in Cesium Vapor Near the 7 P States," presented at the Meet. Am. Phys. Soc., Div. At. Mol. Opt. Phys., Chicago, May 2022,1992

Christophorou, L.G., Datskos, P.G., and Carter, J.G., "Temperature-Enhanced Autodetachment from Long-Lived Parent Negative Ions," presented at the 10th Int. Conf. on Gas Discharges and Their Applications, Swansea, Great Britain, Sept.13-18, 1992

Christophorou, L.G., "Interphase Physics and Electron-Excited Molecules Interactions," presented at the DOE 5-Year Review, ORNL, Oak Ridge, TN, June 17-18, 1992

Christophorou, L.G., Jaffke, T., Hasheimi, R., Illenberger, E., Baumgartel, H., and Pinnaduwage, L.A., "Photoenhanced Dissociative Electron Attachment to $\mathrm{SO}_{2}$," presented at the 59 th Meet. Am. Phys. Soc., Southeastern Section, Oak Ridge, TN, Nov.12-14, 1992 
Christophorou, L.G. and Illenberger, E., "Scattering of Slow Electrons from Excited Atoms: The Dominant Role of the Polarization Potential," presented at the 59th Meet. Am. Phys. Soc., Southeastern Section, Oak Ridge, TN, Nov.12-14, 1992

Christophorou, L.G., "Physical Interactions in Dense Matter," presented at the Dallas Meet. Radiat. Res. Soc./North Am. Hyperthermia Soc., Dallas, Mar.23, 1993

Christophorou, L.G., Datskos, P.G., and Carter, J.G., "Effect of Temperature on the Dissociative and Nondissociative Electron Attachment to Freons," presented at the Bunsen Discussion Meet. on the Physics and Chemistry of the Atmosphere, Schliersee, Bavaria, Germany, Oct.6-9, 1991

Clausing, R.E., Heatherly, L., Thundat, T., and Warmack, R.J., "Morphology of Diamond Films Grown by Hot Filament CVD Process Investigated with AFM," presented at the 39th Annu. Am. Vac. Soc. Symp./Top. Conf., Chicago, Nov.9-13, 1992

Compton, R.N. and Puretzky, A.A., "Fullerenes and YBCO: Molecular Properties Relating to High- $\mathrm{T}_{\mathrm{c}}$ Superconductivity," presented at the High- $\mathrm{T}_{\mathrm{c}}$ Superconductivity Group, ORNL, Oak Ridge, TN, Oct.18, 1991

Compton, R.N., "Buckyballs," presented at the Meet. Am. Vac. Soc., Tennessee Valley Chapter, Oak Ridge, TN, Dec.10, 1991

Compton, R.N., Hettich, R.L., Ritchie, R.H., Britt, P., Puretzky, A.A., Frey, W.F., Adcock, J.L., Mukherjee, P., Diack, M., and Guichon, G., "On the Generation, Separation, Physics, and Chemistry of Large Carbon Clusters," presented at the 181st Electrochem. Soc. Meet., St. Louis, May 17-22, 1992

Compton, R.N., "Physics and Chemistry of Fullerenes (Buckyball)," presented at the Health and Safety Research Div. Information Meet., ORNL, Oak Ridge, TN, Apr.14-15, 1992

Compton, R.N., "Multiphoton Ionization Photoelectron Spectroscopy of Atoms and Molecules," presented at the 43rd Okazaki Conf. on Laser Photoelectron Spectroscopy, Okazaki, Japan, Mar.9-13, 1992

Compton, R.N., "Atomic and Molecular Physics," presented at the OHER Five-Year Review, Oak Ridge, TN, June 17-19, 1992

Compton, R.N. and Hettich, R.L., "The Physics and Chemistry of Large Carbon Clusters," presented at the 45th Annu. Gaseous Electronics Conf., Boston, Oct.27-30, 1992

Compton, R.N., "Buckyball Research at Oak Ridge National Laboratory," presented at the Univ. of Tennessee Governor's School, Oak Ridge, TN, July 8, 1992

Compton, R.N., "Buckyball Research at Oak Ridge Niational Laboratory," presented at the Univ. of Tennessee Summer Science Alliance, Oak Ridge, TN, July 10, 1992

Compton, R.N., "Technology Transfer," presented at the Roane-Anderson Development Council, Oak Ridge, TN, July 17, 1992

Compton, R.N., "Fifty Years of Atomic and Molecular Physics at Oak Ridge," presented at the Meet. Am. Phys. Soc., Southeastern Section, Oak Ridge, TN, Nov.12-14, 1992 
Compton, R.N., "The Physics and Chemistry of Carbon Clusters," presented to the Dept. of Chemistry, Wake Forest Univ., Winston-Salem, NC, Oct.6, 1992

Compton, R.N., "Buckyballs," presented at Berea College, Berea, KY, Feb.12, 1993

Compton, R.N., "Molecular Clusters," presented at the Office of Health and Energy Research Biomedical Directors Meet., ORNL, Oak Ridge, TN, Feb.2-3, 1993

Cosman, M., de los Santos, C., Fiala, R., Hingerty, B., Ibanez, V., Singh, S., Margulis, S., Live, D., Geacintov, N., Broyde, S., and Patel, D., "Solution Conformations of (+)- and (-)-anti-benzo(a)pyrene Diol Epoxide Trans N2-dG DNA Duplex Adducts," presented at the American Assoc. for Cancer Research Conf., San Diego, May 20-25, 1992

Crawford, O.H., Turner, J.E., Hamm, R.N., and Ritchie, R.H., "Calculations of Microdosimetric Energy Deposition Spectra for Beta Particles in Skin," presented at the 11 th Symp. on Microdosimetry, Gatlinburg, TN, Sept.13-18, 1992

Crawford, O.H., "Stopping of Slow Atoms in Solids," presented at the 14th Werner Brandt Workshop on Charged Particle Penetration Phenomena, Oak Ridge, TN, Apr.30-May 1, 1992

Crawford, O.H., "Structure Dependence in Interactions of Particles with Condensed Matter," presented at the DOE/OHER Five-Year Program Review, Oak Ridge, TN, June $17-19,1992$

Cristy, M., "Development and Standardization of Dosimetry Models," presented at the OHER Program Review, ORNL, Oak Ridge, TN, Feb.16-17, 1993

Cronk, T.A. and Kearl, P.M., "The Colloidal Borescope: A Means of Assessing Local Groundwater Flow Velocity," presented at the Subsurface Restoration Conf./3rd Int. Conf. on Ground Water Quality Research, Dallas, June 21-24, 1992

Cronk, T.A. and Kearl, P.M., "Groundwater Particle Velocity Investigations with the Colloidal Borescope," presented at the Health and Safety Research Div. Information Meet., ORNL, Oak Ridge, TN, Apr.14-15, 1992

Cronk, T.A. and Kearl, P.M., "The Colloidal Borescope: A Means of Assessing Local Groundwater Flow Velocity," presented at the Subsurface Restoration Conf., Dallas, June 21-24, 1992

Cronk, T.A. and Kearl, P.M., "The Colloidal Borescope: An Instrument for In Situ Assessment of Local Subsurface Flow Parameters, " presented at the DOE Information Exchange Meet. on Characterization, Monitoring and Sensor Technologies, Dallas, June 3-4, 1992

Datskos, P.G., Christophorou, L.G., and Carter, J.G., "Effective Ionization Coefficients, Electron Drift Velocities, and Limiting Breakdown Fields for Gas Mixtures of Possible Interest to Particle Detectors," presented at the Conf. on Electrical Insulation and Dielectric Phenomena, Knoxville, TN, Oct.20-24, 1991 
Datskos, P.G., Christophorou, L.G., and Carter, J.G., "Temperature-Enhanced Autodetachment from Long-Lived Parent Negative Ions," presented at the 10th Int. Conf. on Gas Discharges and Their Applications, Swansea, Great Britain, Sept.12-19, 1992

Datskos, P.G., Christophorou, L.G., and Carter, J.G., "Variation with Temperature of the Dissociative Electron Attachment to $\mathrm{CH}_{3} \mathrm{Br}$," presented at the 45th Annu. Gaseous Electronics Conf., Boston, Oct.27-30, 1992

Ehrenshaft, A.R. and Wright, L.L., "Energy Crop Information at ORNL," presented at the 205th Am. Chem. Soc. Natl. Meet., Denver, Mar.28-Apr.2, 1993

Ehrenshaft, A.R., Wright, L.L., and Martin, S.A., "Energy Crop Information Resources at ORNL," presented at the 205th Am. Chem. Soc. Natl. Meet., Denver, Mar.28Apr.2, 1993

England, M.W., "Some Multi-Disciplinary Research Areas at Oak Ridge National Laboratory," presented at the Cayey Univ. College, Cayey, PR, Mar.4, 1993

Ferrell, T.L., "Biological Imaging and Analysis in Submicron Physics," presented at the Health and Safety Research Div. Information Meet., ORNL, Oak Ridge, TN, Apr.14. 15,1992

Ferrell, T.L., "Spectroscopic Analysis with the PSTM," presented at the DOE/OHER Five-Year Program Review, Oak Ridge, TN, June 17-19, 1992

Ferrell, T.L., "Recent Progress in Photon Scanning-Tunneling Microscopy," presented at the ORNL Executive Committee Meet., Oak Ridge, TN, Dec.1, 1992

Fields, D.E. and Cottrell, W.D., "Nuclear Radiation Exposures from Petroleum Operations," presented at the Annu. Meet. of Tennessee Academy of Science, Murfreesboro, TN, Nov.22, 1991

Fields, D.E. and Lyster, C., "Balloon Flights for Scientific Research," presented at the 20th Annu. Weld. Test. Technol. Conf., WATTec, Knoxville, TN, Feb. 16-19, 1993

Fields, D.E., "Performing Research Outside the Laboratory - Lessons Learned," presented at the Meet. of Tennessee Chapter of American Assoc. of Physics Teachers, Martin, TN, Mar.26-27, 1993

Fliermans, C.B. and Tyndall, R.L., "Association of Legionella Pneumophila with Natural Ecosystems," presented at the 4th Am. Soc. Microbiol. Symp. on Legionella, Orlando, FL, Jan.26-29, 1992

Fliermans, C.B., Hazen, T.C., and Tyndall, R.L., "Decade of Monitoring Legionella pneumophila in Southeastern Cooling Towers," presented at the 4th Am. Soc.

Microbiol. Symp. on Legionella, Orlando, FL, Jan.26-29, 1992

Fliermans, C.B., Hazen, T.C., and Tyndall, R.L., "Modified Direct Fluorescent Antibody Technique as a Monitoring Tool for Legionella," presented at the 4th Am. Soc. Microbiol. Symp. on Legionella, Orlando, FL, Jan.26-29, 1992

Francis, A.A., "Summary of Hazard Screening Activities in the Health and Safety Research Division," presented at the Summary of Hazard Screening Activities in the Health and Safety Research Div., ORNL, Oak Ridge, TN, June 1992 
Gammage, R., Wheeler, R., and Dempsey, J., "Passive Monitoring of Surface AlphaRadionuclide Contamination in Decontamination and Decommissioning," presented at the Int. Symp. on Environmental Contamination in Central and Eastern Europe, A Forum for Technology Transfer, Budapest, Oct.12-16, 1992

Gammage, R.B., "Exposure Assessment Approaches for the Indoor Air Environment Measuring, Understanding and Predicting Exposures in the 21 st Century," presented at the Int. Soc. Exposure Assess., Atlanta, Nov.18-21, 1991

Gammage, R.B. and Wheeler, R.C., "Passive Monitoring of Surface Alpha Contamination," presented at the Technical Information Exchange Workshop, Augusta, GA, Nov.19-20, 1992

Gammage, R.B., Dudney, C.S., and Wilson, D.L., "Enhanced Indoor Radon and Karst Radon Reservoirs," presented at the Am. Soc. Heat. Refrig. Air Cond. Eng. American Conf. of Governmental Industrial Hygienists and the American Industrial Hygiene Assoc., IAQ '92, San Francisco, Oct.18-21, 1992

Gammage, R.B. and Wheeler, R.V., "Surface Alpha Contamination Measurements with Inexpensive Passive Monitors," presented at the 37th Annu. Meet. Health Phys. Soc., Columbus, OH, June 21-26, 1992

Gammage, R.B., "Passive Monitoring of Surface Alpha Contamination," presented at the DOE Technology Information Exchange (TIE) Workshop, Albuquerque, NM, May 1921,1992

Gammage, R.B., Wachter, E.A., Wade, J., Wilson, D.L., Ahmad, N., Siltain, F., and Raza, M.Z., "Reducing Emissions from High-Sulfur Coal Briquettes," presented at the Int. Symp. on Environmental Contamination in Central and Eastern Europe, A Forum for Technology Transfer, Budapest, Oct.12-16, 1992

Gammage, R.B., Wachter, E.A., Wade, J., Ahmad, N., Sibtain, F., and Raza, M.Z., "Indoor Air Pollution During Buming of Coal Briquettes and Traditional Fuels," presented at the American Industrial Hygiene Conf./Expo., Boston, May 30-June 5, 1992

Gammage, R.B., "Death by Indoor Air: Effects, Measurement, Control, Policy," presented at the Western Management Developing Center Environmental Issues Seminar, Denver, Aug.22, 1992

Gammage, R.B., DePriest, J.C., Wheeler, R.V., Dempsey, J.C., and Kotrappa, P., "Monitoring of Surface Alpha Contamination with Inexpensive Passive Monitors," presented at the Int. Symp. on Environmental Contamination, Budapest, Oct.12-16, 1992

Gammage, R.B., Wachter, E.A., Wade, J., Wilson, D.L., Haas, J.W., Ahmad, N., Siltain, F., and Raza, M.Z., "Reduced Emissions from Inexpensive High-Sulphur Coal Briquettes," presented at the Int. Symp. on Environmental Contamination, Budapest, Oct.12-16, 1992

Gammage, R.B., "Radon in the Home: How Big a Problem," presented to the Physics Dept., Univ. of Puebla, Puebla, Mexico, Nov.1, 1992 
Gammage, R.B., "Environmental Contamination and Monitoring," presented to the Physics Dept., Natl. Autonomous Univ. of Mexico, Univ. of Puebla, Puebla, Mexico, Nov.9, 1992

Gammage, R.B., DePriest, J.C., Wheeler, R.V., Dempsey, J.C., and Kotrappa, P., "In-Situ Passive Monitoring of Alpha-Emitting Radionuclides," presented at the 3rd Natl. Symp. on Field Screening Methods for Hazardous Waste and Toxic Chemicals, Las Vegas, Feb.24-26, 1993

Gammage, R.B., "Environmental Contamination and Possible Solutions," presented at the 25th Mexican Natl. Conf. on Physics, Puebla, Mexico, Oct.26-30, 1992

Gammage, R.B., "Capitalizing on Changing Department of Energy Needs," presented at the OHER Program Review, ORNL, Oak Ridge, TN, Feb.16-17, 1993

Gammage, R.B., "Capitalizing on Changing DOE Needs," presented at the OHER Site Review, ORNL, Oak Ridge, TN, Feb.16-17, 1993

Gammage, R.B., "Field Methods for Measurement of Surface Alpha Contamination," presented at the Office of Environmental Restoration and Waste Management Special Programs (EM-56) Mid-Year Program Review, Washington, DC, Mar.30-Apr.2, 1993

Garrett, W.R., "Alterations of Multiphoton-Resonant Processes Through Wave-Mixing Effects," presented at the 6th Int. Symp. on Resonance Ionization Spectroscopy and Its Applications, Santa Fe, NM, May 24-29, 1992

Garrett, W.R. and Payne, M.G., "Suppression and Shifting of Odd-Photon Resonant Excitations and Stimulated Hyper-Raman Emissions," presented at the Soc. PhotoOpt. Instrum. Eng. Int. Symp. on Lasers, Sensors, and Spectroscopy, Los Angeles, Jan.19-25, 1992

Garrett, W.R., "Basic RIS and Nonlinear Optical Phenomena in Resonant Media: Experiment and Theory," presented at the DOE/OHER Five-Year Program Review, ORNL, Oak Ridge, TN, June 17-19, 1992

Garrett, W.R., Datskou, I., Payne, M.G., and Wray, J.E., "Determinations of a.c. Stark Shift Coefficients in NO Through, Resonance Ionization Spectroscopic Measurements," presented at the 59th Meet. Am. Phys. Soc., Southeastern Section, Oak Ridge, TN, Nov.12-14, 1992

Garrett, W.R., "Experimental and Theoretical Features and Potential Applications of Strong Suppression and Line-Shifting Phenomena in Odd-Photon Resonant Excitations and Stimulated Emissions in Gaseous Media," presented at the DOE Workshop on Advanced Laser Technology for Chemical Measurements, Santa Fe, NM, Oct.19-21, 1992

Gibson, W.A., Hunter, S.R., Hurst, G.S., Turner, J.E., Hamm, R.N., and Wright, H.A., "Optical Detection of Charged-Particle Tracks in a Gas," presented at the 11 th Symp. on Microdosimetry, Gatlinburg, TN, Sept.13-18, 1992

Goudonnet, J.P., Ferrell, T.L., and Warmack, R.J., "Recent Progress in Photon Scanning Tunneling Imaging," presented at the Soc. Photo-Opt. Instrum. Eng. Int. Conf. on Laser Spectroscopy, Los Angeles, Jan.19-24, 1992 
Goudonnet, J.P., de Fornel, F., Salomon, L., Lesniewska, E., Warmack, R.J., and Ferrell, T.L., "An Evanescent Field Optical Scanning Microscope," presented at the 3rd Beijing Conf./Exhib. on Instrumentation Analysis, Beijing, China, Oct.21-23, 1991

Greenbaum, E., MacInnis, J.M., Tevault, C.V., Blankinship, S.L., and Cinco, R., "Biological Physics: Renewable Fuels and Chemicals Synthesis," presented at the Meet. Am. Phys. Soc., Southeastern Section, Oak Ridge, TN, Nov.12-14, 1992

Griffin, G., Tkachuk, L., Baker, M., James, D.R., England, M.W., Sauers, I., and Vo-Dinh, T., "Magnetic Field Effects on Membrane Permeability of Phospholipid Liposomes," presented at the Annu. Review of Research on Biological Effects of Electric and Magnetic Field from Generating, Operating and Using Electricity, San Diego, Nov.9-12, 1992

Griffin, G.D., "Biomonitoring of Toxic Gases," presented at the Health and Safety Research Div. Information Meet., ORNL, Oak Ridge, TN, Apr.14-15, 1992

Griffiths, G.L., Knapp, F.F., Jr., Callahan, A.P., Hansen, H.J., and Goldenberg, D.M., "The Generation of Rhenium-188-Labeled Antibodies by Direct Labeling Methods, " presented at the 39th Annu. Meet. Soc. Nucl. Med., Los Angeles, June 9-12, 1992

Haas, J.W., III, "Field Analytical Studies on the Oak Ridge Reservation," presented at the Technology Transfer Conf. on Environmental Cleanup, Denver, Nov.13-15, 1991

Haas, J.W., "In Situ Fiber Optical Monitors in Site Restoration/Waste Management Programs," presented at the Health and Safety Research Div. Information Meet., ORNL, Oak Ridge, TN, Apr.14-15, 1992

Haas, J.W., "Derivative Ultraviolet Absorption Spectroscopic (DUVAS) Monitoring of Aromatic Contaminants," presented at the DUVAS Program Review, Washington, DC, May 5, 1992

Haas, J.W., III, Welch, S.M., Simpson, B., Carrabba, M.M., and Edmonds, R.B., "New Approaches to Chemical Analysis Using Surface-Enhanced Raman Spectroscopy (SERS)," presented at the 18th Annu. Meet. Fed. Anal. Chem. Spectrosc. Soc., Anaheim, CA, Oct.7-11, 1991

Haas, J.W., III, Welch, S.M., Simpson, B.M., Carrabba, M.M., and Edwards, R.B., "New Approaches to Chemical Analysis Using Surface-Enhanced Raman Spectroscopy (SERS)," presented at the 18th Annu. Meet. Fed. Anal. Chem. Spectrosc. Soc., Anaheim, CA, Oct.7-11, 1991

Haas, J.W., III, Gammage, R.B., Carrabba, M.M., and Edmonds, R.M., "Fiberoptic Spectroelectrochemical Sensor for Characterizing Chlorinated Hydrocarbon Solvents at Hazardous Waste Sites," presented at the Int. Symp. on Environmental Contamination in Central and Eastern Europ :, Budapest, Oct.12-16, 1992

Haas, J.W., III, Matthews, T.G., and Gammage, R.B., "Characterization of Aromatic Compounds at Hazardous Waste Sites Using Derivative Ultraviolet Absorbance Spectroscopy," presented at the Int. Symp. on Environmental Contamination in Central and Eastern Europe, Budapest, Oct.12-16, 1992 
Haas, J.W., III, Matthews, T.G., and Gammage, R.B., "In Situ Fiberoptic Monitors for Site Characterization," presented at the OTD (Office of Technology Development) Semi-Annu. Information Meet., Dallas, June 3-4, 1992

Haas, J.W., III, Fisher, W.G., Bacon, J.A., and Gammage, R.B., "Field Screening Measurement of Polyaromatic Pollutants in Water by Synchronous Scanning Fluorescence Spectroscopy," presented at the Int. Symp. on Environmental Contamination in Central and Eastern Europt. Budapest, Oct.12-16, 1992

Haas, J.W., III, Fisher, W.G., Bacon, J.A., and Gammage, R.B., "Field Screening Measurement of Polyaromatic Pollutants in Water by Synchronous Scanning Fluorescence Spectroscopy," presented at the EPA's 4th Forum on Innovative Hazardous Waste Treatment Technologies: Domestic and Foreign, San Francisco, Nov.17-19, 1992

Haas, J.W., III, Gammage, R.B., Carrabba, M.M., and Edmonds, R.M., "Fiberoptic Spectruelectrochemical Sensor for Characterizing Chlorinated Hydrocarbon Solvents at Hazardous Waste Sites," presented at the EPA's 4th Forum on Innovative Hazardous Waste Treatment Technologies: Domestic and Foreign, San Francisco, Nov.17-19, 1992

Haas, J.W., III, Matthews, T.G., and Gammage, R.B., "Characterization of Aromatic Compounds at Hazardous Waste Sites Using Derivative Ultraviolet Absorbance Spectroscopy," presented at the EPA's 4th Forum on Innovative Hazardous Waste Treatment Technologies: Domestic and Foreign, San Francisco, Nov.17-19, 1992

Hamm, R.N., Turner, J.E., Howell, R.W., Rao, D.V., and Sastry, K.S.R., "Calculations of DNA Damage from 125I," presented at the 40th Annu. Meet. Radiat. Res. Soc., Salt Lake City, Mar.14-18, 1992

Hamm, R.N. and Turner, J.E., "Track Structure Calculations for Biophysical Modeling of Radiation Effects," presented at the 14th Werner Brandt Workshop on Charged Particle Penetration Phenomena, Oak Ridge, TN, Apr.30-May 1, 1992

Hamm, R.N., Turner, J.E., and Hingerty, B.E., "Modeling of Biological Structure Function Relationships Using Monte Carlo Methods," presented at the 25th DOE Radiological and Chemical Physics Contractors' Meet., Wakulla Springs, FL, June 810,1992

Hamm, R.N., "Future Initiatives," presented at the DOE/OHER Five-Year Program Review, Oak Ridge, TN, June 17-19, 1992

Hasan, A., Srivastava, P.C., and Mills, D.C.B., "Synthesis of 2-Substituted Thioadenosine Nucleosides and Nucleotides for Platelet ADP-Receptor Studies," presented at the 204th Natl. Meet. Am. Chem. Soc., Washington, DC, Aug.23-28, 1992

Hergenroder, R., Jacobson, S.C., Koutny, L.B., Warmack, R.J., and Ramsey, J.M., "Microchip Capillary Electrophoresis," presented at the 5th Int. Conf. on High Performance Capillary Electrophoresis (HPCE), Orlando, FL, Jan.25-28, 1993 
Hettich, R. and Yoshida, H., "Matrix-Assisted Laser Desorption FTMS for the Investigation of X-Ray Induced Damage to Nucleic Acid Constituents," presented at the 19th Annu. Meet. Fed. Anal. Chem. Spectrosc. Soc., Philadelphia, Sept.20-25, 1992

Hettich, R.L., Buchanan, M.V., and Compton, R.N., "Characterization of Aluminum and Carbon Cluster Ions by Fourier Transform Ion Cyclotron Resonance Mass Spectrometry," presented at the Eastern Analytical Symp., Somerset, NJ, Nov.11, 1991

Hettich, R.L. and Compton, R.N., "Structural Characterization of Fullerenes by Laser Desorption FTMS," presented at the 32nd ORNL-DOE Conf. on Analytical Chemistry in Energy Technology, Gatlinburg, TN, Oct.1-3, 1991

Hettich, R.L. and Yoshida, H., "Matrix-Assisted Laser Desorption FTMS for the Characterization of Radiation-Induced Damage to DNA," presented at the Am. Soc. Mass Spectrom. Workshop on Lasers in Mass Spectrometry, Sanibel Island, FL, Jan.25-28, 1992

Hettich, R.L. and Compton, R.N., "Characterization of Fullerene Growth and Doping by Laser Desorption FTMS," presented at the Am. Soc. Mass Spectrom. Workshop on Lasers in Mass Spectrometry, Sanibel Island, FL, Jan.25-28, 1992

Hettich, R.L. and Compton, R.N., "Examination of Fullerene Growth and Doping by Laser Desorption FTMS," presented at the 40th Am. Soc. Mass Spectrom. Conf., Washington, DC, May 31-June 5, 1992

Hettich, R.L. and Yoshida, H., "Characterization of Radiation-Induced Damage to Nucleic Acid Constituents by Matrix-Assisted Laser Desorption FTMS," presented at the 40th Am. Soc. Mass Spectrom. Conf., Washington, DC, May 31-June 5, 1992

Hettich, R.L., Buchanan, M.V., and Compton, R.N., "Laser Desorption FTMS for the Structural Characterization of Nucleic Acid Constituents and Fullerenes," presented at the 24th Central Regional Meet. Am. Chem. Soc., Cinciınati, May 27-29, 1992

Hettich, R.L. and Compton, R.N., "Characterization of Modified Fullerenes by Laser Desorption Fourier Transform Mass Spectrometry," Eastern Analytical Symp., Somerset, NJ, Nov.18, 1992

Hettich, R.L., Nourse, B., Yoshida, H., and Buchanan, M., "Matrix-Assisted Laser Desorption FTMS for Modified Nucleotides and Oligonucleotides," presented at the Science Innovation '92, San Francisco, July 21-25, 1992

Hettich, R.L., Jin, C., Britt, P., and Compton, R.N., "Structural Characterization of Fullerene-Based Materials by Laser Desorption Fourier Transform Mass Spectrometry," presented at the Fall Meet. Mater. Res. Soc., Boston, Nov.30-Dec.4, 1992

Hettich, R.L. and Yoshida, H., "Characterization of Radiation-Induced Damage to Nucleic Acid Constituents by Matrix-Assisted Laser Desorption FTMS," presented at the 40th Am. Soc. Mass Spectrom. Conf., Washington, DC, May 31-June 5, 1992

Hettich, R.L. and Compton, R.N., "ORNL Buckyball Research, "presented at the ORNL Directors Executive Committee, ORNL, Oak Ridge, TN, Jan.19, 1993 
Hingerty, B.E., "Molecular Mechanics and Dynamics of DNA Carcinogen Adducts," presented at the Computational Chemistry Roundtable, Indiana Univ.-Purdue Univ., Indianapolis, Nov.26, 1991

Hingerty, B.E., "Conformations of DNA Adducts with Polycylic Aromatic Carcinogens," presented at the DOE Computational Science Education Workshop, Burlingame, CA, Oct.8-9, 1991

Hingerty, B.E., "Vectorization of Semi-Empirical Energy Functions," presented at the DOE Computational Science Education Project, Atlanta, Dec.20-21, 1991

Hingerty. B.E., "Molecular Dynamics Simulations of DNA Modified by Carcinogens," presented at the Computational Science Education Workshop, Denver, Mar.5-8, 1992

Hingerty, B.E., "Molecular Dynamics Simulations of DNA Modified ky Carcinogens," presented at the DOE Computational Science Education Workshop, Washington, DC, June 26-27, 1992

Hingerty, B.E., "The Structure of DNA Modified by Carcinogens," presented at the Pacific Northwest Lab., Richland, Washington, June 24, 1992

Hovatter, P.S. and Gibson, R.E., "Selection of Indicator Chemicals at Hazardous Waste Sites," presented at the Symp. on Superfund Risk Assessment in Soil Contamination Studies, New Orleans, Jan.30-31, 1992

Hovatter, P.S., Ross, R.H., Lu, P.-Y., and Muhly, R., "Nitroaromatics as Soil and Groundwater Contaminants of Concern at Army Superfund Sites: Toxicity and Cleanup Levels," presented at the 12th Annu. Meet. Soc. Environ. Toxicol. Chem., Seattle, Nov.3-7, 1991

Hovatter, P.S., Ross, R.H., Lu, P.-L., and Muhly, R., "Cleanup Levels for MunitionsRelated Chemicals in Surface Water at Army Superfund Sites," presented at the 13th Annu. Meet. Soc. Environ. Toxicol. Chem., Cincinnati, Nov.8-12, 1992

Hull, R.N., "General Overview of the Plant-Wide Ecological Risk Assessment Workplan for the Portsmouth Gaseous Diffusion Plant," presented at the Working Group Meet., Portsmouth Gaseous Diffusion Plant, Portsmouth, OH, Dec.8, 1992

Hunter, S.R., Gibson, W.A., Hurst, G.S., Turner, J.E., Hamm, R.N., and Wright, H.A., "Optical Detection of Charged-Particle Tracks in a Gas," presented at the Site Visit and Technical Review of OHER-Sponsored Research, ORNL, Oak Ridge, TN, Feb.16-17, 1993

Jacobson, K.B., Chen, C.H., Buchanan, M.V., and McLuckey, S.A., "Development of Mass Spectrometric Methods for DNA Sequencing and Genome Analysis," presented at the Future Technologies for DNA Analysis, Washington, DC, Oct.26-27, 1992

Johnson, C.M. and Casson, W.H., Sr., "The Characterization of the X-Ray Beam Quality for a Secondary Calibration Laboratory," presented at the 37th Annu. Meet. Health Phys. Soc., Columbus, OH, June 21-25, 1992

Johnson, C.M., "Results from Recent Personnel Dosimeter Intercomparison Studies," presented at the Harshaw/QS TLD (Thermoluminescent Dosimeter) User Symp., San Antonio, TX, Nov.9-13, 1992 
Jolley, R.L., Donaldson, T.L., Morris, M.D., Siegrist, R.L., Walker, J.F., MacNeill, J.J., Ott, D.W., Machanoff, R.A., Adler, H.I., and Phelps, T.J., "Bioremediation: Effective Treatment of Petroleum-Fuel-Contaminated Soil, a Common Environmental Problem at Industrial and Governmental Agency Sites," presented at the SPECTRUM '92, Int. Top. Meet. on Nuclear and Hazardous Waste Management, Boise, ID, Aug.23-27, 1992

Jones, T.D. and Morris, M.D., "Fallout Radiation Mortality," presented at the DNA Technology Transfer Meet., Alexandria, VA, Nov.30-Dec.3, 1992

Kaye, S.V., "Welcome Address," presented at the 3rd Conf. on Radiation Protection and Dosimetry, Orlando, FL, Oct.21-24, 1991

Kaye, S.V., "HASRD's Contributions to Environmental Restoration and Waste Management," presented at the Health and Safety Research Div. Information Meet., ORNL, Oak Ridge, TN, Apr.14-15, 1992

Kaye, S.V., "Executive Briefing," presented at the Health and Safety Research Div. Information Meet., ORNL, Oak Ridge, TN, Ap: 14-15, 1992

Kaye, S.V., "Welcome Address," presented at the 14th Werner Brandt Workshop on Charged Particle Penetration Phenomena, Oak Ridge, TN, Apr.30, 1992

Kaye, S.V., "Overview of the Health and Safety Research Division," presented at the DOE/OHER Five-Year Program Review, ORNL, Oak Ridge, TN, June 17, 1992

Kaye, S.V., "Welcome Address," presented at the 11th Symp. on Microdosimetry, Gatlinburg, TN, Sept.13-18, 1992

Kaye, S.V., "Risk Analysis and Instrumentation Development in the Health and Safety Research Division, Oak Ridge National Laboratory," presented at the Environmental and Occupational Health Sciences Inst., Rutgers Univ., Piscataway, NJ, Sept.11, 1992

Kerr, G.D., Borges, H.T., Stafford, R.S., and Carter, D.R., "The NRC Health Physics Positions Data Base," presented at the 37th Annu. Meet. Health Phys. Soc., Columbus, OH, June 21-25, 1992

Kerr, G.D., "External Radiation: Techniques and Methods for Occupational Dose Assessment Studies," presented at the 37th Annu. Meet. Health Phys. Soc., Columbus, OH, June 21-25, 1992

Khare, B., Thompson, W.R., Wilson, P., Sagan, C., Arakawa, E.T., Meisse, C., and Gilmour, I., "Optical Constants from 0.19 to 2.5 Micrometer of Organic Residue from the Murchison Meteorite," presented at the 2nd Int. Planetary Science Conf., Div. for Planetary Science of the AAS, Munich, Germany, Oct.12-16, 1992

Khare, B., Thompson, W.R., Wilson, P., Sagan, C., Arakawa, E.T., Meisse, C., and Gilmour, I., "Optical Constants from 0.19 to 2.5 Micrometer of Organic Residue from the Murchison Meteorite," presented at the 4th Int. Conf. on Laboratory Research for Planetary Atmospheres, Munich, Germany, Oct.11-12, 1992 
Khare, B.N., Thompson, W.R., Cheng, L., Sagan, C., Meisse, C., Arakawa, E.T., and Matthews, C.N., "Optical Properties of Tholin from $\mathrm{H}_{2} \mathrm{O} / \mathrm{C}_{2} \mathrm{H}_{6}(6: 1)$ Ice, and Comparison with Titan Tholin, Kerogen and Meteoritic Organics," presented at the 23rd Annu. Meet. Am. Astron. Soc., Div. Planet. Sci., Palo Alto, CA, Nov.4-8, 1991

King, A.D., Doll, W.E., Durfee, R.C., and Bell, D.T., "Aerial Remote Sensing Surveys Oak Ridge Reservation," presented at the DOE Headquarters Meet. on Aerial Remote Sensing, Gaithersburg, MD, Jan.15, 1993

King, A.D., Doll, W.E., and Durfee, R.C., "Aerial Remote Sensing Surveys - Oak Ridge Reservation," presented at the Westinghouse Savannah River Co./Martin Marietta Energy Systems, Inc., Environmental Restoration Technical Information Exchange, Augusta, GA, Feb.10-11, 1993

King, A.D., Carden, D.M., Doll, W.E., and Durfee, R.C., "Aerial Remote Sensing Surveys: Oak Ridge Reservation Remote Sensing," presented to the Liaison Working Group, Desert Research Inst., Las Vegas, Mar.16-17, 1993

Kinser, H.B. and Crawford, O.H., "A Complex Kohn Variational Calculation for p-Wave Scattering of an Electron from a Screened Coulomb Potential," presented at the Annu. Meet. of Georgia Academy of Science, Georgia Southern Univ., Statesboro, May 1-2, 1992

Klein, J.A., Mrochek, J.E., Francis, A.A., Wright, T., Orlando, D.A., and Jones, S., "National Profile on Commercially Generated Low-Levei Radioactive Mixed Waste," presented at the 14th Annu. DOE Low-Level Radioactive Waste Management Conf., Phoenix, AZ, Nov.18-20, 1992

Klots, C.E., "Absolute Tests of the Quasi-Equilibrium Hypothesis," presented at the 9th European Conf. on Dynamics of Molecular Collisions, Prague, Aug.30-Sept.5, 1992

Klots, C.E., "Cluster Dynamics," presented at the OHER Five-Year ProgramReview, Oak Ridge, TN, June 17-19, 1992

Klots, C.E., "Dissociation and Thermionic Emission from the $\mathrm{C}_{60}$ Molecule," presented at the Gordon Conf. on Molecular Clusters, Irsee, Germany, Oct.4-11, 1992

Klots, C.E., "Kinetics of Dissociation and Thermionic Emission in the $\mathrm{C}_{60}$ and $\mathrm{C}_{70}$ Molecules," presented to the Seminar, Universite, Paris-Sud, France, Oct.12, 1992

Knapp, F.F., Jr., "Radioisotopes for Radioimmunodetection (RAID) and Radioimmunotherapy (RAIT) -- Current and New Perspectives," presented at the Meet. Soc. Nucl. Med., Southeastern Chapter, Hollywood, FL, Oct.11-13, 1991

Knapp, F.F., Jr., Kropp, J., Ambrose, K.R., McPherson, D.W., Callahan, A.P., Lambert, C.R., and Biersack, H.-J., "Site Specific/Stable Radioiodination of 1,2Dipalmitoyl-3-((15-p-(I-131)-iodophenyl)penta decan-3-oyl)rac-glycerol (1,2-Pal-3IPPA) for In Vivo Evaluation of Pancreatic Lipase by Urine Analysis," presented at the 39th Annu. Meet. Soc. Nucl. Med., Los Angeles, June 9-12, 1992

Knapp, F.F., Jr. and McPherson, D.W., "Development of Radioiodinated Receptor Ligands for Cerebral Single Photon Emission Tomography," presented at the 2nd Mediterranean Symp. on Nuclear Medicine and Radiopharmaceuticals, Athens, Greece, Apr.7-12, 1992 
Knapp, F.F., Jr., "ORNL Nuclear Medicine Program," presented at the OHER Program Directors' Meet., Oak Ridge, TN, Feb.3, 1993

Knapp, F.F., J-, "Development of Radioiodinated Fatty Acids for Myocardial Imaging," presented at the 17th New Town Conf. on Nuclear Cardiology, Tokyo, Feb.13, 1993

Knapp, F.F., Jr., Kropp, J., Goodman, M.M., Franken, P., Reske, S.N., Ambrose, K.R., Som, P., Biersack, H.-J., Sloof, G.W., and Visser, F.C., "The Development of Iocine-123-Methyl-Branched Fatty Acids and Their Applications in Nuclear Cardiology," presented at the 3rd Int. Symp. on Radioiodinated Free Fatty Acids, Kyoto, Japan, Feb.10-11, 1993

Knapp, F.F., Jr., "The Development of Radioiodinated Fatty Acids for Myocardial Imaging," presented at the 17th New Town Conf., Tokyo, Japan, Feb.13, 1993

Kocher, D.C. and Hoffman, F.O., "A Proposed Framework for Consistent Regulation of Public Exposures to Radionuclides and Other Carcinogens," presented at the 8th Int. Congress of International Radiation Protection Assoc., Montreal, May 17-22, 1992

Kocher, D.C., "Dose Assessment for a ${ }^{137} \mathrm{Cs}$ Contamination Incident," presented at the Winter Meet. Am. Nucl. Soc., San Francisco, Nov.10-15, 1991

Kocher, D.C. and Hoffman, F.O., "Regulating Public Exposures to Radionuclides and Hazardous Chemicals - The Problem and a Solution," presented at the Health and Safety Research Div. Information Meet., ORNL, Oak Ridge, TN, Apr.14-15, 1992

Kocher, D.C. and Eckerman, K.F., "Dose Conversion Factors Pathway Analysis and Risk Assessment for Environmental Compliance and Dose Reconstruction," presented at Kiawah Island, SC, Mar.2-6, 1992

Kocher, D.C., "The Regulations for Radionuclides and Chemicals in the Environment Course on Pathway Analysis and Risk Assessment for Environmental Compliance and Dose Reconstruction," presented at Kiawah Island, SC, Mar.2-6, 1992

Kocher, D.C., "Review of Standards for Limitation of Radiation Dose to Radiation Workers and Members of the Public," presented at the 11th Annu. Int. Panasonic TLD (Thermoluminescent Dosimeter) Users Symp., St. Simons Island, GA, June 8-12, 1992

Kocher, D.C., "Potential Impact of DOE's Performance Objective for Protection of Inadvertent Intruders on Low-Level Waste Disposals at Uak Ridge National Laboratory," presented at the 14th Annu. DOE Low-Level Radioactive Waste Management Conf., Phoenix, AZ, Nov.18-20, 1992

Kocher, D.C., "Regulating Public Exposures to Radionuclides and Hazardous Chemicals The Problem and a Solution," presented at the 8th Annu. DOE Model Conf. on Waste Management and Environmental Restoration, Oak Ridge, TN, Oct.19-22, 1992

Kocher, D.C., "Sources, Classification, and Disposal of Radioactive Wastes - Hiștory and Legal and Regulatory Requirements," presented at the Harvard School of Public Health Office of Continuing Education Course, Boston, July 13, 1992 
Kocher, D.C., "Principles and Criteria for Disposal of Low-Level Radioactive Waste: Status and Unresolved Issues," presented at the Weld. Test. Technol. Conf., WATTec, Knoxville, TN, Feb.16-19, 1993

Korte, N. and Thate, J., "Health and Safety at Hazardous Waste Sites - Is it Possible to be Too Careful?" presented at the Am. Chem. Soc. Natl. Symp. on Health, Safety, and Training Issues During Site Characterization and Remediation, Denver, Mar. 1993

Kress, R.L., Jansen, J.F., and Haas, J.W., "Robotic Arm Design for a Remotely-Deployed, In Situ Waste Characterization Probe," presented at the 18th Am. Nucl. Soc. Symp. on Waste Management, Waste Management '92, Tucson, AZ, Mar.1-5, 1992

Kreutz, T., Clausing, R.E., Heatherly, L., Warmack, R.J., and Feigerle, C.S., "Scanning Tunneling Microscopy of Boron-Doped CVD Diamund Films," presented at the 3rd Int. Conf. on New Diamond Science and Technology/ Diamond Films '92: 3rd European Conf. on Diamond, Diamond-like and Related Coatings, Heidelberg, Germany, Aug.31-Sept.4, 1992

Kropp, J., Kohler, U., Zierz, S., Knapp, F.F., Jr., Briele, B., Smekal, A.V., Hotze, A.L., and Biersack, H.J., "Diagnosis of Myocardial Involvement in Patients with Systemic Myopathies with 15-(p-(I-123)Iodophenyl)pentadecanoic Acid (IPPA) Spect," presented at the 20th Int. Symp. on Radioactive Isotopes in Clinical Medicine and Research, Badgastein, Austria, Jan.7-10, 1992

Kropp, J., Kohler, U., Zierz, St., Knapp, F.F., Jr., Briele, B., Smekal, A.V., and Biersack, H.J., "Oxidative Metabolism of the Myocardium in Patients with Systemic Myopathies. A Study with 123IPPA-SPECT," presented at the European Assoc. of Nuclear Medicine Congress, Lisbon, Portugal, Aug.24-28, 1992

Kropp, J., Jorgens, M., Glanzer, K., Knapp, F.F., Jr., and Biersack, H.J., "Evaluation of Ischemia in Patients with Coronary Artery Disease (CAD) with the Modified Fatty Acid (p-123-Iodophenyl)-3-R,S-methylpentadecanoic Acid (BMIPP)," presented at the 65th Annu. Meet. Am. Heart Assoc., New Orleans, Nov.16-19, 1992

Lee, D.W. and Kocher, D.C., "Performance Assessment of Low-Level Radioactive Waste Disposal at Oak Ridge National Laboratory," presented at the 18th Am. Nucl. Soc. Symp. on Waste Management, Waste Management '92, Tucson, AZ, Mar.1-5, 1992

Lee, D.W., Kocher, D.C., and Bownds, J.M., "Integration and Interpretation of Results from Performance Assessments of Low-level Radioactive Disposal Facilities," presented at the 14th DOE Low-Level Radioactive Waste Management Conf., Phoenix, AZ, Nov.18-20, 1992

Lee, I., Thundat, T., and Ferrell, T.L., "Study of Nuclepore Membranes by PSTM, AFM, and SEM," presented at the 59th Meet. Am. Phys. Soc., Southeastern Section, Oak Ridge, TN, Nov.12-14, 1992

Lee, I., Zheng, X.Y., and Warmack, R.J., "Detection of Local Index Change by Photon Scanning Tunneling Microscope," presented at the 59th Meet. Am. Phys. Soc., Southeastern Section, Oak Ridge, TN, Nov.12-14, 1992 
Lee, I., Thundat, T., Warmack, R.J., Allison, D.P., Ferrell, T.L., Tkachuk, L., and Griffin, G.D., "Atomic Force Microscopy and Photon Scanning Tunneling Microscopy of Liposomes and Filtration Membrane," presented at the March Meet. Am. Phys. Soc., Seattle, Mar.22-26, 1993

Leggett, R.W., "A Generic Biokinetic Model for Bone-Seeking Radionuclides," presented at the Workshop on Age-Dependent Factors in the Biokinetics and Dosimetry of Radionuclides, Schloss Elmau, Klais, Oberbayern, FRG, Nov.5-8, 1991

Lisic, E., Mirzadeh, S., and Knapp, F.F., Jr., "Facile Synthesis of Re-188-Labeled $\operatorname{Re}(\mathrm{V})$-DMSA by Triphenylphosphine Reduction of Perrhenate at Room Temperature," presented at the 39th Annu. Meet. Soc. Nucl. Med., Los Angeles, June 9-12, 1992

Lisic, E.C., Callahan, A.P., Mirzadeh, S., and Knapp, F.F., Jr., "A New Tandem Generator/Ion Exchange System Providing Carrier-Free Rhenium-188-Perrhenic Acid," presented at the 204th Natl. Meet. Am. Chem. Soc., Washington, DC, Aug.23-28, 1992

Lowndes, D.H., Norton, D.P., Zhu, S., Zheng, X.-Y., and Warmack, R.J., "Microstructural and Superconducting Properties of Epitaxial $\mathrm{Yba}_{2} \mathrm{Cu}_{3} \mathrm{O}_{7} / \mathrm{PrBa}_{2} \mathrm{Cu}_{3} \mathrm{O}_{7-\delta}$ Superlattices," presented at the 4th Int. Symp. on Superconductivity, Tokyo, Oct.1417,1991

Lowndes, D.H., Norton, D.P., Zhu, S., and Zheng, X.-Y., "Superconducting Properties and Microstructure of $\mathrm{Yba}_{2} \mathrm{Cu}_{3} \mathrm{O}_{7} / \mathrm{PrBa}_{2} \mathrm{Cu}_{3} \mathrm{O}_{7-\delta}$ Superlattices," presented at the 4 th Int. Symp. on Superconductivity, Tokyo, Oct.14-17, 1991

Lu, P.-Y. and Tsai, S.-C., "Health Criteria to Protect the General Public Near Toxic Waste Sites," presented at the 16 th Chinese-American Academic and Professional Assoc. in Southeastern United States, Aitlanta, June 12-14, 1992

Lu, P.-Y., Hovatter, P.S., Ross, R.H., and Opresko, D.M., "A Resource for Risk Assessment: Toxicity Values," presented at the 205th Am. Chem. Soc. Natl. Meet., Denver, Mar.28-Apr.2, 1993

Lu, P.-Y., Francis, M.W., Houlberg, L.M., and Miller, I.C., "A Proposed Information Resource for Environmental Safety and Health Compliance," presented at the 205th Am. Chem. Soc. Natl. Meet., Denver, Mar.28-Apr.2, 1993

MacInnis, J., "Risk Analysis Support for Demonstration of the Molten Salt Oxidation Technology," presented at the Molten Salt Oxidation Task Force Meet., Canoga Park, CA, Sept.23, 1992

MacInnis, J., "ATSDR Public Health Assessment and Health Consultation Activities at DOE Sites," presented at the Meeting at DOE, Washington, DC, Oct.22, 1992

MacInnis, J., "ATSDR Activities at DOE Facilities," presented at the Meet. at DOE, Washington, DC, Dec.17, 1992

MacInnis, J.M., "The Effectiveness of Groundwater Pumping as a Restoration Technology," presented to the Kentucky Agreement in Principle (AIP) Committee, ORNL, Oak Ridge, TN, Apr.8, 1992 
MacInnis, J.M. and Travis, C.C., "Case Studies in Groundwater Pumping and Vapor Extraction Remediation Technologies," presented at the Natl. Convention of Natl. Ground Water Assoc., Las Vegas, Sept.30-Oct.2, 1992

Mansfield, B.K. and Wassom, J.S., "Human Genome Management Information System," presented at the Meet. Am. Soc. Human Genet., San Francisco, Nov.9-13, 1992

McDowell-Boyer, L., "Radiological Performance Assessments at the Savannah River Site," presented at the 8th Int. Congress of International Radiation Protection Assoc., Montreal, May 17-22, 1992

McDowell-Boyer, L., "Long-Term Uncertainty in Low-Level Waste Performance Assessments," presented at the Midyear Top. Meet. Health Phys. Soc., Dearborn, MI, Jan. 12-15, 1992

McDowell-Boyer, L. and Little, C.A., "Elements of Uncertainty in a Radiological Performance Assessment of a Saltstone Disposal Facility for Low Level Waste," presented at the 25th Midyear Top. Meet. Health Phys. Soc., Dearborn, MI, Jan.1216,1992

McDowell-Boyer, L.M., Kocher, D.C., and Cook, J.R., "Assessing the Performance of the Saltstone Wasteform at the Savannah River Site," presented at the 18th Am. Nucl. Soc. Symp. on Waste Management, Waste Management '92, Tucson, AZ, Mar.1-5, 1992

McDowell-Boyer, L.M. and Thorne, D.J., "Long-Term Uncertainty in Radiological Performance Assessments of Low-Level Waste Facilities at the Savannah River Site," presented at the 8th Meet. Int. Radiation Protection Assoc. (IRPA8), Montreal, May $17-22,1992$

McDowell-Boyer, L.M., "The Radiological Performance Assessment of the Saltstone Disposal Facility at the SRS," presented at the Seminar on Status of Saltstone Performance Assessment, Savannah River Site, Aiken, SC, Jan.26, 1993

McGinn, C.W., "The Background Section," presented at the Agency for Toxic Substances and Disease Registry Health Assessment Workshop, Harrisburg, PA, Dec.9-13, 1991

McGinn, C.W., "Pathways Analyses 1," presented at the Agency for Toxic Substances and Disease Registry Health Assessment Workshop, Harrisburg, PA, Dec.9-13, 1991

McKenzie, S.P., Arakawa, E.T., and Lee, I., "Pulsed UV Laser Ablation Techniques in the Detection of Trace Constituents," presented at the 19th Annu. Weld. Test. Technol. Conf., WATTec, Knoxville, TN, Feb.18-21, 1992

McKenzie, S.P., Arakawa, E.T., Lee, I., Coutant, C.C., and Adams, S.M., "Pulsed UV Laser Ablation Techniques in the Detection of Trace Elements," presented at the Health and Safety Research Div. Information Meet., ORNL, Oak Ridge, TN, Apr.14-15, 1992

McKenzie, S.P., "Pulsed UV Laser Ablation in the Detection of Trace Elements," presented at the DOE/OHER Five-Year Program Review, Oak Ridge, TN, June 17-19, 1992

McPherson, D.W., Callahan, A.P., Lambert, C.R., and Knapp, F.F., Jr., "Synthesis of (I-125) 'Iodoaltanserine' - A Potential Ligand for SPECT Study of Serotonin $S_{2}$ Receptors," 39th Annu. Meet. Soc. Nucl. Med., Los Angeles, June 9-12, 1992 
Meisse, C. and Arakawa, E.T., "Optical Properties of Poly-HCN and Poly $\mathrm{C}_{2} \mathrm{H}_{2}$ for Astronomical Applications," presented at the 38th Annu. Am. Vac. Soc. Symp./Top. Conf., Seattle, Nov.11-15, 1991

Meisse, C., Arakawa, E.T., Khare, B.N., Thomson, W.R., and Sagan, C., "Optical Properties of Poly-HCN for Astronomical Applications," presented at the 10th Int. Conf. on Vacuum Ultraviolet Radiation Physics, Paris, July 17-31, 1992

Meisse, C., Arakawa, E.T., Khare, B.N., Thompson, W.R., and Sagan, C., "Optical Constants of Poly-HCN for Astronomical Applications," presented at the 23. $\mathrm{d}$ Annu. Meet. Am. Astron. Soc., Div. Planet. Sci., Palo Alto, CA, Nov.4-8, 1991

Miao, Y.-S., Hingerty, B.E., Broyde, S., and Shapiro, R., "Mutagenesis by 2Aminofluorene $(\mathrm{AF})$ and 2-Acetylaminofluorene (AAF): Implications from DNA Single Strand Conformations," presented at the American Assoc. for Cancer Research Conf., San Diego, May 20-25, 1992

Miller, D., "Conclusions and Recommendations," presented at the Agency for Toxic Substances and Disease Registry Health Assessment/Risk Communication Workshop, Salt Lake City, Jan.28-30, 1992

Miller, D., "Approach for Streamlining the Remedial Investigation/Feasibility Study Process: Screening Risk Assessment Methodologies," presented at the Savannah River Plant, Aiken, SC, July 30, 1992

Miller, D., "Approach for Streamlining the Remedial Investigation/Feasibility Study Process: Screening Risk Assessment Methodologies," presented at the Subsurface Restoration Conf., Dallas, June 22, 1992

Miller, D., "Case Study Presentation," presented at the Agency for Toxic Substances and Disease Registry Workshop, Emeryville, CA, June 16-18, 1992

Miller, D., "Case Study Presentation," presented at the Agency for Toxic Substances and Disease Registry Workshop, Atlanta, July 14-16, 1992

Miller, D., "Case Study Presentation," presented at the Agency for Toxic Substances and Disease Registry (DOD) Health-Risk Assessment and Communication Workshop, San Antonio, May 19-21, 1992

Miller, D., "Conclusions and Recommendations," presented at the Agency for Toxic Substances and Disease Registry Workshop, Dayton, OH, Aug.25-27, 1992

Miller, D., "Case Study Presentation," presented at the Agency for Toxic Substances and Disease Registry Workshop, Dayton, OH, Aug.25-27, 1992

Miller, D., "Program Overview," presented at the Hazardous Waste Remedial Action Program (HAZWRAP) Meet., Oak Ridge, TN, Sept.25, 1992

Miller, D.B., "Risk Evaluation of Par Pond," presented at the EPA Region IV Meet. on Par Pond Risk Evaluation, Atlanta, Feb.21, 1992

Miller, D.B., "The Background Section," presented at the Agency for Toxic Substances and Disease Registry Health Assessment/Risk Communication Workshop, Dayton, $\mathrm{OH}$, Nov.4-8, 1991 
Miller, D.B., "The Background Section," presented at the Agency for Toxic Substances and Disease Registry Health Assessment Workshop, Atlanta, Oct.21-25, 1991

Miller, D.B., "The Background Section," presented at the Agency for Toxic Substances and Disease Registry Health Assessment/Risk Communication Workshop, Salt Lake City, Jan.28-30, 1992

Miller, D.B., "Pathways Analyses 1," presented at the Agency for Toxic Substances and Disease Registry Health Assessment/Risk Communication Workshop, Dayton, $\mathrm{OH}$, Nov.4-8, 1991

Miller, D.B., "An Overview of Human Health Risk Assessment," presented at the Health and Safety Research Div. Information Meet., ORNL, Oak Ridge, TN, Apr.14-15, 1992

Miller, D.B., "Pathways Analysis," presented at the Agency for Toxic Substances and Disease Registry (ATSDR) Workshop, San Antonio, TX, May 18-22, 1992

Miller, D.B., "Overview of the Public Health Assessment Process," presented at the Agency for Toxic Substances and Disease Registry (ATSDR) Workshop, San Antonio, TX, May 18-22, 1992

Miller, D.B., "Site Characterization: Exposure-Risk Assessment," presented at the Int. Subsurface Restoration Conf., Dallas, June 22, 1992

Miller, D.B., "Overview of the Public Health Assessment Process," presented at the Agency for Toxic Substances and Disease Registry (ATSDR) Workshop, Atlanta, GA, July 14-16, 1992

Miller, D.B., "Pathways Analysis," presented at the Agency for Toxic Substances and Disease Registry (ATSDR) Workshop, Emeryville, CA, June 16-18, 1992

Miller, D.B., "Overview of the Public Health Assessment Process," presented at the Agency for Toxic Substances and Disease Registry (ATSDR) Workshop, Emeryville, CA, June 16-18, 1992

Miller, D.B., "Pathways Analysis," Agency for Toxic Substances and Disease Registry (ATSDR) Workshop, Dayton, OH, Aug.25-27, 1992

Miller, D.B., "Overview of the Public Health Assessment Process," presented at the Agency for Toxic Substances and Disease Registry (ATSDR) Workshop, Dayton, OH, Aug.25-27, 1992

Miller, D.B., "Pathways Analysis," presented at the Agency for Toxic Substances and Disease Registry (ATSDR) Workshop, Atlanta, July 14-16, 1992

Miller, D.B., "Risk Assessment in the RI/FS," presented at the Risk Assessment Seminar, Washington, DC, Sept.17, 1992

Miller, D.B., "An Overview of the CERCLA Baseline Risk Assessment Process," presented at the DOE RI-FS (Remedial Investigation-Feasibility Study) Workshop, Salt Lake City, Nov.18, 1992 
Miller, D.B., "Risk Assessment in the RI/FS," presented at the Risk Assessment Seminar, Washington, DC, Dec.15, 1992

Miller, I.C., Slusher, K.G., Richmond, A.A., and Francis, M.W., "A Resource for Toxicology and Envirommental Regulation Information," presented at the Environmental Resources Expo '92, Orlando, FL, May 2()-21, 1992

Miller, J.C., "Multiphoton Ionization of Weakly Bound Molecules and Clusters," presented at the Hertzberg Inst. of Astrophysics, Ottawa, Canada, Jan. 14, 1992

Miller, J.C., "Multiphoton Ionization of Weakly Bound Molecules and Clusters," presented at the Vanderbilt Univ., Nashville, TN, Feb.4, 1992

Miller, J.C., "Lasers in Science and Society," presented at the Pigeon Forge Middle School, Pigeon Forge, TN, Mar.23, 1992

Miller, J.C., "Spectroscopy and Dynamics of Atmospheric Molecules and Clusters, presented at the DOE/OHER Five-Year Program Review, Oak Ridge, TN, June 17-19, 1992

Miller, J.C., "RIS of Molecules (Study Course)," presented at the 6th Int. Symp. on Resonance Ionization Spectroscopy and Its Applications (RIS-92), Santa Fe, NM, May $25-29,1992$

Miller, J.C., "Magic Numbers in Molecular Clusters," presented at the Laboratoire de Photophysique Moleculaire Universite de Paris-Sud, Orsay, France, Jaly 15, 1992

Miller, J.C., Desai, S.R., and Feigerle, C.S., "Multiphoton Ionization and Photodissociation of $(\mathrm{NO})_{\mathrm{m}} \mathrm{Ar}_{\mathrm{n}}$ Clusters," presented at the 6th Int. Symp. on Small Particles and Inorganic Clusters, Chicago, Sept.16-22, 1992

Miller, J.C., "Magic Numbers in Molecular Clusters," presented at the Laboratoire de Physique des Lasers, Universite de Paris-Nord, Villetaneuse, France, July 26, 1992

Miller, J.C., "Laser Ionization of Atomic and Molecular Clusters," presented to the Dept. of Chemistry, Univ. of Virginia, Charlottesville, Feb.12, 1993

Miller, L.F., Feng, Y., Casson, W., Thein, M., and Mei, G., "Determination of Neutron Dose from Criticality Accidents with Bioassays for Na-24 and P-32," presented at the 3rd Conf. on Radiation Protection and Dosimetry, Orlando, FL, Oct.21-24, 1991

Miller, P.D., "Envirommental Contamination and Other Hazards Data Evaluation," presented at the Agency for Toxic Substances and Disease Registry Health Assessment Workshop, Allanta, Oct.21-25, 1991

Miller, P.D., "Environmental Contamination and Other Hazards Data Evaluation," presented at the Agency for Toxic Substances and Disease Registry Health Assessment/Risk Communication Workshop, Dayton, OH, Nov.4-8, 1991

Miller, P.D., "Environmental Contamination and Other Hazards Data Evaluation," presented at the Agency for Toxic Substances and Disease Registry Health Assessmemt Workshop, Chicago, Nov.18-22, 1991 
Miller, P.D., "Environmental Contamination and Other Hazards Data Evaluation," presented at the Agency for Toxic Substances and Disease Registry Health Assessment Workshop, Harrisburg, PA, Dec.9-13, 1991

Miller, P.D., "Environmental Contamination and Other Hazards Data Evaluation," presented at the Agency for Toxic Substances and Disease Registry Health Assessment Workshop, Harrisburg, PA, Dec.9-13, 1991

Miller, P.D., "On-Site/Off-Site Contamination," presented at the Agency for Toxic Substances and Disease Registry Health Assessment Workshop, Harrisburg, PA, Dec.9-13, 1991

Mirzadeh, S., Rice, D.E., Callahan, A.P., and Knapp, F.F., Jr., "Extraction-Based ${ }^{194}$ Os/194 Ir Generator," presented at the 204th Natl. Meet. Am. Chem. Soc., Washington, DC, Aug.23-28, 1992

Mittelman, J., Bowman, E., and Tyndall, R., "Evaluation of the ENVIROAMPrM Polymerase Chain Reaction (PCR) Legionella Test Kit," presented at the 92nd General Meet. Am. Soc. Microbiol., New Orleans, May 26-29, 1992

Morris, J., "Scale-Up Approach for the DOE Prograrnmatic Environmental Impact Statement," presented at the 5th Environmental Restoration PEIS Coordination Meet., Idaho Falls, ID, Nov.5, 1992

Morris, J., "Risk Reduction Factors for Use in the PEIS ER Public Health Risk Assessment," presented at the PEIS (Programmatic Environmental Impact Statement) Working Group, Gaithersburg, MD, Mar.23, 1993

Morris, J.M. and Travis, C.C., "An Overview of Risks at 24 DOE Sites," presented at the Annu. Meet. Soc. Risk Anal., San Diego, Dec.8, 1992

Nikjoo, H., Hamm, R.N., Michalik, V., Paretzke, H.G., Terrissol, M., Turner, J.E., and Goodhead, D.T., "Comparison of Energy Deposition in Small Cylindrical Volumes by Electrons Generated by Monte Carlo Track Structure Codes for Gaseous and Liquid Water," presented at the 11 th Symp. on Microdosimetry, Gatlinburg, TN, Sept.1318,1992

Owens, E.T., Andreadis, D.K., Campbell, S.J., Wassom, J.S., and Woychik, R.P., "An International Database for Transgenic Mice," presented at the Mouse Molecular Genetics, Cold Spring Harbor, NY, Aug.26-30, 1992

Parks, J.E., II and Arakawa, E.T., "Evaluation of Soft X-Ray Yield of Al from $50 \mathrm{MeV}$ Neutral Particles," presented at the Meet. Am. Phys. Soc., Indianapolis, Mar.16-20, 1992

Pfiffner, S.M., Tyndall, R.L., and White, D.C., "Sterol Compositions of Free-Living Amoebae," presented at the 6th Int. Conf. on Biology and Pathogenicity of FreeLiving Amoebae, Richmond, VA, Aug.2-7, 1992

Pfiffner, S.M., Tyndall, R.L., and White, D.C., "Phospholipid Fatty Acid Methyl Ester Compositions of Free-Living Amoebae," presented at the 6th Int. Conf. on Biology and Pathogenicity of Free-Living Amoebae, Richmond, VA, Aug.2-7, 1992 
Pinnaduwage, L.A. and Christophorou, L.G., "Enhanced Electron Attachment to Superexcited States of Nitric Oxide," presented at the 44th Annu. Gaseous Electronics Conf., Albuquerque, NM, Oct.22-25, 1991

Pinnaduwage, L.A., "Electron Attachment to Superexcited Molecules," presented at the DOE/OHER Five-Year Program Review, ORNL, Oak Ridge, TN, June 17-19, 1992

Pinnaduwage, L.A. and Christophorou, L.G., "Enhanced Electron Attachment to LaserIrradiated Molecular Hydrogen," presented at the 45th Annu. Gaseous Electronics Conf., Boston, Oct.27-30, 1992

Pinnaduwage, L.A. and Christophorou, L.G., "The Possible Role of Highly Excited Rydberg States of Hydrogen on $\mathrm{H}^{-}$Formation in a Hydrogen Plasma," presented at the 59th Meet. Am. Phys. Soc., Southeastern Section, Oak Ridge, TN, Nov.12-14, 1992

Rajic, S., Elnicki, M.E., Chen, W., Maxey, L.C., and Rogers, J.E., "'Snap Together' Directed Energy Threat Protection System," presented at the Optical Fabrication and Testing Workshop, Boston, Nov.16-20, 1992

Rawl, R.R., Eckerman, K.F., Wangler, M.E., Punch, F., and Carriker, A.W., "Potential Impacts of ICRP 60 and 61 on the Transportation Regulations," presented at the 10th Int. Symp. on Packaging and Transportation of Radioactive Materials, PATRAM '92, Yokohama City, Japan, Sept.13-18, 1992

Ritchie, R.H., Hamm, R.N., and Ashley, J.C., "Electron and Positron Mean Free Paths in an Electron Gas," presented at the Annu. Meet. Am. Phys. Soc., Southeastern Section, Durham, NC, Nov.11-13, 1991

Ritchie, R.H., "History and Overview," presented at the DOE/OHER Five-Year Program Review, Oak Ridge, TN, June 17-19, 1992

Ritchie, R.H., Hamm, R.N., and Turner, J.E., "Interactions of Low-Energy Electrons with Condensed Matter in the Early Physical Stage," presented at the 41st Annu. Meet. Radiat. Res. Soc., Dallas, Mar.20-25, 1993

Ritchie, R.H., "The Interaction of Swift Electrons with Surface Excitations," presented at the 7th Latin-American Symp. on Surface Science, Bariloche, Argentina, Nov.14-21, 1992

Ross, R.H. and Lu, P.-Y., "Toxicity Assessment of Hazardous Waste Sites at a Federal Facility," presented at the Symp. on Superfund Risk Assessment in Soil Contamination Studies, Philadelphia, Jan.30-31, 1992

Ross, R.H. and O'Bryan, T.R., "Carcinogenicity Ranking of Polycyclic Aromatic Hydrocarbon Compounds," presented at the 31st Annu. Meet. Soc. Toxicol., Seattle, Feb.23-27, 1992

Ross, R.H., Young, R.A., and Lu, P.Y., "Use of Toxicity Equivalence Factors in Assessing the Hazard of Related Compounds in Occupational Settings and at Superfund Sites," presented at the 204th Natl. Meet. Am. Chem. Soc., Washington, DC, Aug.24-27, 1992 
Ross, R.H. and Lu, P.-Y., "Federal-State Toxicology and Risk Alliance Committee (FSTRAC)," presented to the Federal-State Toxicology and Risk Alliance Committee, EPA, Region 6 Headquarters, Dallas, Apr.1-3, 1992

Ross, R.H., Lu, P.Y., Hovatter, P.S., and Etnier, E.L., "Toxicity Assessment and ARAR Determination for Superfund Risk Assessment," presented at the 204th Natl. Meet. Am. Chem. Scs., Washington, DC, Aug.23-28, 1992

Ross, R.H., "An Overview of Principles of Toxicology - IX. Use of Toxicologic Data in Risk Assessment," presented at ORNL, Oak Ridge, TN, Nov.12, 1991

Ross, R.H., Young, R.A., and Lu, P.Y., "Use of Toxicity Equivalence Factors in Assessing the Hazard of Related Compounds in Occupational Settings," presented at the Annu. Meet. Soc. Toxicol., New Orleans, Mar.14-16, 1993

Ryman, J.C., Eckerman, K.F., Tang, J.S., Williams, L.R., and Pace, J.V., III, "Organ Doses Due to Exposure to External Radiation Fields," presented at the 3rd Conf. on Radiation Protection and Dosimetry, Orlando, FL, Oct.21-24, 1991

Sales, B.C., Thundat, T., Chakoumakos, B.C., Boatner, L.A., and Warmack, B., "Direct AFM Observation of Surface Defects and Scanning Induced Atom Removal on $\mathrm{Pb}_{2} \mathrm{P}_{2} \mathrm{O}_{7}$ Surfaces," presented at the March Meet. Am. Phys. Soc., Seattle, Mar.22-26, 1993

Sauers, I., "Evidence for $\mathrm{SF}_{4}$ and $\mathrm{SF}_{2}$ Formation in $\mathrm{SF}_{6}$ Corona Discharge," presented at the Conf. on Electrical Insulation and Dielectric Phenomena, Knoxville, TN, Oct.20-24, 1991

Siegrist, R.L., Morris, M.I., West, O.M., Gates, D.D., Pickering, D.A., Jenkins, R.A., Mitchell, T.J., Greene, D.W., Muhr, C.A., Herbes, S.E., Gilliam, T.M., Jennings, H.L., Lucero, A.J., Zutman, J., McKnight, T., Gierke, J.S., Robinson, K.G., Davenport, D.T., Barnett, R.O., Jr., and Watson, J.S., "Evaluation of In Situ Treatment Technologies for Contaminated Clay Soils: Highlights of the X-231B Technology Demonstration," presented at the 8th Annu. DOE Model Conf., Oak Ridge, TN, Oct.19-22, 1992

Sims, C.S., "The Status of ANSI N 13.11 - The Dosimeter Performance Test Standard," presented at the 3rd Conf. on Radiation Protection and Dosimetry, Orlando, FL, Oct.21-24, 1991

Sims, C.S., "The Status of ANSI N13.11 - The Dosimeter Performance Test Standard," presented at the Harshaw Thermoluminescent Dosimeter User Symp., New Orleans, Nov.11-15, 1991

Sims, C.S., Casson, W.H., and Buckner, M.A., "Personnel Dosimetry Intercomparison Study Results," presented at the 37th Annu. Meet. Health Phys. Soc., Columbus, $\mathrm{OH}$, June $21-25,1992$

Sjoreen, A.L., Athey, G.F., Ramsdell, J.V., and McKenna, T.J., "Radiological Assessment System for Consequence Analysis," presented at the 37th Annu. Meet. Health Phys. Soc., Columbus, OH, June 21-25, 1992 
Skiles, J.L., Redfearn, A., and White, R.K., "Determining the Number of Samples Required for Decisions Concerning Remedial Actions at Hazardous Waste Sites," presented at the AWAWT '91, Air, Water, and Waste Technologies Environmental Management Conf./Expo., Detroit, Nov.11-14, 1991

Smith, S.M., Wilson, M.J., and Espegren, M.L., "An Application of the Ultrasonic Ranging and Data System (USRADS) as a Verification Tool," presented at the Waste Management '93, Tucson, AZ, Feb.28-Mar.4, 1993

Smuin, D.R., Schlosser, R.M., and Van Ryn, F.R., "Groundwater Screening Surveys Using Small Diameter Boreholes," presented at the Natl. Waterwell Assoc. Innovative Technologies Meet., Washington, DC, Oct.21, 1991

Srivastava, P.C. and Hasan, A., "S-Adenosyl-L-Homocysteine Hydrolase as a Potential Target for Diagnosis with Radiohalogenated Nucleosides," presented at the 9th Int. Symp. on Radiopharmaceutical Chemistry, Paris, Apr.6-10, 1992

Srivastava, P.C. and Hasan, A., "Study of Radiolabeled Nucleosides as Potential Indicators of Enzymes of Nucleotide Metabolism," presented at the 23rd Annu. Conf. Soc. Nucl. Med., India ${ }^{\prime}$ 't. Seminar of Indo-American Soc. Nucl. Med., Agra, India, Dec.9-12, 1991

Srivastava, P.C., Hasan, A., and Lambert, C.R., "Synthesis and In Vivo Metabolism Studies of (125I)-Iodoacycloadenosin-4'-ene, A Potential Inhibitor of S-Adenosyl-LHomocysteine Hydrolase," presented at the 39th Annu. Meet. Soc. Nucl. Med., Los Angeles, June 9-12, 1992

Stabin, M.G., Turner, J.E., Hamm, R.N., and Bolch, W.E., "Track-Structure Simulation and Determination of Product Yields in the Electron Radiolysis of Water Containing Various Solutes," presented at the 11 th Symp. on Microdosimetry, Gatlinburg, TN, Sept.13-18, 1992

Steiner, T., Zabel, V., Hingerty, B.E., Mason, S.A., and Saenger, W., "Neutron Diffraction Study of Nondeuterated and Partially Deuterated Gamma-Cyclodextrin Hydrate at Room Temperature," presented at the 1st Annu. Meet. German Soc. Crystallogr., Mainz, Germany, June 9-12, 1992

Stevens, G.H. and Egidi, P.V., "Independent Verification Contractor Process," presented at the 3rd Technology Information Exchange, Pleasanton, CA, Nov.17-19, 1992

Stevenson, C.L. and Vo-Dinh, T., "Laser-Excited Synchronous Luminescence Spectroscopy for Sub-Attomole Detection of Polyaromatic Hydrocarbons," presented at the 44th Pittsburgh Conf./Expo. on Analytical Chemistry and Applied Spectroscopy, Atlanta, Mar.8-12, 1993

Stokes, D.L., Alarie, J.P., Sutherland, W.S., Edwards, A.C., and Vo-Dinh, T., "Using a Red-Enhanced Intensified Charge-Coupled Device (ICCD) Detection System," presented at the 44th Pittsburgh Conf./Expo. on Analytical Chemistry and Applied Spectroscopy, Atlanta, Mar.8-12, 1993

Swaja, R.E., "The Status and Directions of Dosimetry Programs at ORNL's Radiation Calibration Laboratory," presented at the OHER Program Review, ORNL, Oak Ridge, TN, Feb.16-17, 1993 
Swindle, D.W., Jr., Vo-Dinh, T., and Yalcintas, M.G., "Technology Transfer and Application of SERS Continuous Monitor for Trace Organic Compounds," presented at the Mediterranean Conf. on Environmental Geotechnology, Cesme, Turkey, May 25-27, 1992

Talmage, S.S. and Walton, B.T., "Uptake of Mercury by Components of Terrestrial Food Chains," presented at the 12th Annu. Meet. Soc. Environ. Toxicol. Chem., Seattle, Nov.3-7, 1991

Tang, K., Allman, S.L., and Chen, C.H., "Laser Mass Spectrometry for Biopolymers," presented at the 6th Int. Symp. on Resonance Ionization Spectroscopy and Its Applications, Santa Fe, NM, May 24-29, 1992

Tang, K., Allman, S.L., Chen, C.H., and Haglund, R.F., "Matrix Assisted Laser Desorption/Ionization Mass Spectrometry of Oligonucleotides," presented at the Science Innovation '92, San Francisco, July 21-25, 1992

Thomas, J.K., "Living in a Material World - Risks and Benefits," presented to the 8th Grade Science Class, Sevierville Middle School, Sevierville, TN, Jan.22, 1992

Thorne, D.J., Kearl, P.M., and McDowell-Boyer, L.M., "International Atomic Energy Agency Coordinated Research Program on the Safety Assessment of Near-Surface Radioactive Waste Disposal Facilities (NSARS)," presented at the 2nd Coordinated Research Program of the IAEA NSARS (Near Surface Safety Assessment Reliability Study), Augusta, GA, Nov.20, 1992

Thorne, D.J., "Comparison of the Results for the International Atomic Energy Agency's Coordinated Research Program on the Safety Assessment of Near-Surface Radioactive Waste Disposal Facilities," presented at the DOE Performance Assessment Task Team, Washington, DC, Dec.10, 1992

Thundat, T., Allison, D.P., Warmack, R.J., and Ferrell, T.L., "Imaging DNA Molecules by Atomic Force Microscopy," presented at the 38th Annu. Am. Vac. Soc. Symp./Top. Conf., Seattle, Nov.11-15, 1991

Thundat, T., Warmack, R.J., Allison, D.P., Lourenco, A.J., Ferrell, T.L., and Bottomley, L.A., "Atomic Force Microscopy of DNA Strands Adsorbed on Mica: The Effect of Humidity on Apparent Width and Image Contrast," presented at the 38th Annu. Am. Vac. Sor. Symp./Top. Conf., Seattle, Nov.11-15, 1991

Thundat, T., Allison, D.P., Warmack, R.J., Brown, G.M., Jacobson, K.B., and Ferrell, T.L., "Atomic Force Microscopy of DNA Molecules," presented at the Meet. on Scanning Microscopy and Food Structure, Chicago, May 9, 1992

Thundat, T., Warmack, R.J., Allison, D.P., Brown, G.M., and Ferrell, T.L., "Adsorption of Biopolymers on Chemically Modified Surfaces Investigated with AFM," presented at the 39th Annu. Am. Vac. Soc. Symp./Top. Conf., Chicago, Nov.9-13, 1992

Thundat, T., Warmack, R.J., Allison, D.P., Sales, B., and Boatner, L.A., "Direct AFM Observations of Surface Defects and Atomic Rearrangements or Lead Pyrophosphate Crystal Surfaces," presented at the 59th Meet. Am. Phys. Soc., Southeastern Section, Oak Ridge, TN, Nov.12-14, 1992 
Thundat, T., Warmack, R.J., Allison, D.P., Doktycz, M.J., and Jacobson, K.B., "Atomic Force Microscopy of Single-Stranded and Double-Stranded DNA Adsorbed on Chemically Treated Mica," presented at the March Meet. Am. Phys. Soc., Seattle, Mar.22-26, 1993

Travis, C.C., "Risk Assessment as an Aid to Decision Making," presented at the DOE Model Conf. on Waste Management and Environmental Restoration, Oak Ridge, TN, Oct.14-17, 1991

Travis, C.C., "Cell Proliferation: Application to Carcinogen Risk Assessment," presented at the American College of Toxicology Symp. on Role of Cell Proliferation in Carcinogenesis: Application to Risk Assessment, Savannah, GA, Oct.21-23, 1991

Travis, C.C., "Dosimetrics for Use in Risk Analysis," presented at the Int. Soc. Exposure Analysis Meet., Atlanta, Nov.18-21, 1991

Travis, C.C., "Global Chemical Pollution," presented at the Calcashiu League for Environmental Action Now (CLEAN) Health Conf., Lake Charles, LA, Oct.26, 1991

Travis, C.C., "Risk Assessment as an Aid to Decision-Making," presented at the 7th Annu. DOE Model Conf., Oak Ridge, TN, Oct.14-17, 1991

Travis, C.C., "Risk Analysis and Priority Setting for Environmental Policy," Intergovernmental Risk Assessment Public Hearing Meet., Washington, DC, Nov.19, 1991

Travis, C.C., "Dosimetrics for Use in Risk Analysis," presented at the Int. Soc. Exposure Anal. Annu. Meet. on Measuring, Understanding, and Predicting Exposure in the 21 st Century, Atlanta, Nov.20, 1991

Travis, C.C., "Diethylnitrosamine-Induced Hepatocarcinogenesis in Rats: A Theoretical Study," presented to the Dept. of Mathematical Sciences Meet., Johns Hopkins Univ., Baltimore, Apr.9, 1992

Travis, C.C., "Research Needs and Risk Reassessment of Dioxin," Quarterly Technical Meet. of Amoco Oil, Naperville, IL, Mar.26, 1992

Travis, C.C., "Hazardous Waste Cleanup at Federal Facilities: The Need for an Integrated Policy," presented at the Board on Radioactive Waste Management Workshop on Critical Issues in Environmental Remediation, Woods Hole, MA, July 20, 1992

Travis, C.C., "Risk Assessment for Programmatic Environmental Impact Statement," presented at U.S. EPA, Washington, DC, July 27, 1992

Travis, C.C., "Risk Analysis Potpourri," presented at the Meet. Soc. Risk Anal., Washington, DC, Sept.16, 1992

Travis, C.C., "Scaling Factors in Applying Animal Data to Humans," presented at the Harvard School of Public Health, Risk Analysis in Occupational and Environmental Health Course, Boston, Sept.9, 1992

Travis, C.C., "What is Risk Assessment? - Part I," presented at the Risk Assessment Seminar, Germantown, MD, Sept.17, 1992 
Travis, C.C., "Issues of Concern for Risk Assessors - Part II," presented at the Risk Assessment Seminar, Germantown, MD, Sept.17, 1992

Travis, C.C., "Case Studies in Groundwater Pumping and Vapor Extraction Remediation Technologies," presented at the Aquifer Restoration: Pump and Treat and the Alternatives Meet., Las Vegas, Oct.1, 1992

Travis, C.C., "Risk Assessment for Programmatic Environmental Impact Statement," presented to Glen Paulson at META/Berger, Gaithersburg, MD, Oct.13, 1992

Travis, C.C., "Risk Assessment for Programmatic Environmental Impact Statement," presented at the Meeting at DOE, Germantown, MD, Oct.23, 1992

Travis, C.C., "Use of Risk Assessment in Setting Priorities for Superfund Sites," presented at the Eckenfelder Seminar, Vanderbilt Univ., Nashville, TN, Oct.26, 1992

Travis, C.C., "Priority System Application," presented at the Meet. of Natl. Academy of Sciences Panel on the DOE Environmental Restoration Priority System, Knoxville, TN, Feb.25, 1993

Travis, C.C., "Hazardous Waste Cleanup at Federal Facilities: The Need for an Integrated Policy," Industry Forum, Oak Ridge, TN, Feb.18, 1993

Travis, C.C., "Installation Level Baseline Risk Scale-Up Approach for the DOE Programmatic Environmental Impact Statement," presented at the Installation Level Scale-Up Methodologies and Data Requirements for the U.S. DOE Programmatic Environmental Impact Statement, Washington, DC, Jan.26, 1993

Tuinman, A.A., Mukhopadhyay, P., Adcock, J., and Compton, R.N., "Fullerene Fluorination: Evidence for Product Instability at $\mathrm{C}_{60} \mathrm{~F}_{48}, "$ presented at the 40th Am. Soc. Mass Spectrom. Conf., Washington, DC, May 31-June 5, 1992

Turner, J.E., Hamm, R.N., Stabin, M.G., and Bolch, W.E., "Calculation of Radical Yields and Their Dependences on Time and Solute Concentration in the Radiolysis of Water," presented at the 40th Annu. Meet. Radiat. Res. Soc., Salt Lake City, Mar. 1418,1992

Turner, J.E., "Effective Dose Equivalent: What Is It and How Should It Be Used?" presented at the 3rd Conf. on Radiation Protection and Dosimetry, Orlando, Oct.2124,1991

Turner, J.E., "Principles of External Dosimetry," presented at the Health Phys. Soc. Midyear Symp., Dearborn, MI, Jan.12, 1992

Turner, J.E., "Calculations of Product Yields from Molecules Irradiated in Liquid Water," presented at the DOE/OHER Five-Year Program Review, Oak Ridge, TN, June 17-19, 1992

Turner, J.E., "Microdosimetry," presented to ORAU, Oak Ridge, TN, Apr.29, 1992

Turner, J.E., "Principles of External Dosimetry," presented at the 37 th Annu. Meet. Health Phys. Soc., Professional Enrichment Program, Columbus, OH, June 21, 1992 
Turner, J.E., "Radiation Quantities and Units," East Tennessee Chapter Health Phys. Soc. Review Course, Oak Ridge, TN, Aug.25, 1992

Turner, J.E., "Radiation Interaction and Detection Principles," Training Course on Modern Methods in Radiation Measurements and Dosimetry, Bad Honnef, Germany, Nov. $23-27,1992$

Turner, J.E., "A New Method for Neutron Dosimetry," presented at the Site Visit and Technical Review of OHER-Sponsored Research, ORNL, Oak Ridge, TN, Feb.16-17, 1993

Turner, J.E. and Fry, R.J.M., "High-LET Radiation Carcinogenesis: What Do We Know and What Do We Need to Know?" presented at the 11th Symp. on Microdosimetry, Gatlinburg, TN, Sept.13-18, 1992

Turner, J.E., Hamm, R.N., Ritchie, R.H., Wright, H.A., and Bolch, W.E., "Monte Carlo Track-Structure Calculations in Liquid Water," presented at the Meet. Radiat. Res. Soc., Dallas, Mar.22-23, 1993

Tyndall, R.L., Vass, A.A., and Fliermans, C.B., "Mixed Bacterial Populations Derived from Legionella-Infected Free Living Amoebae," presented at the 4th Am. Soc. Microbiol. Int. Symp. on Legionella, Orlando, FL, Jan.26-29, 1992

Vass, A. and Tyndall, R., "The Use of COSTAR'TM Microtiter Plates to Study AmoebicBacterial Interactions," presented at the General Meet. Am. Soc. Microbiol., New Orleans, May 26-29, 1992

Vass, A. and Tyndall, R., "Interactions of Free-Living Amoebae with Bacteria Resulting in Bacterial Diversity," presented at the 6th Int. Conf. on Biology and Pathogenicity of Free-Living Amoebae, Richmond, VA, Aug.2-7, 1992

Vass, A.A., Tyndall, R.L., Mittelman, J.S., Bowman, E.K., and Ironside, K.S., "Amoebic-Bacterial Consortium Capable of Degrading Toxic Wastes," presented at the Health and Safety Research Div. Information Meet., ORNL, Oak Ridge, TN, Apr. $14-15,1992$

Vo-Dinh, T., "Luminescence and Raman Spectroscopies: The New Frontiers," presented at the Eastern Analytical Symp., Somerset, NJ, Nov.13, 1991

Vo-Dinh, T., "Luminescence and Raman Spectroscopies: The New Frontiers," presented at the Conf. Honoring J.D. Wineforner, Univ. of Florida, Gainesville, Jan.2-4, 1992

Vo-Dinh, T., Griffin, G.D., Baker, M.R., Miller, G.H., Alarie, J.P., Burlage, R., and White, D.C., "Fiberoptic Monitor Using Bioengineered Microbial Reporter for Hazardous Waste Bioremediation," presented at the Environmental and Process Monitoring Technologies, Los Angeles, Jan.2()-23, 1992

Vo-Dinh, T., "Advanced Spectroscopic Techniques for Chemical and Biological Applications," presented at the DOE Briefing, Washington, DC, Feb.11, 1992

Vo-Dinh, T., "Surface-Enhanced Raman Techniques for Pharmaceutical Characterization," presented at the Meet. of American Assoc. of Pharmaceutical Scientists, Austin, TX, Nov.15-19, 1992 
Vo-Dinh, T., "Measurement Techniques of DNA-Adducts and Biomarkers of Health Effects Related to the Petroleum Industry," presented at the Int. Congress on Medicine in the Oil Industry, Mexico, City, Mexico, Dec.3-5, 1992

Voorhees, L.D., McCord, R.A., Olson, R.J., and Land, M.L., "Update and Plans for OREIS Development and Prototype Demonstration," presented at the OREIS Steering Committee, Environmental Science Div., ORNL, Oak Ridge, TN, Apr.2, 1992

Walton, B.T., Talmage, S.S., and DeAngelis, D.L., "A Critique of Small Mammal Population Studies as Endpoints of Toxicant Exposure," presented at the 13th Annu. Meet. Soc. Environ. Toxicol. Chem., Cincinnati, Nov.8-12, 1992

Ward, R.C. and Eckerman, K.F., "General Principles Behind the Internal Dosimetry Codes RBD and DOSEXPRT," presented at the 3rd Conf. on Radiation Protection and Dosimetry, Orlando, FL, Oct.21-24, 1991

Ward, R.C. and Eckerman, K.F., "Simulation Modeling Using a Convolution Approach," presented at the 59th Meet. Am. Phys. Soc., Southeastern Section, Oak Ridge, TN, Nov.12-14, 1992

Warmack, R.J., Thundat, T., Allison, D.P., and Ferrell, T.L., "Contrast Mechanisms in STM and AFM of Biological Samples," presented at the 39th Annu. Am. Vac. Soc. Symp./Top. Conf., Chicago, Nov.9-13, 1992

Warmack, R.J., "Advanced Microscope Techniques," presented at the ORNL Showcase Lecture, ORNL, Oak Ridge, TN, May 15, 1992

Warmack, R.J., "Surface Plasmon Effects," presented at the DOE/OHER Five-Year Program Review, Oak Ridge, TN, June 17-19, 1992

Warmack, R.J., Thundat, T., Zheng, X.Y., and Allison, D.P., "Contrast Mechanisms in AFM," presented at the March Meet. Am. Phys. Soc., Seattle, Mar.22-26, 1993

Warmack, R.J., Allison, D.P., Ferrell, T.L., and Thundat, T., "Advances in Scanning Probe Microscopy," presented at the OHER Program Directors' Meet., Oak Ridge, TN, Feb.2-3, 1993

Warmack, R.J., "Adventures in Inner Space," presented at the Rotary Club Seminar, Oak Ridge, TN, Jan.27, 1993

Warmack, R.J., "Advances in Scanning Probe Microscopy: Biological Imaging," presented at the OHER Program Directors' Meet., Oak Ridge, TN, Feb.3, 1993

Warmack, R.J., "Development of the Photon Scanning Tunneling Microscope," presented at the March Meet. Am. Phys. Soc., Optical Imaging Workshop, Seattle, Mar.22-26, 1993

Watson, A.P. and Hess, T.L., "Reentry and Restoration Management for Areas Contaminated with Chemical Warfare Agents," presented at the Annu. Meet. of Academy of Certified Hazardous Materials Managers, Milwaukee, June 23-25, 1992

Watts, W., Vo-Dinh, T., Frazier, D., Panjehpour, M., and Overholt, B., "Sensitive and Selective Detection of Photodynamic Therapy Drugs in Biological Samples," presented at the Pittsburgh Conf., Allanta, Mar.8-12, 1993 
White, R.K., "Health Outcome Data," presented at the Agency for Toxic Substances and Disease Registry Health Assessment/Risk Communication Workshop, Dayton, $\mathrm{OH}$, Nov.4-8, 1991

White, R.K., "The Background Section," Agency for Toxic Substances and Disease Registry Health Assessment Workshop, Chicago, Nov.18-22, 1991

White, R.K., "The Use of Institutional Controls at DOE-OR/ER Sites," presented at the DOE/OR, EPA, TDEC (Tennessee Dept. of Environment and Conservation) Senior Managers Meet., Oak Ridge, TN, Oct.17, 1992

White, R.K., "On-Site/Off-Site Contamination," presented at the Agency for Toxic Substances and Disease Registry Health Assessment Workshop, Chicago, Nov.21-25, 1991

White, R.K., "On-Site/Off-Site Contamination," presented at the Agency for Toxic Substances and Disease Registry Health Assessment/Risk Communication Workshop, Dayton, OH, Nov.4-8, 1991

White, R.K., "On-Site/Off-Site Contamination," presented at the Agency for Toxic Substances and Disease Registry Health Assessment Workshop, Atlanta, Oct.21-25, 1991

White, R.K., Redfearn, A., Shaw, R.A., and King, A.D., "Impacts of the Use of Institutional Controls on Risk Assessments for Department of Energy Facilities," presented at the SPECTRUM '92, Int. Top. Meet. on Nuclear and Hazardous Waste Management, Boise, ID, Aug.23-27, 1992

White, R.K., Swindle, D.W., Jr., Redfearn, A., King, A.D., and Shaw, R.A., "Impacts of the Use of Institutional Controls on Risk Assessments at Department of Energy Facilities," presented at the 65th Annu. Conf. of the Water Environment Federation, New Orleans, Sept.23, 1992

White, R.K., "Institutional Controls and Their Role in the RI/FS Process," presented at the Institutional Controls Coordinators Meet., Arlington, VA, Oct.20-21, 1992

White, R.K., "Oak Ridge Land Use Plan Development Strategy," presented at the Land Use Workshop, Oak Ridge, TN, Feb.26, 1993

Wilson, D.L., Dudney, C.S., and Gammage, R.B., "Testing for Radon in the Work Place: The Development of a Protocol," presented at the American Industrial Hygiene Conf./Expo., Boston, May 30-June 5, 1992

Wilson, D.L., Dudney, C.S., and Gammage, R.B., "Radon Mitigation Training for U.S. Air Force Personnel," presented as a Training Module, Air Force Personnel, Agana, Guam, Jan.6-20, 1992

Wilson, D.L., "Lead - Latest Perspectives and Approaches," presented at the American Industrial Hygiene Assoc., Tennessee Valley Section, Knoxville, TN, July 21, 1992

Wilson, M.J., Mather, S.K., and Stowe, G.K., "Anthropogenic and Naturally Occurring Radioactive Materials Detected on Radiological Surveys of Properties in Monticello, Utah," presented at the 26th Midyear Top. Meet. Health Phys. Soc. on Environmental Health Physics, Lake Coeur d'Alene, ID, Jan.24-29, 1993 
Wray, J.E., Brandon, W.D., and Garrett, W.R., "Influence of Third Harmonic Fields on Two-Photon Excitation Spectra of NO in Resonance Ionization Spectroscopic

Measurements," presented at the 59th Meet. Am. Phys. Soc., Southeastern Section, Oak Ridge, TN, Nov.12-14, 1992

Wu, Z.-C., Arakawa, E.T., Jimenez, J., and Schowalter, L.J., "Optical Properties of Epitaxial $\mathrm{CoS}_{2}$ Films and Particles in Si from $0.06-2.75 \mathrm{eV}$," presented at the 16th Annu. Conf. on Composites, Materials, and Structures, Cocoa Beach, FL, Jan.12-15, 1992

Yoshida, H., Hettich, R.L., Turner, J.E., and Cadet, J., "Radiation-Induced Products in Thymidine Monophosphate Characterized by Laser Desorption FTMS and HPLC," presented at the 40th Annu. Meet. Radiat. Res. Soc., Salt Lake City, Mar.14-18, 1992

Yoshida, H., "Concentration and pH Dependent Ammonia Yields After X-Irradiation of Oxygen-Free Aqueous Solutions of Glycylglycine," presented at the 11 th Symp. on Microdosimetry, Gatlinburg, TN, Sept.13-18, 1992

Yoshida, H. and Hettich, R., "Characterization and Identification of Radiation-Induced Products from Irradiated Thymine and Related Compounds by Laser Desorption Fourier Transform Mass Spectrometry," presented at the DOE/OHER Five-Year Program Review, Oak Ridge, TN, June 17-19, 1992

Yoshida, H. and Hettich, R.L., "Radiation Chemistry of Thymidylyl (3'->5') Thymidine in Oxygen-Free Aqueous Solution," presented at the 41 st Meet. Radiat. Res. Soc., Dallas, Mar.20-25, 1993

Young, R.A., "An Overview of Principles of Toxicology - Section I. General Principles and Concepts," presented at ORNL, Oak Ridge, TN, Nov.12, 1991

Young, R.A., "An Overview of Principles of Toxicology - Section II. Pulmonary Toxicology," presented at ORNL, Oak Ridge. TN, Nov.12, 1991

Young, R.A., "An Overview of Principles of Toxicology - VIII. Neurotoxicology," presented at ORNL, Oak Ridge, TN, Nov.12, 1991

Young, R.A. and Ross, R.H., "Derivation of a Site-Specific Risk Value for Insoluble Inorganic Mercury in Soil and Sediment," presented at the Annu. Meet. Soc. Toxicol., New Orleans, Mar.14-16, 1993

Zheng, X.-Y., Lowndes, D.H., Zhu, S., and Warmack, R.J., "Scanning Tunneling Microscope Studies of Epitaxial Growth of $\mathrm{YBa}_{2} \mathrm{Cu}_{3} \mathrm{O}_{7-\delta}$ Thin Films," presented at the Spring Meet. Mater. Res. Soc., Boston, Apr.27-May 1, 1992

Zheng, X.-Y., Thundat, T., Allison, D.P., Sharp, S.L., Warmack, R.J., and Ferrell, T.L., "Calibration of AFM Tips," presented at the Meet. on Scanning Microscopy and Food Structure, Chicago, May 9, 1992

Zhu, S., Lowndes, D.H., Norton, D.P., Zheng, X.-Y., and Warmack, R.J., "Epitaxial $\mathrm{YBa}_{2} \mathrm{Cu}_{3} \mathrm{O}_{7-x}$ Thin Films: Scanning Tunneling Microscope Study of Initial Stages of Growth, Growth Mechanism, and Surface Microstructure," presented at the Fall Meet. Mater. Res. Soc., Boston, Dec.2-6, 1991 
Zuo, J.-K., Zehner, D.M., Wendelken, J.F., and Warmack, R.J., "A High Resolution LEED and STM Study of Reconstructed TaC(110)," presented at the 8th Int. Conf. on Solid Surfaces, Utrecht, Netherlands, Oct.12-16, 1992

Zuo, J.-K., Warmack, R.J., Zehner, D.M., and Wendelken, J.F., "A Direct Observation of Periodic (100) Faceting on TaC(110) by STM," presented at the 39th Annu. Am. Vac. Soc. Symp./Top. Conf., Chicago, Nov.9-13, 1992

Zuo, J.-K., Zehner, D.M., Wendelken, J.F., and Warmack, R.J., "A High Resolution LEED and STM Study of Reconstructed TaC(110)," presented at the 12th Int.

Vacuum Congress/8th Int. Conf. on Solid Surface, Hague, Netherlands, Oct.12-16, 1992 


\section{APPENDIX J. PUBLICATIONS}

Adamson, A.E., Casey, D.K., Mansfield, B.K., Wyrick, J.M., Martin, S.A., Davidson, K.A., Yust, L.N., Langston, M., Stinnett, D., and Mavournin, K., Human Genome 1991-92 Program Report, ORNL/M-2082

Adamson, A.E., Wyrick, J.M., Mansfield, B.K., Casey, D.K., Martin, S.A., Davidson, K.A., and Yust, L.N., Human Genome News, Vol. 4, No. 6, March 1993, ORNL/M2743

Agency for Toxic Substances and Disease Reg., Stockstill, J., and Caton, G., Cancer Policy Framework, ORNL/M-2789

Alarie, J.P. and Vo-Dinh, T., "Fiber-Optic Cyclodextrin-Based Sensor," Talanta 38, 529-34 (1991)

Alarie, J.P., Stokes, D.L., Sutherland, W.S., Edwards, A.C., and Vo-Dinh, T., "Intensified Charge Coupled Device-Based Fiber-Optic Monitor for Rapid Remote Surface-Enhanced Raman Scattering Sensing," Appl. Spectrosc. 46(11), 1608-12 (1992)

Allison, D.P., Warmack, R.J., Bottomley, L.A., Thundat, T., Brown, G.M., Woychik, R.P., Schrick, J.J., Jacobson, K.B., and Ferrell, T.L., "Scanning Tunneling Microscopy of DNA: A Novel Technique Using Radiolabeled DNA to Evaluate Chemically Mediated Attachment of DNA to Surfaces," Ultramicroscopy 42-44, 1088-94 (1992)

Allison, D.P., Bottomley, L.A., Thundat, T., Brown, G.M., Woychik, R.P., Schrick, J.J., Jacobson, K.B., and Warmack, R.J., "Immobilization of DNA for Scanning Probe Microscopy," Proc. Natl. Acad. Sci. USA 89, 10129-33 (1992)

Arakawa, E.T. and Inagaki, T., "Liquid Mercury (Hg)," Handbook of Optical Consultants of Solids II, Academic Press, Inc., 1991, V. 2, pp. 461-68

Arakawa, E.T., Lee, I., and Callcott, T.A., "Desorption of Al, Au, and Ag Using Surface Plasmon Excitation, "Proc. Workshop on Laser Ablation-Mechanisms and Applications, Oak Ridge, TN, Apr.8-10, 1991, Springer-Verlag, New York, 1991, pp. $82-86$

Arakawa, E.T., Young, D.W., Zhang, J.M., Eklund, P.C., Khare, B.N., Thompson, W.R., and Sagan, C., "Optical Constants of Basaltic Glass from 0.0173 to $50 \mu \mathrm{m}$," Proc. Int. Astronomical Union Colloquium No. 126 on Origin and Evolution of Interplanetary Dust,., Kyoto, Japan, Aug.27-30, 1990, Kluwer Academic Press, 1991, pp. 102-4

Arakawa, E.T. and Lee, I., "Yields and Kinetic Energy Distribution of Laser-Desorbed Al, Au, and Ag Atoms," Bull. Am. Phys. Soc. 37, 83 (1992)

Armstrong, A.Q., "Performance Assessment Activities of the Uranium Soils Integrated Demonstration," Proc. Information Exchange Meet. on Waste Retrieval, Treatment, and Processing, Houston, Mar.15-17,1993 (1993), pp. 486-91

Armstrong, A.Q., Technology Information Profile, ORNL/M-2721 
Ashley, J.C., "Optical-Data Model for the Stopping Power of Condensed Matter for Protons and Antiprotons," J. Phys.: Condens. Matter 3, 2741-53 (1991)

Bancel, F., Salmon, J.-M., Vigo, J., Vo-Dinh, T., and Viallet, P., "Investigation of NonCalcium Interactions of Fura-2 by Classical and Synchronous Fluorescence Spectroscopy," Anal. Biochem. 204, 231-38 (1992)

Bast, C.B. and Ross, R.H., "Comparison of Structure, Mutagenic Potential, and Carcinogenic Potential of Three Benzidine-Based Azo Dyes," Environ. Mol. Mutagenesis 19 (Suppl. 20), 4 (1992)

Belcher, G.D. and Travis, C.C., "The Food Chain as a Source of Human Exposure from Municipal Waste Combustion," Proc. Int. Conf. on Municipal Waste Combustion, Hollywood, FL, Apr.11-14, 1989, EPA-600/R-92-(052b, 1992, v. 1, Session 2C

Belcher, G.D., Travis, C.C., and Bruins, R.F., "The Food Chain as a Source of Human Exposure from Municipal Waste Combustion: An Uncertainty Analysis," Municipal Waste Incineration Risk Assessment, Plenum Publ. Corp., New York, 1991, pp. 175-215

Belcher, G.D. and Travis, C.C., "An Uncertainty Analysis of Food Chain Exposures to Pollutants Emitted from Municipal Waste Combustors," Health Effects of Municipal Waste Incineration, CRC Press, Boca Raton, FL, 1991, pp. 211-35

Bello, J.M., Narayanan, V.A., and Vo-Dinh, T., "Surface-Enhanced Raman Scattering Interaction of p-Aminobenzoic Acid on a Silver-Coated Alumina Substrate," Spectrochim. Acta A 48, 563-67 (1992)

Berven, B.A., Little, C.A., and Blair, M.S., "A Method to Automate Radiological Surveys: The Ultra Sonic Ranging and Data System," Health Phys. 60, 367-73 (1991)

Blasing, T.J., Brown, R.A., Cada, G.F., Easterly, C., Feldman, D.L., Hagan, C.W., Harrington, R.M., Johnson, R.O., Ketelle, R.H., Kroodsma, R.L., McCold, L.N., Reich, W.J., Schofield, P.A., Socolof, M.L., Taleyarkhan, R.P., and Van Dyke, J.W., Phase I Environmental Report for the Advanced Neutron Source at Oak Ridge National Laboratory, ORNL/TM-12069

Blaylock, B.P. and Travis, C.C., "In Search of Safety - Book Review," J. Hazardous Mater. 31, 99-100 (1992)

Blaylock, B.P. and Travis, C.C., "Toil and Toxics: Workplace Struggles and Political Strategies for Occupational Health - Book Review," J. Hazardous Mater. 31, 99-100 (1992)

Bodenstein, G.W., Bonczek, R.R., Early, T.O., Hale, T.B., Huff, D.D., Nickelson, M.D., and Rightmire, C.T., Evaluation of the Proposed Pilot Groundwater Pump and Treat Demonstration for the Paducah Gaseous Diffusion Plant, ORNL/M-2542

Borges, H.T., Glauert, H.P., Peterson, R.E., Pitot, H.C. .W., and Robertson, L.W., "Lack of Promoting Activity of Perfluorodecanoic Acid (PFDA) in 2-Stage Hepatocarcinogenesis," The Toxicologist 11, 678 (1991) 
Borges, H.T., Robertson, L.W., Peterson, R.E., and Glauert, H.P., "Dose-Related Effects of Perfluorodecanoic Acid on Growth, Feed Intake and Hepatic Peroxisomal BetaOxidation," Arch. Toxicol. 66, 18-27 (1992)

Borges, H.T., "Perfluorodecanoic Acid (PFDA) is a Noncompetitive Inhibitor of the Peroxisomal Bifunctional Protein," The Toxicologist 12, 38 (1992)

Borges, H.T., Toxicity Summary for Trinitrophenylmethylnitramine (Tetryl), ORNL/M-2785

Borges, T., Robertson, L.W., and Glauert, H.P., "Perfluorodecanoic Acid (PFDA) Inhibits the Bifunctional Protein of Peroxisomal B-Oxidation In Vitro," FASEB J. 5, A-145 (1991)

Bottomley, L.A., Haseltine, J.N., Allison, D.P., Warmack, R.J., Thundat, T., Sachleben, R.A., Brown, G.M., Woychik, R.P., Jaccoson, K.B., Ferrell, T.L., and Schrick, J.J., "Scanning Tunneling Microscopy of DNA: The Chemical Modification of Gold Surfaces for Immobilization of DNA," J. Vac. Sci. Technol. A 10(4), 591-95 (1992)

Bowyer, J.R., Alarie, J.P., Sepaniak, M.J., Vo-Dinh, T., and Thompson, R.Q., "Construction and Evaluation of a Regenerable Immunochemical-Based Fiber Optic Biosensor," Analyst 116, 117 (1991)

Brackett, E.M. and Eckerman, K.F., "Urinary Excretion of lodine in Subject with NonFunctioning Thyroid," Health Phys. 60 (Suppl. 2), S15 (1991)

Brandon, W.D., Allman, S.L., Garrett, W.R., Chen, C.H., Payne, M.G., and Parks, J.E.," Isotope Biases in RIMS Utilizing Broad-Band Long-Pulsed Lasers," Proc. 6th Int. Symp. on Resonance Ionization Spectroscopy, Santa Fe, NM, May 24-29, 1992, Inst. of Phys. Conf. Ser. No. 128: Section 3, 1992, pp. 119-22

Brooks, P.R., Harland, P.W., Phillips, L.F., and Carman, H.S., Jr., "Collision Dynamics of Alkali-Metal Atoms with Oriented Symmetric-Top Molecules," J. Phys. Chem. 96, 1557-61 (1992)

Brothers, R.A., Preliminary Health Assessment for Williams Pipe Line Company, Twelfth Street Terminal, Sioux Falls, Minnehaha County, South Dakota (CERCLIS No. SDD000694596), ORNL/M-1778

Brown, G.M., Allison, D.P., Warmack, R.J., Jacobson, K.B., Larimer, F.W., Woychik, R.P., and Carrier, W.L., "Electrochemically Induced Adsorption of Radio-Labeled DNA on Gold and HOPG Substrates for STM Investigations," Ultramicroscopy 38, 253-64 (1991)

Brown, G.M., Thundat, T., Allison, D.P., and Warmack, R.J., "Electrochemical and In Situ Atomic Force Microscopy and Scanning Tunneling Microscopy Investigations of Titanium in Oxalic Acid Solution," J. Vac. Sci. Technol. A 10(5), 3001-6 (1992)

Broyde, S., Hingerty, B.E., Xu, R., O'Handley, S.F., and Krugh, T.R., "Static and Animated Molecular Views of a Tumorigenic Chemical Bound to DNA," Proc. 1st Energy Research Power Supercomputer Users Symp., Gaithersburg, MD, May 21, 1991, CONF-9105202, DOE, 1991, Chapter 4 
Broyde, S., Hingerty, B.E., Xu, R., O'Handley, S.F., and Krugh, T.R., "Static and Animated Molecular Views of a Tumorigenic Chemical Bound to DNA," Computing at the Leading Edge: Research in the Energy Sciences National Energy Research Supercomputer Center, UCRL-TB-111084, LLNL, 1993, pp. 14-21

Buckner, M.A. and Sims, C.S., "Explaining Some Observed Response Anomalies of the BD100R Bubble Detector," Radiat. Prot. Dosim. 40, 63-64 (1992)

Buckner, M.A., "The Utilization of Bubble Detector Technology in the Development of a Combination Area Neutron Spectrometer (CANS)," Programs and Abstracts, 3rd Conf. on Radiatiation Protection and Dosimetry, Orlando, FL, Oct.21-24, 1991 (1991), p. 46

Buckner, M.A., "JAVA, Version 1.40. (Software Review)," Health Phys. 60, 268-69 (1992)

Buckner, M.A., Casson, W.H., and Sims, C.S., "Advancement and Application of Bubble Detector Technology," Proc. 3rd Conf. on Radiation Protection and Dosimetry, Orlando, FL, Oct.21-24, 1991 (1991), pp. 41-50

Buckner, M.A. and Sims, C.S., "Neutron Dosimetric Quantities for Several Radioisotopic Neutron Sources," Health Phys. 63(3), 352-55 (1992)

Buckner, M.A., Improving Neutron Dosimetry Using Bubble Detector Technology, ORNL/TM-11916

Burman, S.N., Brown, K.S., Bohrman, D.E., and Landguth, D.C., Work Plan, Health and Safety Plan, and Quality Assurance Project Plan for K-1414 Underground Storage Tank, ORNL/M-1764

Burman, S.N., Landguth, D.C., Uziel, M.S., Hatmaker, T.L., and Tiner, P.F., Comprehensive Work Plan and Health and Safety Plan for the 7500 Area Contamination Site Sampling at Oak Ridge National Laboratory, Oak Ridge, Tennessee, ORNL/ER-93

Burman, S.N., Brown, K.S., and Landguth, D.C., Work Plan nd Health and Safety Plan for Building 3019B Underground Storage Tank at Oak Ridge National Laboratory, Oak Ridge, Tennessee, ORNL-6738

Callahan, A.P., Rice, D.E., McPherson, D.W., Mirzadeh, S., and Knapp, F.F., Jr., "The Use of Alumina 'SepPaks' as a Simple Method for the Removal and Determination of Tungsten-188 Breakthrough from Tungsten-188/Rhenium-188 Generators," Appl. Radiat. Isot. 43(6), 801-4 (1992)

Callahan, A.P., Mirzadeh, S., and Knapp, F.F., Jr., "Large Scale Production of Tungsten188," Meeting Abstracts, Proc. 204th Natl. Meet. Am. Chem. Soc., Washington, DC, Aug.23-28, 1992 (1992)

Callahan, A.P., Mirzadeh, S., and Knapp, F.F., Jr., "Large Scale Production of Tungsten188," Radioact. Radiochem. 3(4), 46-48 (1992)

Carman, H.S., Jr. and Compton, R.N., "Electron Attachment to Small Carbon Clusters," Bull. Am. Phys. Soc. 37, 1660-61 (1992) 
Carman, H.S., Jr., Klots, C.E., and Compton, R.N., "Negative Ion Formation by Rydberg Electron Transfer: Isotope-Dependent Rate Constants," Proc. 201st Am. Chem. Soc. Natl. Meet. on Isotope Effects in Gas-Phase Chemistry, Atlanta, Apr.14-19, 1991, Am. Chem. Soc. Symp. Ser. 502, Am. Chem. Soc. Press, Washington, DC, 1992, p. 181

Carman, H.S., Jr. and Compton, R.N., "Electron Attachment to $C_{n}$ Clusters ( $<=30$ )," J. Chem. Phys. 98(3), 2473-76 (1993)

Carman, H.S., Jr. and Compton, R.N., "Negative Ion Formation in Small Carbon Clusters," Book of Abstracts, 2nd Int. Conf. on Laser Ablation, Knoxville, TN, Apr.19-22, 1993 (1993)

Casey, D.K. and Mansfield, B.K., "Nonprofit Biological Resource Centers," Trends Biotechnol. 10, 70-73 (1992)

Casey, D.K., Wyrick, J.M., Adamson, A.E., Drell, D.W., and Mansfield, B.K., DOE Human Genome Program: Primer on Molecular Genetics, ORNL/M-2026

Caton, G.M. and Elledge, T.G., Radon Research Notes, No. 7, March 1992, ORNL/M-1995

Caton, G.M., Haas, R.T., Haufe, J.C., Francis, M.W., and Lu, P.-Y., "PC-Based System for Integrated Assessment of Environmental Compliance," Extended Abstracts, 204th Natl. Meet. Am. Chem. Soc., Div. of Chemical Health and Safety, Washington, DC, Aug.23-28, 1992, ACS, San Francisco, 1992, v. 2(2), pp. 115-17

Caton, G.M. and Elledge, T.G., Radon Research Notes, No. 6, October 1991, ORNL/M1702

Caton, G.M. and Elledge, T.G., Radon Research Notes, No. 8, July 1992, ORNL/M-2239

Caton, G.M. and Elledge, T.G., CFCC News, No. 1, Winter 1992, ORNL/M-2538

Caton, G.M., Editor, Radon Research Notes , No. 9, December 1992, ORNL/M-2532

Chen, C.H. and Phillips, R.C., "Desorption Spectra of Laser Ablation of $\mathrm{Bi}_{2} \mathrm{Sr}_{2} \mathrm{CaCu}_{2} \mathrm{O}_{8+\mathrm{x}}, " J$. Appl. Phys. 70, 4643-45 (1991)

Chen, C.H., McCann, M.P., and Phillips, R.C., "Laser Surface Interactions of High-T Superconductors," Proc. Advances in Material Science and Applications of High Temperature Superconductors Conf., AMSAHTS '90, NASA Goddard Space Center, Greenbelt, MD, Apr.2-6, 1990, NASA Publ., 1991, v. 1, pp. 271-78

Chen, C.H., Phillips, R.C., and McCann, M.P., "Desorption Spectra of Laser Ablation of Tl-Ca-Ba-Cu-O Superconductors," J. Appl. Phys. 73(2), 522-25 (1993)

Chen, C.H., Phillips, R.C., Morrison, P.W., Jr., Hamblen, D.G., and Solomon, P.R., "InSitu Monitoring of Laser Ablation of Superconductors," Proc. Workshop on Laser Ablation - Mechanisms and Applications, Oak Ridge, TN, Apr.8-10, 1991, SpringerVerlag, 1991, pp. 16-27

Chen, C.H., Payne, M.G., and Jacobson, K.B., "A Novel Vacuum Ultraviolet Ionizer Mass Spectrometer for DNA Sequencing," Int.J. Genome Res. 1(1), 25-43 (1992) 
Chen, C.H., Phillips, R.C., and Morrison, P.W., "Monitoring of Photodeposited Superconductive Films," Thin Solid Films 218, 291-303 (1992)

Chen, C.H., Garrett, W.R., Allman, S.L., and Phillips, R.C., "New Mass Spectroscopic Methods for Waste Management," Proc. SPECTRUM '92, Int. Top. Meet. on Nuclear and Hazardous Waste Management, Boise, Aug.23-27, 1992, Am. Nucl. Soc., 1992, v. 1, pp. 414-18

Chidambariah, V. and White, R.K., Health Risk Assessment for the Building 3001 Storage Canal at Oak Ridge National Laboratory, Oak Ridge, Tennessee, ORNL/ER-51

Chidambariah, V., Travis, C.C., Trabalka, J.R., and Thomas, J.K., Risk-Based Prioritization for the Interim Remediation of Inactive Low-Level Liquid Radioactive Waste Underground Storage Tanks at Oak Ridge National Laboratory, Oak Ridge, Tennessee, ORNL/ER-84

Choudhury, H., Davidson, K.A., Cubbison, C., Peirano, W.B., and DeRosa, C., "Alternate Approach to Develop Reportable Quantities (RQs) for Lead Compounds," The Toxicologist 11, 196 (1991)

Christophorou, L.G., Pinnaduwage, L.A., and Bitouni, A.P., "A Technique for the Measurement of Electron Attachment to Short-Lived Excited Species," Proc. 6th Int. Symp, on Gaseous Dielectrics, Knoxville, TN, Sept.23-27, 1990, Pienum Press, New York, 1991, pp. 9-17

Christophorou, L.G., "Radiation Interactions in High-Pressure Gases," Proc. Conf. on Physical and Chemical Mechanisms in Molecular Radiation Biology, Woods Hole, MA, Sept.3-7, 1990, Plenum Press, New York, 1991, pp. 183-230

Christophorou, L.G., "Radiation Interactions in High-Pressure Gases," Physical and Chemical Mechanisms in Molecular Radiation Biology, Plenum Press, 1991, pp. 183-230

Christophorou, L.G., Datskos, P.G., and Carter, J.G., "Gases for an SSC Muon Detector," Detector Research and Development for the Superconducting Super Collider, World Scientific, 1991, v. 1, pp. 637-39

Christophorou, L.G., Datskos, P.G., and Carter, J.G., "Gases of Possible Interest to SSC Muon Detectors," Nucl. Instrum. Methods Phys. Res. A 309, 160-68 (1991)

Christophorou, L.G., "Electron-Excited Molecule Interactions, "Proc. 20th Int. Conf. on Ionization Phenomena in Gases, Pisa, Italy, July 8-12, 1991, Inst. of Atomic and Molecular Physics, 1992, pp. 3-13

Christophorou, L.G., Datskos, P.G., and Carter, J.G., "Effect of Vibrational Excitation on Electron Transport in Gases," Chem. Phys. Lett. 186(1), 11-14 (1991)

Christophorou, L.G. and Illenberger, E., "Scattering of Slow Electrons from Excited Atoms: The Dominant Role of the Polarization Potential," Phys. Lett. A 173, 78-82 (1992)

Cites, J., Sanghadasa, M.F.M., Sung, C.C., Reddick, R.C., Warmack, R.J., and Ferrell, T.L., "Analysis of Photon Scanning Tunneling Microscope Images," J. Appl. Phys. 71, 7-10 (1992) 
Cook, R.B., Adams, S.M., Beauchamp, J.J., Bevelhimer, M.S., Blaylock, B.G., Brandt, C.C., Etnier, E.L., Ford, C.J., Frank, M.L., Gentry, M.J., Greeley, M.S., Halbrook, R.S., Harris, R.A., Holladay, S.K., Hook, L.A., Howell, P.L., Kszos, L.A., Levine, D.A., Skiles, J.L., and Suter, G.W., Phase 2 Sampling and Analysis Plan, Quality Assurance Project Plan, and Environmental Health and Safety Plan for the Clinch River Remedial Investigation: An Addendum to the Clinch River RCRA Facility Investigation Plan, ORNL/ER-156\&D1

Cosman, M., de los Santos, C., Fiala, R., Hingerty, B., Ibanez, V., Singh, S., Margulis, S., Live, D., Geacintov, N., Broyde, S., an'd Patel, D., "Solution Conformations of (+)and (-)-anti-benzo(a)pyrene Diol Epoxide Trans N(2-dG DNA Duplex Adducts," Abstract Booklet, American Assoc. for Cancer Research Conf., San Diego, May 20-25, 1992 (1992), v. 33, p. 140

Cosman, M., de los Santos, C., Fiala, R., Hingerty, B.E., Singh, S.B., Ibanez, V., Margulis, L.A., Live, D., Geacintov, N.E., Broyde, S., and Patel, D.J., "Solution Conformation of the Major Adduct Between the Carcinogen (+)-Anti-benzo(a)pyrene Diol Epoxide and DNA," Proc. Natl. Acad. Sci. USA 89, 1914-18 (1992)

Crawford, O.H., "Cluster-Impact Fusion: Yields from Binary-Collision Sequences," Radiat. Effects Defects Solids 117, 43-52 (1991)

Crawford, O.H., Turner, J.E., Hamm, R.N., and Ashley, J.C., "Effects of the Tissue-Air Interface in Calculations of Beta-Particle Skin Dose at at Depth of 70 Microns," Health Phys. 61, 641-45 (1991)

Crawford, O.H., "Examination of a Proposed Phonon-Coupling Mechanism for Cold Fusion," Fusion Technol. 21, 161-62 (1992)

Cronk, T.A., Smuin, D.R., and Schlosser, R.M., Development of Remedial Process Options, Phase II - Feasibility Study, Installation Restoration Program, Naval Air Station Fallon, Fallon, Nevada, ORNL/TM-11979

Crotwell, A.T., Waehner, M.J., Lyon, B.F., MacInnis, J.M., and Travis, C.C., An Evaluation of Vapor Extraction of Vadose Zone Contamination, ORNL/TM-12117

Dai, S., Compton, R.N., Young, J.P., and Mamantov, G., "Preparation of C70-Doped Silica Glass Via Sol-Gel Process," J. Am. Ceram. Soc. 10, 2865-66 (1992)

Datskos, P.G., Christophorou, L.G., and Carter, J.G., "Temperature Dependence of the Dissociative Electron Attachment to $\mathrm{CH}_{3} \mathrm{Cl}$ and $\mathrm{C}_{2} \mathrm{H}_{5} \mathrm{Cl}$," Proc. 6th Int. Symp. on Gaseous Dielectrics, Knoxville, TN, Sept.23-27, 1990, Plenum Press, New York, 1991, pp. $35-52$

Datskos, P.G., Carter, J.G., and Christophorou, L.G., "Ionization Coefficients in Selected Gas Mixtures of Interest to Particle Detectors," J. Chem. Phys. 71, 15-21 (1992)

Datskos, P.G., Christophorou, L.G., and Carter, J.G., "Effective Ionization Coefficients, Electron Drift Velocities, and Limiting Breakdown Fields for Gas Mixtures of Possible Interest to Particle Detectors," Proc. IEEE Conf. on Electrical Insulation and Dielectric Phenomena, Knoxville, TN, Oct.20-24, 1991, IEEE Annu. Report, IEEE Dielectrics and Electrical Insulation Soc., 1991, pp. 474-79 
Datskos, P.G., Christophorou, L.G., and Carter, J.G., "Temperature-Enhanced Autodetachment from $\mathrm{C}_{-} \mathrm{C}_{4} \mathrm{~F}_{6}{ }^{-*}$," Chem. Phys. Lett. 195(4), 329-32 (1992)

Datskos, P.G., Christophorou, L.G., and Carter, J.G., "Temperature-Enhanced Autodetachment from Long-Lived Parent Negative Ions of Gaseous Dielectrics," Proc. 10th Int. Conf. on Gas Discharges and Their Applications, Swansea, Great Britain, Sept.1219, 1992 (1992), pp. 472-75

Datskos, P.G., Christophorou, L.G., and Carter, J.G., "Effect of Temperature on the Attachment of Slow ( $<=1 \mathrm{eV}$ ) Electrons to $\mathrm{CH}_{3} \mathrm{Br}, "$ J. Chem. Phys. 97(12), 9031-35 (1992)

Daugherty, M.L., Toxicity Summary for Tetrachloroethylene, ORNL/M-2772

Daugherty, M.W., Watson, A.P., and Vo-Dinh, T., "Currently Available Permeability and Breakthrough Data Characterizing Organophosphates and Warfare Agent Simulants in Civilian Protective Clothing Materials," J. Hazardous Mater. 30, 243-67 (1992

Dawson, P., Haas, J.W., III, Alexander, K.B., Thompson, J., and Ferrell, T.L., "Surface Enhanced Raman Scattering from Mildly Roughened Surfaces: Variation of Signal with Metal Grain Size," Surf. Sci. 250, L383-88 (1991)

de los Santos, C., Cosman, M., Hingerty, B.E., Ibanez, V., Margulis, L.A., Geacintov, N.E., Broyde, S., and Patel, D.J., "Influence of Benzo(a)pyrene Diol Epoxide Chirality on Solution Conformations of DNA Covalent Adducts: The (-)-Trans-anti-(BP)G.C Adduct Structure and Comparison with the (+)-Trans-anti Enantiomer, "Biochemistry 31(23), 5245-52 (1992)

Desai, S., Feigerle, C.S., and Miller, J.C., "Magic Numbers in (NO) ${ }^{+}{ }_{m} \mathrm{Ar}_{n}$ Heteroclusters Produced by a Two-Photon lonization in a Supersonic Expansion," J. Chem. Phys. 97(3), 1793-99 (1992)

Desai, S., Feigerlie, C.S., and Miller, J.C., "Nitric Oxide Containing Heteroclusters Probed by Two-Photon Ionization in a Supersonic Expansion," Proc. 6th Int. Symp. on Resonance Ionization Spectroscopy, RIS 92, Santa Fe, NM, May 24-29, 1992, Inst. of Physics Conf. Ser. 128, 1992, pp. 173-76

Desai, S., Feigerle, C.S., and Miller, J.C., "Magic Cluster Ion Distributions: $(\mathrm{NO})_{3}{ }^{+}\left(\mathrm{N}_{2} \mathrm{O}\right)_{\mathrm{n}}$ and $(\mathrm{NO})_{3}+\left(\mathrm{CO}_{2}\right)_{n}, "$ Bull. Am. Phys. Soc. 37, 1661 (1992)

Ding, D., Puretzky, A.A., and Compton, R.N., "Multiphoton Ionization/Dissociation of Osmium Tetroxide," J. Chem. Phys. 98(2), 951-58 (1993)

Ding, D., Compton, R.N., Haufler, R.E., and Klots, C.E., "Multiphoton Ionization of $\mathrm{C}_{6()}$," J. Phys. Chem. 97(11), 2500-4 (1993)

Ding, J., Steiner, T., Zabel, V., Hingerty, B.E., Mason, S.A., and Saenger, W., "Neutron Diffraction Study of the Hydrogen Bonding in Partially Deuterated GammaCyclodextrin $15.7 \mathrm{D}_{2} \mathrm{O}$ at $\mathrm{T}=110 \mathrm{~K}, "$ J. Am. Chem. Soc. 113, 8081-89 (1991) 
Doll, W.E., Nyquist, J.E., King, A.D., Bell, D.T., Holladay, J.S., Labson, V.F., and Pellerin, L., Aerial Remote Sensing Surveys Progress Report: Helicopter Geophysical Survey of the Oak Ridge Reservation, ES/ER/TM-62

Doty, C.B. and Travis, C.C., "Risk Assessment and Remedial Technology Effectiveness at Superfund Sites," How Clean is Clean? Proc. Air and Waste Management Assoc. Conf. on Cleanup Criteria for Contaminated Soils and Ground Water, Boston, Nov.6-8, 1990, Air and Waste Management Assoc., 1991, pp. 112-20

Douthat, D., Hanson, M., Brothers, R., and Miller, D.B., Risk Evaluation of Existing Data for Par Pond, ORNL/M-1894

Dudney, C.S., Hawthorne, A.R., Wilson, D.L., and Gammage, R.B., "Indoor ${ }^{222}$ Rn in Tennessee Valley Houses: Seasonal, Building, and Geological Factors," Indoor Air 2, 32-39 (1992)

Dudney, C.S., Wilson, D.L., Saultz, R.J., and Matthews, T.G., "One-Year Follow-Up Study of Performance of Radon Mitigation Systems Installed in Tennessee Valley Houses," Proc. Int. Symp. on Radon and Radon Reduction Technology, Atlanta, Feb.1923, 1990 (1991), v. 1, pp. 7-59--7-71

Easterly, C.E. and Glass, L.R., "Relative Potency as a Means of Evaluating ELF Health Risks," Proc. 6th Int. Symp. on Gaseous Dielectrics, Knoxville, TN, Sept.23-27, 1990, Plenum Publ. Corp., 1991, pp. 373-82

Easterly, C.E., "Residential Exposures to Indoor Air Pollutants Could Yield Childhood Leukemia Risk Levels Similar to Those Associated with 60-Hz Magnetic Fields," Abstract Booklet, 1st World Congress for Electricity and Magnetism in Biology and Medicine, Lake Buena Vista, FL, June 14-19, 1992 (1992)

Eastwood, D., Lidberg, R.L., Simon, S.J., and Vo-Dinh, T., "An Overview of Advanced Spectroscopic Field Screening and In-Situ Monitoring Instrumentation and Methods," Chemistry for the Protection of the Environment, Plenum Press, New York, 1991, pp. 97-111

Eastwood, D. and Vo-Dinh, T., EPA Project Summary: Molecular Optical Spectroscopic Techniques for Hazardous Waste Site Screening, ORNL/M-2121

Eckerman, K.F., Leggett, R.W., Ward, R.C., and Bhat, R.K., "Excretion Functions Derived from Physiologically-Based Biokinetic Models," Health Phys. 60 (Suppl. 2), S14 (1991)

Eckerman, K.F., Ryman, J.C., Tang, J.S., Williams, L.R., and Pace, J.V., III, "Improved Dose Rate Factors for Exposure to Photons from Contaminated Soil," Health Phys. 60 (Suppl. 2), S83 (1991)

Eckerman, K.F., "Health and Dosimetry Considerations in the ICRP 1990 Formulation of Effective Dose," Proc. Sth Int. Radiopharmaceutical Dosimetry Symp., Oak Ridge, TN, May 7-10, 1991, CONF-910529, 1992, pp. 28-40

Eckerman, K.F. and Leggett, R.W., "Review of NCRP Report No. 108: Conceptual Basis for Calculations of Absorbed-Dose Distributions," Nucl. Saf. 33, 219 (1992) 
Eckerman, K.F., Leggett, R.W., and Williams, L.R., "An Elementary Method for Solving Compartmental Models with Time-Dependent Coefficients," Radiat. Prot. Dosim. 41, 257-63 (1992)

Eckerman, K.F., Ward, R.C., and Maddox, L., U.S. Army Radiological Bioassay and Dosimetry: the RBD Software Package, ORNL/TM-11858

Ehrenshaft, A.R. and Wright, L.L., "The Short Rotation Woody Crops Program Data Base," Bioresour. Technol. 36, 241-46 (1991)

Ehrenshaft, A.R., "Article in Peer to Peer Column," InfoWorld 14(30) (1992)

Ehrenshaft, A.R., Energy Crops Forum, Summer 1992, ORNL/M-2207

Ehrenshaft, A.R., Energy Crops Forum, Fall 1991, ORNL/M-1738

England, M.W., Faust, J.B., Wilkerson, E.K., and Jacobson, K.B., "Strontiun Toxicity in Drosophila melanogaster," Toxicology 65, 251-57 (1991)

Espegren, M.L., Jensen, M.K., Smith, S.M., and Pierce, G.A., Reconnaissance Missile Site, San Pedro, California, ORNL/TM-12265

Espinosa, G., Castano, V.M., Golzarri, J.I., and Gammage, R., "Permeability of Some Materials to Radon," Nucl. Tracks Radiat. Meas. 19, 307-8 (1991)

Etnier, E.L., Implementation of the Natural Resource Damage Assessment Rule - Workshop Summary Interim Notification Policy, ES/ER/TM-24

Etnier, E.L., McDonald, E.P., and Houlberg, L.M., Applicable or Relevant and Appropriate Requirements (ARARs) for Remedial Action at the Oak Ridge Reservation - $A$ Compendium of Major Environmental Laws, ES/ER/TM-1/R1

Etnier, E.L. and Eaton, L.A., Applicable or Relevant and Appropriate Requirements (ARAR.s) for Remedial Actions at the Paducah Gaseous Diffusion Plant: A Compendium of Environmental Laws and Guidance, ORNL/M-2131

Faidas, H., Christophorou, L.G., McCorkle, D.L., and Carter, J.G., "Electron Drift Velocities in Fast Dielectric Liquids and Their Vapors," Proc. 6th Symp. on Gaseous Dielectrics, Knoxville, TN, Sept.23-27, 1990, Plenum Publ. Corp., 1991, pp. 179-85

Faidas, H., McCorkle, D.L., and Christophorou, L.G., "Warm Liquids for SSC Calorimetry: Electron Transport and Electrical Properties," Detector Research and Development for the Superconducting Super Collider, World Scientific, 1991, v. 1, pp. 365-67

Faidas, H., Christophorou, L.G., and McCorkle, D.L.," Electron Transport in Fast Dielectric Liquids at High Applied Electric Fields," Electron Transport in Fast Dielectrics Liquids at High Applied Electric Fields, IEEE, 1991, v. 26, pp. 568-73

Faidas, H., Christophorou, L.G., and McCorkle, D.L., "Laser Photodetachment in Liquids: $\mathrm{C}_{6} \mathrm{~F}_{6}-$ in Tetramethylsilane," Chem. Phys. Lett. 193, 487-92 (1992) 
Faidas, H. and Christophorou, L.G., "The Low Field Electron Mobility of Tetramethylsilane," Nucl. Instrum. Methods Phys. Res. A 320, 608-9 (1992)

Faust, R A., Toxicity Summary for Trichloroethene, ORNL/M-2771

Faust, R.A., Toxicity Summary for Nitrobenzene, ORNL/M-2768

Faust, R.A., Toxicity Summary for Vinyl Chloride, ORNL/M-2769

Faust, R.A., Toxicity Summary for Napthalene, ORNL/M-2783

Faust, R.A., Toxicity Summary for Silver, ORNL/M-2786

Faw, R.E., Eckerman, K.F., and Ryman, J.C., "X-Ray and Radioiodine Dose to Thyroid Follicular Cells," Proc. Radiopharmaceutical Dosimetry Symp., ORAU, Oak Ridge, TN, May 7-10, 1991, CONF-910529, 1992, pp. 557-76

Ferrell, T.L., Sharp, S.L., and Warmack, R.J., "Progress in Photon Scanning Tunneling Microscopy (PSTM)," Ultramicroscopy 42-44, 408-15 (1992)

Foley, R.D. and Floyd, L.M., Radiological Survey of the Former Baker Brothers, Inc. Site, 2551-2555 Harleau Place, Toledo, Ohio (BTO001), ORNL/RASA-90/8

Foley, R.D. and Uziel, M.S., Results of the Radiological Survey at the Former McKinney Tool and Manufacturing Company, 1688 Arabella Road, Cleveland, Ohio (MTC001 and MT(O02), ORNL/RASA-91/7

Foley, R.D. and Carrier, R.F., Radiological Characterization Survey of the Former Diamond Magnesium Company Site, 720 Fairport-Nursery Road, Painesville, Ohio (DMP001, DMPO02), ORNL/TM-11817

Foley, R.D. and Uziel, M.S., Radiological Survey Results at 9 and 11 Congress Street, Beverly, Massachusetts (VB002), ORNL/RASA-91/13

Foley, R.D. and Johnson, C.A., Radiological Survey Results at 5 Porter Street, Beverly, Massachusetts (VBO19), ORNL/RASA-91/16

Foley, R.D. and Johnson, C.A., Radiological Survey Results at 9 Porter Street, Beverly, Massachusetts (VBO2O), ORNL/RASA-91/15

Foley, R.D. and Johnson, C.A., Radiological Survey Results at 10 Cliff Street, Beverly, Massachusetts (VBO21), ORNL/RASA-91/14

Foley, R.D. and Johnson, C.A., Radiological Survey Results at 30 Cliff Street, Beverly, Massachusetts (VBO22), ORNL/RASA-91/11

Foley, R.D. and Johnson, C.A., Radiological Survey Results at 19 Wellman Street, Beverly, Massachusetts (VBO24), ORNL/RASA-91/10

Foley, R.D. and Johnson, C.A., Radiological Survey Results at 34 School Street, Beverly, Massachusetts (VB023), ORNL/RASA-91/9 
Foley, R.D. and Uziel, M.S., Radiological Survey Results at 17 Congress Street, Beverly, Massachusetts (VBOO6), ORNL/RASA-91/30

Foley, R.D. and Uziel, M.S., Radiological Survey Results at 15 Congress Street, Beverly, Massachusetts (VBOO4), ORNL/RASA-91/21

Foley, R.D. and Uziel, M.S., Radiological Survey Results at 13 Congress Street, Beverly, Massachusetts (VBO03), ORNL/RASA-91/20

Foley, R.D. and Johnson, C.A., Radiological Survey Results at 13 Cliff Street, Beverly, Massachusetts (VBO15), ORNL/RASA-91/19

Foley, R.D. and Johnson, C.A., Radiological Survoy Results at 9 Cliff Street, Beverly, Massachusetts (VBO17), ORNL/RASA-91/18

Foley, R.D. and Uziel, M.S., Radiological Survey Results at the Former Chapman Valve Manufacturing Company, Indian Orchard, Massachusetts (CIOOO1), ORNL/RASA-92/1

Foley, R.D. and Johnson, C.A., Radiological Survey Results at Porter Street City Park, Beverly, Massachusetts (VBO26), ORNL/RASA-91/12

Foley, R.D. and Johnson, C.A., Radiological Survey Results at 5 Cliff Street, Beverly, Massachusetts (VBO18), ORNL/RASA-91/17

Foley, R.D., Cottrell, W.D., and Carrier, R.F., Results of the Radiological Survey at the Sacandaga Site, Glenville, New York, ORNL-6638

Foley, R.D. and Carrier, R.F., Radiological Survey Results at 18 Cliff Street, Beverly, Massachusetts (VBO/2), ORNL/RASA-91/26

Foley, R.D. and Carrier, R.F., Radiological Survey Results at 15 Cliff Street, Beverly, Massachusetts (VB()/4), ORNL/RASA-91/28

Foley, R.D. and Carrier, R.F., Radiological Survey Results at 20 Cliff Street, Beverly, Massachusetts (VBO13), ORNL/RASA-91/27

Foley, R.D. and Carrier, R.F., Radiological Survey Results at 8 Cliff Street, Beverly, Massachusetts (VBO09), ORNL./RASA-92/3

Foley, R.D. and Carrier, R.F., Radiological Survey Results at 6 Cliff Street, Beverly, Massachusetts (VBOOS), ORNL/RASA-92/2

Foley, R.D. and Johnson, C.A., Radiological Survey Results at Beverly Harbor, Beverly, Massachusetts (VBO25), ORNL/RASA-91/29

Foley, R.D. and Carrier, R.F., Radiological Survey Results at 14 Cliff Street, Beverly, Massachusetts (VBOll), ORNL/RASA-91/25

Foley, R.D. and Carrier, R.F., Radiological Survey Results at 12 Cliff Street, Beverly, Massachusetts (VBO10), ORNL/RASA-91/24 
Foley, R.D. and Carrier, R.F., Radiological Survey Results at 2 Cliff Street, Beverly, Massachusetts (VB007), ORNL/RASA-91/23

Foley, R.D. and Carrier, R.F., Radiological Survey Results at 2 Porter Street, Beverly, Massachusetts (VBO05), ORNL/RASA-91/22

Foley, R.D. and Brown, K.S., Results of the Radiological Survey at 27 Schlosser Drive, Rochelle Park, New Jersey (RJ004), ORNL/RASA-92/7

Foley, R.D. and Brown, K.S., Results of the Radiological Survey at 48 Schlosser Drive, Rochelle Park, New Jersey (RJ005), ORNL/RASA-92/6

Foley, R.D. and Brown, K.S., Results of the Radiological Survey at the former ALCOA New Kensington Works, Pine and Ninth Streets, New Kensington, Pennsylvania (ANKO02), ORNL/RASA-92/5

Foley, R.D. and Brown, K.S., Results of the Radiological Survey at 37 Schlosser Drive, Rochelle Park, New Jersey (RJO02), ORNL/RASA-92/9

Foley, R.D. and Brown, K.S., Results of the Radiological Survey at 31 Schlosser Drive, Rochelle Park, New Jersey (RJ003), ORNL/RASA-92/8

Foley, R.D. and Brown, K.S., Results of the Radiological Survey at the ALCOA Research Laboratory, 600 Freeport Road, New Kensington, Pennsylvania (ANK001), ORNL/RASA-92/5

Foley, R.D., Cottrell, W.D., and Carrier, R.F., Radiological Survey Results for the Peek Street Site Properties, Schenectady, New York, ORNL-6623

Francis, A.A., Toxicity Summary for Bis(2-Ethylhexyl)Phthalate, ORNL/M-2773

Franken, P.R., Dobbeleir, A.A., Ham, H.R., Ranquin, R., Lieber, S., Van Den Branden, F., Van Den Heuvel, P., Brihaye, C., Guillaume, M., Knapp, F.F., Jr., and Vandevivere, J., "Discrepancy Between Myocardial Perfusion and Regional Wall Motion at Rest and During Exercise in Patients with Coronary Artery Disease," Nucl. Med. Commun. 12, 473-84 (1991)

Frazier, D.L., Barnhill, M.A., VoDinh, T., Legendre, A.M., and Overholt, B.F., "Comparative Pharmacokinetics of the Photosensitizer Tin-Etiopurpurin in Dogs and Rats," J. Vet. Pharmacol. Ther. 15, 275-280 (1992)

Fujibayashi, Y., Som, P., Yonekura, Y., Knapp, F.F., Jr., Tamaki, N., Yamamoto, K., Konishi, J., and Yokoyama, A., "Myocardial Accumulation of Iodinated Beta-methylBranched Fatty Acid Analog, Iodine-125-(p-iodophenyl)-3-(R,S)-methylpentadecanoic Acid (BMIPP), and Correlation to ATP Concentration. II. Studies in Salt-Induced Hypertensive Rats," J. Nucl. Med. Biol. 20, 163-66 (1993)

Gammage, R.B., Haas, J.W., III, and Allen, T.M., "Synchronous Fluorescence (SF): A Versatile Field Screening Method for Polynuclear Aromatics in Groundwater," Proc. 2nd Int. Symp. on Field Screening Methods for Hazardous Wastes and Toxic Chemicals, Las Vegas, Feb.12-14, 1991 (1991), pp. $673-76$ 
Gammage, R.B., Haas, J.W., III, and Allen, T.M., "Screening of Groundwater for Aromatics by Synchronous Fluorescence," Proc. 2nd Int. Symp. on Field Screening Methods for Hazardous Wastes and Toxic Chemicals, Las Vegas, Feb.12-14, 1991, pp. 673-76

Gammage, R.B., Wilson, D.L., Dudney, C.S., and Saultz, R.J., "Seasonally Elevated Indoor Radon Caused by Air Movements in Porous Limestone," Abstract Book, American Industrial Hygiene Conf., Salt Lake City, May 18-24, 1991 (1991), p. 65

Gammage, R.B., Wachter, E.A., Wade, J., Wilson, D.L., Ahmad, N., Siltain, F., and Raza, M.Z., "Impact on Indoor Air Quality During Burning of Pakistani Coal Briquettes," Environ. Int. 19, 133-45 (1993)

Gammage, R.B., Dudney, C.S., Wilson, D.L., Saultz, R.J., and Bauer, B.C., "Subterranean Transport of Radon and Elevated Indoor Radon in Hilly Karst Terrains," Atmos. Environ. 26A(12), 2237-46 (1992)

Gammage, R.B., Wade, J., Wilson, D.L., and DePriest, J.C., "Evaluation of Indoor Air Pollution During Burning of Coal Briquettes and Traditional Fuels," Proc. American Industrial Hygiene Conf./Expo., Boston, May 30-June 5, 1992 (1992), p. 63

Gammage, R.B. and Berven, B.A. (editors), Tenth ORNL Life Sciences Symposium: Hazardous Wate Site Investigations: Toward Better Decisions, Gatlinburg, TN, May 21 24, 1990, CONF-900556, ORNL, 1992

Garrett, W.R., Hart, R.C., Miller, J.C., Payne, M.G., and Wray, J.E., "Large Spectral Shifts of Stimulated Hyper-Raman Scattering: Predictions and Observations in Xe," Opt. Commun. 86, 205-10 (1991)

Garrett, W.R., Moore, M.A., Hart, R.C., Payne, M.G., and Wunderlich, R., "Suppression Effects in Stimulated Hyper-Raman Emissions and Parametric Four-Wave Mixing in Sodium Vapor," Phys. Rev. A 45, 6687-709 (1992)

Garrett, W.R. and Payne, M.G., "Suppression and Shifting of Odd-Photon Resonant Excitations and Stimulated Hyper-Raman Emissions," Nonlinear Optics III, Proc. Soc. Photo-Opt. Instrum. Eng. Symp. on Lasers, Sensors, and Spectroscopy, Los Angeles, Jan.19-25, 1992, SPIE, Bellingham, WA, 1992, pp. 337-47

Gatrett, W.R., "Alterations of Multiphoton-Resonant Processes Through Wave-Mixing Effects," Proc. 6th Int. Symp. on Resonance lonization Spectroscopy and Its Applications, Santa Fe, NM, May 24-29, 1992, Inst. of Physics Conf. Ser. No. 128 : Section 3, 1992, pp. 111-17

Glass, L.R. and Easterly, C.E., "Ranking of PAH Carcinogenic Potencies," Polynuclear Aromatic Hydrocarbons: Measurements, Means and Metabolism, Proc. Il th Int. Symp. on Polynuclear Aromatic: Hydrocarbons, Gaithersburg, MD, Sept.23-25, 1987, Battelle Press, Ohio, 1993, pp. 341-55

Glass, L.R., Easterly, C.E., Jones, T.D., and Walsh, P.J., "Ranking of Carcinogenic Potency Using a Relative Potency Approach," Arch. Environ. Contam. Toxicol. 21, 169$76(1991)$ 
Glass, L.R., Jones, T.D., Easterly, C.E., and Walsh, P.J., "Use of Short-Term Test Systems for the Prediction of the Hazard Represented by Potential Chemical Carcinogens," Environ. Auditor 2, 1-67 (1991)

Glauert, H.P., Srinivasan, S., Tatum, V.L., Chen, L.-C., Saxon, D.M., Lay, L.T., Borges, T., Baker, M., Chen, L.H., Robertson, L.W., and Chow, C.K., "Effect of the Peroxisome Proliferators Ciprofibrate and Perfluorodecanoic Acid on Hepatic Cellular Antioxidants and Lipid Peroxidation in Rats," Biochem. Pharmacol. 43, 1353-59 (1992)

Goodman, M.M., Kabalka, G.W., Marks, R.C., Knapp, F.F., Jr., Lee, J., and Liang, Y., Synthesis and Evaluation of Radioiodinated 5-Iodo-(2-thienyl)Amphetamines as Brain Imaging Agents," J. Med. Chem. 35, 280-84 (1992)

Goudonnet, J.P., Ferrell, T.L., and Warmack, R.J., "Recent Progress in Photon Scanning Tunneling Imaging," Proc. Soc. Photo-Opt. Instrum. Eng. Int. Conf. on Laser Spectroscopy, Los Angeles, Jan.19-24, 1992 (1992)

Goudonnet, J.P., de Fornel, F., Salomon, L., Lesniewska, E., Warmack, R.J., and Ferrell, T.L., "An Evanescent Field Optical Scanning Microscope," Proc. 3rd Beijing Conf./Exhib. on Intrumentation Analysis, Oct.21-23, 1991 (1991)

Griest, W.H., Tyndall, R.L., Stewart, A.J., Ho, C.-H., Ironside, K.S., Caton, J.E., Caldwell, W.M., and Tan, E., Characterization of Explosives Processing Waste Decomposition Due to Composting, ORNL/TM-12029

Griffin, G.D., Ryan, M.S., Kurka, K., Nolan, M.G., Sauers, I., and James, D.R., "Disulfur Decafluoride $\left(\mathrm{S}_{2} \mathrm{~F}_{10}\right)$ : A Review of the Biological Properties and Our Experimental Studies of this Breakdown Product of SF6," Proc. 6th Int. Symp. on Gaseous Dielectrics, Knoxville, TN, Sept.27-30, 1990, Plenum Press, 1991, pp. 545-52

Griffin, G.D., Sauers, I., "Letter to the Editor," Electr. Rev., February 11, 1992

Griffiths, G.L., Knapp, F.F., Jr., Callahan, A.P., Chang, C.-H., Hansen, H.J., and Goldenberg, D.M., "Direct Radiolabeling of Monoclonal Antibodies with GeneratorProduced Rhenium-188 for Radioimmunotherapy," Cancer Res. 51, 4592-602 (1991)

Griffiths, G.L., Knapp, F.F., Jr., Callahan, A.P., Ostella, F., Hansen, H.J., and Goldenberg, D.M., "The Generation of Rhenium-188-Labeled Antibodies by Direct Labeling Methods," Abstracts of Meeting, 7th Int. Symp. on Radiopharmacology, Boston, June 3-6, 1991 (1991)

Griffiths, G.L., Knapp, F.F., Jr., Callahan, A.P., Hansen, H.J., and Goldenberg, D.M., "The Generation of Rhenium-188-Labeled Antibodies by Direct Labeling Methods," $J$. Nucl. Med. 33, 910 (1992)

Haas, J.W., III, Matthews, T.G., and Gammage, R.B., "In Situ Detection of Toxic Aromatic Compounds in Groundwater Using Fiberoptic UV Spectroscopy," Proc. 2nd Int. Symp. on Field Screening Methods for Hazardous Wastes and Toxic Chemicals, Las Vegas, Feb.12-14, 1991 (1991), pp. 677-81 
Haas, R. and Caton, G., "The NEPA Environmental Review and Compliance Expert System," Proc. INFOTECH'9l DOE Technical Information Meet., Oak Ridge, TN, May 22-23, 1991, CONF-9105153, 1991, pp. 33-40

Halbrook, R.S., Cuzman, C.E., Wilkinson, K.J., Shugart, L.R., Watson, A.P., and Munro, N.E., "Rapid Whole-Blood Cholinesterase Assay with Potential Use for Biological Monitoring During Chemical Weapons Disposal," J. Assoc. Off. Anal. Chem. 75(3), $549-53$ (1992)

Halbrook, R.S., Shugart, L.R., Watson, A.P., Munro, N.B., and Linnabary, R.D., "Characterizing Biological Variability in Livestock Blood Cholinesterase Activity for Biomonitoring Organophosphate Nerve Agent Exposure," J. Am. Vet. Med. Assoc., 201, 714-25 (1992)

Hamm, R.N., Turner, J.F., Jones, T.D., and Preston, R.J., "Calculations of DNA Damage from Photon and $\mathrm{N}_{\mathrm{c}}$. Iron Irradiation," Congress Abstracts, 9th Int. Congress of

Radiation Research, Toronto, July 7-12, 1991, Academic Press, Inc., San Diego, 1991, v. 1, p. 406

Hamm, R.N. and Turner, J.E., "Mociel Calculations of Radiation-Induced DNA Damage," Proc. Workshop on Biophysical Modelling of Radiation Effects, Padua, Italy, Sept.2-5, 1991, U.S. Government, 1992, pp. 53-60

Hamm, R.N., Turner, J.E., Howell, R.W., Rao, D.V., and Sastry, K.S.R., "Calculations of DNA Damage from 125I," Abstract Booklet, 40th Annu. Meet. Radiat. Res. Soc., Salt Lake City, Mar.14-18, 1992, Radiat. Res. Soc., 1992, p. 41

Hammonds, J.S., Hoffman, F.O., White, R.K., and Miller, D.B., Background Risk Information to Assist in Risk Management Decision Making, ES/ER/TM-40

Hanson, M., Miller, P.D., Jones, J., Miller, D.B., Kirkpatrick, C., Wicker, L., and Kszos, L., Tcxicity Study of Selected Military Batteries, ORNL/M-1958

Harland, P.W., Carman, H.S., Jr., Phillips, L.F., and Brooks, P.R., "Effects of Molecular Orientation on Electron-Transfer Collisions," J. Phys. Chem. 95, 8137-42 (1991)

Hart, R.C., Garrett, W.R., and Payne, M.G., "Suppression of a Four-Photon Resonance by Four-Wave Mixing Near an Intermediate Three-Photon Resonance," Phys. Rev. A 46(7), 4213-19 (1992)

Hasan, A. and Srivastava, P.C., "Synthesis and Biological Studies of Unsaturated Acyclonucleoside Analogues of S-Adenosyl-L-homocysteine Hydrolase Inhibitors," J. Med. Chem. 35, 1435-39 (1992)

Hasan, A., Srivastava, P.C., and Mills, D.C.B., "Synthesis of 2-Substituted Thioadenosine Nucleosides and Nucleotides for Platelet ADP-Receptor Studies," Meeting Booklet, Proc. 204th Natl. Meet. Am. Chem. Soc., Washington, DC, Aug.23-28, 1992 (1992)

Hashemi, R., Jaffke, T., Christophorou, L.G., and Illenberger, E., "The Role of Inelastic Electron Scattering by $\mathrm{N}_{2}$ in the Formation of $\left(\mathrm{O}_{2}\right)_{n}$ - Anions in Mixed $\mathrm{O}_{2} / \mathrm{N}_{2}$ Clusters," J. Chem. Phys. 96, 10605-7 (1992) 
Hattemer-Frey, H.A. and Travis, C.C., "A Perspective on Municipal Waste Combustors as a Source of Environmental Dioxin," Health Effects of Municipal Waste Incineration, CRC Press, Boca Raton, Fl, 1991, pp. 327-38

Hattemer-Frey, H.A. and Travis, C.C., "Characterizing the Extent of Human Exposure to PCDDs and PCDFs Emitted from a Typical, Modern Municipal Waste Combustor," Health Effects of Municipal Waste Incineration, CRC Press, Boca Raton, FL, 1991, pp. $339-48$

Hattemer-Frey, H.A. and Travis, C.C., "An Overview of Food Chain Impacts from Municipal Waste Combustion," Municipal Waste Incineration Risk Assessement, Plenum Publ. Corp., 1991, pp. 87-124

Hattemer-Frey, H.A. and Travis, C.C., "Assessing the Extent of Human Exposure Through the Food Chain to Pollutants Emitted from an Arbitrary Municipal Solid Waste Combustor," Health Effects of Municipal Waste Incineration, CRC Press, Boca Raton, FL, 1991, pp. 83-101

Hattemer-Frey, H.A. and Travis, C.C., "Benzo-a-pyrene Environmental Partitioning and Human Exposure," Toxicol. Ind. Health 7(3), 141-57 (1991)

Hattemer-Frey, H.A. and Travis, C.C., "PCDD/PCDF Emissions from Municipal Solid Waste Incinerators and the Potential for Human Exposure," Proc. Conf. on Municipal Solid Waste Management: Making Decisions in the Face of Uncertainty, Toronto, Apr.25-27, 1990, Univ. of Waterloo Press, Murray Haight, 1991, pp. 275-300

Hattemer-Frey, H.A. and Travis, C.C., "Characterizing the Extent of Human Exposure to PCDDs and PCDFs Emitted from Municipal Solid Waste Incinerators," Health Effects of Municipal Waste Incineration, Proc. Int. Conf. on Municipal Waste Combustion, Hollywood, FL, Apr.10-14, 1989, CRC Press, 1991, pp. 339-48

Hawkins, G.T. and Baes, C.F., II, Environmental Guidance Regulatory Bulletin, May 4, 1992, ORNL/M-2075

Helmenstine, A.M., Li, Y.S., and Vo-Dinh, T., "Surface-Enhanced Raman Scattering Analysis of Etheno Adducts of Adenine," Vib. Spectrosc. 4, 359 (1993)

Hetrick, D.M., Jarabek, A.M., and Travis, C.C., "Sensitivity Analysis for Physiologically Based Pharmacokinetic Models," J. Pharmacokinetics \& Biopharm. 19, 1-20 (1991)

Hetrick, D.M., McDowell-Boyer, L.M., Sjoreen, A.L., Thorne, D.J., and Patterson, M.R., RIVER-RAD: A Computer Code for Simulating the Transport of Radionuclides in Rivers, ORNL/TM-12169

Hettich, R.L. and Yoshida, H., "Characterization of Radiation-Induced Damage to Nucleic Acid Constituents by Matrix-Assisted Laser Desorption FTMS," Proc. 40th Am. Soc. Mass Spectrom. Conf., Washington, DC, May 31-June 5, 1992, ASMS, 1992, p. 316

Hingerty, B.E., Broyde, S., and Shapiro, R., "Predicting Structures of DNA and Carcinogen-Modified DNA by Build-Up Techniques," Proc. Ist Int. Conf. on Electrophoresis, Supercomputing, and the Human Genome, Florida State Univ., Tallahassee, Apr.10-13, 1990, World Scientific Publ., 1991, pp. 96-100 
Hingerty, B.E., DUPLEX: A Molecular Mechanics Program in Torsion Angle Space for Computing Structures of DNA and RNA, ORNL/TM-12138

Hoffman, F.O. and Hammonds, J.S., An Introductory Guide to Uncertainty Analysis in Environmental and Health Risk Assessment, ES/ER/TM-35

Houlberg, L.M., Hawkins, G.T., and Salk, M.S., Environmental Regulatory Update Table November 1991, ORNL-6658/R 10

Houlberg, L.M., Hawkins, G.T., and Salk, M.S., Environmental Regulatory Update Table October 1991, ORNL-6658/R9

Houlberg, L.M., Hawkins, G.T., and Salk, M.S., Environmental Regulatory Update Table December 1991, ORNL-6658/R11

Houlberg, L.M., Hawkins, G.T., and Salk, M.S. Environmental Regulatory Update Table January/February 1992, ORNL/M-1929

Houlberg, L.M., Hawkins, G.T., and Salk, M.S., Environmental Regulatory Update Table, March/April 1992, ORNL/M-1929/R 1

Houlberg, L.M., Hawkins, G.T., Lewis, E.B., and Salk, M.S., Environmental Regulatory Update Table - May/June 1992, ORNL/M-1929/R2

Houlberg, L.M., Hawkins, G.T., Lewis, E.B., and Salk, M.S., Environmental Regulatory Update Table, July/August 1992, ORNL/M-1929/R3

Houlberg, L.M., Hawkins, G.T., Lewis, E.B., and Salk, M.S., Environmental Regulatory Update Table - November/December 1992, ORNL/M-1929/R5

Houlberg, L.M., Hawkins, G.T., Salk, M.S., Danford, G.S., and Lewis, E.B., Environmental Regulatory Update Table - Jantuary/February 1993, ORNL/M-2648

Houlberg, L.M., Hawkins, G.T., Lewis, E.B., and Salk, M.S., Environmental Regulatory Update Table - SeptemberiOctober 1992, ORNL/M-1929/R4

Hovatter, P.S., Ross, R.H., Lu, P.-Y., and Muhly, R., "Nitroaromatics as Soil and Groundwater Contaminants of Concern at Army Superiund Sites: Toxicity and Cleanup Levels," Proc. 12th Annu. Meet. Soc. Environ. Toxicol. Chem., Seattle, Nov.3-7, 1991, SETAC, 1991, p. 32

Hushon, J.M., Read, M.W., Morris, J.M., and Zaragoza, L., "Comparison of Hazardous Waste Site Ranking Models," Proc. of Federal Environmental Restoration Conf./Exhib., Washington, DC, May 25-17, 1993 (1993), pp. 8()-84

Illman, B.L., Anderson, V.E., Warmack, R.J., and Ferrell, T.L., "Energy-Loss Profiles of Transmitted Electrons Incident on Dielectric Spheroids," Ultramicroscopy 35, 1-10) (1991)

Jacobson, K.B., Arlinghaus, H.F., Buchanan, M.V., Chen, C.H., Glish, G.L., Hettich, R.L., and McLuckey, S.A., "Applications of Mass Spectrometry to DNA Sequencing," GATA 8, 223-29 (1991) 
Jacobson, K.B., Arlinghaus, H.F., Schmitt, H.W., Sachleben, R.A., Brown, G.M., Thonnard, N., Sloop, F.V., Foote, R.S., Larimer, F.W., Woychik, R.P., England, M.W., Burchett, K.L., and Jacobson, D.A., "An Approach to the Use of Stable Isotopes for DNA Sequencing," Genomics 9, 51-59 (1991)

Jaffke, T., Meinke, M., Hashemi, R., Christophorou, L.G., and Illenberger, E., "Dissociative Electron Attachment to Singlet Oxygen," Chem. Phys. Lett. 193, 62-68 (1992)

Jaffke, T., Hashemi, R., Christophorou, L.G., and Illenberger, E., "Mechanisms of Anion Formation in $\mathrm{O}_{2}, \mathrm{O}_{2} / \mathrm{Ar}$ and $\mathrm{O}_{2} / \mathrm{Ne}$ Clusters," Z. Phys. D 25, 77-85 (1992)

Jenkins, R.A., Buchanan, M.V., Merriweather, R., Ilgner, R.H., Gayle, T.M., Moneyhun, J.H., and Watson, A.P., Protocol for Determination of Chemical Warfare Agent Simulant Movement Through Porous Media, ORNL/TM-12002

Jones, T.D., Owen, B.A., and Trabalka, J.R., "Protection of Human Health from Mixtures of Radionuclides and Chemicals in Drinking Water," Arch. Environ. Contam. Toxicol. 20, 143-50 (1991)

Jones, T.D., Morris, M.D., and Young, R.W., "A Mathematical Model for RadiationInduced Myelopoiesis," Radiat. Res. 128, 258-66 (1991)

Jones, T.D., Owen, B.A., Trabalka, J.R., Barnthouse, L.W., Easterly, C.E., and Walsh, P.J., "Chemical Pollutants: A Caricaturized Logos for Future Planning," Environ. Auditor 2, 71-88 (1991)

Jones, T.D., "On the Future of Regulating Chemicals," Environ. Auditor 2(3), 101-2 (1991)

Jones, T.D. and Easterly, C.E., "On the Rodent Bioassays Currently Being Conducted on 44 Chemicals: A RASH Analysis to Predict Test Results from the National Toxicology Program," Mutagenesis 6, 507-14 (1991)

Kavlock, R.J., Greene, J.A., Kimmel, G.L., Morrissey, R.E., Owens, E.T., Rogers, J.M., Sadler, T.W., Stack, H.F., Waters, M.D., and Welsch, F., "Activity Profiles of Developmental Toxicity: Design Considerations and Pilot Implementation," Teratology 43, 159-85 (1991)

Kaye, S.V., Health and Safety Research Division Progress Report for the Period April 1, 1990 - September 30, 1991, ORNL-6693

Kearl, P.M., Korte, N.E., and Cronk, T.A., "Suggested Modifications to Ground Water Sampling Procedures Based on Observations from the Colloidal Borescope," Ground Water Monit. Rev., Spring, 155-61 (1992)

Kearl, P.M., Gardner, F.G., and Gunderson, M.J., Groundwater Flow Delineation Study at the Massachusetts Military Reservation Using the Colloidal Borescope, ORNI,/TM-12139 
Kerr, G.D., "The Relative Biological Effectiveness of Radiations of Different Quality - Book Review," Nucl. Saf. 32, 229 (1991)

Kerr, G.D., Borges, T., Stafford, R.S., Lu, P.Y., and Carter, D., Health Physics Positions Data Base, ORNL/TM-12067

Kerr, G.D., Ritchie, R.H., Kaye, S.V., and Wassom, J.S., A Brief History of the Health and Safety Research Division, ORNL/M-2108

Khare, B.N., Thompson, W.R., Cheng, L., Sagan, C., Meisse, C., Arakawa, E.T., and Matthews, C.N., "Optical Properties of Tholin from $\mathrm{H}_{2} \mathrm{O} / \mathrm{C}_{2} \mathrm{H}_{6}(6: 1)$ Ice, and Comparison with Titan Tholin, Kerogen and Meteoritic Organics," Proc. 23rd Annu. Meet. Am. Astron. Soc., Div. Planet. Sci., Palo Alto, CA, Nov.4-8, 1991 (1991), p. 16.10)

Khare, B.N., Thompson, W.R., Sagan, C., Arakawa, E.T., Meisse, C., and Gilmour, I., "Optical Constants of Kerogen from 0.15 to $40 \mu \mathrm{m}$ : Comparison with Meteoritic Organics," Proc. Int. Astronomical Union Colloquium No. 126 on Origin and Evolution of Inter-planetary Dust, Kyoto, Japan, Aug.27-30, 1990, Kluwer Academic Press, 1991, pp. 99-101

King, A.D. and Miller, D.B., Interim Proposed Plan: M-Area Settling Basin at the Savannah River Site, Savannah River/Westinghouse ER Document, 1992

King, A.D. and Miller, D.B., Interim Proposed Plan for the Metallurgical Basin and Vicinity, Savannah River/Westinghouse ER Document, 1992

Klein, J.A., Mrochek, J.E., Jolley, R.L., Osborne-Lee, I.W., Francis, A.A., and Wright, T., National Profile on Commercially Generated Low-Level Radioactive Mixed Waste, ORNL-6731

Klots, C.E., "Systematics of Evaporation," Z. Phys. D 20, 105-9 (1991)

Klots, C.E., "Kinetic Methods for Quantifying Magic," Z. Phys. D 21, 335-42 (1991)

Klots, C.E., "Magic Numbers from Metastable Decay of Ablated $\mathrm{C}_{\mathrm{n}}+$ Ions," Book of Abstracts, Workshop on Laser Ablation-Mechanisms and Applications, Oak Ridge, TN, Apr.8-11, 1991, ORNL (1991), p. 77

Klots, C.E., "Evaporation as a Diagnostic Test for Hydrodynamic Cooling of Laser-Ablated Clusters," Proc. Workshop on Laser Ablation - Mechanisms and Applications, Oak Ridge, TN, Apr.8-10, 1991, Springer-Verlag (1991), pp. 294-97

Klots, C.E., "Arrhenius Parameters for Ionic Fragmentations," J. Phys. Chem. 96, 1733-37 (1992)

Klots, C.E., "Quasiequilibrium Rate Constants for Thermionic Emission from Small Particles," Chem. Phys. Lett. 186, 73-76 (1991)

Klots, C.E., "Steric Factors for Bimolecular Reactions," Chem. Phys. Lett. 192, 41-44 (1992) 
Klots, C.E., "Unimolecular Decomposition in a Spherically Symmetric Potential," J. Chem. Phys. 98(2), 1110-15 (1993)

Klots, C.E., "Angular Momentum in Unimolecular Reactions," J. Chem. Phys. 98(1), 20610 (1993)

Knapp, F.F., Jr., Callahan, A.P., Mirzadeh, S., Brihaye, C., and Guillaume, M., "The Development of New Radionuclide Generator Systems for Nuclear Medicine," Progress in Radiopharmacy, Kluwer Academic Publ., 1992, pp. 67-88

Knapp, F.F., Jr., Lisic, E.C., Mirzadeh, S., Callahan, A.P., and Rice, D.E, "A New Clinical Prototype W-188/Re-188 Generator to Provide High Levels of Carrier-Free Rhenium-188 for Radioimmunotherapy (RAIT)," Eur. J. Nucl. Med. 18, 538 (1991)

Knapp, F.F., Jr., "Radioisotopes for Radioimmunodetection (RAID) and Radioimmunotherapy (RAIT) -- Current and New Perspectives," Proc. Meet. Soc. Nucl. Med., Southeastern Chapter, Miami Beach, FL, Oct.11-13, 1991, Soc. Nucl. Med., 1992, pp. XIII 2-16

Knapp, F.F., Jr., Lisic, E.C., Mirzadeh, S., Callahan, A.P., and Rice, D.E, "A New Clinical Prototype Tungsten-188/Rhenium-188 Generator to Provide High Levels of Carrier-Free Rhenium-188 for Radioimmunotherapy (RAIT)," Nuclear Medicine - Nuclear Medicine in Research and Practice, Proc. European Assoc. of Nuclear Medicine, Vienna, Sept.1-5, 1991, Schattauer, Stuttgart, 1992, pp. 183-86

Knapp, F.F., Jr., Kropp, J., Ambrose, K.R., McPherson, D.W., Callahan, A.P., Lambert, C.R., and Biersack, H.-J., "Site Specific/Stable Radioiodination of 1,2-Dipalmitoyl-3((15-p-(I-131)-iodophenyl)pentadecan-3-oyl)rac-glycerol (1,2-Pal-3-IPPA) for In Vivo Evaluaton of Pancreatic Lipase by Urine Analysis," J. Nucl. Med. 33, 1028 (1992)

Knapp, F.F., Jr., Ambrose, K.R., Callahan, A.P., McPherson, D.W., Mirzadeh, S., Srivastava, P.C., Hasan, A., Lambert, C.R., Lambert, S.J., and Rice, D.E., Nuclear Medicine Program Progress Report for Quarter Ending September 30, 1991, ORNL/TM11992

Knapp, F.F., Jr. and McPherson, D.W., "Development of Radioiodinated Receptor Ligands for Cerebral Single Photon Emission Tomography," Brain Diagnosis with Radionuclides Current Status and Future Aspects, Proc. 2nd Mediterranean Symp., Athens, Greece, Apr.7-12, 1992, Mediterra Publ., Athens, Greece, 1992, pp. 37-52

Knapp, F.F., Jr., Ambrose, K.R., Callahan, A.P., McPherson, D.W., Mirzadeh, S., Srivastava, P.C., Hasan, A., Lambert, C.R., Lambert, S.J., Rice, D.E., Nuclear Medicine Program Progress Report for Quarter Ending December 31, 1991, ORNL/TM12054

Knapp, F.F., Jr., Ambrose, K.R., Callahan, A.P., McPherson, D.W., Mirzadeh, S., Hasan, A., Lambert, C.R., and Rice, D.E., Nuclear Medicine Program Progress Report for Quarter Ending March 31, 1992, ORNL/TM-12110

Knapp, F.F., Jr., Ambrose, K.R., Callahan, A.P., McPherson, D.W., Mirzadeh, S., Hasan, A., Lambert, C.R., Rice, D.E., and Srivastava, P.C., Nuclear Medicine Program Progress Report for Quarter Ending June 30, 1992, ORNL/TM-12159 
Knapp, F.F., Jr., Mirzadeh, S., and Callahan, A.P., "Editorial for the Proceedings of the 'Symposium on Radionuclide Generator Systems for Nuclear Medicine Applications,' Washington, DC, Aug.24-28, 1992," Radioact. Radiochem. 3(4), 3-4 (1993)

Knapp, F.F., Jr., Ambrose, K.R., Beets, A.L., Callahan, A.P., McPherson, D.W., Mirzadeh, S., Hasan, A., and Lambert, C.R., Nuclear Medicine Program Progress Report for Quarter Ending September 30, 1992, ORNL/TM-12222

Knapp, F.F., Jr., Ambrose, K.R., Beets, A.L., Callahan, A.P., McPherson, D.W. Mirzadeh, S., Hasan, A., and Lambert, C.R., Nuclear Medicine Program Progress Report for Quarier Ending December 31, 1992, ORNL/TM-12312

Kocher, D.C. and Lee, D.W., "Disposal of Low-Level Radioactive Wastes on the Oak Ridge Reservation. I. Preliminary Screening Analysis for Identification of Important Radionuclides," Radioact. Waste Manage. Nucl. Fuel Cycle 61, 83-99 (1991)

Kocher, D.C. and Hoffman, F.O., "Regulating Environmental Carcinogens: Where Do We Draw the Line?" Environ. Sci. Technol. 25, 1986-89 (1991)

Kocher, D.C., "Dose Assessment for a ${ }^{137} \mathrm{Cs}$ Contamination Incident," Trans. Am. Nucl. Soc. 64, 120-21 (1991)

Kocher, D.C. and Hoffman, F.O., "Worldwide Achievement in Public and Occupational Health Protection Against Radiation," Proc. 8th Int. Congress of the International Radiation Protection Assoc., Montreal, May 17-22, 1992 (1992), v. 2, pp. 1214-17

Kocher, D.C. and Hoffman, F.O., "Reply to Weisburger Regarding 'Regulating Environmental Carcinogens'," Environ. Sci. Technol. 26, 845-46 (1992)

Kocher, D.C. and Hoffman, F.O., "Regulation of Environmental Carcinogens: The Problem and a Solution," ORNL Rev. 26, 22-29 (1993)

Kocher, D.C., "Potential Impact of DOE's Performance Objective for Protection of Inadvertent Intruders on Low-Level Waste Disposals at Oak Ridge National Laboratory," Proc. 14th Annu. DOE Low-Level Radioactive Waste Management Conf., Phoenix, AZ, Nov.18-20, 1992 (1993), pp. 204-13

Korte, N.E., Muhr, C.A., and Greene, D.W., Potential Soil Contaminant Levels of Polychlorinated Dibenzodioxins and Dibenzofurans at Industrial Facilities Employing Heat Transfer Operations, ORNL/TM-11730

Kramel, R., Hanson, M., and Miller, D.B., A Preliminary Evaluation of the Contaminants of Concern and the Potential Exposure Pathways for the Metallurgical Basin Carolina Bay Site, Department of Energy, Savannah River Site, Aiken, South Carolina, ORNL/M-1893

Krewski, D., Withey, J.R., Ku, L.F., and Travis, C.C., "Physiologically Based Pharmacokinetic Models: Applications in Carcinogenic Risk Assessment," New Trends in Pharmacokinetics, Plenum Publ. Corp., 1991, pp. 355-90 
Miao, Y.-S., Hingerty, B.E., Broyde, S., and Shapiro, R., "Mutagenesis by 2-Aminofluorene $(\mathrm{AF})$ and 2-Acetylaminofluorene $(\mathrm{AAF})$ : Implications from DNA Single Strand Conformations," Abstract Booklet, American Assoc. for Cancer Research Conf., San Diego, May 20-25, 1992 (1992), v. 33, p. 142

Miller, D. and Nyberg, N., Remedial Site Evaluation Report on the K-1070-A Landfarm, Oak Ridge K-25 Site, Oak Ridge, Tennessee, ORNL/M-2035

Miller, D.R., Allison, D.P., Rorvik, M.C., and Slaga, T.J., "Inhibited Morphological Terminal Differentiation and Enhanced Proliferation of Cultured Mouse Epidermal Cells at Different Concentrations of Dimethyl Sulphoxide," Cell Proliferation 24, 191-210 (1991)

Miller, I.C., Slusher, K.G., Richmond, A.A., and Francis, M.W., Toxicology Information Response Center - TIRC (Handout), ORNL/M-2150

Miller, I.C., Slusher, K.G., Richmond, A.A., and Francis, M.W., Toxicology Information Response Center - TIRC (Brochure), ORNL/M-2151

Miller, J.C. and Smith, D.B., "Resonance Ionization Spectroscopy of Molecular Clusters Using Picosecond Lasers," Resonance Ionization Spectroscopy 1990, Proc. 5th Int. Symp. on Resonance Ionization Spectroscopy and Its Applications, Varese, Italy, Sept.16-21, 1990, Inst. of Physics, Bristol, 1991, pp. 163-68

Miller, J.C. and Barton, D., "Picosecond Multiphoton Ionization of Atomic and Molecular Clusters," Proc. 5th Int. Conf. on Multiphoton Processes, ICOMP V, Paris, Sept.24-28, 1990, CEA Press, France, 1991, pp. 283-92

Miller, J.C., Payne, M.G., Garrett, W.R., and Hart, R.C., "Novel Nonlinear Processes in Rare Gases," Proc. 10th Int. Conf. on Laser Spectroscopy (TENICOLS '91), Villetaneuse, France, June 17-21, 1991, World Scientific Publ. Co., 1992, pp. 328-29

Mirzadeh, S. and Chu, Y.Y., "Production of Gallium-66, A Positron Emitting Nuclide for Radioimmunotherapy," Proc. Int. Conf. on Nuclear Data for Science and Technology, Juelich, Germany, May 1991, Springer Verlag, New York, 1991, pp. 619-21

Mirzadeh, S., Knapp, F.F., Jr., and Callahan, A.P., "Production of Tungsten-188 and Osmium-194 in a Nuclear Reactor for New Clinical Generators," Proc. Int. Conf. on Nuclear Data for Science and Technology, Juelich, Germany, Nay 1991, Springer Verlag, New York, 1991, pp. 595-97

Mirzadeh, S., Callahan, A.P., and Knapp, F.F., Jr., "Iridium-194 - A New Candidate for Radioimmunotherapy (RAIT) from an Osmium-194/Iridium-194 Generator System," $J$. Nucl. Med. 32, 1089 (1991)

Mirzadeh, S., Rice, D.E., and Knapp, F.F., Jr., "Carrier-Free ${ }^{194}$ Ir from an ${ }^{194}$ Os/ ${ }^{194}$ Ir Generator - A New Candidate for Radioimmunotherapy (Technical Note)," Appl. Radiat. Isot. 43(5), 689-92 (1992)

Mirzadeh, S., Kumar, K., and Gansow, O.A., "The Chemical Fate of 212Bi-DOTA Formed by Beta- Decay of 212Pb(DOTA)2-," Radiochim. Acta 60, 1-10 (1993) 
Mirzadeh, S., Rice, D.E., Callahan, A.P., and Knapp, F.F., Jr., "The ${ }^{194} \mathrm{Os} /{ }^{194} \mathrm{Ir}$ Generator--Production and Purification of ${ }^{194} \mathrm{Os}$," J. Labelled Compd. Radiopharm. 23, $471-73$ (1992)

Mirzadeh, S. and Knapp, F.F., Jr., "Spontaneous Electrochemical Separation of Carrier-Free Copper-64 and Copper-67 from Zinc Targets," Radiochim. Acta 57, 193-99 (1992)

Mirzadeh, S., Rice, D.E., and Knapp, F.F., Jr., "Spontaneous Electrochemical Separation of Carrier-Free ${ }^{64} \mathrm{Cu}$ and ${ }^{78} \mathrm{Cu}$ from $\mathrm{Zn}$ Targets," J. Labelled Compd. Radiopharm. 23, 474-76 (1992)

Mirzadeh, S., Rice, D.E., Callahan, A.P., and Knapp, F.F., Jr., "Extraction-Based ${ }^{194}$ Os ${ }^{194}$ Ir Generator," Meeting Abstracts, 204th Natl. Meet. Am. Chem. Soc., Washington, DC, Aug.23-28, 1992 (1992)

Mirzadeh, S., Callahan, A.P., and Knapp, F.F., Jr., "Extraction-Based Osmium194/Iridium-194 Generator," Radioact. Radiochem. 3(4), 31-32 (1992)

Mirzadeh, S., Schenter, R.E., Callahan, A.P., and Knapp, F.F., Jr., Production Capabilities in U.S. Nuclear Reactors for Medical Radioisotopes, ORNL/TM-12010

Mirzadeh, S., Rice, D.E., and Knapp, F.F., Jr., "Application of Spontaneous Electrochemical Techniques for Separation of Carrier-Free ${ }^{64} \mathrm{Cu}$ and ${ }^{67} \mathrm{Cu}$ from $\mathrm{Zn}$ Targets," Proc. 205th Am. Chem. Soc. Natl. Meet., Denver, Mar.28-Apr.2, 1993 (1993)

Morris, J.M. and Travis, C.C., "Significance and Treatment of Volatile Organic Compounds in Water Supplies - Book Review," Risk Anal. 12(1), 161-62 (1992)

Morris, J.M. and Miller, D.B., Human Health Risk Evaluation of Closure Options, Savannah River Laboratory Seepage Basins, ORNL/M-1983

Morris, J.M. and Travis, C.C., Risk Assessment for Environmental Safety and Health Tank Systems, ORNL/M-2417

Morris, J.M., Harstin, J.B., Miller, D.B., Phillips, S.D., and Sherrod, R.E., Programmatic Environmental Impact Statement Human Health Risk Evaluation Pilot Study, ORNL/M2474

Morris, J.M., Programmatic Environmental Impact Statement Public Health Risk Installation Level Scale-Up Pilot Study, ORNL/M-2719

Morris, M.D., Jones, T.D., and Young, R.W., "Estimation of Coefficients in a Model of Radiation-Induced Myelopoiesis from Mortality Data for Mice Following X-Ray

Exposure," Radiat. Res. 128, 267-75 (1991)

Morris, M.D. and Jones, T.D., Marrow Cell Kinetics Model: Equivalent Prompt Dose Approximations for Two Special Cases, ORNL/TM-12255

Moss, O.R. and Eckerman, K.F., "Proposed NCRP Respiratory Tract Model: Geometric Basis for Estimating Absorbed Dose," Radiat. Prot. Dosim. 38, 185-91 (1991) 
Munro, N.B., Shugart, L.R., Watson, A.P., and Halbrook, R.S., "Cholinesterase Activity in Domestic Animals as a Potential Biomonitor for Nerve Agent and Other Organo-phosphate Exposure," J. Am. Vet. Med. Assoc. 199, 103-15 (1991)

Murray, M.E. and Uziel, M.S., Results of the Radiological Survey at the New Betatron Building, Granite City Steel Facility, Granite City, Illinois (GSG002), ORNL/RASA-91/8

Murray, M.E., Brown, K.S., and Mathis, R.A., Results of the Radiological Survey at the Former Alba Craft Laboratory Site Properties, Oxford, Ohio (OXO001), ORNL/RASA$92 / 14$

Murray, M.E., Carrier, R.F., and Mathis, R.A., Results of the Radiological Survey at the Former Associate Aircraft Tool and Manufacturing Company Site, Fairfield, Ohio (FOH001), ORNL/RASA-93/2

Narayanan, V.A., Bello, J.M., Stokes, D.L., and Vo-Dinh, T., "Surface-Enhanced Raman Anlysis of Vitamin B Complex: Quantitative Detection of p-Aminobenzoic Acid," $J$. Raman Spectrosc. 22, 327-31 (1991)

Narayanan, V.A., Begun, G.M., Stump, N.A., Stokes, D.L., and Vo-Dinh, T., "Vibrational Spectra of Fluvalinate," J. Raman Spectrosc. 24, 123-28 (1993)

Narayanan, V.A., Begun, G.M., Stokes, D.L., Sutherland, W.S., and Vo-Dinh, T., "Normal Raman and Surface-Enhanced Raman Scattering (SERS) Spectra of Some Fungicides and Related Chemical Compounds," J. Raman Spectrosc. 23, 281-86 (1992)

Narayanan, V.A., Stokes, D.L., Stump, N.A., Begun, G.M., and Vo-Dinh, T., "SurfaceEnhanced Raman Analysis of Some Polycyclic Aromatic Dyes Used in the Cosmetic and Food Industries," Polycyclic Aromat. Compd. 3, 137-46 (1993)

Norton, D.P., Lowndes, D.H., Zheng, X., Warmack, R.J., Pennycook, S.J., and Budai, J.D., "Superconducting Transport Properties and Surface Microstructure for $\mathrm{YBa}_{2} \mathrm{Cu}_{3} \mathrm{O}_{7}$. $\delta$-Based Superlattices Grown by Pulsed Laser Deposition," Proc. Workshop on Laser Ablation Mechanisms and Applications, Oak Ridge, TN, May 15-17, 1991, SpringerVerlag, Berlin, 1991, pp. 311-19

Norton, D.P., Lowndes, D.H., Zheng, X.-Y., Zhu, S., and Warmack, R.J., "Scanning Tunneling Microscopy of Pulsed-Laser-Deposited $\mathrm{YBa}_{2} \mathrm{Cu}_{3} \mathrm{O}_{7-\delta}$ Epitaxial Thin Films: Surface, Microstructure and Growth Mechanism," Phys. Rev. B 44, 9760-63 (1991)

Norton, D.P., Lowndes, D.H., Zheng, Z.-Y., Feenstra, R., and Zhu, S., "Properties of Epitaxial YBa $\mathrm{Cu}_{3} \mathrm{O}_{7-\delta}$-Based Superconducting Superlattices," Proc. 5 th Annu. Conf. on Superconductivity and Applications, Buffalo, NY, Sept.24-26, 1991, Am. Inst. Phys. Conf. Proc. 251, 1992, pp. 33-43

O'Handley, S.F., Sanford, D.G., Xu, R., Lester, C.C., Hingerty, B.E., Broyde, S., and Krugh, T.R., "Structure of an Acetylaminofluorene (AAF) Modified DNA Oligomer," Structure and Function (Nucleic Acids, v. 1), Adenine Press, 1992, pp. 137-45

Opresko, D.M., Toxicity Summary for Selenium and Selenium Compounds, ORNL/M-2770 
Opresko, D.M., Toxicity Summary for Molybdenum and Molybdenum Compounds, ORNL/M-2784

Pal, A., Watts, W., Caraway, J., and Vo-Dinh, T., "Enhanced Room Temperature Phosphorescence Using Sodium Lauryl Sulphate-Treated Solid Substrate," Analusis: I. Physiochim. Anal. l'Analyse Indust. 20, 149-53 (1992)

Pal, T., Pal, A., Miller, G.H., and Vo-Dinh, T., "Passive Dosimeter for Monitoring Ammonia Vapor," Anal. Chim. Acta 263, 175-78 (1992)

Pal, T., Griffin, G.D., Miller, G.H., Watson, A.P., Daugherty, M.W., and Vo-Dinh, T., "Permeation Measurements of Chemical Agent Simulants Through Protective Clothing Materials," J. Hazardous Mater. 33, 123-41 (1993)

Panter, M.S., Burman, S.N., Landguth, D.C., and Uziel, M.S., Work Plan, Health and Safety Plan, and Quality Assurance Project Plan for Hazardous Waste Removal at the CTF $K-1654 B$ Underground Collection Tank, ORNL-6697

Paretzke, H.G., Turner, J.E., Hamm, R.N., Ritchie, R.H., and Wright, H.A., "Spatial Distributions of Inelastic Events Produced by Electrons in Gaseous and Liquid Water," Radiat. Res. 127, 121-29 (1991)

Parks, J.E., II and Arakawa, E.T., "Evaluation of Soft X-Ray Yield of Al from $50 \mathrm{MeV}$ Neutral Particles," Bull. Am. Phys. Soc. 37, 546 (1992)

Payne, M.G., Allman, S.L., and Parks, J.E., "Effect of Hyperfine Structure on Ionization Efficiencies in Stepwise Ionization Using Broad Bandwidth Lasers," Spectrochim. Acta B 46, 1439-57 (1991)

Payne, M.G., Miller, J.C., Hart, R.C., and Garrett, W.R., "Effects of Four-Wave Mixing on Four-Photon Resonance Excitation and Ionization in the Presence of a Three-Photon Intermediate State Resonance Enhancement," Phys. Rev. A 44, 7684-701 (1991)

Payne, M.G., Chen, C.H., Garrett, W.R., and Templeton, D., "High-Intensity Laser Beam Attenuation Based on Two-Step Absorption Mechanism," J. Appl. Phys. 72(9), 4281-87 (1992)

Pennycook, S.J., Chisholm, M.F., Jesson, D.E., Feenstra, R., Zhu, S., Zheng, X.Y., and Lowndes, D.J., "Growth and Relaxation Mechanisms of $\mathrm{YBa}_{2} \mathrm{Cu}_{3} \mathrm{O}_{7-\mathrm{m}}$ Films," Physica C 202, 1-11 (1992)

Pfiffner, S.M. and Tyndall, R.L., "The Effects of Legionella pneumophila Infection on the Sterol Composition of Naegleria lovaniensis," Abstracts of 91 st Annu. Meet. Am. Soc. Microbiol., Dallas, May 5-9, 1991 (1991), p. 36

Pfuderer, H.A. and Miller, K.C., "Choosing a User-System Interface," Interfaces for Information Retrieval and On-Line Systems: The State of the Art, Greenwood Press, Inc., 1991, pp. 219-26

Pinnaduwage, L.A. and Christophorou, L.G., "Enhanced Electron Attachment to Superexcited States of Saturated Tertiary Amines," J. Chem. Phys. 95, 274-87 (1991) 
Pinnaduwage, L.A. and Christophorou, L.G., "A Novel Technique for the Measurement of Photoenhanced Electron Attichment: Implications for an Optically-Controlled Diffuse Discharge Opening Switch," Proc. 8th Inst. Electr. Electron. Eng. Int. Conf. on Pulsed Power, San Diego, June 17-19, 1991, IEEE 91CH3052-8, 1991, pp. 486-90

Pinnaduwage, L.A. and Christophorou, L.G., "Enhanced Electron Attachment to Superexcited States of Nitric Oxide," Chem. Phys. Lett. 186, 4-10 (1991)

Pinnaduwage, L.A. and Christophorou, L.G., "Enhanced Electron Attachment to Superexcited States of Nitric Oxide," Program and Abstracts, 44th Annu. Gaseous Electronics Conf., Albuquerque, NM, Oct.22-25, 1991 (1991), p. 35

Pinnaduwage, L.A.and Christophorou, L.G., "H- Formation in Laser-Excited Molecular Hydrogen," Phys. Rev. Lett. 70(6), 754-57 (1993)

Pitarke, J.M., Ritchie, R.H., and Echenique, P.M., "Radiative Electron Capture by Channeled Ions," Phys. Rev. B 43, 62-70 (1991)

Pollutant Assessments Group, Pollutant Assessments Group Procedures Manual, Volume 1: Administrative and Support Procedures, ORNL-6645/V1/R1

Pollutant Assessments Group, Pollutant Assessments Group Procedures Manual, Volume 2: Technical Procedures, ORNL-6645/V2/R1

Purucker, S.L., Tonn, B.E., Goeltz, R.T., James, R.D., Kercel, S., Rizy, D.T., Simpson, M.L., and Van Dyke, J.W., Feasibility Study: Application of RCM Techniques for Substation Maintenance at the Bonneville Power Administration, ORNL/TM-12051

Ritchie, R.H., Echenique, P.M., Flores, F., and Manson, J.R., "The Image Potential in Scanning Transmission Electron Microscopy and Scanning Tunneling Microscopy," Radiat. Effects Defects Solids 117, 163-68 (1991)

Ritchie, R.H., Manson, J.R., and Echenique, P.M., "A Surface Plasmon Model for Laser Ablation of $\mathrm{Ag}^{+}$Ions from a Roughened Ag Surface," Proc. Workshop on Laser Ablation: Mechanisms and Applications, Oak Ridge, TN, Apr.8-10, 1991, CONF-9104192, Springer-Verlag, 1991, pp. 239-45

Ritchie, R.H., Hamm, R.N., and Ashley, J.C., "Electron and Positron Mean Free Paths in an Electron Gas," Bull. Am. Phys. Soc. 36, 2750 (1991)

Ritchie, R.H., Echenique, P.M., and Flores, F., "Image Potential Effects for Low- and HighEnergy Electrons," Surf. Sci. 251, 119 (1991)

Ritchie, R.H., Hamm, R.N., Ashley, J.C., and Echenique, P.M., "Electron Spectra in Solids," NATO Advanced Study Inst. on Interaction of Charged Particles with Solids and Surfaces, Alacant, Spain, May 6-18, 1990, Plenum Press, New York, 1991, pp. 197-225

Ritchie, R.H., The 14th Werner Brandt Workshop on Charged Particle Penetration Phenomena, Oak Ridge, TN, April 30 - May 30, 1992, Oak Ridge National Laboratory, CONF-9204144 
Rodriguez, R.E., Tiner, P.F., and Williams, J.K., Surface Debris Inventory at White Wing Scrap Yard, Oak Ridge Reservation, Oak Ridge, Tennessee, ORNL/ER-135

Rodriguez, R.E., Floyd, L.M., and Carrier, R.F., Results of the Outdoor Radiological Survey at the Portsmouth Gaseous Diffusion Plant Site, Piketon, Ohio, ORNL/TM-11952

Rodriguez, R.E., Murray, M.E., and Uziel, M.S., Results of the Radiological Survey at the Town of Tonawanda Landfill, Tonawanda, New York (TNY001), ORNL/RASA-92/12

Ross, R.H. and O'Bryan, T.R., "Chemical Scoring System for Hazard and Exposure Identification," The Toxicologist 11, 916(1991)

Ross, R.H. and O'Bryan, T.R., "Carcinogenicity Ranking of Polycyclic Aromatic Hydrocarbon Compounds," The Toxicologist 12, 94 (1992)

Ross, R.H., Davidson, K.A., Lu, P.-Y., and Young, R.A., "Toxicity Assessment of Hazardous Waste Sites at a Federal Facility," The Toxicologist 12, 305 (1992)

Ross, R.H., Redfearn, A., White, R.K., and Shaw, R.A., Approach and Strategy for Developing Human Health Toxicity Information for Contaminants of Concern at Sites Administered by the U.S. Department of Energy Oak Ridge Field Office, Environmental Restoration Program, ES/ER/TM-38

Ryman, J.C., Eckerman, K.F., Tang, J.S., Williams, L.R., and Pace, J.V., III, "Organ Doses Due to Exposure to External Radiation Fields," Proc. 3rd Conf. on Radiation Protection and Dosimetry, Orlando, FL, Oct.21-24, 1991 (1991)

Sachleben, R.A., Brown, G.M., Sloop, F.V., Arlinghaus, H.F., England, M.W., Foote, R.S., Larimer, F.W., Woychik, R.P., Thonnard, N., and Jacobson, K.B., "Resonance Ionization Spectroscopy for Multiplex Sequencing of Tin-Labeled DNA," GATA 8, 167 (1991)

Salk, M.S., Heckman, C.G., Langston, M.E., and Jenning, L.J., Environmental Guidance Program Reference Books Hazardous Materials Transportation Act, Revision 5 , ORNL/M-1717

Salk, M.S., Heckman, C.G., and Langston, M.E., Environmental Guidance Program Reference Book, Resource Conservation and Recovery Act (Revision 11), ORNL/M-1897

Salk, M.S., Heckman, C.G., and Langston, M.E., Environmental Guidance Program Reference Book, Atomic Energy Act and Related Legislation (Revision 6), ORNL/M-1900

Salk, M.S., Heckman, C.G., and Langston, M.E., Clean Water Act (Excluding Section 404), Revision 6, ORNL/M-2263

Salk, M.S., Heckman, C.G., and Langston, M.E., Environmental Guidance Program Reference Book - Safe Drinking Water Act, Revision 6, ORNL/M-1899

Salk, M.S., Principal Investigator and Heckman, C.G., Environmental Guidance Program Reference Book - Toxic Substances Control Act (Revision 6), ORNL/M-1898 
Salk, M.S. (Principal Investigator) and Heckman, C.G., Environmental Guidance Program Reference Books - Clean Water Act (Section 404) and Rivers and Harbors Act (Sections 9 and 10), ORNL/M-1573

Salk, M.S., Principal Investigator, Heckman, C.G., and Langston, M.E., Environmental Guidance Program Reference Book, Comprehensive Environmental Response, Compensation, and Liability Act, Revision 12, ORNL/M-2261

Sandler, P., Lifshitz, C., and Klots, C.E., "Kinetics of Dissociation and Thermionic Emission in the $\mathrm{C}_{6 \mathrm{C}}$ and $\mathrm{C}_{70}$ Molecules," Chem. Phys. Lett. 200(5), 445-50 (1992)

Sauers, I., Christophorou, L.G., and Spyrou, S.M., "Negative Ion Formation in Compounds Relevant to $\mathrm{SF}_{6}$ Decomposition in Electrical Discharges," Plasma Chem. Plasma Process. 13(1), 17-35 (1993)

Schwartzman, G. and Opresko, D.M., "Infrared Spectrum of the Skeletal Axis of Antipatharian Corals (Cnidaria:Anthozoa)," Bull. Mar. Sci. 50(2), 352-56 (1992)

Sharkey, R.M., Goldenberg, D.M., Levine, G., Vagg, R., Ahmad, M., Pawlyk, D., Siegel, J.A., Griffiths, G.L., Hansen, H.J., Callahan, A.P., and Knapp, F.F., Jr., "Phase-I Radioimmunotherapy (RAIT) Using a Rhenium-188-Labeled Murine Monoclonal Antibody (MAb)," J. Nucl. Med. 34, 54 (1993)

Shea, M.J. and Compton, R.N., "Surface-Plasmon Ejection of $\mathrm{Ag}^{+}$Ions from Laser Irradiation of a Roughened Silver Surface," Phys. Rev. B 47, 9967-70 (1993)

Siegrist, R.L., Morris, M.I., West, O.M., Gates, D.D., Pickering, D.A., Jenkins, R.A., Mitchell, T.J., Greene, D.W., Muhr, C.A., Herbes, S.E., Gilliam, T.M., Jennings, H.L., Lucero, A.J., Zutman, J., McKnight, T., Gierke, J.S., Robinson, K.G., Davenport, D.T., Barnett, R.O., Jr., and Watson, J.S., "Evaluation of In Situ Treatment Technologies for Contaminated Clay Soils: Highlights of the X-231B Technology Demonstration," Proc. 8th Annu. DOE Model Conf., Oak Ridge, TN, Oct.19-20, 1992 (1992)

Simmons, W.M. and Travis, C.C., "Book Review: Bargaining with Uncertainty: DecisionMaking in Public Health, Technological Safety, and Environmental Quality," $J$. Hazardous Mater. 32, 122-23 (1992)

Simmons, W.M. and Travis, C.C., "Book Review of The Toxicity of Anticancer Drugs," Risk Anal. 12(4), 628 (1992)

Sims, C.S., "Neutron Personnel Dosimetry Intercomparison Studies," Proc. 11 th DOE Workshop on Personnel Neutron Dosimetry, Las Vegas, June 4-7, 1991, CONF9106235, PNL-SA-21596, 1993, pp. 51-54

Sims, C.S. and Swaja, R.E., "Summary Statements from the Third Conference on Radiation Protection and Dosimetry," Health Phys. 63(2), 192-94 (1992)

Sims, C.S., "High Dose Dosimetry for Radiation Processing - Book Review,' Health Phys. Soc. Newslett. 20(3), 7 (1992) 
Sinclair, L.D., Dudney, C.S., Wilson, D.L., and Saultz, R.J., "Air Pressure Distribution and Radon Entry Processes in East Tennessee Schools," Proc. Int. Symp. on Radon and Radon Reduction Technology, Atlanta, Feb.19-23, 1990 (1991), v. 1, pp. 9-61--9-68

Singh, J., Reghebi, K., Lazarus, C.R., Clarke, S.E.M., Callahan, A.P., Knapp, F.F., Jr., and Blower, P.J., "Studies on the Preparation and Isomeric Composition of (186Re)- and (188Re)-Pentavalent Rhenium Dimercaptosuccinic Acid Complex," Nucl. Med. Commun. 14, 197-203 (1993)

Singh, M.P. and Travis, C.C., "Environmental Risk Analysis: An Overview," Risk Anal. 11(3), 377-79 (1991)

Singh, S.B., Hingerty, B.E., Geacintov, N.E., Greenberg, J., and Broyde, S., "Molecular Dynamics Analyses of Duplex Dodecamer Modified by $(+)$ and $(-)$ Anti BPDE and Modified Controls," Biophys. J. 59 (W-VCR3), 495a (1991)

Skiles, J., Clinch River Contaminated Concrete Investigation Report for the K-770 Area at the Oak Ridge K-25 Site, ORNL/M-2302

Skiles, J.L., Redfearn, A., and White, R.K., "Determining the Number of Samples Required for Decisions Concerning Remedial Actions at Hazardous Waste Sites," Water Quality Management, AWAWT'91, Air, Water, and Waste Technologies Environmental Management Conf./Expo., Detroit, Nov.11-14, 1991, ESD--The Engineering Society, 1991 , v. 2, pp. $49-57$

Skiles, J.L., Redfearn, A., and White, R.K., "Determining the Number of Samples Required for Decisions Concerning Remedial Actions at Hazardous Waste Sites," J. Environ. Eng. Manage. 1, 57-61 (1991)

Skiles, J.L., Redfearn, A., and White, R.K., "Determining the Number of Samples Required for Decisions Concerning Remedial Action at Hazardous Waste Sites," Proc.

Environmental Restoration '91, Cleaning up the Environment for the 21st Century, Pasco, WA, Sept.8-11, 1991, Office of Energy Research, DOE, 1991, pp. 195-98

Solomon, A.D., Nyquist, J.E., Alexiades, V., Jacobs, G.K., and Lenhart, S.M., A Preliminary Study of the Controls on Melting During In Situ Vitrification, ORNL/ER-30

Som, P., Wang, G.-J., Oster, Z.H., McPherson, D.W., and Knapp, F.F., Jr., "Wholebody Distributions of a New Selective Muscarinic Antagonist: Radioiodinated IQNP," J. Nucl. Med. 34, 197 (1993)

Srivastava, P.C., Hasan, A., and Buchsbaum, D.J., "Iodoazomycin Acyclonucleoside: A Potential SPECT Imaging Agent with High Tumor Uptake," J. Labelled Compd. Radiopharm. XXX, 424-25 (1991)

Srivastava, P.C., Buchsbaum, D.J., and Hasan, A., "Design, Synthesis and Tumor Specificity of Azomycin Ribo- and Acyclonucleosides," Nucleosides \& Nucleotides 10, 235-38 (1991)

Srivastava, P.C., Tedjamulia, M.L., Owen, B.A., and Knapp, F.F., Jr. ,"Synthesis and Myocardial Specificity of p-(n-Alkyl)-( ${ }^{125}$ I)Iodophenyl Fatty Acid Analogues," Indian I. Chem. 30B, 188-94 (1991) 
Stack, M. and Armstrong, A., Response to Comments on Remedial Investigation Report for the Plating Shop Container Areas (S-344 and S-351) at the Oak Ridge Y-12 Plant, Oak Ridge, Tennessee, ES/ER-36\&D2

Stack, M.E., Draft Waste Coolant Processing Facility Remedial Investigation Report, ORNL/M-2078

Stack, M.E., Draft Rust Spoil Area Remedial Investigation Report, ORNL/M-2079

Stevenson, C.L. and Vo-Dinh, T., "Laser-Excited Synchronous Luminescence Spectroscopy," Appl. Spectrosc. 47, 430 (1993)

Suter, G.W., II, Redfearn, A., White, R.K., and Shaw, R.A., Approach and Strategy for Performing Ecological Risk Assessments for the Department of Energy Oak Ridge Field Office Environmental Restoration Program, ES/ER/TM-33

Swaja, R.E. and Sims, C.S., Proceedings of the Third Conference on Radiation Protection and Dosimetry, Orlando, Florida, October 21-24, 1991, ORNL/TM-11882

Swindle, D.W., Jr., Vo-Dinh, T., and Yalcintas, M.G., "Technology Transfer and Application of SERS Continuous Monitor for Trace Organic Compounds," Proc. Mediterranean Conf. on Environmental Geotechnology, Cesme, Turkey, May 25-27, $1992(1992)$

Talmage, S.S. and Walton, B.T., "Uptake of Mercury by Components of Terrestrial Food Chains," Proc. 12th Annu. Meet. Soc. Environ. Toxicol. Chem., Seattle, Nov.3-7, 1991, SETAC, 1991, p. 245

Talmage, S.S., Environmental and Human Safety of Major Surfactants, Volume 2. Nonionic Surfactants, Part 2. Alkyphenol Ethoxylates, ORNL/M-2750

Talmage, S.S., Environmental and Human Safety of Major Surfactants, Volume 2. Nonionic Surfactants, Part 1. Alcohol Ethoxylates, ORNL/M-2749

Tan, E., Ho, C.-H., Griest, W.H., and Tyndall, R.L., "Mutagenicity of Trinitrotoluene and Its Metabolites Formed During Composting," J. Toxicol. Environ. Health 36, 165-75 (1992)

Tang, K., Allman, S.L., and Chen, C.H., "Mass Spectrometry of Laser-Desorbed Oligonucleotides," Rapid Commun. Mass Spectrom. 6, 365-68 (1992)

Tang, K., Allman, S.L., and Chen, C.H., "Laser Mass Spectrometry for Biopolymers," Proc. 6th Int. Symp. on Resonance Ionization Spectroscopy and Its Applications, Santa Fe, NM, May 24-29,1992, Inst. of Physics Conf. Ser. No. 128: Section 8, 1992, pp. $289-92$

Tang, K., Allman, S.L., Jones, R.B., Chen, C.H., and Araghi, S., "Laser Mass Spectrometry of Polydeoxyribothymidylic Acid Mixtures," Rapid Commun. Mass Spectrom. 7, 63-66 (1993)

Thate, J.E., Health and Safety Research Division Health and Safety Procedures for Hazardous Waste Sites, ORNL-6605 
Thomas, J.K., Land, M.L., Voorhees, L.D., McCord, R.A., Olson, D., and Allison, L.J., OREIS ... More than a Data Base, Vol. 1, No. 1, February 1992 - Technical Brief, ORNL/M-1908

Thompson, J.S., Pegg, D.J., Dellwo, J., Compton, R.N., and Alton, G.D., "Photodetachment of Metastable He-," Nucl. Instrum. Methods Phys. Res. B 56/57, 211-15 (1991).

Thorne, D.J., McDowell-Boyer, L.M., Roemer, E.K., and Little, C.A., NSARS Coordinated Research Programme on "The Safety Assessment of Near-Surface Radioactive Waste Disposal Facilities," Progress Report No. 1, (Individual Predictions for Test Case 1, v. 2), IAEA, 1992

Thundat, T., Warmack, R.J., Allison, D.P., and Ferrell, T.L., "Electrostatic Spraying of DNA Molecules for Investigation by Scanning Tunneling Microscopy," Ultramicroscopy 42-44, 1083-87 (1992)

Thundat, T., Warmack, R.J., Allison, D.P., Bottomley, L.A., Lourenco, A.J., and Ferrell, T.L., "Atomic Force Microscopy of Deoxyribonucleic Acid Strands Adsorbed on Mica: The Effect of Humidity on Apparent Width and Image Contrast," J. Vac. Sci. Technol. A 10(4), 630-35 (1992)

Thundat, T., Allison, D.P., Warmack, R.J., and Ferrell, T.L., "Imaging Isolated Strands of DNA Molecules by Atomic Force Microscopy," Ultramicroscopy 42-44, 1101-6 (1992)

Thunda:, T., Zheng, X.-Y., Sharp, S.L., Allison, D.P., Warmack, R.J., Joy, D.C., and Ferrell, T.L., "Calibration of Atomic Force Microscope Tips Using Biomolecules," Scanning Microsc. 6(4), 903-10 (1992)

Thundat, T., Allison, D.P., Warmack, R.J., Brown, G.M., Jacobson, K.B., Schrick, J.J., and Ferrell, T.L., "Atomic Force Microscopy of DNA on MICA and Chemically Modified Mica," Scanning Microsc. 6(4), 911-18 (1992)

Thundat, T., Warmack, R.J., Allison, D.P., Doktycz, M.J., and Jacobson, K.B., "Atomic Force Microscopy of Single-Stranded and Double-Stranded DNA Adsorbed on Chemically Treated Mica," Bull. Am. Phys. Soc. 38(1), 118 (1993)

Tobita, S., Meinke, M., Illenberger, E., Cirristophorou, L.G., Baumgartel, H., and Leach, S., "Polycyclic Aromatic Hydrocarbons (PAHs): Negative Ion Formation Following Low Energy (0-15 e V) Electron Impact," Chem. Phys. 161, $501-8$ (1992)

Travis, C.C. and Hattemer-Frey, H.A., "Physiological Pharmacokinetic Models," Statistics in Toxicology Research, Gordon \& Breach Science, 1991, pp. 161-90

Travis, C.C. and Bowers, J.C., "Interspecies Scaling of Anesthetic Potency," Toxicol. Ind. Health 9(4), 249-60 (1991)

Travis, C.C. and Hattemer-Frey, H.A., "Human Exposure to Dioxin," Sci. Total Environ. 104, 97-127 (1991) 
Travis, C.C. and Doty, C.B., "Remedial Action Decision Process," Hazardous Waste Site Investigations Toward Better Decisions, Proc. ORNL Life Sciences Symp., Gatlinburg, TN, May 24, 1990, CRC Press, Boca Raton, FL, 1992, pp. 261-71

Travis, C.C., Wang, L.A., and Waehner, M.J., "Quantitative Correlation of Carcinogenic Potency with Four Different Classes of Short-Term Test Data," Mutagenesis 6(5), 353-60 (1991)

Travis, C.C. and Doty, C.B., "Risk Management at Hazardous Waste Sites," Effective and Safe Waste Management: Interfacing Sciences and Engineering with Monitoring and Risk Analysis,, Proc. 200th Natl. Meet. Am. Chem. Soc., Washington, DC, Aug.26-31, 1990, Lewis Publ., 1992, Section 7, pp. 283-92

Travis, C.C. and Hester, S.T., "Global Chemical Pollution," Environ. Sci. Technol. 25(5), 814-19 (1991)

Travis, C.C., Craig, P.H., and Bowers, J.C., "Characterization of Human Exposure to Ambient Levels of Benzene Using Pulmonary 'Wash-Out' Data,"Atmos. Environ. 25A(8), 1643-47 (1991)

Travis, C.C., "Interspecies Extrapolation of Toxicological Data," Health Risk Assessment Through Dermal and Inhalation Exposure and Absorption of Toxicants, CRC Press, Boca Raton, FL, 1992, pp. 387-413

Travis, C.C. and Gamble, V., "Book Review: Developmental Toxicology: Risk Assessment and the Future," J. Hazardous Mater. 27, 351-52 (1991)

Travis, C.C. and Gamble, V.L., "Managing Industrial Hazardous Waste - Book Review," J. Hazardous Mater. 30, $377-78$ (1992)

Travis, C.C. and Belefant, H., "Promotion as a Factor in Carcinogenesis," Toxicol. Lett. 60(1), 1-9 (1992)

Travis, C.C. and Priebel, B.M., "Validation of a Terrestrial Food Chain Model," Exposure Anal. Environ. Epidemiol. 2(2), 221-40 (1992)

Travis, C.C. and Yambert, M.W., "Accounting for Dry Deposition in Incineration Risk Assessments," Municipal Waste Incineration Risk Assessment, Plenum Press, New York, 1991, pp. 53-63

Travis, C.C., "Toxic Waste in Groundwater: Can It Be Removed?" J. NIH Res. 4(2), 49-51 (1992)

Travis, C.C., McClain, T.W., and Birkner, P.D., "Diethylnitrosamine-Induced Hepatocarcinogenesis in Rats: A Theoretical Study," Toxicol. Appl. Pharmacol. 109, 289-304 (1991)

Travis, C.C. and Blaylock, B.P., "Setting Priorities for Environmental Policy," Environ. Sci. Technol. 26(2), 215 (1992)

Travis, C.C., "Hazardous Waste Remediation: Can We Afford the Cost?" Forum Appl. Res. Public Policy 8(1), 57-59 (1993) 
Travis, C.C. and Morris, J.M., "The Emergence of Ecological Risk Assessment," Risk Anal. 12(2), 167-68 (1992)

Travis, C.C. and Morris, J.M., "On the Use of 0.75 as an Interspecies Scaling Factor," Risk Anal. 12(2), 311-13 (1992)

Travis, C.C., Simmons, W.M., Lyon, B.F., and Fox, M.T., "Co-Exposure to Gasoline Vapor Decreases Benzene Metabolism in Fischer 344 Rats," Toxicol. Lett. 62, 231-40 (1992)

Travis, C.C., Wang, L.A., and Morris, J.M., "Comparison of the Gene-Tox and RTECS Data Bases as Predictors of Carcinogenic Potency," Mutat. Res. 279, 261-68 (1992)

Travis, C.C. and Simmons, W.M., "Studying Risk at the Oak Ridge National Laboratory," Fed. Facil. Environ. J. 3(3), 295-300 (1992)

Travis, C.C. and MacInnis, J.M., "Vapor Extraction of Organics from Subsurface Soils: Is It Effective?" Environ. Sci. Technol. 26(10), 1885-87 (1992)

Travis, C.C., Center for Risk Management (Brochure), ORNL/M-2000

Travis, C.C., Morris, J.M., and Blaylock, B.P., U.S. Department of Energy Development of Risk- and Cost-Estimate Process Pilot Study for the Office of Management and Budget, ORNL/M-2475

Travis, C.C. and Gamble, V., "Book Review: Chemicals in the Human Food Chain," $J$. Hazardous Mater. 27, 351 (1991)

Tuinman, A.A., Mukherjee, P., Adcock, J.L., Hettich, R.L., and Compton, R.N., "Characterization and Stability of Highly Fluorinated Fullerenes," J. Chem. Phys. 96(19), 7584-89 (1992)

Turner, J.E., Bolch, W.E., Yoshida, H., Jacobson, K.B., Wright, H.A., Hamm, R.N., Ritchie, R.H., and Klots, C.E., "Radiation Damage to a Biomolecule: New Physical Model Successfully Traces Molecular Events," Appl. Radiat. Isot. 42, 995-1001 (1991)

Turner, J.E. and Huston, T.E., "ALDOSE: A Computer Code to Calculate Absorbed-Dose Rate, Dose-Equivalent Rate, and Dose-Weighted LET as Functions of Depth in Water Irradiated by an Alpha-Particle Disc Source," Health Phys. 60, 581-85 (1991)

Turner, J.E., Hamm, R.N., Bolch, W.E., Yoshida, H., Jacobson, K.B., and Stabin, M.G., "Calculations for Irradiation of Formic Acid Solutions with ${ }^{4} \mathrm{He}$ Ions," Radiation Research: A Twentieth.Century Perspective, Volume 1: Congress Abstracts, Academic Press, Inc., San Diego, 1991, p. 292

Turner, J.E., "The Dosimetry of Ionizing Radiation, Vol. III - Book Review," Radiat. Res. 125, 114-15 (1991)

Turner, J.E., "The Relative Biological Effectiveness of Radiations of Different Quality, NCRP Report No. 104, National Council on Radiation Protection and Measurements (Book Review)," Radiat. Res. 128, 231-32 (1991) 
Turner, J.E., "An Introduction to Microdosimetry," Radiat. Prot. Manage. 9(3), 25-58 (1992)

Turner, J.E., "Biophysical Modelling of Radiation Effects - Book Review," Health Phys. 64, 200 (1993)

Turner, J.E., "Review of Radiological Assessment," Radiat. Res. 134, 125-26 (1993)

Tyndall, R.L., Bowman, E.K., Ironside, K.S., Milton, D., Barbaree, J., and Lehman, E., "Aerosolization of Microorganisms and Endotoxin from Home Humidifiers," Proc. Meet. Am. Soc. Microbiol., Dallas, May 5-9, 1991 (1991), p. 47

Uziel, M., Miller, G.H., Ward, R., Watts, W., and Vo-Dinh, T., "Screening Benzo(a)pyrene Metabolites in Urine Using Synchronous Room Temperature Phosphorescence,"

Polycyclic Aromat. Compd. 3, 17-27 (1992)

Uziel, M., Munro, N.B., Katz, D.S., Vo-Dinh, T., Zeighami, E.A., Waters, M.D., and Griffith, J.D., "DNA Adduct Formation by 12 Chemicals with Populations Potentially Suitable for Molecular Epidemiological Studies," Mutat. Res. 277, 35-90 (1992)

Uziel, M. and Houck, K., "Direct Labeling of DNA-Adducts Formed from Carcinogenic Diol-Epoxides with a Fluorescent Reporter Compound Specific for the Cis Vic-Diol Group," Biochem. Biophys. Res. Commun. 180, 1233-40 (1991)

Uziel, M.S., Tiner, P.F., and Williams, J.K., Surface Radiological Investigations at Environmental Research Area 11, ${ }^{137} \mathrm{Cs}$ - and ${ }^{60}$ Co-Contaminated Plots at Oak Ridge National Laboratory, Oak Ridge, Tennessee, ORNL/ER-138

Visser, F.C., Sloof, G.W., and Knapp, F.F., "Myocardial Metabolic Imaging with Iodine123 Fatty Acids," What's New in Cardiac Imaging?, Kluwer Academic Publ., The Netherlands, 1992, pp. 229-47

Visser, F.C., Sloof, G.W., Comans, E.F.I., and Knapp, F.F., "Relation Between 15-(PIodophenyl)-3,3-Dimethyl-Pentadecanoic Acid Uptake and Blood Flow in Normal and Ischemic Canine Myocardium," J. Nucl. Med. 34, 649-57 (1993)

Visser, F.C., Sloof, G.W., Comans, E.F.I., and Knapp, F.F., "Metabolism of Radioiodinated Heptadecanoic Acid in Normal, Ischemic and Hypoxic Canine Myocardium," J. Nucl. Med. 34, 15 (1993)

Vo-Dinh, T., Alarie, J.P., Johnson, R.W., Sepaniak, M.J., and Santella, R.M., "Evaluation of Fiber-Optic Antibody-Based Fluoroimmunosensor for DNA-Adducts in Human Placenta Samples," Clin. Chem. 37, 532-35 (1991)

Vo-Dinh, T., "Chemiluminescence Spectroscopy," Encyclopedia of Applied Physics, VCH Publ., Inc., 1992, v. 3, pp.413-26

Vo-Dinh, T. and Pal, T., "Development of a Spectrochemical Modification (SM) Technique to Detect Permeation of Chemical Warfare Agent Simulants Through Protective Clothing Materials," Appl. Spectrosc. 46, 677-81 (1992) 
Vo-Dinh, T., Griffin, G.D., Alarie, J.P., Sepaniak, M.J., and Bowyer, J.R., "Development of Fiberoptic Immunosensors for Environmental Analysis," Pollution Prevention in Industrial Processes, ACS Publ., 1992, v. 508, pp. 270-83

Vo-Dinh, T., Alarie, J.P., Sutherland, W.S., Stokes, D.L., and Miller, G.H., "Chemical Monitors Based on Surface-Enhanced Raman Scattering (SERS)," Proc. Int. Conf. on Monitoring Toxic Chemicals and Biomarkers, Berlin, June 22-26, 1992, SPIE Publ., Bellingham, WA, 1992, pp. 517-24

Vo-Dinh, T., Alarie, J.P., and Sepaniak, M.J., "Laser-Based Fiberoptic Immunosensors," Proc. Int. Conf. on Monitoring Toxic Chemicals and Biomarkers, Berlin, June 22-26, 1992, SPIE Publ., Bellingham, WA, 1992, pp. 37-43

Vo-Dinh, T., "A Global Environment, A Common Future," Analusis: J. Physiochim. Anal. l'Analyse Indust. 21, M5 (1993)

Voorhees, L.D., McCord, R.A., Durfee, R.C., Goyert, J.C., Land, M.L., Olson, R.J., Thomas, J.K., and Tinnel, E.P., Oak Ridge Environmental Information System (OREIS) Phase I - System Definition Document, ES/ER/TM-34

Voorhees, L.D., McCord, R.A., Durfee, R.C., Land, M.L., Olson, R.J., Thomas, J.K., and Tinnel, E.P., Data Management Plan for the Oak Ridge Environmental Information System, Version 1.1, ES/ER/TM-39

Voorhees, L.D., McCord, R.A., Durfee, R.C., Land, M.L., Olson, R.J., Palmer, M.R., Thomas, J.K., Tinnel, E.P., and Zygmunt, B.C., Oak Ridge Environmental Information System (OREIS) Site Workstation Information Packet for OREIS V1.2, ES/ER/TM-57

Wachter, E.A., Moore, A.K., and Haas, J.W., "Fabrication of Tailored Needle Substrates for SERS," Vib. Spectrosc. 3, 73-78 (1992)

Wachter, E.A., Gammage, R.B., Haas, J.W., III, Wilson, D.L., DePriest, J.C., Wade, J., Ahmad, N., Sibtain, F., and Zahid Raza, M., Comparative Study of Combustion Product Emissions of Pakistani Coal Briquettes and Traditional Pakistani Domestic Fuels, ORNL/TM-12087

Ward, R.C. and Eckerman, K.F., DOSEXPRT-A Bioassay Dosimetry Code for Martin Marietta Energy Systems, Inc., ORNL/TM-11857

Wassom, J.S. and Von Halle, E.S., "Mutation Research and the Literature of Genetic Toxicology - Another Milestone," Mutat. Res. 250, 499-502 (1991)

Watson, A.P. and Griffin, G.D., "Toxicity of Vesicant Agents Scheduled for Destruction by the Chemical Stockpile Disposal Program," Environ. Health Perspect. 98, 259-80 (1992)

Watson, A.P., Jones, T.D., and Adams, J.D., "A Relative Potency Approach for Estimating Allowable Residues and Reentry Intervals Following Organophosphate Nerve Agent Release," Ecotoxicol. Environ. Saf. 23, 328-42 (1992)

Watson, A.P., Sidell, F.R., Leffingwell, S.S., and Munro, N.B., General Guidelines for Medically Screening Mixed Population Groups Potentially Exposed to Nerve or Vesicant Agents, ORNL/TM-12()34 
Watson, A.P., Adams, J.D., Cerar, R.J., Hess, T.L., Kistner, S.L., Leffingwell, S.S., MacIntosh, R.G., and Ward, J.R., Estimated General Population Control Limits for Unitary Agents in Drinking Water, Milk, Soil, and Unprocessed Food Items, ORNL/TM12035

Watts, W., Pal, A., Ford, L., Miller, G.H., Vo-Dinh, T., Eastwood, D., and Lidberg, R., "Improved Methods for Screening of Polychlorinated Biphenyls (PCBs) Using Room Temperature Phosphorescence," Appl. Spectrosc. 46(8), 1235-39 (1992)

White, R.K., "Book Reviews for the Journal of Risk Analysis - December 1991," Risk Anal. 11(4), 707-9 (1991)

White, R.K., "Book Reviews for the Journal of Risk Analysis - March 1992," Risk Anal. 12(1), 161-65, (1992)

White, R.K., "Book Reviews for the Journal of Risk Analysis, June 1992," Risk Anal. 12(2), 323-26 (1992)

White, R.K., Dietary Intakes and Exposure Parameters for Screening Calculations, ORNL/M2374

White, R.K., Swindle, D.W., Redfearn, A., and King, A.D., The Use of Institutional Controls at Department of Energy Oak Ridge Field Office Environmental Restoration Sites, ES/ER/TM-28

Williams, M.W., Arakawa, E.T., and Inagaki, T., "Optical and Dielectric Properties of Materials Relevant to Biological Research," Handbook on Synchrotron Radiation, Elsevier Science Publ., 1991, v. 4, pp. 95-145

Wilson, D.L., Dudney, C.S., and Gammage, R.B., "Quality Assurance and Control of Passive Radon Monitors," Abstract Book, American Industrial Hygiene Conf., Salt Lake City, May 19-24, 1991 (1991), p. 65

Wilson, J.E., A Computer Program Integrating a Multichannel Analyzer with Gamma Analysis for the Estimation of 226Ra Concentration in Soil Samples, ORNL/TM-12096

Wilson, M.J., Crutcher, J.W., and Halford, D.K., "Determination of the Probability for the Presence of Radioactive Materials on Properties in Monticello, Utah," Health Phys. 62(5), 407-12 (1992)

Wright, L.L., Cushman, J.H., Erenshaft, A.R., McLaughlin, S.B., McNabb, W.A., Ranney, J.W., Tuskan, G.A., Turhollow, A.F., Biofuels Feedstock Development Program Annual Progess Report for 1991, ORNL-6742

Wu, Z.-C., Arakawa, E.T., Jimenez, J.R., and Schowalter, L.J., "Optical Properties of Epitaxial $\mathrm{CoSi}_{2} / \mathrm{Si}$ and $\mathrm{CoSi}_{2}$ Particles in Si from 0.062 to $2.76 \mathrm{eV}, " J$. Appl. Phys. 71, 5601-5 (1992)

Wu, Z.-C., Arakawa, E.T., Jimenez, J.R., and Schowalter, L.J., "Optical Properties of Epitaxial CoSi2 on Si from 0.062 to $22.3 \mathrm{eV}, "$ Phys. Rev. B 47(8), 4356-62 (1993) 
Wyrick, J.M. and Caton, G.M., Ceramic Technology Newsletter, No. 36, July-September 1992, ORNL/M-2345

Wyrick, J.M. and Caton, G.M., Ceramic Technology Newsletter, No. 35, April-June 1992 ORNL/M-2247

Wyrick, J.M., Martin, S.A., Adamson, A.E., Casey, D.K., Davidson, K.A., Mansfield, B.K., Yust, L.N., and Stinnett, D., Human Genome Program Contractor-Grantee Workshop III, Santa Fe, New Mexico, February 7-10, 1993, ORNL/M-2588

Wyrick, J.M. and Caton, G.M., Ceramic Technology Newsletter, No. 37, October-December 1992, ORNL/M-2586

Yambert, M.W., Belcher, G.D., and Travis, C.C., "Evaluation of Flat Versus Complex Terrain Models in Estimating Pollutant Transport and Deposition in Complex Terrain," Municipal Waste Incineration Risk Assessment, Plenum Publ. Corp., New York, 1991, pp. $1-19$

Yavari, H. and Etnier, E.L., Personal Communication - Air Stripper Permits, 4-8-92, ORNL/M-2305

Yoshida, H., Turner, J.E., Bolch, W.E., Jacobson, K.B., and Garrison, W.M., "Measurement of Products from X-Irradiated Glycylglycine in Oxygen-Free Aqueous Solutions," Radiat. Res. 129, 258-64 (1992)

Yoshida, H., Hettich. R.L., LaVerne, J.A., Jacobson, K.B., and Turner, J.E., "Characterization of Radiation-Induced Products in Thymidine 3'-Monophosphate by Laser Desorption FTMS," Radiation Research: A Twentieth-Century Perspective, Volume 1: Congress Abstracts, Academic Press, Inc., San Diego, 1991, p. 40

Yoshida, H., Hettich, R.L., Turner, J.E., and Cadet, J., "Radiation-Induced Products in Thymidine Monophosphate Characterized by Laser Desorption FTMS and HPLC," Abstract and Program, 40th Annu. Meet. Radiat. Res. Soc., Salt Lake City, Mar.14-18, 1992 (1992), p. 51

Yoshida, H., "Concentration and pH Dependent Ammonia Yields After X-Irradiation of Oxygen-Free Aqueous Solutions of Glycylglycine," Abstracts of 11 th Symp. on Microdosimetry, Gatlinburg, TN, Sept.13-18, 1992, OHER, DOE, 1992, p. 119

Yoshida, H. and Hettich, R.L., "Radiation Chemistry of Thymidylyl (3'->5') Thymidine in Oxygen-Free Aqueous Solution," Abstracts of 41 st Meet. Radiat. Res. Soc., Dallas, Mar.20-25, 1993 (1993), p. 76

Young, R.A., Daugherty, M.W., Talmage, S.S., and McKean, D., "An Overview of the Toxicology of Methyl Methacrylate," The Toxicologist 11, 243 (1991)

Zhang, J., Lambropoulos, P., Zei, D., Compton, R.N., and Stockdale, J.A.D., "Resonantly Enhanced Two-Photon Excitation of Sodium Atoms in a Heat Pipe," Z. Phys. D 23, 21925 (1992)

Zheng, X.-Y., Lowndes, D.H., Zhu, S., Budai, J.D., and Warmack, R.J., "Early Stages of $\mathrm{YBa}_{2} \mathrm{Cu}_{3} \mathrm{O}_{7-\delta}$ Epitaxial Growth on $\mathrm{MgO}$ and $\mathrm{SrTiO}_{3}, "$ Phys. Rev. B 45, 7584-87 (1992) 
Zheng, X.-Y., Lowndes, D.H., Zhu, S., and Warmack, R.J., "Scanning Tunneling Microscope Studies of Epitaxial Growth of $\mathrm{YBa}_{2} \mathrm{Cu}_{3} \mathrm{O}_{7-\delta}$ Thin Films," Proc. Spring Meet. Mater. Res. Soc., San Francisco, Apr.27-May 1, 1992, Mater. Res. Soc., 1992, v. 263, pp. 41-46 
ORNL-6752

Dist. Category UC-407

\section{INTERNAL DISTRIBUTION}

1. J. P. Alarie

2. W. J. Allen

3. D. P. Allison

4. S. L. Allman

5. K. R. Ambrose

6. E. T. Arakawa

7. A. Q. Armstrong

8. C. L. Arquiett

9. B. G. Ashdown

10. J. C. Ashley

11. J. B. Ball

12. C. B. Bast

13. D. R. Baumgardner

14-63. B. A. Berven

64. B. P. Blaylock

65. J. S. Bogard

66. R. R. Bonczek

67. H. T. Borges

68. P. A. Brimer

69. R. A. Brothers

70. K. J. Brown

71. M. A. Buckner

72. S. N. Burman

73. A. P. Callahan

74. T. A. Callcott

75. R. S. Carlsmith

76. H. S. Carman, Jr.

77. R. F. Carrier

78. J. G. Carter

79. W. H. Casson

80. G. M. Caton

81. S. S. Chang

82. C. H. Chen

83. L. G. Christophorou

84. R. L. Coleman

85. R. N. Compton

86. W. D. Cottrell

87. D. F. Craig

88. O. H. Crawford

89. M. T. Cristy

90. G. S. Danford

91. M. W. Daugherty

92. K. A. Davidson

93. H. C. Dees

94. K. S. Dickerson

95. C. E. Dixon

96. D. M. Douthat

97. C. S. Dudney
98. M. D. Dykes

99. C. E. Easterly

100. K. F. Eckerman

101. A. R. Ehrenshaft

102. A. E. Ekkebus

103-105. J. R. Ellis

106. M. W. England

107. M. L. Espegren

108. E. L. Etnier

109. R. A. Faust

110. T. L. Ferrell

111. D. E. Fields

112. L. M. Floyd

113. R. D. Foley

114. A. A. Francis

115. M. W. Francis

116. R. B. Gammage

117. F. G. Gardner

118. W. R. Garrett

119. R. K. Genung

120. H. A. Glovier

121. P. Y. Gray

122. D. W. Greene

123. J. H. Greene

124. G. D. Griffin

125. R. T. Haas

126. D. K. Halford

127. S. C. Hall

128. R. N. Hamm

129. F. C. Hartman

130. G. T. Hawkins

131. C. G. Heckman

132. B. E. Hingerty

133. J. P. Hitch

134. L. M. Houlberg

135. P. S. Hovatter

136. D. R. James

137. C. A. Johnson

138. J. E. Jones

139. T. D. Jones

140. G. D. Kerr

141. B. W. Kline

142. C. E. Klots

143. F. F. Knapp, Jr.

144. D. C. Kocher

145. B. J. Krall

146. C. Krause

147. E. H. Kreig, Jr. 
148. M. L. Land

149. D. C. Landguth

150. R. W. Leggett

151. E. B. Lewis

152-161. C. A. Little

162. P. Y. Lu

163. J. M. MacInnis

164. B. K. Mansfield

165. K. H. Mavournin

166. C. J. Maxwell

167. L. M. McDowell-Boyer

168. C. W. McGinn

169. S. P. McKenzie

170. D. W. McPherson

171. D. B. Miller

172. I. C. Miller

173. J. C. Miller

174. P. D. Miller

175. S. Mirzadeh

176. J. M. Morris

177. M. T. Muck

178. C. A. Muhr

179. N. B. Munro

180. M. E. Murray

181. J. O. Mynatt

182. B. D. Nourse

183. D. M. Opresko

184. E. T. Owens

185. D. A. Pickering

186. L. A. Pinnaduwage

187. M. L. Poutsma

188. C. E. Pugh

189-191. D. E. Reichle

192. J. B. Richard

193. A. A. Richmond

194. R. H. Ritchie

195. J. B. Roberto

196. R. E. Rodriguez

197. P. S. Rohwer

198. R. H. Ross

199. M. J. Saltsmarsh

200. I. Sauers

201. W. D. Shults

202. C. S. Sims

203. J. L. Skiles
204. K. G. Slusher

205. M. E. Stack

206. R. S. Stafford

207. G. H. Stevens

208. S. E. Stinnette

209. J. M. Stockstill

210. R. E. Swaja

211. S. S. Talmage

212. J. E. Thate

213. J. K. Thomas

214. D. J. Thorne

215. T. G. Thundat

216. C. C. Travis

217. J. L. Trimble

218. J. E. Turner

219. R. L. Tyndall

220. S. Y. Uppuluri

221. M. Uziel

222. M. S. Uziel

223. A. A. Vass

224. T. Vo-Dinh

225. E. A. Wachter

226. S. J. Wallace

227. R. C. Ward

228. R. J. Warmack

229. J. S. Wassom

230. A. P. Watson

231. R. K. White

232. B. L. Whitfield

233. J. K. Williams

234. D. L. Wilson

235. J. E. Wilson

236. L. A. Wilson

237. M. J. Wilson

238. H. Yoshida

239. R. A. Young

240. L. N. Yust

241. E. A. Zeighami

242. Biology Division Library

243-244. Central Research Library

245. CRL-Document Reference Section

246-247. Laboratory Records

248. Laboratory Records - RC

249. Patent Office 


\section{EXTERNAL DISTRIBUTION}

250. T. E. Aldrich, Central Cancer Registry, Cancer Surveillance Section, P. O. Box 27687, Raleigh, NC 27611-7687

251. R. E. Alexander, The Alexander Corporation, 13131 Maltese Lane, Fairfax, VA 22033

252. J. R. Anderson, Department of Energy, 5301 Central Avenue NE, Albuquerque, NM 87115

253. C. M. Auer, Director, Existing Chemical Assessment Division (TS-778), Environmental Protection Agency, 401 M St., S.W., Washington, DC 20460

254. J. Auxier, Auxier \& Associates, Inc., 111 Mabry Hood Road,Suite 500, Knoxville, TN 37922

255. W. Bair, Pacific-Northwest Laboratory, Battelle Boulevard, P. O. Box 999, Richland, WA 99352

256. J. Barkley, Army Biomedical Research and Development Laboratory, Health Effects Research Division, Fort Detrick, Frederick, MD 21701

257. N. F. Barr, Office of Health and Environmental Research, ER-72, Department of Energy, Washington, DC 20585

258. I. Baumel, USABRDL, Bldg. 568, Fort Detrick, Frederick, MD 21702-5010

259. J. Beck, Energy/Environment System Division, Oak Ridge Associated Universities, Oak Ridge, TN 37830

260. J. M. Becker, Microbiology Department, University of Tennessee, Knoxville, TN 37916

261. H. M. Borella, EG\&G, Inc., Santa Barbara Operations, 130 Robin Hill Road, Goleta, CA 93117

262. J. N. Bradford, RADC/ESR, Hanscom AFB, MA 01731

263. A. B. Brill, University of Massachusetts Medical School, Department of Nuclear Medicine, Worcester, MA 01605

264. J. Broadway, Environmental Protection Agency, P. O. Box 3009, Montgomery, AL 36109

265. A. Brodsky, Allen B. Consultants, Inc., 16412 Kipling Road, Derwood, MD 20855-1927

266. P. A. Buffler, Professor of Epidemiology and Associate Dean for Research, University of Texas at Houston, School of Public Health, P. O. Box 20186, Houston, TX 77025

267. T. A. Butler, 119 Dana Drive, Oak Ridge, TN 37830 
268. J. R. Cameron, University of Wisconsin Medical Center, Department of Radiology, 1300 University Avenue, Madison, WI 53706

269. A. Chatterjee, Lawrence Berkeley Laboratory, University of California, Berkeley, CA 94720

270. A. R. Chernoff, UMTRA Project Office, Department of Energy, 5301 Central Ave., NE, Suite 1700, Albuquerque, NM 87108

271. Lt. Col. T. Childress, Toxicology Division, WPAFB, OL AL HSC/OET, Bldg. 79, 2856 G St., Wright-Patterson AFB, OH 45433-7400

272. R. J. Cloutier, 168 Cumberland View, Oak Ridge, TN 37830

273. C. B. Coburn, Jr., Biology Department, Tennessee Technological University, Campus Box 5127, Cookeville, TN 38501

274. J. Cogliano, Carcinogen Assessment Toxicology Branch (RD-689), Office of Health and Environmental Assessment, Environmental Protection Agency, $401 \mathrm{M}$ St. SW, Washington, DC 20460

275. D. Cole, Office of Health and Environmental Research, ER-73, Department of Energy, Washington, DC 20585

276. Commander, U.S. Army Environmental Center, Attention: ENAEC-IR (Dr. Bob York), Aberdeen Proving Ground, MD 21010-5401

277. F. J. Congel, Division of Systems Integration, Office of Nuclear Reactor Regulation, Nuclear Regulatory Commission, Washington, DC 20545

278. W. K. Cook, P.E., Senior Vice President, ATEC Associates, Inc., 1300 Williams Drive, Suite A, Marietta, GA 30066-6299

279. T. W. Crawford, Savannah River Company, P. O. Box 616, Aiken, SC 29801

280. J. Darr, Office of Toxic Substances, Existing Chemicals Assessment Division (TS-778), Environmental Protection Agency, 402 M St SW, East Tower, Washington, DC 20460

281. L. T. Dillman, 184 West Lincoln Avenue, Delaware, $\mathrm{OH} 43015$

282. L. J. Doemeny, Deputy Director, Physical Sciences and Engineering Division, NIOSH, 4676 Columbia Parkway, Cincinnati, OH 45266

283. P. M. Echenique, Departmento de Fisica de Materiales, Universidad del Pais Vasco, 20080 San Sebastian, Spain

284. W. H. Farland, Director, Office of Health and Environmental Assessment, MS RD-689, Environmental Protection Agency, 401 M Street SW, Washington, DC 20460

285. C. Feldman, Office of Standards Development, Nuclear Regulatory Commission, MS-1130SS, Washington, DC 20555 
286. P. Fenner-Crisp, Office of Pesticide Program, H-7509-C, Environmental Protection Agency, 401 M. Street SW East Tower, Washington, DC 20460

287. J. J. Fiore, Department of Energy, EM-423, Washington, DC 20585

288. D. R. Fisher, Pacific-Northwest Laboratory, Battelle Boulevard, P. O. Box 999, Richland, WA 99352

289. F. Flores, Departmento de Fisica del Estado Solido, Universidad Autonoma de Madrid Cantoblanco, Madrid, Spain

290. D. Fulmer, Department of Energy, EM-43, Washington, DC 20585

291. D. J. Galas, Associate Director, Office of Healih and Environmental Research, ER-70, Department of Energy, Washington, DC 20585

292. J. H. Gibbons, Director, Office of Technology Assessment, Congress of the United States, Washington DC 20510

293. D. M. Goldenberg, Center for Molecular Medicine and Immunology, 100 Bergen Street, Newark, NJ 07103

294. G. Goldstein, Office of Health and Environmental Research, ER-74, Department of Energy, Washington, DC 20585

295. M. M. Goodman, Radiology Departmen:, U.T. Memorial Hospital, 1924 Alcoa Highway, Knoxville, TN 37920

296. R. Goyer, Deputy Director, National Institute of Environmental Health Sciences, P. O. Box 12233, Research Triangle Park, NC 27709

297. D. Greathouse, Environmental Protection Agency, 26 W. St. Clair, Cincinnati, OH 45268

298. R. A. Griesemer, National Institute of Environmental Health Sciences, P. O. Box 12233, Research Triangle Park, NC 27709

299. E. J. Hall, Radiological Research Laboratory, College of Physicians and Surgeons of Columbia University, 630 West 168th Street, New York, NY 10032

300. T. Harvey, Director, Environmental Criteria and Assessment Office, Environmental Protection Agency, 26 W. St. Clair, Cincinnati, OH 45268

301. G. Heuter, Environmental Protection Agency, Research Triangle Park, NC 27711

302. R. Hirsch, Office of Health and Environmental Research, ER-74, Department of Energy, TN 37920

303. F. O. Hoffman, Senes Oak Ridge Inc., 677 Emory Valley Road, Suite C, Oak Ridge TN 37830 
304. S. Hossain, Division of Nuclear Fuel Cycle and Waste Management, IAEA, Wagramerstrasse 5, P. O. Box 100, A-1400 Vienna, Austria

305. A. Howie, Cavendish Laboratory, Madingley Road, Cambridge CB30HE, England

306. J. H. Hubbell, Center for Radiation Research, National Institute of Standards and Technology, Washington, DC 20434

307. S. R. Hunter, Pellissippi International, 114 Ridgeway Center, Oak Ridge, TN 37830

308. G. S. Hurst, Consultec Scientific, Inc., Pellissippi Center, Suite 110, 725 Pellissippi Parkway, Knoxville, TN 37932-3300

309. T. Inagaki, Department of Physics, Osaka Kyoiku University, Tennoji, Osaka, 543 Japan

310. B. Jinkerson, University Programs Division, Oak Ridge Associated Universities, P. O. Box 117, Oak Ridge, TN 37831

311. R. Katz, Department of Physics, University of Nebraska, Lincoln, NE 68588

312. S. V. Kaye, General Manager, Analysas Corporation, Oak Ridge Corporate Center, 151 Lafayette Drive, Oak Ridge, TN 37830

313. T. W. Kerlin, Department of Nuclear Engineering, 315 Pasqua Building, University of Tennessee, Knoxville, TN 37996

314. G. Killough, 105 Netherland Rd, Oak Ridge, TN 37830

315. Lt. Col. E. Langford, SGRD-UBG-O, Bldg. 824, 2800 Q Street, WrightPatterson AFB, OH 45433-7947

316. W. E. Legg, Army Environmental Hygiene Agency (ATTN: HSHB-ME-SR), Aberdeen Proving Ground, MD 21010-5422

317. J. C. Lehr, Department of Energy, EM-442, Washington, DC 20585

318. R. Lightner, DOE, EM-45, Washington, DC 20585

319. W. C. Lineberger, Department of Chemistry and Joint Institute for Laboratory Astrophysics, University of Colorado, Boulder, CO 80302

320. Capt. D. Macys, Naval Medical Research Institute, Toxicology Detachment, NMRI/TD, Bldg. 433, Area B, Wright-Patterson AFB, OH 45433-6503

321. D. T. Mage, Senior Scientific Advisor, Data Management and Analysis Division (MD-56), EPA/EMSL, Research Triangle Park, NC 27711

322. J. L. Magee, Biology and Medicine Department, University of California, Berkeley, CA 94720

323. S. A. Mann, Department of Energy, EM-451, Washington, DC 20585 
324. J. R. Manson, Department of Physics, Clemson University, Clemson, SC 29631

325. T. J. McKenna, Office of Inspection and Enforcement, MS EWW-359, Nuclear Regulatory Commission, Washington, DC 20555

326. C. B. Meinhold, President, NCRP, 7910 Woodmont Avenue, Suite 800, Bethesda, MD 20814

327. E. Merzbacher, Professor, Department of Physics and Astronomy, University of North Carolina, Chapel Hill, NC 27599

328. C. W. Miller, Radiation Studies Branch, Centers for Disease Control, MS-F-28, 1600 Clifton Road, Atlanta, GA 30333

329. A. A. Moghissi, P.O. Box 7166, Alexandria, VA 22307

330. J. A. Morley, Department of Energy, Dayton Area Office, P.O. Box 66, Miamisburg, $\mathrm{OH} 45342$

331. P. E. Morrow, The University of Rochester School of Medicine and Dentistry, Rochester, NY 14620

332. C. B. Nelson, Environmental Protection Agency, ANR-461, Washington, DC 20460

333. D. R. Nelson, Office of Nuclear Safety, Department of Energy, EH 331.2, Washington, DC 20545

334. N. S. Nelson, Environmental Protection Agency, $401 \mathrm{M}$ Street SW, Mail Code 6602J, Washington, DC 20460

335. B. Parks, Office of Radiation Programs (ANR-460), Environmental Protection Agency, Washington, DC 20460

336. R. Perhac, Electric Power Research Institute, 3412 Hillview Avenue, P. O. Box 10412, Palo Alto, CA 94303

337. J. W. Poston, Department of Nuclear Engineering, Texas A\&M, College Station, TX 77843-3133

338. C. J. Powell, Electron Physics Section, National Institute of Standards and Technology, Washington, DC 20234

339. G. Purcell, Director, GGSLIS, The University of Tennessee, 804 Volunteer Boulevard, Knoxville, TN 37996-4330

340. D. P. Rall, Director, National Institute of Environmental Health Sciences, P. O. Box 12233, Research Triangle Park, NC 27709

341. A. Richardson, Office of Radiation Programs, Environmental Protection Agency, Crystal Mall \#2, 1921 Jefferson Davis Hwy., Crystal City, VA 22202

342. R. Rieger, Appalachian Regional Laboratory, NIOSH, Morgantown, WV 26505 
343. S. L. Rose, Manager, Radon Research Program, Office of Health and Environmental Research, ER-73, Department of Energy, Washington, DC 20585

344. G. S. Roessler, Route 1, Box 139H, Elysian, MN 56028

345. J. Salecki, Manager, DOE Grand Junction Projects Office, P. O. Box 2567, Grand Junction, CO 81502

346. B. A. Schwetz, Chief, Systemic Toxicology Branch, NIEHS, P. O. Box 12233, Research Triangle Park, NC 27709

347. R. F. Sena, Department of Energy, Environmental Restoration Project Office, P. O. Box 5400, Albuquerque, NM 87115

348. K. Sexton, Director, Office of Health Research, RD-683, Room 3100, Environmental Protection Agency, 401 M Street, SW, Washington, DC 20460

349. G. L. Sherwood, NE 52, Office of Nuclear Energy, MS-B107, Department of Energy, Washington, DC 20585

350. C. Shoaf, Environmental Criteria and Assessment Office (MD052), Environmental Protection Agency, Research Triangle Park, NC 27711

351. C. M. Shy, Department of Epidemiology, C.B. 8050, NCNB Plaza, Suite 32, University of North Carolina, Chapel Hill, NC 27599-8050

352. A. G. Sinkankas, The University of Tennessee, GSLIC, 804 Volunteer Boulevard, Temple Court, Room 304, Knoxville, TN 37996-4330

353. R. Snelling, Environmental Protection Agency, Las Vegas, NV 89193-3478

354. R. Snyder, Professor and Director, Department of Pharmacology and Toxicology, College of Pharmacy, Busch Campus, Rutgers University, PIscataway, NJ 08855-1179

355. P. C. Srivastava, Office of Health and Environmental Research, ER-74, Department of Energy, Washington, DC 20585

356. D. Straw, W. J. Schafer Associates, Inc., 1600 Randolph Court SE, \#2, Albuquerque, NM 87106

357. J. W. Thiessen, Radiation Effects Research Foundation, 5-2 Hijiyama Park, Minani-ku, Hiroshima 732, Japan

358. J. E. Thompson, Associate Professor, College of Law, University of Tennessee, 1505 W. Cumberland Avenue, Knoxville, TN 37996-1800

359. L. H. Toburen, Pacific-Northwest Laboratory, Battelle Boulevard, P. O. Box 999, Richland, WA 99352

360. A. Ulsamer, Consumer Products Safety Commission, 5401 Westbard Avenue, Washington, DC 20207 
361. M.Varma, Pollutant Characterization and Safety, Office of Health and Environmental Research, ER-74, Department of Energy, Washington, DC 20585

362. J. M. Veigel, President, Oak Ridge Associated Universities, 130 Badger Avenue, Oak Ridge, TN 37830

363. Col. Erik K. Vermulen, Deputy Director, Occupational and Environmental Health Directorate, AL/OE, 2402 E Drive, Brooks Air Force Base, TX 78235-5114

364. J. Villforth, Bureau of Radiological Health, U.S. Public Health Service, 5600 Fishers Lane, Parklawn Building, Rockville, MD 20582

365. P. Voytek, Vice President, Clement Associates, 9300 Lee Highway, Fairfax, VA 22031-1207

366. P. Wagner, Office of Toxic Substances, Health and Environmental Review Division (TS-796), Environmental Protection Agency, 401 M St. SW, East Tower, Washington, DC 20460

367. B. Wallace, Appalachian Regional Laboratory, NIOSH, Morgantown, WV 26505

368. A. Wallo, Department of Energy, EH-231, 1000 Independence Avenue, Washington, DC 20581

369. P. J. Walsh, H \& R Technical Associates, Inc., P. O. Box 4159, Oak Ridge, TN 37831-4159

370. M. D. Waters, Director, Genetic Toxicology Division, Environmental Protection Agency, Health Effects Research Laboratory, Research Triangle Park, NC 27711

371. J. E. Watson, 517 Yorktown Drive, Chapel Hill, NC 27514

372. W. Weyzen, Electric Power Research Institute, 3412 Hillview Avenue, P. O. Box 10412, Palo Alto, CA 94303

373. F. W. Whicker, Professor, Department of Radiological Health Sciences, Colorado State University, Ft. Collins, CO 80523

374. R. P. Whitfield, Department of Energy, EM-40, Washington, DC 20585

375. L. R. Williams, Environmental Protection Agency-QAD, Environmental Monitoring System Laboratory, P. O. Box 93478, Las Vegas, NV 89193-3478

376. R. Wirtz, Dean, College of Law, University of Tennessee, 1505 W. Cumberland Avenue, Knoxville, TN 37996-1800

377. R. W. Wood, Director, Medical Applications and Biophysical Research Division, Office of Health and Environmental Research, ER-73, Department of Energy, Washington, DC 20585

380. H. A. Wright, Consultec Scientific, Inc., Pellissippi Center, 725 Pellissippi Parkway, Knoxville, TN 37932-3300 
381. H. O. Wyckoff, 4108 Montpelier Road, Rockville, MD 20854

382. Deputy Assistant Manager, Energy Research and Development, Department of Energy, DOE Oak Ridge Operations, P. O. 2008, Oak Ridge, TN 37831-6269

381-425. Given distribution as shown in DOE/OSTI-4500 under UC-407, Health and Safety 


$$
\longrightarrow
$$
1

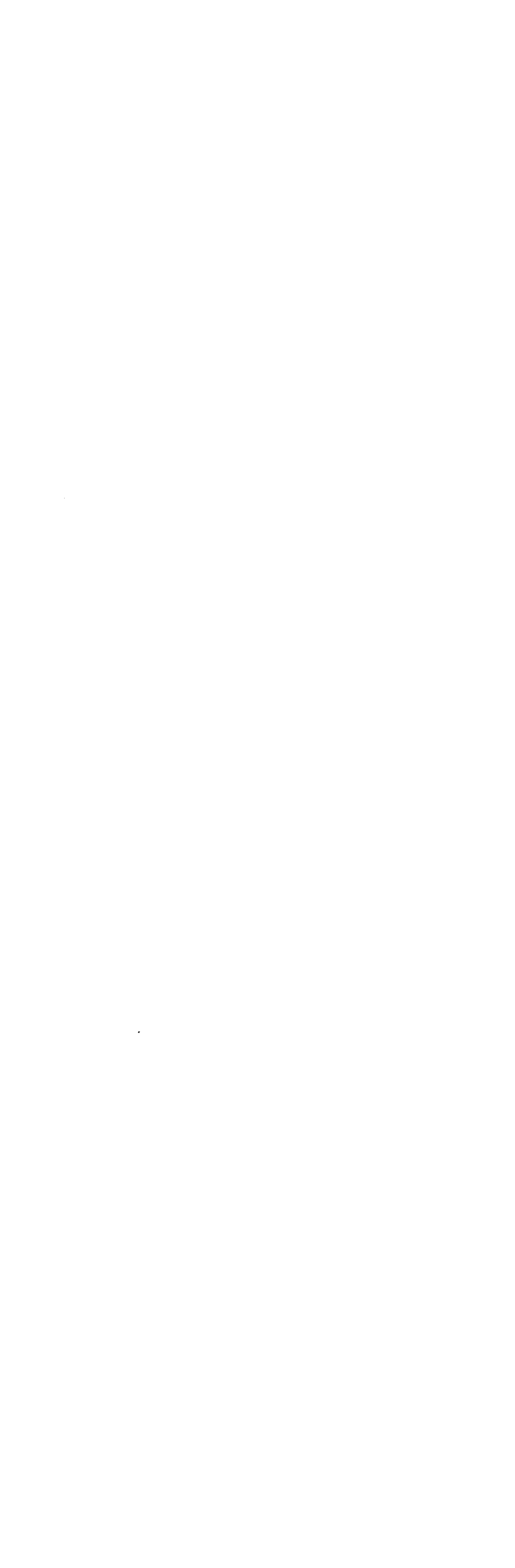

